María José José Luis

Arrojo Piñel

Balina Raigada

Coordinadores

Contenidos digitales y multipantalla

Prólogo - María José Arrojo Baliña / José Luis Piñuel Raigada

Cuadernos Artesanos de Comunicación / 95

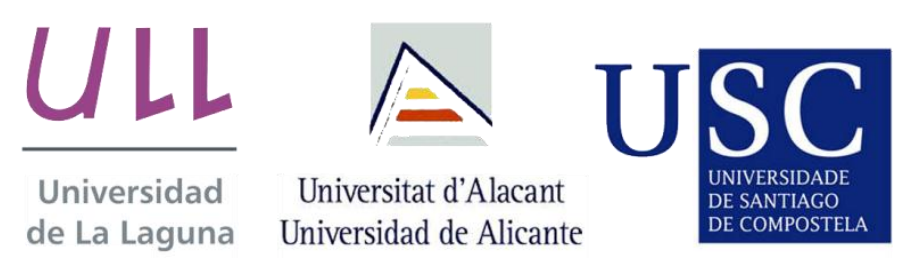

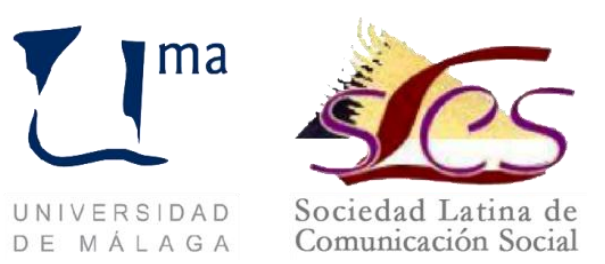




\section{Cuadernos Artesanos de Comunicación}

Coordinador editorial: José Manuel de Pablos

Comité Científico

Presidencia: José Luis Piñuel Raigada (UCM)

Secretaría: Concha Mateos (URJC)

- Carlos Elías (Universidad Carlos III de Madrid, UC3M)

- Paulina B. Emanuelli (Universidad Nacional de Córdoba, UNC)

- José Luis González Esteban (Univ. Miguel Hernández de Elche)

- Marisa Humanes (Universidad Rey Juan Carlos, URJC)

- Juan José Igartua (Universidad de Salamanca, USAL)

- Xosé López (Universidad de Santiago de Compostela)

- Maricela López-Ornelas (Universidad Autónoma de Baja California)

- Javier Marzal (Universidad Jaume I, UJI)

- José Antonio Meyer (Benemérita Universidad Autónoma de Puebla)

- Ramón Reig (Universidad de Sevilla, US)

- Miquel Rodrigo Alsina (Universidad Pompeu Fabra, UPF)

- Xosé Soengas (Universidad de Santiago de Compostela)

- José Luis Terrón (Universidad Autónoma de Barcelona, UAB)

- José Miguel Túñez (Universidad de Santiago, USC)

- Victoria Tur (Universidad de Alicante, UA)

- Miguel Vicente (Universidad de Valladolid, UVA)

- Ramón Zallo (Universidad del País Vasco, UPV-EHU)

- Núria Almiron (Universidad Pompeu Fabra, UPF)

- Francisco Campos Freire (Universidad de Santiago de Compostela)

- José Cisneros (Benemérita Universidad Autónoma de Puebla)

- Bernardo Díaz Nosty (Universidad de Málaga, UMA)

* Queda expresamente autorizada la reproducción total o parcial de los textos publicados en este libro, en cualquier formato o soporte imaginables, salvo por explícita voluntad en contra del autor o autora o en caso de ediciones con ánimo de lucro. Las publicaciones donde se incluyan textos de esta publicación serán ediciones no comerciales y han de estar igualmente acogidas a Creative Commons. Harán constar esta licencia y el carácter no venal de la publicación.

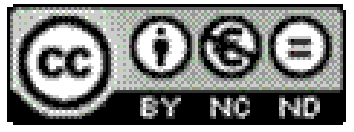

Este libro y cada uno de los capítulos que contiene (en su caso), así como las imágenes incluidas, si no se indica lo contrario, se encuentran bajo una Licencia Creative Commons Atribución-No Comercial-Sin Derivadas 3.0 Unported. Puede ver una copia de esta licencia en http://creativecommons.org/licenses/by-nc-nd/3.0/ Esto significa que Ud. es libre de reproducir y distribuir esta obra, siempre que cite la autoría, que no se use con fines comerciales o lucrativos y que no haga ninguna obra derivada. Si quiere hacer alguna de las cosas que aparecen como no permitidas, contacte con los coordinadores del libro o con el autor del capítulo correspondiente. ${ }^{*}$ La responsabilidad de cada texto es de su coordinador-autor 
María José Arrojo Baliña y José Luis Piñuel Raigada

\title{
Contenidos digitales y multipantalla
}

\author{
Prólogo \\ María José Arrojo Baliña \\ José Luis Piñuel Raigada
}

Cuadernos Artesanos de Comunicación / 95

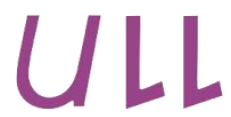

Universidad de La Laguna
Universitat d'Alacant Universidad de Alicante
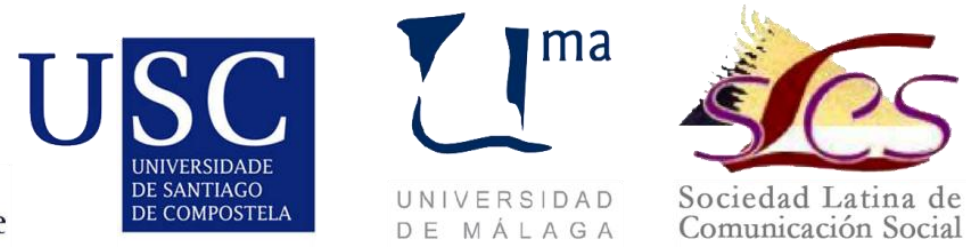
$95^{\circ}$ - Contenidos digitales y multipantalla - María José Arrojo y José Luis Piñuel (coords.)

Precio social: 9,40€| Precio en librería: 12,20€ |

Editores: Javier Herrero y Alberto Ardèvol Abreu

Diseño: F. Drago

Ilustración de portada: Fragmento del cuadro Árboles y viento, de Juan Davó (sin fecha).

Imprime y distribuye: F. Drago. Andocopias S. L.

c/ La Hornera, 41. La Laguna. Tenerife.

Teléfono: 922250554 | fotocopiasdrago@telefonica.net

Edita: Sociedad Latina de Comunicación Social - edición no venal

- La Laguna (Tenerife), 2015 - Creative Commons

http://www.revistalatinacs.org/14SLCS/portada2014.html

Descargar en pdf:

http://www.cuadernosartesanos.org/\#95

Protocolo de envío de manuscritos

http://www.cuadernosartesanos.org/protocolo.html

ISBN - 13: 978-84-16458-24-0

DL: TF-880-2015

DOI: $\underline{10.4185 / \mathrm{cac} 95}$ 


\section{Indice}

Prólogo: Los medios de comunicación digital. Un nuevo contexto comunicativo, por María José Arrojo y José Luis Piñuel_........... 9

\section{De You'Tube a las páginas web especializadas como}

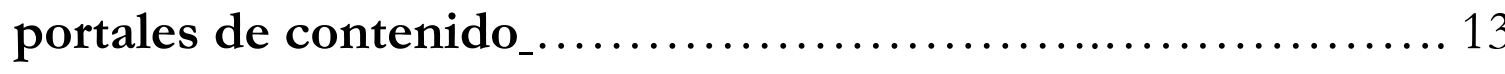

1. YouTube como nuevo fenómeno comunicativo. Análisis de sus objetivos, procesos y resultados desde la perspectiva de las Ciencias Aplicadas de Diseño ................................María José Arrojo .. 13

2. La vídeo-noticia: Tendencias en la prensa digital. El caso de The Guardian y la cobertura del Referéndum de Escocia .Sara Ortells-Badenes... 41

3. Video como servicio agregado en los portales de los medios impresos mexicanos ...............Claudia Alicia Lema Noriega ... 61

II. Multimedia, multipantalla, multitarea, y emociones_......73

4. Los videojuegos como proceso multimedia Enrique Morales Corral ... 73

5. Multitarea, Multipantalla y Práctica social del consumo de medios entre los jóvenes de 16 a 29 años en España. Gemma Teso Alonso, José Luis Piñuel Raigada

6. Emociones: Importancia y fundamento en los contenidos televisivos María José Labrador 


\section{English Version}

\section{Index}

Prologue: Digital Media. A New Communicative Context, by Maria Jose Arrojo and Jose Luis Piñuel ................................ 125

\section{From YouTube to specialized webpages as portals of content}

1. YouTube considered as new communicative phenomenon. Analyse of aims, processes and results from the perspective of Applied Science of Design......................... Maria Jose Arrojo ... 129

2. Video News: Trends in the Digital Press. The Case of The Guardian and the Scottish Referendum Coverage.............................Sara Ortells-Badenes ... 155

3. Video as added value at Mexican print media website................................Claudia Alicia Lerma ... 173

\section{Multimedia, multiscreen, multitask, and emotions_... 183}

4. Video games as multimedia process ....... Enrique Morales ... 183

5. Multitask, multiscreen and social practice of the use of Media among young spanish people between the ages of 16 to 29 years old Gemma Teso; Jose Luis Piñuel ... 201

6. Emotions. Importance and basis in the TV contents Maria Jose Labrador ... 215 


\title{
Contenidos Digitales y Multipantalla
}

\author{
María José Arrojo Baliña, José Luis Piñuel Raigada (Coords.)
}

\begin{abstract}
Este volumen hace una aportación científica en el ámbito de los medios de comunicación digitales. A partir del trabajo realizado por siete investigadores, se analiza cuáles son los diseños comunicativos que modulan los objetivos, procesos y resultados de los agentes comunicativos en el entorno digital.

La novedad del tema, así como las propuestas teóricas y metodológicas formuladas en este volumen sin duda captarán la atención y el interés de los círculos académicos internacionales. Por este motivo se tomó la decisión de que el libro fuese bilingüe. Los trabajos se presentan en español y en inglés, como modo de contribuir a que la difusión de estos estudios sea mayor.

\section{Keywords}

Diseño, medios de comunicación, prensa digital, YouTube; multipantalla, multiplataforma, videojuego, video-periodismo, consumo.
\end{abstract}

\section{Forma de citar este libro}

Autor/ra del capítulo (2015): “Título del capítulo", en Contenidos digitales y multipantalla (María José Arrojo Baliña, José Luis Piñuel Raigada, Coods.). Cuadernos Artesanos de Comunicación, 95. La Laguna (Tenerife): Latina. 



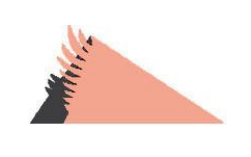

\title{
Prólogo
}

\section{Los medios de comunicación digital. Un nuevo contexto comunicativo}

\author{
María José Arrojo y José Luis Piñuel
}

$\mathrm{E}$ $\mathrm{N}$ los últimos años, gracias a las innovaciones tecnológicas, la creatividad desarrollada en el ámbito de los medios digitales, ha provocado impresionantes cambios comunicativos, que no tienen precedentes en las sociedades occidentales. Estos cambios comunicativos se pueden apreciar en seis aspectos principales: (i) los contenidos comunicativos; (ii) las estrategias de programación; (iii) los procesos de producción; (iv) los mecanismos de distribución; (v) las vías de financiación; y (vi) los usos que las audiencias hacen de esos contenidos.

Estas transformaciones requieren una profunda investigación que permita averiguar cuáles son los diseños comunicativos que subyacen tras las innovaciones comunicativas. Además, la investigación debe aclarar los objetivos, procesos y resultados de estos nuevos diseños. Esta investigación es particularmente importante, ya que es la única manera de poder hacer contribuciones científicas en el campo de los medios digitales. El resultado de la investigación debe permitirnos predecir el futuro posible, incluyendo nuevos problemas, para poder prescribir pautas de actuación con el fin de resolver esos problemas dentro del entorno comunicativo. 
Por otra parte, debido a que las Ciencias de la Comunicación son Ciencias Aplicadas, uno de los cometidos de estas Ciencias es encontrar soluciones a los problemas de comunicación específicos. Este objetivo de estas Ciencias Aplicadas es la base para una ulterior aplicación de la ciencia por parte de los profesionales de los medios digitales. El conocimiento profundo de estos fenómenos comunicativos emergentes es el paso necesario para desarrollar protocolos de actuación para el profesional. Estos protocolos prácticos deberían ser más precisos que los que resultan de la mera intuición de los profesionales.

Con el fin de estudiar estos fenómenos comunicativos desde una doble perspectiva -estructural y dinámica-, este volumen se compone de dos secciones diferentes, tituladas "De YouTube a las páginas web especializadas como nuevos portales de contenido", y "Multimedia, multipantalla, multitarea y emociones". En estas secciones se abordan los temas señalados: los contenidos comunicativos de los nuevos medios digitales, las estrategias de programación en estos medios, las estrategias de producción introducidas por ellos, los nuevos mecanismos de distribución que aparecen, las nuevas rutas de financiación y, finalmente, el uso que el público hace de estos contenidos comunicativos.

"De YouTube a las páginas web especializadas como nuevos portales de contenido", la primera parte de este volumen, que consta de tres capítulos. En el primer capítulo, María José Arrojo analiza este nuevo ámbito comunicativo desde una nueva perspectiva, las Ciencias de la Comunicación como Ciencias Aplicadas de Diseño. Este enfoque se ocupa de los objetivos comunicativos de la plataforma YouTube, los procesos que se llevan a cabo para la consecución de esos objetivos y los resultados que finalmente se obtengan. Esta forma de investigación para analizar la innovación comunicativa introducida por la plataforma también considera una triangulación entre los productores de contenidos, los usuarios de tales contenidos, y el entorno publicitario.

En el segundo capítulo, titulado "La vídeo-noticia: Tendencias en la prensa digital. El caso de The Guardian y la cobertura del Referéndum de Escocia”, Sara Ortells analiza los rasgos internos y externos que 
caracterizan a las video-noticias alojadas en páginas web especializadas, como nuevos formatos de comunicación. Después, en el tercer capítulo - "Video como servicio agregado en los portales de los medios impresos mexicanos"-, Claudia Alicia Lerma, en un estudio de caso, analiza el uso que la prensa mexicana está haciendo de las dos plataformas antes mencionadas: YouTube y páginas web especializadas. Este análisis nos permite conocer el grado de adaptación de los medios de comunicación convencionales al nuevo entorno digital en un área geográfica concreta.

"Multimedia, multipantalla, multitarea y emociones" incluye tres trabajos que conforman la segunda parte de este volumen. Así, en el capítulo cuatro, "Los videojuegos como proceso multimedia", Enrique Morales identifica los elementos principales que caracterizan a los videojuegos como realidades comunicativas únicas. En este capítulo, el autor hace explícitos cuatro aspectos esenciales de un entorno de comunicación multimedia: (1) el desarrollo tecnológico; (2) el factor económico; (3) el ámbito de la producción de contenidos culturales; y (4) los usos de esos contenidos por parte de la audiencia.

Este último aspecto, los nuevos usos que la audiencia hace de los contenidos en el entorno multimedia, es la idea central de los otros dos capítulos de la segunda sección de este volumen. Así, el trabajo "Multitarea, multipantalla y práctica social del consumo de medios entre los jóvenes de 16 a 29 años en España", escrito por Gemma Teso y José Luis Piñuel, se centra en el análisis del consumo de contenidos audiovisuales entre los jóvenes. Además, este quinto capítulo trata sobre cómo los nuevos avances comunicativos determinan y moldean sus propias pautas de relación social.

Mientras tanto, en "Emociones: Importancia y fundamento en los contenidos televisivos", que es el sexto capítulo, María José Labrador se centra en un target más específico. Ella trabaja en el entorno de los niños, y en la importancia de las emociones en el proceso de consumo de los contenidos audiovisuales. Labrador concluye su capítulo con un estudio sobre las nuevas formas de consumo audiovisual, lo que permitirá sentar las bases para la industria, con el objeto de que se pueda producir contenidos audiovisuales digitales creados específicamente para los niños. 
Una característica importante de este libro es ser bilingüe. Los documentos se presentan en español y en inglés. Esto puede contribuir a difundir aún más estos estudios que, sin duda, captarán la atención y el interés de los círculos académicos internacionales. Este interés se debe a la novedad del tema, así como las propuestas teóricas y metodológicas formuladas en este volumen. Este estudio permite así profundizar en nuevos procesos y contenidos comunicativos en un entorno digital y multipantalla. 


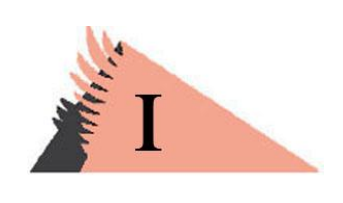

\title{
De YouTube a las páginas web especializadas como portales de contenido
}

\section{1 \\ YouTube como nuevo fenómeno \\ comunicativo. Análisis de sus objetivos, procesos y resultados desde la perspectiva de las Ciencias Aplicadas de Diseño}
María José Arrojo Baliña, Universidad de A Coruña, España Perfil en (D) orcid.org/0000-0002-2385-5461
y en $\mathbf{G}$ http://goo.gl/cYhcD0

\begin{abstract}
En este trabajo se reflexiona sobre el cambio comunicativo introducido por YouTube, en tres aspectos centrales: 1) del contenido que se expone en esta plataforma; 2) de los procesos de producción del contenido; y 3) del papel del ciudadano ante ese nuevo contenido. Este análisis se realiza bajo el prisma de las Ciencias Aplicadas de Diseño, al entender que los fenómenos comunicativos tienen unos
\end{abstract}


objetivos específicos, que tratan de alcanzar mediante unos procesos, para finalmente llegar a unos resultados concretos.

Para acometer este estudio, la hipótesis propuesta lleva consigo una triangulación entre los agentes productores de contenido, los usuarios y el entorno publicitario. Esa triangulación se realiza teniendo en cuenta la vertiente interna y externa del fenómeno analizado. La vertiente interna atiende al diseño que guía el fenómeno comunicativo, que lleva a rebasar la mera esfera sociológica del usuario; y la vertiente externa, analiza el peso de la Tecnología en este nuevo escenario comunicativo y su uso concreto por los ciudadanos.

Para contrastar la hipótesis de partida se realiza un estudio empírico, en el que se analiza la evolución de los contenidos de YouTube que han conseguido un mayor número de seguidores y de visualizaciones en todo el mundo, durante el primer semestre del año 2014.

\section{Keywords}

YouTube; Multi Channel Network; Ciencias de Diseño; Contenido Audiovisual; Comunicación.

\section{Introducción}

¿CUÁL es la novedad aportada por YouTube? ¿Cuáles son sus contribuciones respecto de los objetivos, los procesos y los resultados comunicativos alcanzados hasta la fecha? Estas son las dos cuestiones que conviene plantearse. Para llevar a cabo este cometido, se analiza aquí la novedad que, en cuanto fenómeno comunicativo, introduce YouTube. Este rasgo se investiga en tres planos principales: (i) novedad en cuanto a la programación y distribución de contenidos audiovisuales; (ii) aportación que, con esta plataforma, realizan los productores de contenidos audiovisuales al sistema comunicativo; y (iii) contribución que hacen sus usuarios a esta plataforma, como parte activa del fenómeno comunicativo considerado.

Como marco teórico, el análisis considera que las Ciencias de la Comunicación pueden analizar los objetivos, los procesos y los resultados comunicativos de YouTube, en cuanto que son Ciencias Aplicadas de Diseño. Esto supone que son Ciencias que buscan la 
resolución de problemas concretos en el entorno comunicativo. En este caso, el nuevo fenómeno comunicativo de YouTube soluciona diversos problemas comunicativos y abre nuevas expectativas de futuro. Estas Ciencias Aplicadas de Diseño parten de la existencia diseños comunicativos concretos, que cuentan con objetivos, procesos que los desarrollan y unos resultados esperados o esperables (Arrojo, 2012).

Junto con analizar lo que ya existe -el fenómeno de YouTube actualmente conocido-, estas Ciencias Aplicadas de Diseño permiten apreciar la vertiente artificial de la Comunicación. Con ella, como se aprecia con YouTube, hay tres aspectos sucesivos: a) los agentes tienen nuevos objetivos que potencian la comunicación y que aparecen en los diseños; b) esos agentes utilizan unos procesos para la consecución de esas metas; y c) los agentes obtienen unos resultados concretos, que pueden ser empíricamente evaluados. En tal caso, se puede decir que las Ciencias de la Comunicación encajan dentro de los moldes de las Ciencias de Diseño, en cuanto que potencian las posibilidades humanas de comunicación mediante esos diseños (González, 2007b).

\section{El fenómeno de YouTube en su contexto: Los nuevos usos comunicativos en el entorno digital}

Actualmente hay un cambio adaptativo constante en los diseños comunicativos de las empresas en el entorno digital, que afecta a sus objetivos, procesos y resultados. Junto al interés por los nuevos contenidos, influye en gran medida el tipo de soporte tecnológico. Así, mediante los nuevos contenidos a transmitir y los avances tecnológicos, se ha dado una evolución comunicativa sin precedentes. Se aprecia en cinco aspectos del entorno digital: 1) hay cambios en los lenguajes empleados por los gestores de los contenidos; 2) se dan nuevas políticas de programación; 3) varía el papel desempeñado por los usuarios; 4) se dan nuevos tipos de distribución de los contenidos audiovisuales; y 5) aparecen nuevos flujos comerciales. 


\subsection{Objetivos iniciales y desarrollo}

En este escenario aparece YouTube. Es un nuevo fenómeno comunicativo que nace ligado a un desarrollo tecnológico. Propicia nuevos objetivos comunicativos, cuyas metas llegan hasta cotas insospechadas. YouTube surge en febrero del año 2005 como una plataforma de un portal de alojamiento de vídeo online. Tres antiguos empleados de la empresa PayPal (Chad Hurley, Steve Chen y Jawed Karimy) pusieron en marcha este servicio con tres objetivos principales. I) El objetivo comunicativo era facilitar que personas de cualquier lugar del mundo pudiesen ver y compartir sus videos de manera gratuita. II) El objetivo social era crear un nuevo ámbito de relaciones sociales mediadas a través de pantallas (ordenadores, tabletas electrónicas, etc.). III) El objetivo comercial estaba en la venta de espacio publicitario y de acuerdos específicos con empresas dedicadas a la producción cultural: productoras, televisiones, discográficas, etc. (Pérez Rufí, 2011: 149).

La novedad en sus objetivos comunicativo, social y comercial, junto con el éxito inicial de la plataforma, atrajo la inversión de grupos como Time Warner y Secuoia Capital. Un año después de su puesta en marcha, en 2006, la empresa la adquiere Google por 1.650 millones de dólares. Se convierte en una de las adquisiciones de sitios web más comentadas (Snickars y Vonderau, 2009). En estos años, las cifras -tanto de usuarios como de productores y de horas de video consumido en esa plataforma- no han hecho más que incrementarse.

Para explicar el porqué del éxito, cabe acudir a la combinación de varias causas. a) Oportunidad a la hora de dar respuesta a una necesidad comunicativa concreta, que surge con el desarrollo de los usos de Internet, por razones tecnológicas y culturales. b) Bajo coste de la Tecnología utilizada para la producción de contenidos audiovisuales (cámaras y sistemas de edición de video). Así, más personas tuvieron la oportunidad de erigirse como creadores de sus propios contenidos audiovisuales. c) El surgimiento de un cambio cultural: el deseo de ampliar la difusión de ciertos contenidos comunicativos. Ahora se pueden compartir los videos tanto con personas cercanas como con cualquier sujeto que esté dispuesto a disfrutar con su visionado. 
Se democratizan las posibilidades de producción de contenidos audiovisuales, lo que coincide con un cambio social en la relación con la información y con los contenidos comunicativos en general. Se produce la explosión de lo que, posteriormente, se denominó la "Web 2.0", expresión acuñada por Tim O'Rilley y Dale Dougherty (2005). La Web 2.0 es una forma de entender Internet, basada en las comunidades de usuarios". Este "giro social", donde tiene un protagonismo el individualismo metodológico, se refleja en una generación de personas: los denominados milennial. Estos agentes han crecido en una cultura que, progresivamente, va abandonando la estructura comunicativa jerárquica, que era la dominante en el modelo de comunicación convencional, donde unos pocos individuos eran los que alimentaban las ideas de los espectadores pasivos (García Cay y otros, 2013). El desarrollo de esa cultura participativa -desde una instancia extrínseca a la propia plataforma- ha hecho que la sociedad haya adoptado plataformas como YouTube y haya propiciado su rápida evolución (Jenkins, 2007).

YouTube se ha convertido en un nuevo fenómeno comunicativo con entidad propia. Lo siguen una comunidad de 1.000 millones de usuarios únicos en todo el mundo, localizados en 61 países (Parejo, 2014). Es la plataforma con videos en línea más importante del mundo, tanto por el número de usuarios como por la cantidad de contenidos que maneja. El volumen de tráfico de visitas lo sitúa como el tercer sitio de Internet, después de Google y Facebook (Alexa Internet, Inc., 2014). En este desarrollo, YouTube ha superado su estatuto inicial -una plataforma en la que consumir y compartir videos- y se ha convertido en una red social. En esta nueva entidad se han añadido de facto nuevas funciones: se comparte, se crea y se comentan todo tipo de contenidos audiovisuales.

\footnotetext{
${ }^{1}$ El usuario, a través del manejo de herramientas informáticas, promueve que "la organización y el flujo de información dependan del comportamiento de las personas que acceden a ella, permitiéndose no sólo un acceso mucho más fácil y centralizado a los contenidos, sino su propia participación tanto en la clasificación de los mismos como en su propia construcción, mediante herramientas cada vez más fáciles e intuitivas de usar" (De la Torre, A., 2006).
} 


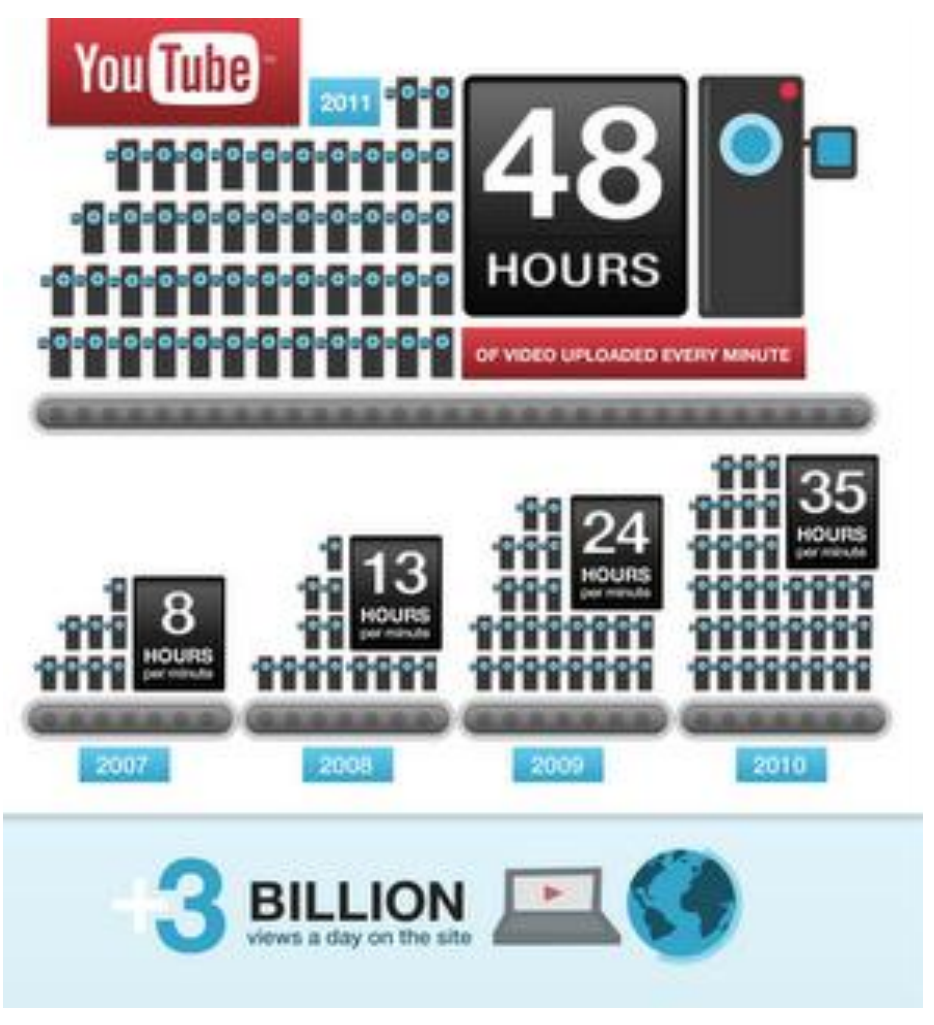

A partir de los objetivos iniciales y su desarrollo en el tiempo, cabe resaltar en YouTube varias características. (i) Como plataforma comunicativa audiovisual, surge de la creatividad en el diseño de nuevas formas de comunicación -de carácter directo y fácilmente accesibles-, que usa las herramientas tecnológicas (las TICs) para hacer viables sus objetivos y procesos. (ii) Sus diseños tienen una clara accesibilidad a los contenidos y hay una participación activa en tiempo real de los usuarios -el consumidor individual o institucional-, lo que se consigue mediante los nuevos desarrollos tecnológicos. (iii) Los procesos que realiza esta actividad comunicativa son novedosos en dos direcciones: en cuanto a la relación con la propia plataforma y por las interacciones sociales que propicia. (iii) Su organización para el logro de actividad comunicativa más participativa se lleva a cabo como entidad comercial con ánimo de lucro, pero es transcultural y netamente internacional en su proyección. Estas características ofrecen una Ontología comunicativa novedosa, que rebasa el mero marco del entretenimiento, hasta el punto que algunos teóricos lo consideran como un nuevo medio de comunicación. 


\subsection{Cambios introducidos}

Para este cambio sin precedentes en el ámbito de la comunicación, hay en primer lugar dos elementos interdependientes: nuevos diseños comunicativos y nuevos soportes tecnológicos. Ambos se complementan para ampliar las formas de distribución y consumo comunicativos. En segundo término, hay unas nuevas relaciones comunicativas: los usuarios son ahora agentes activos, pues generan contenido propio: no se conforman con el consumo de contenidos "recibidos" (Levinson, 2012), sino que son coautores de esos contenidos (Renó, 2011). En tercera instancia, los usuarios tienen la oportunidad de convertirse en "prosumidores" (agentes que producen contenidos mientras los consumen). Cambia entonces su papel: ahora pueden pasar a ser socios valiosos del profesional (Merino, 2013: 254).

Al profundizar en los cambios de YouTube en el entorno comunicativo, se aprecian -a mi juicio- tres perspectivas complementarias acerca del cambio interno. Son las que atañen al diseño que guía el propio fenómeno. Primero cabe estudiar lo relacionado con los objetivos: la programación del contenido de YouTube y sus posibles vías de producción y distribución. Después, se pueden analizar los procesos: los cambios en los procesos de producción del contenido que se expone en YouTube. Por último, se pueden evaluar los resultados y el papel del ciudadano ante ese nuevo contenido en este entorno emergente.

Esto supone que hay una nueva dinámica comunicativa introducida por YouTube, que afecta a objetivos, procesos y resultados, dentro de un dominio inicialmente artificial con una clara proyección social. Este primer elemento de la hipótesis -la existencia de un triple cambio en la dinámica comunicativa que introduce YouTube- se puede contrastar empíricamente. Si admitimos que es un sistema complejo, entonces se pueden acudir a la sobriedad de factores o parsimonious factors para abarcar este sistema comunicativo. ${ }^{2}$ Esto comporta iden-

\footnotetext{
${ }^{2}$ El estudio de la sobriedad de factores tiene lugar en un marco de Ciencias de la Complejidad, como es el caso de las Ciencias de Comunicación en cuanto Ciencias Aplicadas de Diseño. La indagación inicial en el ámbito de las Ciencias de lo Artificial la realizó Herbert Simon. Véase a este respecto GONZÁLEZ, W.
} 
tificar los elementos necesarios y suficientes que sustenta este sistema comunicativo y los nuevos diseños comunicativos en él.

Un segundo elemento de la hipótesis a contrastar es que el cambio es tan profundo que afecta a conceptos centrales de la comunicación audiovisual. Este cambio es externo, atañe al peso creciente de la Tecnología disponible y a su uso concreto por los usuarios y se refleja en dos direcciones: por un lado, el surgimiento de nuevos aspectos de lenguaje comunicativo, donde se supere la antigua unidireccionalidad de la comunicación audiovisual; y, por otro lado, hay nuevos tipos de relación entre los distintos agentes comunicativos. Junto a la plataforma que sustenta lo accesible, hay una serie de relaciones interindividuales entre los agentes productores de contenido, los usuarios y el entorno publicitario, que dan lugar a formas de interacción audiovisual hasta ahora no conocidas.

\subsection{Objetivos actuales y sus agentes}

Progresivamente se ha dado una variación en los objetivos de YouTube. La variación pasa por seguir contando con el apoyo de youtubers y de la audiencia ampliada. Para seguir creciendo, hay que buscar nuevos públicos, lo cual comporta profesionalizarse. Dentro de este nuevo escenario, los Multi Channel Networks (MCN) se presentan como piezas clave en este escenario. Esto se aprecia en la información empírica disponible. Se detecta en la evolución de los contenidos que han conseguido un mayor número de seguidores y de visualizaciones en YouTube en todo el mundo entre los meses de enero y septiembre de 2014. Este análisis permite, además, el ilustrar algunos aspectos de los cambios señalados, que han sido observados empíricamente. Estos cambios han llevado a modificar algunos de los objetivos actuales de la plataforma y los agentes que intervienen en ella.

J. (2012). "Las Ciencias de Diseño en cuanto Ciencias de la Complejidad: Análisis de la Economía, Documentación y Comunicación”. En GONZÁLEZ, W. J. (ed), Las Ciencias de la Complejidad: Vertiente dinámica de las Ciencias de Diseño y sobriedad de factores. A Coruña: Netbiblo, pp. 7-30. 
1) El objetivo comunicativo de YouTube continúa siendo inmediato: busca facilitar que personas de cualquier lugar del mundo puedan compartir y ver videos; pero ya no siempre de una manera gratuita. YouTube ha comenzado a introducir canales de pago y cada vez se acerca más a la industria para incrementar la calidad de estos contenidos. Hay una clara evolución del contenido ofrecido, que comporta además una modificación en el concepto de "programación". 2) El objetivo social -el dar a conocer el talento creativo en forma de contenidos audiovisuales- sigue siendo una de las características de identidad de esta plataforma. Pero hay una creciente profesionalización de YouTube ${ }^{3}$. 3) El objetivo comercial el conseguir beneficios económicos a través de la utilización de la plataforma- acarrea nuevas consecuencias al entorno comunicativo de YouTube. a) Las consecuencias internas: la propia estructura de la plataforma se ve condicionada por un modelo de negocio propio, característico y novedoso: hay una relación directa de los agentes productores con las marcas. b) Las consecuencias externas se dan en cuanto que permite construir modelos de negocio complementarios a los ya existentes en la industria audiovisual.

Se aprecia entonces la aparición de nuevos agentes, que nacen ya con una nueva cultura en la Red. Se trata de las empresas de Redes Multicanal (Multi Channel Network, MCN). Son empresas especializadas en la gestión de derechos de producción intelectual. Son capaces de gestionar el talento creativo, hacerlo visible para los usuarios y representarlos ante las casas comerciales. Los MCN cada vez cobran más importancia. Se están erigiendo como intermediarios en este nuevo entorno. Esto está afectando ya a la propia estructura interna de las relaciones en la plataforma. El modelo de organización y difusión comunicativa, en un primer momento absolutamente horizontal, está empezando a jerarquizarse ${ }^{4}$.

\footnotetext{
${ }^{3}$ La elaboración y difusión de contenidos audiovisuales no está limitada a los agentes broadcast, pero ya existe un expertise sobre cuáles son las claves para tratar de conseguir que un contenido consiga empatizar con el público y generar así una comunidad de fans en torno a una marca.

${ }^{4}$ A medida que el número de productores amateurs que pretenden profesionalizarse aumenta, y que la industria convencional ha empezado a ver un nicho de negocio en este nuevo entorno, se generan nuevos procesos de
} 


\section{Aportación de YouTube a los nuevos sistemas de programación y distribución de contenidos audiovisuales}

Para delimitar la aportación de YouTube a los nuevos sistemas de programación y distribución de contenidos audiovisuales, la clave no está en que en cada minuto se suben 100 horas de contenido nuevo y se registra un consumo de 6.000 millones de horas de video al mes ${ }^{5}$. Estos datos -el volumen de consumo y de generación de contenido audiovisual- solo indican un factor externo: señalan algo que no era alcanzable en una empresa broadcast de televisión. Tampoco está la clave en que intervienen tres tipos de agentes: los productores, los usuarios y los encargados de la publicidad.

La verdadera aportación de esta plataforma aparece en sus objetivos: modifican el nivel de relaciones existentes en el modelo audiovisual tradicional y esto afecta a la programación y a la producción de contenidos audiovisuales. En YouTube el nuevo diseño de distribución y de programación de contenidos audiovisuales se hace sin que, para poder visionarlos y crearlos, cada agente tenga que crear un espacio virtual con su propia Tecnología (Mier y Porto-Renó, 2005: 208). El objetivo buscado en el diseño de YouTube -Broadcast Yourself- es el individuo como protagonista tanto de la generación de vídeo como de su experiencia de usuario.

Aquí las reglas de juego son claras, directas y transparentes. Los ingresos económicos vendrán determinados por el tamaño de la comunidad que los visualice ${ }^{6}$, con independencia de que el contenido esté producido por profesionales o por amateurs. Cuanto mayor sea

relación entre los agentes, en los que unos pasan a representar a otros -factores internos $-\mathrm{y}$ se hace necesario, para la industria convencional, buscar modelos de negocio complementarios -factores externos-.

${ }^{5}$ Según los datos facilitados por YouTube (youtube.com, acceso del 6/11/2014).

${ }^{6}$ Según los datos oficiales proporcionados por la propia plataforma (Parejo, 2014) el 60\% del tráfico de visualizaciones de un canal de You'Tube procede de países distintos a donde se generó el contenido. Esto traducido en términos de mercado, supone que la exportación de contenidos audiovisuales representa un $60 \%$. 
esa comunidad mayor será también el volumen de ingresos económicos del productor de ese contenido ${ }^{7}$. Por tanto, YouTube es en una plataforma de consumo de contenidos audiovisuales, pero también un lugar de conversación y de encuentro de personas con inquietudes y con gustos similares. El principal reto al que se enfrentan los generadores de contenidos en esta plataforma es cómo conseguir ser descubiertos, vistos y seguidos por la comunidad de internautas que navegan por YouTube ${ }^{8}$.

En la televisión tradicional, mucho más sencilla en volúmenes de contenidos y de actores participantes, los programadores son los que hacen posible que algo sea accesible o alcanzable. Con YouTube hay un nuevo orden comunicativo: son las nuevas formas de programación las que permiten el descubrimiento del contenido. Se basan en dos pilares fundamentales: 1) los sistemas de búsqueda, y 2) la intervención de agentes a través de la comunidad. ${ }^{9}$

\footnotetext{
${ }^{7}$ En el año 2007 YouTube pone en marcha un programa de partners, que permite al creador ganar dinero en el caso de que su contenido obtenga reconocimiento por parte de la comunidad (un reconocimiento traducido en visionados). Se considera partner a todo aquel que tenga los derechos de copyright y de distribución de sus contenidos para su distribución online (Larrañaga y Ruiz, 2009: 122).

Según las estimaciones de Credit Suisse, en el año 2013 el estándar del coste de publicidad por cada mil anuncios vistos en TouYube (Cost Per Mille CPM) era de aproximadamente ocho dólares (CNN Expansión, 2014). No obstante, algunos agentes de publicidad en la red aseguran poder conseguir sponsors con hasta 25-40 dólares por CPM con publicidad prerroll o insertada en el vídeo (Fullscreen, 2014).

${ }^{8}$ Según Alexa.com (2014) YouTube es ya la segunda herramienta de búsqueda en Internet, por detrás de Google. Se trata de un espacio global en el que participan personas de 61 países distintos que conversan en 72 idiomas diferentes y generan contenidos de manera colaborativa.

${ }^{9}$ 1) Los sistemas de búsqueda son los que le aportan un orden y una estructura a la plataforma. Estos sistemas de búsqueda no son inocuos, sino que vienen determinados por criterios establecidos por la propia plataforma, y se fundamentan en la articulación de categorías, en criterios semánticos y en criterios cuantitativos: (i) Sistema de categorías. YouTube ofrece 15 tipos de categorías distintas para poder alojar los contenidos audiovisuales. Esto le permite arbitrar una estructura interna y categorizar los contenidos, de tal modo que aporte un orden dentro de ese universo de videos; (ii) Motores de
} 


\subsection{Novedad aportada por los agentes productores de contenido en YouTube}

Tanto en su estructura como en sus lenguajes, la novedad en los procesos de relación y de programación tiene un efecto directo en los agentes productores y en los propios contenidos. En la actualidad pueden diferenciarse cuatro categorías de agentes productores de contenidos en YouTube: 1) los amateurs que se conforman con dar rienda suelta a su creatividad bien generando material ex-novo o utilizando contenido previamente producido por terceros; 2) los amateurs que pretenden profesionalizarse; 3) las empresas profesionales que nacen ya en el entorno de YouTube; y 4) la industria convencional, que encuentra en Internet una plataforma para acercar sus contenidos a públicos complementarios.

Si se observa el ranking de los 12 canales de YouTube más vistos del mundo entre los meses de enero y agosto del año 2014, aparecen contenidos producidos por las tres primeras categorías. Hay siete canales con contenido musical, que los han producido empresas profesionales que nacen en el entorno digital. El resto de canales, que en estos momentos son los más vistos del mundo en YouTube, están

búsqueda. La plataforma permite trabajar con dos sistemas de búsqueda distintos: uno basado en la búsqueda semántica, en función de las etiquetas o metadatos que se le asignen a un video; y otro basado en el número de visualizaciones que haya tenido un video previamente y del tiempo que se haya permanecido viéndolo. Es decir, en función del volumen de tráfico que hayan tenido esos contenidos ordenará los resultados de la búsqueda de mayor a menor. De este modo los resultados que ofrece al realizar una búsqueda combina estos dos criterios; y (iii) Recomendaciones. Los usuarios registrados, al marcar sus videos preferidos y al suscribirse a unos canales determinados, le dan información suficiente a la plataforma como para que esta les recomiende contenidos similares.

2) Por lo que respecta a la intervención de agentes a través de la comunidad. Todavía hay usuarios que se limitan a consumir videos. Frente a estos existe otro perfil de usuario activo que acaba convirtiéndose en prescriptor. El hecho de que los usuarios puedan comentar los videos y expresar sus opiniones posibilita que aquellos con más reputación social (en esta u otras redes sociales) se conviertan en prescriptores de contenidos. Estos agentes más activos, con sus sugerencias de contenidos, asumen parte del rol de los programadores convencionales. Se trata de sujetos con capacidad para influir en su entorno. 
producidos por youtubers que comienzan siendo amateurs y que, poco a poco, se van profesionalizando. Lo hacen a través de un nuevo tipo de empresas que surgen para representarlos y darles asistencia técnica.

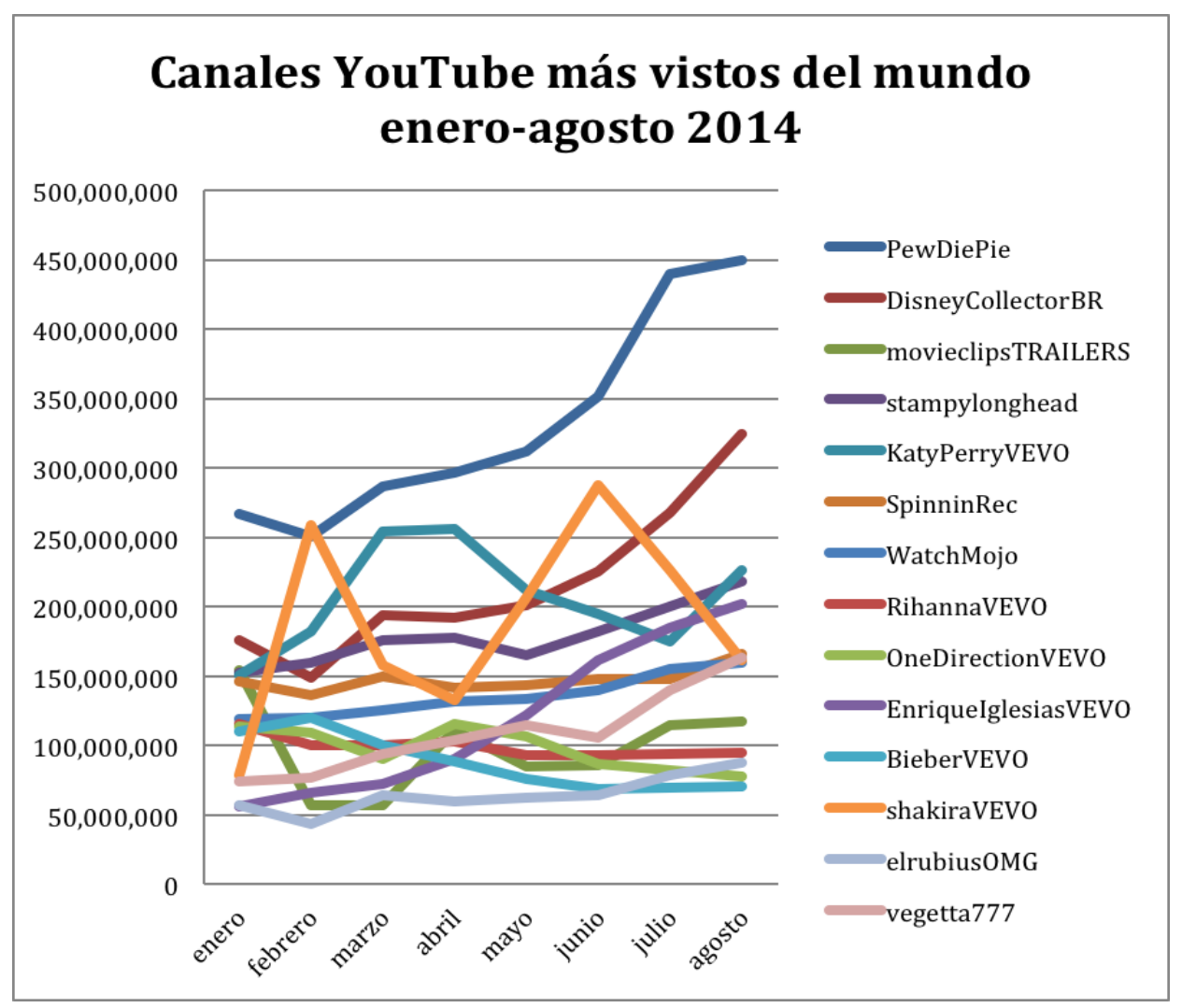

Fuente: elaboración propia a través de los datos ofrecidos por YouTube en cada uno de los canales

Esto significa dos cosas: a) que la industria convencional todavía no ha encontrado un espacio destacado en este nuevo entorno comunicativo, y b) que está surgiendo una nueva categoría de agentes en este escenario digital que cada vez adquieren un mayor peso. Se trata de las Redes de Canales en YouTube o MCN (Multi Channel Network). Son compañías u organizaciones creadas para mediar en esos entornos de creadores, audiencias y publicidad. Son los agentes llamados a poner orden, gracias a su conocimiento experto del nuevo modelo de diseño que se está instaurando en YouTube. La novedad aportada por estas productoras estriba en que son empresas genuinamente digitales que desarrollan o ayudan a desarrollar canales de todo tipo de categorías (música, comedia, lifestyle, juego, deporte, 
noticias, niños, educación). Conectan directamente los contenidos con la audiencia y con los agentes económicos.

¿Qué está haciendo la industria convencional en este entorno? Ahora mismo está desarrollando dos estrategias diferenciadas y complementarias: (i) utiliza YouTube como altavoz de sus contenidos en el entorno digital; y (ii) está intentando cobrar protagonismo en YouTube vía adquisición o formando parte del accionariado de estas nuevas Networks. La meta de la industria convencional es aprovechar el conocimiento que estos nuevos agentes tienen del entorno digital. Así, pretenden hacer contenidos específicos con ellos para YouTube. Quieren llegar a una audiencia que ya no está descubriendo sus contenidos. Estas nuevas empresas también ofrecen soluciones tecnológicas para posicionar los contenidos y los canales en YouTube; aportan servicios de apoyo en la gestión de derechos de contenidos de terceros para su utilización en la red (Tubefilter, 2012b), y aglutinan un conocimiento experto del comportamiento de la audiencia en un nuevo entorno comunicativo, para encontrar la demanda global de consumo.

\subsection{Contribución realizada por los usuarios en YouTube: De consumidores pasivos a agentes interactivos}

Cuando surge YouTube, la principal característica de la Web 2.0. es que hay una parte de los usuarios que quieren dejar de ser espectadores pasivos y desean participar de un modo activo en el proceso comunicativo (Cabrera, 2010). Esa participación se puede materializar en la producción de contenidos (textos, fotos, videos) o, simplemente, con la aportación de opiniones (foros, encuestas, chats), o recomendaciones de contenidos a través de un sistema de compartición de esos contenidos o de suscripción. Pero no todos los usuarios son agentes activos en YouTube.

Patricia G. Lange identifica 5 tipos distintos de usuarios. (i) Antiguos participantes. Personas que en su día fueron activos en YouTube y que en la actualidad mantienen su cuenta abierta solo para comentar o visionar algún video. (ii) Usuarios ocasionales. No suelen tener una cuenta. Acceden a la plataforma para buscar algo concreto, o porque 
un tercero les ha enviado un enlace. (iii) Participantes activos. Tienen cuenta, suelen comentar videos de terceros y en ocasiones suben videos propios a la plataforma. (iv) Youtubers. Son personas comprometidas con la plataforma. Generan contenidos con asiduidad, participan en debates, establecen una fuerte relación de compromiso con la plataforma, y normalmente pasan al menos una hora diaria en YouTube. (vi) Celebridades de YouTube. Son youtubers que han conseguido éxito con sus contenidos. Se convierten es prescriptores y agentes con clara influencia en el entorno de YouTube a través de sus videos, comentarios, boletines, u otras formas de interacción (Lange, 2007:4).

Ante la variedad de comportamientos de los usuarios, cabe preguntarse qué les lleva a inclinarse a ir hacia delante, para crear con los contenidos o interactuar con ellos, y por qué acaban siendo fans. Para tratar de contestar a estas preguntas, se pueden encontrar razones tanto en criterios sociales, como culturales, históricos y estéticos.

1) Por lo que respecta a los criterios sociales, se trata de la construcción de una identidad propia en la red. En función de los canales que un individuo siga, de los contenidos que recomiende, o de los comentarios que haga, está construyendo una personalidad virtual que, en ocasiones, puede ser distinta a la personalidad real ${ }^{10}$. A través de esa identidad puede sentirse parte de una comunidad y llegar a convertirse en prescriptor, es decir, en fuente de información para seguir a otros (Lange, 2008) ${ }^{11}$.

\footnotetext{
10 "People don't just suscribe because they want to get the content, they suscribe because they want to be a suscriber. They want to be able to say $\mathrm{Oh}$ yeah, Vice totally, I'm suscribed like I've already seen all their stuff. I'm as cool as Vice. That's what's it about, it's about them" (Stevens, 2014).

${ }^{11}$ Relacionado con esto hay también un claro elemento de identificación. ¿Por qué tienen éxito los canales de youtubers de videojuegos?, por ejemplo. En realidad se está portando un modelo real que puede servir de pauta de comportamiento y de identificación. Detrás subyace un modelo descriptivo "Yo también podría hacerlo".
} 
2) En cuanto a los criterios culturales, la estructura abierta de YouTube, combinada con las redes sociales, les permite dar a conocer cosas que piensan que son valiosas.

3) También intervienen criterios históricos: les permite sentirse agentes activos en algo que puede tener trascendencia histórica.

4) Asismimo hay un componente estético: se convierten en fans de un contenido por su belleza, armonía, o equilibrio.

Una vez que ya se puede predecir el comportamiento de la comunidad fan en Internet, entonces se puede prescribir qué características deben tener los contenidos y la estrategia comunicativa, para que los canales tengan éxito en este nuevo escenario digital ${ }^{12}$. El diseño de la estrategia comunicativa -en cuanto a los contenidos- se basa en unos elementos comunes. Se establecen una vez que se tiene ese conocimiento experto de la parte tecnológica (funcionamiento de los sistemas de búsqueda de Google) y de la parte social (tipo de usuarios y su comportamiento en el entorno digital). Tras un primer periodo de observación del nuevo fenómeno comunicativo, se pueden identificar los elementos necesarios y suficientes para que la estrategia comunicativa pueda convertirse en un éxito.

\section{Caracterización científica del nuevo fenómeno comunicativo de YouTube: objetivos, procesos y resultados}

Después de un primer periodo de observación del fenómeno comunicativo estudiado, se pueden establecer las bases para una segunda tarea: la "cientificación" (scientification) de unas prácticas profesionales emergentes (Niiniluoto, 1993 y 2014). Consiste en extraer, a partir de las pautas profesionales, criterios asumidos para los objetivos y los procesos que puedan llevar los resultados buscados. En esto se aprecia que las Ciencias de la Comunicación son Ciencias Aplicadas, en cuanto que buscan resolver problemas

${ }^{12}$ Sobre predicción y prescripción en las Ciencias de Diseño, cfr. GONZALEZ,
W. J. (2007). "Análisis de las Ciencias de Diseño desde la racionalidad limitada,
la predicción y la prescripción". En GONZALEZ, W. J. (ed), Las Ciencias de
Diseño: Racionalidad limitada, predicción y prescripción. A Coruña: Netbiblo, pp. 3-38.
GONZALEZ, W. J., (1998). "Prediction and Prescription in Economics: A
Philosophical and Methodological Approach", Theoria, v. 13, n. 32, pp. 321-345. 
comunicativos concretos $y$ trabajan con predicciones $y$ prescripciones. Para cumplir con este cometido de la "cientificación" que permita obtener soluciones operativas a problemas concretos, estas Ciencias han de indagar en los fenómenos comunicativos. En el caso de YouTube, hay que ser conscientes de la resolución de problemas en cuanto condicionada por la novedad del propio fenómeno comunicativo y por el entorno en el que se desarrolla.

Dentro de este marco aplicado, las Ciencias de la Comunicación han de ser capaces de identificar las metas comunicativas que buscan los agentes y los diseños que subyacen en los modelos comunicativos (con sus objetivos, procesos y resultados). A partir de ese momento, ya se pueden establecer métodos de investigación científicos. Primero han de poder predecir la evolución de los nuevos fenómenos mediante modelos sobre el futuro posible- $y$, después, han de ofrecer prescripciones para la actuación, esto es, han de dar pautas que orienten para resolver problemas concretos (González, 2007c).

\subsection{El nuevo marco teórico: Las Ciencias de la Comunicación como Ciencias Aplicadas de Diseño}

El marco teórico ha de estar conectado con los fenómenos estudiados. En este caso, la comunicación, en general, y YouTube, en particular, surgen como un fenómeno intencional, que está modelado por objetivos, procesos y resultados. Estos tres elementos señalados son característicos del campo de estudio de las Ciencias de Diseño y potencian las posibilidades humanas mediante la resolución de problemas concretos. Para la potenciación de las posibilidades humanas, la comunicación utiliza artefactos tecnológicos como soporte para la transmisión, distribución, producción y almacenamiento de los contenidos audiovisuales, todos ellos componentes de las Ciencias de lo Artificial. (Arrojo, 2007). Es decir, para que se produzca novedad en los nuevos entornos comunicativos es necesario que haya la Tecnología adecuada en los procesos.

(i) Hay un componente social -las acciones de los agentes en un medio social- que acompaña al diseño artificial. Esta dualidad de las Ciencias de la Comunicación -social y artificial- le confiere 
complejidad. (ii) Hay también una vertiente estructural y otra dinámica, pues el diseño comunicativo está en continua evolución. (iii) Ese diseño tiene unos objetivos concretos, marcados por las propias metas del agente comunicativo. Después, la viabilidad depende de una serie procesos, que tienen un componente contextual: dependerán de los medios disponibles en un entorno social, económico, tecnológico, político y legislativo determinado. Con estos procesos se intenta conseguir unos resultados que alcancen metas nuevas, cada vez más sofisticadas. Esos resultados han de plantearse a partir de las metas inicialmente marcadas, que buscan dilatar las posibilidad humanas existentes. Estos diseños con sus objetivos, los procesos que siguen y los resultados obtenidos constituyen el campo de estudio de las Ciencias de lo Artificial, en concreto de las Ciencias Aplicadas de Diseño. (iv) Otro elemento de complejidad de estas disciplinas es que tienen un alto nivel de dependencia respecto de las Tecnologías.

\subsection{El enfoque metodológico para el estudio del nuevo fenómeno comunicativo: La sobriedad de factores (los parsimonious factors)}

Desde las Ciencias de la Comunicación se puede estudiar la Web 2.0 -origen, configuración y límites- y, en concreto, la aparición de YouTube, que ha producido un auténtico cambio de fondo respecto de los diseños comunicativos existentes. Existe una auténtica novedad en los procesos de relación de los agentes: Se establece una relación de horizontalidad entre el talento creativo y los usuarios que interactúan con esos contenidos. Así, ahora se establecen flujos de relación bidireccionales.

No todos los usuarios están dispuestos a explotar esta posibilidad al máximo y hay quien se conforma con utilizar la plataforma como un mero escaparate de visionado de videos. Pero los procesos de participación entre los agentes (la vertiente "externa") ha provocado cambios estructurales en el modelo comunicativo (la componente "interna"). Así, el nivel de conversación directa y bidireccional entre productores, usuarios y marcas comerciales ha obligado a cambiar los objetivos y los procesos de producción y programación de los agentes. 
El análisis metodológico de las Ciencias de la Comunicación debe atender a los elementos señalados de complejidad para su configuración como Ciencia de Diseño, que trata de dar solución a problemas comunicativos concretos en un entorno dinámico. Por este motivo, primero hace falta identificar el diseño que está detrás del nuevo fenómeno comunicativo, en función de los objetivos que se pretendan alcanzar. Al estar en constante evolución, los diseños se apoyan en criterios profesionales que intentan adaptarse al entorno cambiante, como la aparición de YouTube en su momento, y su posterior evolución. A partir de ahí es necesaria la investigación, para poder cientificar los comportamientos observados y guiar las pautas de actuación para el futuro, que se dan en un entorno cambiante. Después, han de identificar la sobriedad de factores (parsimonious factors): los elementos necesarios y suficientes que abarcan el sistema comunicativo considerado.

Para identificar la sobriedad de factores, hay que partir del principal objetivo comunicativo de YouTube: se creó para que los contenidos puedan ser encontrados de manera accesible en la plataforma de distribución. Después de un periodo de observación, se pueden identificar los elementos estructurales que, para facilitar su visualización dentro de este entorno, deben tener esos contenidos audiovisuales: (i) tener temática clara; (ii) estar dirigidos a una audiencia muy definida; (iii) ser fácilmente compartibles; (iv) estar accesibles para que cada pieza se pueda entender por sí misma; y (v) han de promover la interactividad con los usuarios, a través de una conversación directa que se refleje en los propios contenidos ${ }^{13}$.

Estos cinco elementos son comunes a todos los contenidos de éxito de YouTube. Cabe considerarlos necesarios para poder establecer una estrategia creativa de éxito. a) Esto viene a corroborar la hipótesis de que existe un nuevo modelo comunicativo, y b) en este nuevo modelo la gente recibe mejor la comunicación cuando esta es inmediata, focalizada e interactiva. Pero el cambio comunicativo introducido por YouTube es tan profundo que también atañe al

\footnotetext{
${ }^{13}$ Para conseguir esta interactividad, los creadores recurren en ocasiones a herramientas adicionales al propio entorno de YouTube como otro tipo de redes sociales, videoblogs, etc.
} 
propio concepto de programación. Para que los usuarios puedan descubrir los contenidos e interactuar con ellos, es necesario aportar un orden interno en la propia estructura del sistema, de modo que permita la aparición de nuevos elementos de programación adaptados a las características específicas de la plataforma. Esos nuevos elementos son dinámicos y han evolucionado con el propio desarrollo de YouTube.

El orden interno en la estructura se consigue a través de las categorías en las que se engloban los canales. A partir de ahí, los elementos dinámicos que conforman las nuevas reglas de programación en la plataforma son cuatro: 1) los algoritmos de búsqueda que se establecen en los robots de YouTube; 2) las recomendaciones de contenidos que hace la plataforma a partir de los datos que va aportando el usuario a través de su navegación e interacción con la plataforma; 3) las recomendaciones de los prescriptores en el entorno digital; y 4) las estrategias implementadas por los nuevos agentes mediadores (MCN) para conseguir contenidos "descubribles" para los usuarios.

En cuanto a los factores externos, que son aquellos que atañen a los usuarios y al medio social en el que tienen lugar, también hay cambios. En el entorno de YouTube se le brinda la oportunidad de relacionarse directamente con la fuente, con el creador. Incluso puede dejar de ser un meno usuario a convertirse en "prosumidor": genera contenido mientras lo consume. En este escenario, los youtubers deben retroalimentar sus propios contenidos con las aportaciones de los ciudadanos. Esto supone una interacción dinámica en los objetivos, procesos y resultados respecto a lo que hacen los profesionales de los diseños.

\subsection{Resultados esperables a medio y largo plazo en cuanto fenómeno comunicativo}

Detrás del diseño de YouTube, junto al fenómeno comunicativo y su componente social, hay una empresa con unos objetivos empresariales que acompañan a los comunicativos y los sociales. Hay entonces tres factores en liza que inciden en los resultados esperables 
a medio y largo plazo: el comunicativo, el social y el empresarial. Los tres hacen que el modelo comunicativo de YouTube se vaya actualizando en el tiempo, a medida que se adquiere un mayor conocimiento del papel que desempeñan cada uno de los agentes, y de las posibilidades que propicia el propio modelo en sí mismo. Una vez que ese modelo ya está asentado, el siguiente objetivo es que cada vez resulte más atractivo y consiga ampliar su radio de acción.

Una vez pasado un primer periodo de observación del fenómeno, las Ciencias de la Comunicación, entendidas como Ciencias Aplicadas de Diseño, están en disposición de poder hacer cientificación de lo que hasta ahora eran unas meras prácticas profesionales, sociales y empresariales (con su componente tecnológica). El conocimiento experto que ya se tiene de YouTube permite predecir el futuro posible y, después, hacer la prescripción del fenómeno, es decir, orientar qué se puede hacer. Estas pautas de actuación, tras delimitar el futuro accesible, consisten en señalar qué pasos se deben dar para ampliar este fenómeno comunicativo. Una vez hecha la sucesión entre predicción y prescripción, se observa los resultados: qué funciona y qué no en este ámbito real.

Después, de nuevo, se pueden predecir los resultados esperables (la predicción): cómo cabe esperar que evolucione la plataforma, sobre la base de la información actualmente disponible, para dar las prescripciones adecuadas para resolver los problemas planteados. A mi juicio, esto se traduce en lo siguiente:

(i) YouTube continuará la evolución que comenzó hace ya algunos años, de plataforma de vídeos a red social, hasta llegar a convertirse en un medio de comunicación en sí mismo, por volumen de contenidos y por agentes implicados en su comunidad.

(ii) Cada vez habrá un mayor espacio en la plataforma para nuevos creadores que se profesionalicen.

(iii) El éxito de YouTube está suponiendo ya un efecto llamada para otras empresas que han nacido en su propio entorno. El universo de plataformas online irá incrementándose 
para dar lugar a un nuevo ecosistema de medios digitales mucho más complejo que el que tenemos ahora.

(iv) Para poder continuar expandiéndose en un entorno de nueva competencia, YouTube necesita ampliar los segmentos de edad (por arriba y por abajo). Para conseguir esto, debe ampliar también el segmento de contenidos. La plataforma irá evolucionando de la cultura de lo efímero a otro tipo de contenidos más profesionales, que satisfagan la demanda de un público más adulto.

(v) Si se consigue dar ese salto cualitativo, se irá desarrollando un modelo premium de contenidos de pago.

(vi) Se producirá una evolución en el tipo de usuario que pasará de ser un usuario más genérico a un usuario más especializado.

(vii) Continuará ampliando la cobertura internacional. Para ello es necesario que se mejore el sistema de subtitulado de los contenidos.

\section{Consideraciones finales}

YouTube ha permitido el desarrollo de un nuevo modelo audiovisual, que solo es posible en un entorno socio económico y cultural desarrollado ${ }^{14}$, que demanda un nuevo tipo de dinámicas comunicativas, representadas por la cultura de la Web 2.0 y donde su racionalidad está orientada hacia algo virtual. Hay una serie de realidades que no son explicables en el modelo audiovisual tradicional, como el hecho de que los usuarios desarrollen una personalidad virtual propia, en función de cuál sea su

\footnotetext{
${ }^{14}$ Para que un modelo de estas características se pueda desarrollar es necesario, por un lado, disponer de recursos tecnológicos suficientes (software, hardware y capacidad de conexión). Por otro lado, es necesario disponer de tiempo libre para dedicarlo al ocio y a la expresión de la creatividad. Ese tiempo libre solo se tiene cuando se han conseguido satisfacer las necesidades más básicas de subsistencia. Es decir, en las sociedades más desarrolladas desde un punto de vista social y económico.
} 
comportamiento en la plataforma. En un entorno natural el ser humano es el que es; en un entorno social la identidad viene dada por la aceptación o reconocimiento social; y en un entorno digital, a través de las redes sociales, se puede llegar a generar una nueva realidad: el individuo es en función de cómo es percibido a través de una pantalla.

En este nuevo modelo el individuo, al menos de un modo aparente, es el centro de proceso comunicativo. Tiene a su disposición un nuevo entorno para expresarse libremente, en igualdad de oportunidades que cualquier otro agente, para elegir qué contenidos quiere consumir, y para decidir qué grado de interactividad quiere desarrollar con sus iguales. La acción individual de cada uno de esos agentes es lo que permite construir comunidades virtuales, sin fronteras geográficas, a través de una Tecnología transparente, al servicio de permitir esa interconectividad global e inmediata.

Este escenario, aparentemente democrático y de estructura horizontal, está sustentado en un diseño comunicativo que ha desarrollado unas dinámicas de uso interno en los procesos (marcadas por la propia plataforma o por los nuevos agentes que aparecen en este ecosistema) que están estableciendo un nuevo orden de jerarquías, distinto a las que rigen el sistema audiovisual convencional.

Esas jerarquías vienen marcadas por el conocimiento experto del comportamiento de los individuos en el nuevo entorno. Ese cocimiento experto tiene varios criterios: tipo de contenidos que se consumen, características narrativas de los contenidos que más se consumen; tipologías y grados de interacción más demandadas y más efectivas; tiempos de visionado.

En el panorama actual hay dos tipos de agentes que acumulan ese conocimiento experto: i) la propia plataforma a través de algoritmos de búsqueda y análisis de los datos a gran escala; y ii) los nuevos agentes profesionales que han nacido ya en este entorno digital y que manejan los nuevos usos, los nuevos lenguajes y las nuevas dinámicas de trabajo en este entorno.

El sector audiovisual tradicional necesita ser un agente activo en el nuevo entorno. Por el momento, entiende Internet como una 
extensión de su modelo de negocio convencional. Ha comenzado a hacer tímidas incursiones a través de la creación de canales en YouTube. De este modo, consigue aumentar el tiempo de exposición de sus contenidos, crear marca alrededor de ellos y que más gente los descubra. No obstante, a medio plazo, su papel en el nuevo escenario ha de ser más activo, si no quiere perder peso dentro de la industria.

Desde el año 2010 están emergiendo un nuevo tipo de empresas especializadas en gestionar los derechos de propiedad intelectual de los contenidos. Su objetivo es que los usuarios puedan utilizar los contenidos profesionales y expresar con ellos su contenido creativo. Esto supone un cambio en la mentalidad empresarial sin precedentes. La industria convencional ha empezado a entender que los usuarios desean interactuar de una manera activa con sus contenidos y que esto los retroalimenta. Un claro ejemplo es la película "Frozen" de la factoría Disney. En este caso, la major permitió que los usuarios utilizasen las imágenes y el audio de la película sin restricciones. Esto dio lugar a miles de videos sobre la temática de la película con millones de visionados en todo el mundo.

El sector tradicional no perderá peso siempre y cuando desarrolle políticas de programación complementarias en el entorno de Internet. Han de ser actuaciones que permitan que sus propios contenidos sean descubribles por un nuevo tipo de usuario que tiene unas pautas de comportamiento distintas a las convencionales. Por este motivo, la industria convencional necesita hacerse con el nuevo talento creativo, con los expertos en los nuevos lenguajes y en las nuevas narrativas del entorno audiovisual. Esta realidad constatada permite predecir que cada vez tendrán una presencia mayor, en el entramado audiovisual, las Redes Multicanales de Networks.

\section{Bibliografía}

ALEXA INTERNET, INC. (2014). Top sites. The top 500 sites on the web. The web information company. Disponible en: http://www.alexa.com/topsites. (Acceso 12.10.14).

BURGESS, J. y GREEN, J. (2011). YouTube: online video and participatory culture. Cambridge: Polity Press. 
CARLOSS, A. (2014). “The power of Choice”. Conferencia del Global head of enterteinment Youtube USA, en Mipcom el 8 de abril de 2014. Disponible en: https://www.youtube.com/watch?v=GrpolzBsdq8. (Acceso 10.2.2015).

CNNExpansión.com (2014). Vevo busca seducir a usuarios de YouTube. Disponible en:

http://www.cnnexpansion.com/tecnologia/2014/05/01/vevodesea-seducir-a-usuarios-de-youtube. (Acceso 10.12.2014).

CHENG, X., DALE, C., y LIU, J. (2007). Understanding the characteristics of Internet short video sharing: YouTube as a case study. Disponible en: http://arxiv.org/pdf/0707.3670.pdf (Acceso 09.12.2014).

DE LA TORRE, A. (2006). Web Educativa 2.0. Revista Electrónica de Tecnología Educativa. No 20. Enero. Disponible en:

http://www.uib.es/depart/gte/gte/edutece/revelec20/anibal20.htm - See more at: http://www.nosolousabilidad.com/articulos/web20.htm\#sthas h.fYFeQow7.dpuf. (Acceso 10.12.2014).

ERTIVI, M.C. y LEÓN, B. (2014). La comunicación de la ciencia a través del video online: contenidos populares en Youtube. En SIERRA, J. y RODRIGUES D. (coord..) Contenidos digitales en la era de la sociedad conectada. Madrid: Ed. Fragua, pp. 129-146.

FÍAS, A. (2014). El País

http://politica.elpais.com/politica/2014/11/14/actualidad/141 5995907 985209.html. (Acceso 10.12.2014).

FULLSCREEN (2014) https://www.fullscreen.com/es/artists-andcreators/ (Acceso 10.12.2014).

GALLARDO, J. (2010). La televisión tradicional quiere gobernar Internet. El fenómeno YouTube España. Euro Editions.

GARCÍA CAY, GARCÍA PEÑA, M., KENDALL LÓPEZ, L.G., LIMA FLORIDO, C.I. (2013). Youtube: la clave de los canales con mayor número de suscriptores en España. En PÉREZ RUFI, J.P. (Coord.) Industrias audiovisuales: producción y consumo en el s. XX (pp. 6-28). Málaga: Universidad de Málaga.

GONZALEZ, W. J. (2012a). "Las Ciencias de Diseño en cuanto Ciencias de la Complejidad: Análisis de la Economía, Documentación y Comunicación”. En GONZALEZ, W. J. 
(ed), Las Ciencias de la Complejidad: Vertiente dinámica de las Ciencias de Diseño y sobriedad de factores, A Coruña: Netbiblo, pp. 7-30.

GONZALEZ, W. J. (2012b) "Complejidad estructural en Ciencias de Diseño y su incidencia en la predicción científica: El papel de la sobriedad de factores (parsimonious factors)". En GONZALEZ, W. J. (ed), Las Ciencias de la Complejidad: Vertiente dinámica de las Ciencias de Diseño y sobriedad de factores. A Coruña: Netbiblo, pp. 143-167.

IAB MÉXICO (Interactive Advertising Bureau), Millard Brown y Televisa (2013). Estudio de consumo de Medios entre internautas mexicanos. $5^{\text {a }}$ edición. Disponible en: http://boletines.prisadigital.com/Estudio $\% 20 \mathrm{de} \% 20$ consumo $\% 20 \mathrm{de} \% 20$ medios $\% 20 \mathrm{en} \% 20 \mathrm{Mexico}$.pdf. (Acceso 10.12.2014).

KIM, J. (2012). The intitutionalition of YouTube: From user generated content to professionally generated content. Media, Culture \& Society, 34 (1), pp. 53-67.

LANGE, P. (2007). Commenting on Comments: Investigating Responses to Antagonismo on YouTube. Disponible en: http://anthropology.usf.edu/cma/Lange-SfAA-Paper2007.pdf. (Acceso 09.12.2014).

LANGE, P. (2008). Publicity Privete and Privately Public: Social Networking on YouTube. Journal of Computer-Mediated Communication (13), pp. 361-380.

MIER, C., PORTO-RENÓ, D., (2009). Blogosfera y YouTube como espacios para la exhibición de productos audiovisuales interactivos. Palabra Clave, V.12, n.2, diciembre 9, pp. 207-214.

O'RILLEY, T. (2005). What is 2.0? Design Patterns and Business Models for the Next Generation of Software. Disponible en: http://www.oreilly.com/pub/a/web2/archive/what-is-web20.html. (Acceso 14.01.2015).

LARRAÑAGA, J. y RUIZ, A. (2009): "El modelo de negocio de YouTube". En Icono 14, no 12, pp. 109-131 Disponible en: http://www.icono14.net/ojs/index.php/icono14/article/viewF ile/336/213. (Acceso 14.01.2015).

MAKERSTUDIOS www.makerstudios.com

PAREJO, M. (2014). Conferencia impartida en el Máster de Producción y Gestión Audiovisual, mayo, A Coruña. 
PÉREZ RUFÍ, J.P. (2011): "YouTube ya no es "tu televisión": cultura colaborativa y red comercial en el video online". En Revista Comunicación, no 9, Vol. 1, pp. 146-162. Disponible en: http://www.revistacomunicacion.org/pdf/n9/monografico/M 11.-

YouTube ya no es tu television cultura colaborativa $y$ red comercial en el video online.pdf. (Acceso 14.01.2015).

RIPERT, D. (2014): How to build a sustainable audience on YouTube. Conferencia del responsable de You'Tube Next Lab EMEA en Mipcom, Cannes, 9 de abril de 2014. Disponible en: https://www.youtube.com/watch?v=iV8sDDLZB2k. (Acceso 16.01.2015).

REALINREAL (2014). Disponible en: http://www.reelnreel.com/watchmojo-youtube-mcn-successstrategy-overview/ (Acceso 14.01.2015).

SNICKARS, P. y VONDERAU, P. (eds.) (2009). The YouTube reader. Estocolmo: National Library of Sweden. Disponible en: http://www.kb.se/dokument/aktuellt/youtube reader inledni ng.pdf. (Acceso 14.01.2015).

STEVENS, M. (2014). How to build a sustainable audience on YouTube. Conferencia del creador de Vsauce en Mipcom, Cannes, 9 de abril de 2014. Disponible en: https://www.youtube.com/watch?v=iV8sDDLZB2k. (Acceso 14.01.2015)

STRANGELOVE, M. (2010). Watching YouTube: Extraordinary videos by ordinary people. University of Toronto Press.

SUSTER, M. (2013). Why the Media has been Wrong about YouTube Networks. Disponible en:

http://www.bothsidesofthetable.com/2013/09/15/why-themedia-has-mostly-been-wrong-about-youtube/ (Acceso 22.02.2015).

TUBEFILTER (2012). http://www.tubefilter.com/2012/10/15/zefr-movieclipsbrand-copyright-youtube/

TUBEFILTER (2012, b). http://www.tubefilter.com/2012/10/15/zefr-movieclipsbrand-copyright-youtube/ 
YOUTUBE.COM https://www.youtube.com/yt/press/es/

ZEFR (2014). www.zefr.com 


\title{
La vídeo-noticia: tendencias en la prensa digital. El caso de The Guardian y la cobertura del Referéndum de Escocia
}

\author{
Sara Ortells-Badenes, Universitat Jaume I (Castellón), España

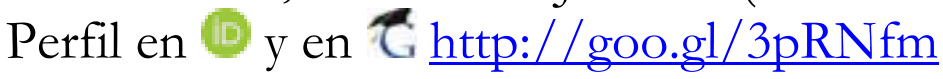

\begin{abstract}
Cada vez resulta más frecuente que los medios digitales incluyan contenidos en formato vídeo para narrar la actualidad. A pesar de que las vídeo-noticias están ganando peso en la oferta informativa, la mayoría de estas piezas proceden de agencias de noticias. No obstante, recientes estudios desvelan que los vídeos de producción propia, elaborados por los propios medios para ser consumidos exclusivamente a través de la web, también están experimentando un crecimiento paulatino. Este trabajo analiza el caso concreto de The Guardian, en su versión digital, y el uso de vídeos para realizar la cobertura del Referéndum de Escocia, un tema político incluido en la agenda del medio. El análisis realizado en este capítulo se centra en el estudio de los rasgos estilísticos de estos vídeos de producción propia. Su objetivo consiste en determinar cuáles son los rasgos que identifican este tipo de piezas. Los principales resultados revelan que en el caso de la cabecera británica se apuesta por reportajes en los que los ciudadanos son la fuente principal, el periodista aparece en pantalla y presentan una estética muy cuidada, características que fácilmente podrían asociarse al fenómeno del infoentretenimiento.
\end{abstract}




\section{Keywords}

Prensa digital, vídeos de producción propia, Referéndum de Escocia, The Guardian, videoperiodismo online.

\section{Introducción}

T A crisis que atraviesan los medios de comunicación genera la 1 necesidad de realizar una serie de cambios en la gestión y producción de los contenidos informativos. En el caso de la prensa, el actual escenario, junto con la total implantación de las tecnologías de la información, tiene un doble efecto: por un lado, facilita la creación de medios nativos digitales o pure players mientras que, por otro, favorece que las cabeceras tradicionales integren Internet en sus estrategias. Crean portales informativos online que, no sólo se convierten en plataformas de distribución de sus noticias offline, sino que devienen un factor clave para remodelar su modelo de negocio. Actualmente, esa apuesta por rentabilizar y potenciar sus versiones digitales se traduce en una tendencia creciente de elaborar contenidos producidos exclusivamente para ser consumidos a través de la web.

Estos cibermedios comparten una serie de características que los diferencian de la prensa clásica, tanto en la elaboración de las noticias, como en su posterior consumo. Siguiendo la propuesta de diferentes autores (Díaz-Noci y Meso-Ayerdi, 1998; Deuze, 2003; Salaverría, 2005; Larrondo, 2009; Guallar y Abadal, 2010; Masip, Díaz-Noci, Domingo y Micó-Sanz, 2010) las características fundamentales de la prensa digital son las siguientes: hipertextualidad, interactividad, multimedialidad, actualización, personalización y documentación. Se trata por tanto de una serie de cualidades que hacen únicos a estos medios puesto que permiten combinar diferentes tipos de contenidos y, además, integran la posibilidad de interactuar con la audiencia.

Precisamente, dada la peculiaridad de estos medios online, su implantación está ligada a la redefinición tanto de los perfiles profesionales de los periodistas, ahora más polivalentes y capaces de trabajar simultáneamente para diferentes soportes (Rintala y Suolanen, 2005; Scolari y otros, 2008; Micó-Sanz, 2011), como de los contenidos. Este tipo de publicaciones utiliza diferentes recursos para 
narrar la información. Si bien es cierto que el texto y las fotografías siguen acumulando el mayor peso informativo (Marrero Santana, 2008; Guallar, Rovira y Ruiz, 2010), cada vez las infografías pero, sobre todo, el vídeo cobran mayor relevancia (Masip y Micó-Sanz, 2008; Mayoral y Edo, 2014).

En este nuevo escenario online todos los medios, tradicionales y digitales, compiten en igualdad de condiciones, puesto que, haciendo uso de la multimedialidad pueden ofrecer información utilizando texto, fotografías, infografías o vídeo. Un cambio en la concepción de la oferta informativa que, por ejemplo, acaba con la idea clásica de que el vídeo sólo puede emitirse a través de la televisión, puesto que ahora cualquier medio en su versión online puede incluirlo como un elemento enriquecedor de la noticia (Guallar, Rovira y Ruiz, 2010).

Esta investigación se centra en el análisis del uso del vídeo por parte de la cabecera británica The Guardian en su versión digital durante la cobertura del Referéndum de Escocia celebrado el 18 de septiembre de 2014. El objetivo de este estudio es analizar la estrategia seguida por este periódico para documentar mediante vídeo-noticias esta temática dura, prevista en la agenda. A través de una metodología de análisis cuantitativo se ha comprobado el volumen de vídeos utilizado, su procedencia (producción propia o ajena) y sus características. Los principales resultados desvelan que, al igual que sucede en los medios españoles, los vídeos de producción propia son escasos pero de calidad superior a aquellos que proceden de otras fuentes.

\section{El uso de vídeos en medios digitales: una tendencia creciente}

La integración del vídeo en los cibermedios ha sido paulatina. A pesar de que los medios tradicionales más avanzados pusieron en marcha su versión digital a principios del año 2000 (Greer y Mensing, 2006), no fue hasta 2007 cuando realmente la presencia del vídeo empezó a ser relevante (Guallar, 2008). Actualmente, el uso de vídeos en los medios digitales es cada vez mayor, de hecho, resulta muy común encontrar noticias de este tipo en sus portadas (Mayoral y Edo, 2014). 
El incremento de este formato de noticia va ligado a la evolución constante que están experimentando los contenidos en Internet. A diferencia de los pure players, los medios tradicionales han tenido que adaptar sus modelos consolidados al entorno 2.0. La inclusión de vídeo-noticias está siendo lenta precisamente porque el desarrollo de estos medios también está siendo escalonado. Cabrera-González (2001) distingue cuatro fases que explican el progreso de este proceso: a) la facsimilar, b) la adaptada, c) la digital y d) la digital multimedia. En la primera etapa, la facsimilar, los contenidos ofrecidos por la versión digital de la prensa tradicional se basaba únicamente en clonar las noticias previamente publicadas en la versión en papel. En la segunda fase, la adaptada, se pasó a adecuar mínimamente esos contenidos offline al entorno web. Las dos últimas fases, la digital y la digital multimedia, se caracterizan por difundir contenidos producidos exclusivamente para el cibermedio. Esta última etapa, en la que nos encontramos inmersos actualmente, también ha sido denominada fase multimedia social puesto que, a parte de los contenidos multimedia, también se incluye el uso de las redes sociales por parte de los medios para dar difusión a sus contenidos e interactuar con la audiencia. Precisamente es en esta última fase en la que se potencia el uso del vídeo.

Existen diferentes factores que justifican que ese aumento en la publicación de vídeo-noticias se esté produciendo ahora. López (2008) señala tres motivos principales: a) las nuevas técnicas que permiten la compresión de datos facilitando que los vídeos sean menos pesados y conserven su calidad y que, por tanto, sean más fáciles de distribuir, b) el abaratamiento del acceso a Internet para los usuarios, así como la ampliación de la velocidad de descarga de datos que agiliza el visionado de estas piezas informativas y, c) la bajada en el precio de los equipos tecnológicos utilizados para hacer este tipo de noticias.

Todos estos avances favorecen la proliferación del uso de vídeos por parte de los cibermedios. Si bien es cierto que su presencia se incrementa notablemente en los últimos años, no todos los medios de comunicación lo integran del mismo modo. Micó-Sanz y Masip (2008) distinguen cuatro grandes tendencias en el panorama español: 
1) Portales informativos de medios audiovisuales que aparte de ofrecer contenidos en formato vídeo también apuestan por la integración de otros recursos multimedia.

2) Periódicos que empiezan a integrar vídeos en sus contenidos aunque todavía prevalecen los contenidos en formato texto.

3) Cibermedios que habilitan canales televisivos online asociados a su publicación.

4) Periódicos que dan un giro y abandonan las noticias en formato texto para convertirse en contenedores de vídeos.

En lo que respecta al tipo de vídeo-noticias, las posibilidades son ilimitadas, siguiendo la propuesta de López (2008) y Bradshaw y Rohumaa (2011) estos son los formatos más comunes:

- Noticias en formato vídeo: se trata de piezas informativas que normalmente proceden de agencias periodísticas, de medios tradicionales o de YouTube. Suelen presentarse embebidos en noticias que combinan texto y vídeo.

- Vídeo-noticia de producción propia: se trata de VTRs completos que además de imagen pueden contener voz en off, entrevistas y gráficos que ayuden a ilustrar la noticia. Realizados por el propio medio.

- Vídeo guías: se trata de vídeos que enseñan a los usuarios a hacer diferentes cosas, ya sean manualidades, recetas o a utilizar aparatos electrónicos.

- Vblogs: diseño de blog dentro del cibermedio que solo incluye vídeos.

- Streaming: retransmisiones en directo que pueden seguirse a través de la red.

- Programas realizados exclusivamente para ser difundidos a través de la red.

A pesar de que el peso del vídeo en las publicaciones online sigue creciendo, demostrando una sensibilidad notable por el uso de este tipo de contenidos, resulta curioso destacar que recientes investigaciones demuestran que el uso de vídeos de producción propia continúa teniendo una presencia casi residual, menos de uno de cada tres vídeos, siendo aquellas informaciones procedentes de 
fuentes ajenas las que siguen manteniendo una presencia mayor (Mayoral y Edo, 2014).

\section{Características de los vídeos en los medios digitales}

El videoperiodismo online no debe de entenderse como la "televisión en la web" (Bradshaw y Rohumaa, 2011: 106). Los vídeos producidos para los cibermedios tampoco deben de asociarse a contenidos de baja calidad o calidad amateur. A pesar de que la forma y los contenidos sean similares a la manera en que se ofrece la información en televisión, los vídeos creados para Internet poseen una serie de características propias, algunas tan específicas como su interactividad. La diferencia por tanto, no reside en el proceso de elaboración de la noticia, sino en la manera de contar las historias. El hecho de que en las redacciones digitales los plazos de entrega sean más flexibles favorece la realización de vídeos con una duración superior que, a su vez, permiten incluir características propias del documental (Bock, 2012). Incluso pueden propiciar la creación de nuevos formatos que permitan contar las historias de una manera diferente más adecuada para el entorno online. De hecho, Bock afirma que el uso de narrativas alternativas que contrastan con la manera tradicional de contar las noticias en televisión, favorece que los videoperiodistas online estén considerados como profesionales con un perfil más creíble y serio que los de los medios televisivos tradicionales.

La escasa producción propia de contenidos se traduce en la publicación de vídeos editados, por norma general, de manera muy básica (Masip, 2008). Lo más común es encontrar vídeos que únicamente incluyen imágenes sin ningún otro tipo de material o cortes de voz extraídos de ruedas de prensa, puesto que se conciben como elementos que complementan el texto de la noticia, contextualizan los acontecimientos o muestran algún tipo de información difícil de describir (Masip, Micó-Sanz y Meso, 2010; Mayoral y Edo, 2014). Asimismo, la calidad de imagen de este tipo de contenidos está directamente relacionada con la finalidad que persiga el periodista con la publicación de su vídeo. En el caso de los live blogs o crónica en directo (Salaverría, 2005) prima la inmediatez, y por 
tanto, no se espera una imagen cuidada porque prevalece el valor informativo por encima de la calidad de imagen. Por el contrario, en el resto de publicaciones primará la calidad y la duración será más extensa (Bradshaw y Rohumaa, 2011).

No existe consenso respecto a los rasgos estilísticos que deberían seguir para asegurar su éxito en Internet, pero sí que inciden en que la televisión es un medio de recepción masiva mientras que en Internet el consumo de estos contenidos es individual e interactivo y, por tanto, habría que adecuar el lenguaje y la imagen a este escenario (Cebrián Herreros, 2009; Bradshaw y Rohumaa, 2011). De hecho, no existen directrices que establezcan la duración de este tipo de vídeos. Se trata de un fenómeno que impulsa un formato que impone una nueva narrativa audiovisual basada en la fugacidad, el consumo compulsivo de pequeñas píldoras informativas y en la brevedad (Díaz Arias, 2009). Algunos investigadores aconsejan que no superen los tres minutos (Luckie, 2010; Masip, 2008), aunque explican que la importancia del tema será la que finalmente establecerá la duración del vídeo (Bock, 2012).

Tampoco existe ningún tipo de consenso sobre las temáticas puesto que cualquier información puede narrarse utilizando este formato. Sin embargo, algunos investigadores afirman que a pesar de que el vídeo sea cada vez la fuente más utilizada por los ciudadanos para mantenerse informado (Van der Haak, Park, y Castells, 2012) porque les resulta más atractivo (Canavilhas, 2007), se tiene que decidir muy bien qué temáticas se abordarán de esta manera y promocionar este tipo de contenidos puesto que se destinan muchos recursos económicos y humanos a su realización (Luckie, 2010).

\section{Metodología}

Se ha diseñado una metodología basada en un análisis cuantitativo de contenido para alcanzar los objetivos de esta investigación. La muestra toma como caso de estudio el periódico británico The Guardian en su edición online. El objetivo de este trabajo se centra en analizar la estrategia adoptada por este medio para integrar vídeos en su publicación digital. Se ha seleccionado un periodo de análisis que 
incluye la cobertura de un tema previsto en la agenda. De esta manera, se puede comprobar si su previsión incluye destinar recursos humanos y técnicos a la elaboración de vídeo-noticias de producción propia. El periodo que abarca este trabajo se extiende del 15 al 19 de septiembre de 2014, semana en la que se llevó a cabo la votación del referéndum de Escocia que tuvo lugar el día 18 de septiembre. Se ha seleccionado este periodo para poder incluir la cobertura previa y posterior a la votación. En total se han analizado 281 piezas informativas.

Para llevar a cabo esta investigación se ha diseñado un modelo para analizar las piezas informativas que se han publicado en la web. La investigación se ha llevado a cabo en dos fases. En la primera etapa se han analizado las 281 piezas que inicialmente conformaban la muestra para seleccionar únicamente aquellas noticias que incluyen vídeos. En total se han encontrado 38 piezas informativas que incluyen contenidos audiovisuales. Para analizar estos vídeos, se ha elaborado un modelo de análisis que incluye 60 variables divididas en 4 grandes grupos:

1) Posición y procedencia. Se determina si el vídeo analizado es de producción propia o si procede de fuentes ajenas (agencias de comunicación, otros medios, señales oficiales de ruedas de prensa, mítines...). Asimismo, también se clasificarán dependiendo de su posición en la noticia (vídeo como noticia independiente o combinado con texto).

2) Formato de noticia. Después de realizar un análisis preliminar se han seleccionado las siguiente categorías: reportajes, reportajes infográficos, pastillas y no comments. Asimismo, se ha incluido una categoría llamada "otros" para clasificar aquellos vídeos que no encajan en las propuestas anteriores.

3) Rasgos estilísticos. Se incluyen diferentes variables: duración de la pieza, uso de entradilla, redirección del vídeo al repositorio del medio, uso de cabecera de entrada y salida e infografía propia del medio, uso de voz en off y uso de música. Además, en esta sección también se analiza si se potencia la interactividad con los ciudadanos facilitando su compartición en las redes sociales o si permite dejar comentarios. 
4) Tipo de fuentes. Se ha incluido la siguiente tipología: político, ciudadano, experto y periodista.

\section{Exposición de resultados}

\subsection{Fórmulas de presentación de los vídeos}

Durante el periodo analizado se han publicado un total de 281 noticias en la versión online de The Guardian. Todas ellas forman parte de una sección especializada creada ad hoc para cubrir el referéndum de Escocia llamada Scottish Independence Blog. A pesar del elevado volumen de producción informativa tan sólo el 13,5\% de las noticias (38 en total) incluyen vídeos para enriquecer su contenido, 6 de producción propia y 32 de procedencia ajena.

Los datos obtenidos a partir de este análisis permiten determinar que The Guardian combina el uso de dos estrategias diferenciadas para integrar vídeos en sus contenidos dependiendo de la importancia otorgada a cada noticia. En los casos en los que el vídeo se erige como una vídeo-noticia, es decir, el vídeo contiene toda la información de la pieza, este se presentará de manera independiente, constituyendo por sí solo una publicación en el blog. El 63\% de los vídeos emitidos (24 en total) se han presentado como vídeo-noticias independientes, redirigiendo al lector al repositorio del medio para su visionado (Gráfico 1). Todas las noticias de producción propia, 6 en total, se han presentado como vídeo-noticias independientes, posiblemente para centrar la atención en la pieza audiovisual y, de esta manera, potenciar su visionado y posterior distribución a través de las redes sociales.

Tan solo en el 39\% de las ocasiones, 14 en total, el vídeo se concibe como un elemento que refuerza el texto de la noticia y aparece incrustado en una publicación que combina la parte escrita con imágenes en movimiento. Este tipo de vídeos amplían o contextualizan los hechos o, incluso, muestran algún tipo de información difícil de describir (Mayoral y Edo, 2014). Además, a diferencia de las vídeo-noticias independientes, en este caso, únicamente el $57 \%$ de estos reportajes, 8 en total, están enlazados a la videoteca del medio, puesto que los 6 vídeos restantes están 
hipervinculados directamente a su página de origen, YouTube. Por tanto, aquellos vídeos embebidos en entradas combinadas con texto sólo en la mitad de los casos pasan a formar parte de la videoteca del medio.

\section{Gráfico 1. Posición del vídeo}

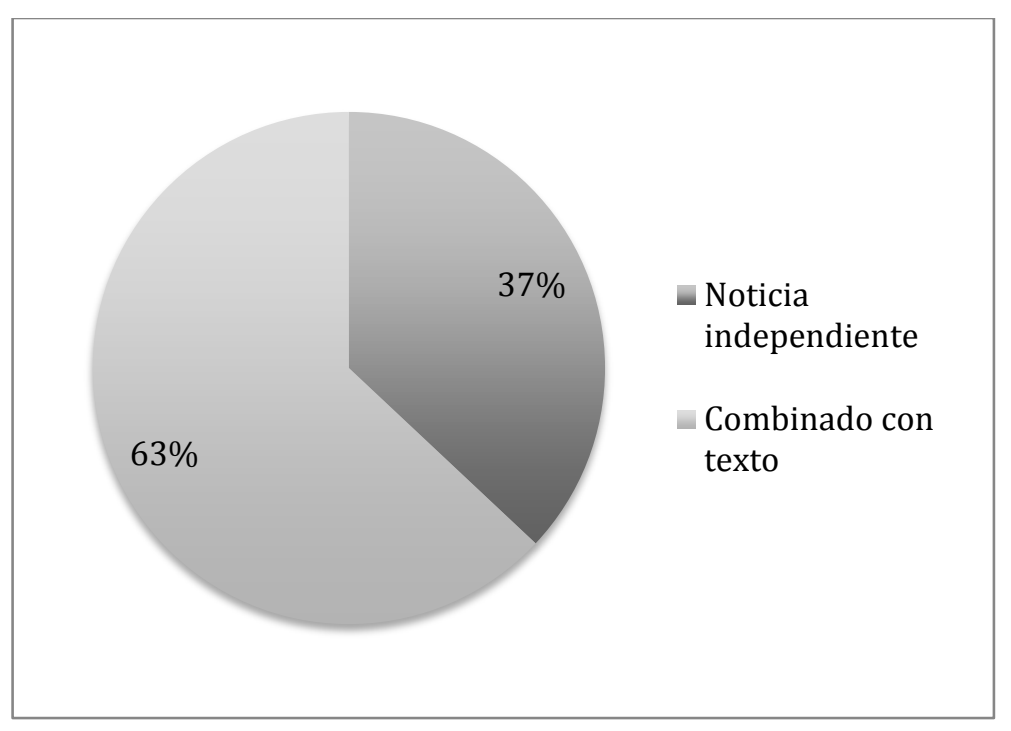

Fuente: elaboración propia

\subsection{Procedencia de los vídeos}

La cobertura de la celebración del referéndum de Escocia forma parte de la planificación a largo plazo de The Guardian. De hecho, el blog especializado Scottish Independence Blog empezó a publicar noticias sobre el tema de forma regular a parir del 1 de mayo de 2014. A pesar de que se trata de un tema previsto en la agenda, a lo largo del periodo analizado únicamente se han publicado 6 reportajes audiovisuales $(15,7 \%$ del total) creados exclusivamente para la versión online. Resulta relevante destacar que todas las vídeo-noticias de producción propia fueron publicadas entre el 15 y el 17 de septiembre, es decir, durante los días previos a la celebración de la votación. Ningún vídeo de producción propia fue incluido durante o después de la jornada de votación. Por tanto, al igual que reflejan las investigaciones llevadas a cabo en España (Micó-Sanz y Masip, 2008; López 2008; Mayoral y Edo, 2014) la elaboración de vídeos de producción propia en el caso de The Guardian es reducida. 
El 84,3\% de los vídeos restantes (30 en total) proceden de fuentes ajenas. El $80 \%$ de estas piezas han sido proporcionadas por agencias de noticias como ITN y Reuters; el 13\% por cadenas de televisión como la BBC o Skynews, y tan sólo el $6 \%$ proceden de fuentes ciudadanas o de imágenes de archivo (gráfico 2). A diferencia de lo que sucede con los vídeos de producción propia, en este caso, la mayor publicación de estos contenidos se produce el día previo a la votación (17 de septiembre: 8 vídeos) y el día posterior (19 de septiembre: 12 vídeos). Por tanto, actualmente, los vídeos de agencia siguen perfilándose como el recurso más utilizado para obtener vídeos para ser publicados por los cibermedios.

\section{Gráfico 2. Procedencia del vídeo}

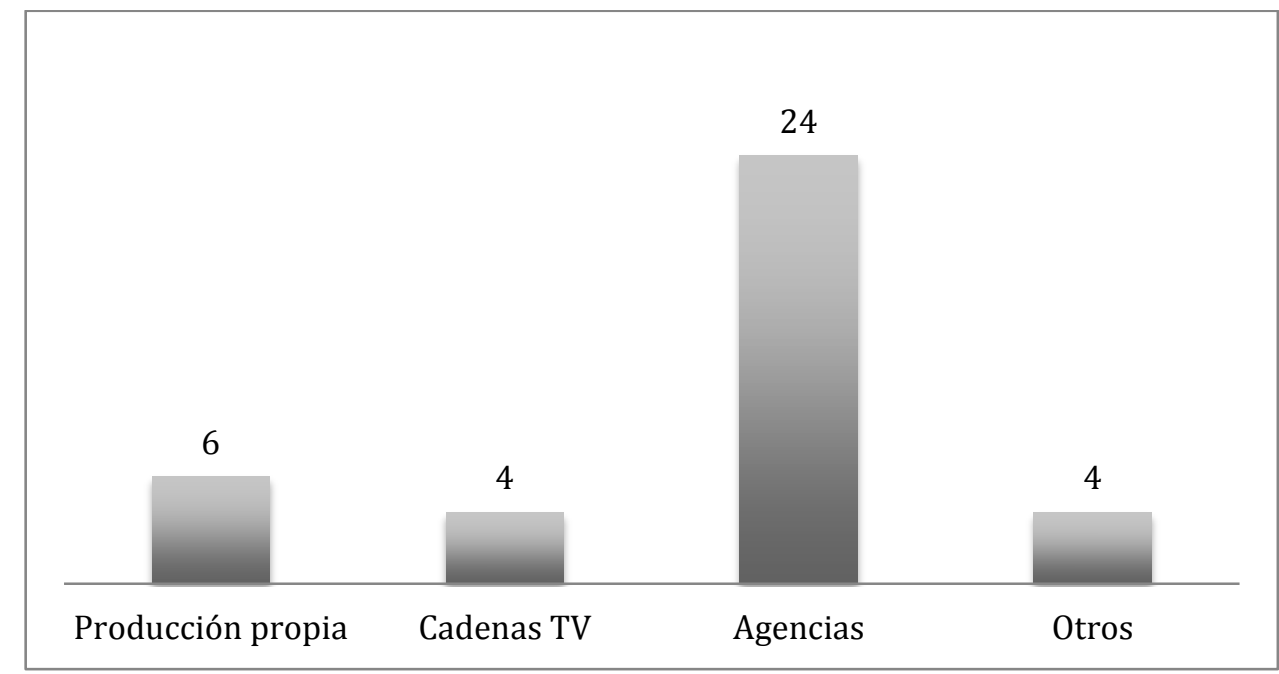

Fuente: elaboración propia

\subsection{Características de los vídeos: formatos de noticia}

En lo que concierne al tipo de formato utilizado en cada vídeo, se aprecian diferencias notables entre las noticias de producción propia y aquellas elaboradas por fuentes ajenas. Todas las vídeo-noticias de producción propia utilizan el formato del reportaje para presentar su información. Se han publicado cinco noticias producidas con imágenes reales y un reportaje elaborado íntegramente con 
infografías. Se trata de piezas audiovisuales con una duración que oscila entre los 02:39 minutos y los 09:21 minutos.

En el caso de las piezas con procedencia de fuentes ajenas al medio se combina el uso de diferentes formatos de noticia. El dato más relevante es que durante el periodo analizado no se ha emitido ningún reportaje. En este caso, el formato más utilizado es la pastilla, 22 piezas en total $(68,7 \%)$. El $54,5 \%$ de estas pastillas (12 en total) proceden de entrevistas pactadas, el 40,9\% (9 en total) están extraídas de ruedas de prensa, y el 4,5\% restante (1 pieza en total) de canutazos. Los no comments, piezas que únicamente incluyen imágenes y sonido ambiente, representan el 12,5\% del total de piezas de procedencia ajena, mientras que la variable "otros", que comprende fragmentos de programas o de series televisivas, representa el 18,7\% (Gráfico 3). En estas noticias, únicamente se han incluido imágenes reales para narrar la información, es decir, no se incluye ningún vídeo elaborado con infografía. Su duración oscila entre los 0:49 segundos y los 04:25 minutos, aunque durante el periodo analizado se ha encontrado el enlace a un capítulo completo de una serie que tiene una duración de 27:27 minutos.

\section{Gráfico 3. Uso total de cada formato}

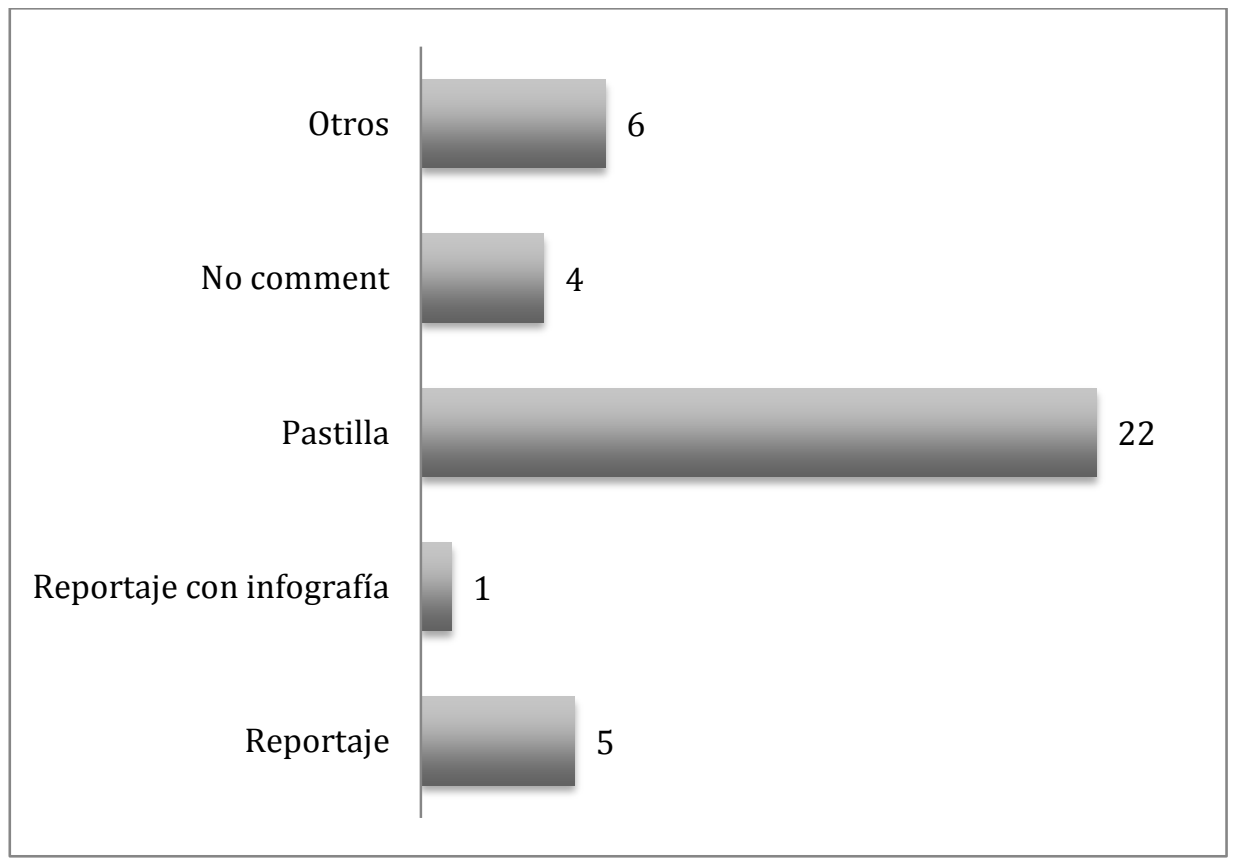

Fuente: elaboración propia 


\subsection{Características de los vídeos: rasgos estilísticos}

Todos los vídeos de producción propia comparten una serie de característica de presentación y edición que contribuyen a crear la imagen de marca del medio. Siempre van acompañadas por una entradilla redactada que presenta el contenido de la noticia. Además, todos van precedidos por la cabecera de The Guardian. Se trata de una cabecera corporativa de entrada y salida que dura 3 segundos. Además, excepto uno de los reportajes, que prescinde del uso de rótulos, todos utilizan infografía corporativa.

En cuanto a los rasgos estilísticos de edición de este tipo de noticias se caracterizan porque todas han sido producidas siguiendo un método de edición muy cuidado, utilizando en muchos casos características propias del reportaje documental: uso de diferentes escalas de plano, combinación de grabación con cámara al hombro y trípode, planos de duración superior a los 3 segundos, uso de voz en off para estructurar el vídeo e inserción de música para dotar de dinamismo a la pieza.

Por tanto, los datos revelan que aquellas vídeo-noticias producidas por The Guardian para su versión online se caracterizan por precisar una planificación y preproducción previa, puesto que los reportajes que se han analizado tienen una alta calidad tanto en la edición de la pieza como en el contenido de la misma.

La cosa difiere considerablemente en el caso de los vídeos de fuentes ajenas. En lo relativo a los rasgos estilísticos de estas piezas resulta necesario destacar que dado que su procedencia es variable, no se encuentran características comunes que contribuyan a reforzar la imagen de marca de The Guardian. Las fuentes de procedencia marcarán el estilo en cada una de las piezas. Por lo que respecta a la presentación de estas piezas el 65\% (21 en total) van acompañadas por una entradilla y el $75 \%$ de los vídeos (24 en total) van precedidos por la cabecera corporativa de The Guardian. En lo que respecta al uso de rótulos, el 53\% no lleva ningún tipo de infografía (17 en total), el $37 \%$ (12 en total) incluye infografía propia de The Guardian, y sólo el 9\% (3 en total) utiliza la infografía de la fuente de procedencia. 
Se han detectado mayoritariamente dos técnicas de grabación: a) imágenes realizadas en directo lanzadas por señales oficiales y b) imágenes grabadas con cámara al hombro. Por norma general, se trata de vídeos editados de manera muy sencilla en los que únicamente se ha limpiado el principio y el final del vídeo, es decir, no ha habido un proceso creativo en su edición puesto que se emiten casi idénticamente como las ofrecen las fuentes de procedencia. Ninguna de las piezas de fuentes ajenas incluye voz en off o música. Por tanto, la abundancia de vídeos de procedencia ajena se caracteriza por la sencillez de montaje, por no precisar una preproducción previa y por no contribuir a la formación de la imagen de marca del medio.

En cuanto a la interactividad, característica propia de los cibermedios, no existe ninguna diferencia entre los tipos de vídeos. Siempre se utiliza la misma estrategia. Todos los vídeos pueden ser compartidos a través de Twitter, Facebook, Google+, in Share y correo electrónico. Además, los usuarios pueden dejar comentarios en todas las noticias.

\subsection{Las fuentes informativas}

Los datos revelan que también existen diferencias en la tipología de fuentes utilizadas por las vídeo-noticias de producción propia y aquellas de procedencia ajena. Los vídeos elaborados exclusivamente por el medio se caracterizan por incluir principalmente fuentes ciudadanas. Todos los vídeos, excepto el reportaje realizado únicamente con infografía, tienen como protagonista principal a ciudadanos anónimos, y sólo uno de ellos contiene además a actores políticos. Se trata de vídeos que pretenden mostrar la opinión de los votantes. Además, en este tipo de vídeos de producción propia, el periodista cobra relevancia, se convierte en coprotagonista de la información. El reportero aparece en pantalla continuamente, incluso cuando realiza entrevistas y en 4 de los vídeos hace un speech.

El uso de fuentes informativas utilizadas por parte de aquellas piezas producidas por fuentes ajenas se caracteriza porque el 93,8 \% (presentes en 29 vídeos) de las fuentes incluidas en este tipo de piezas son actores políticos. Las fuentes expertas representan el 6,2\% 
(presentes en 3 piezas). Durante el periodo analizado no se ha detectado la presencia de ninguna fuente ciudadana en este tipo de vídeos. Además, en este tipo de piezas el periodista desaparece por completo, puesto que el peso recae directamente en las fuentes y la información.

\section{Gráfico 4. Tipología de fuentes informativas utilizadas en los diferentes vídeos}

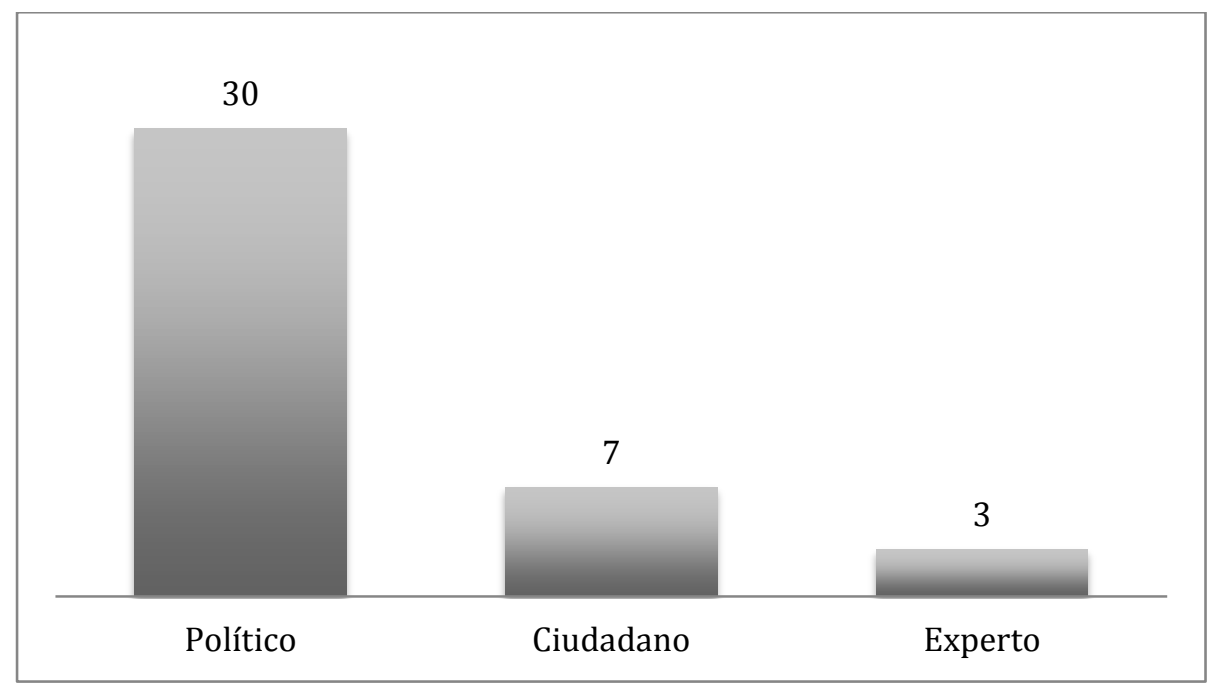

Fuente: elaboración propia

\section{Discusión}

Los datos obtenidos desvelan que al igual que en el caso español, el uso de vídeos ocupa un espacio significativo en la cabecera británica The Guardian. Asimismo, también se constata que los vídeos procedentes de agencias se convierten en la primera fuente de abastecimiento de este tipo de contenidos. A pesar de que las vídeonoticias de producción propia siguen teniendo una representación menor, es necesario subrayar que se trata de reportajes de gran calidad que pueden configurarse como una buena estrategia para desmarcarse de la competencia. Se trata de vídeos que tienen una duración superior a aquellos ofrecidos por la televisión tradicional, que no suele superar los dos minutos, y que adoptan las características propias del género del documental. Se trata de 
temáticas originales y exclusivas narradas a partir de imágenes de calidad.

Su fuente principal son los ciudadanos y, además, en este tipo de piezas, el propio periodista pasa a desempeñar un papel fundamental, no sólo como hilo conductor de la noticia con el uso de la voz en off, sino como coprotagonista de las piezas apareciendo en pantalla constantemente.

Se trata de un recurso en auge que pretende contribuir a la estrategia de marca del medio y que, por tanto, comparte una serie de pautas estilísticas que contribuyen a homogeneizar este tipo de piezas. El uso común de cabecera e infografía propia del medio permite unificar estos contenidos. A pesar de que la cobertura del referéndum de Escocia se trata de una temática ligada a las hard news, este tipo de vídeos de producción propia se caracterizan también por utilizar un lenguaje sencillo y buscar la ironía para mantener la atención del espectador.

El referéndum de Escocia es un tema de agenda, por esta razón, todos los vídeos de producción propia se han publicado en los días previos a su celebración, puesto que este tipo de contenidos precisan una planificación previa.

Para investigaciones futuras sobre este tema sería necesario analizar más vídeos de producción propia de The Guardian para determinar las características generales que comparten estas piezas. Este análisis preliminar permite esbozar algunas hipótesis sobre cuáles podrían ser esos rasgos identificativos. Con un análisis más profundo se podría determinar si la estrategia diseñada por los cibermedios para elaborar sus vídeos de producción propia se asemeja a las características propias de los programas de infoentretenimiento (Ortells-Badenes, 2011). Puesto que características como el uso de vídeos con mayor duración, la apuesta por el uso de imágenes cuidadas pero con prevalencia del uso de la cámara al hombro, convertir al ciudadano en el protagonista de la información, la adopción del periodista de un rol de coprotagonista de la noticia y la búsqueda de un tono irónico, son rasgos fácilmente reconocibles en los programas de infoentretenimiento. 


\section{Bibliografía}

BOCK, A. (2012): "Newspaper journalism and video: Motion, sound, and new narratives". En New Media \& Society, 14(4), pp. 600616.

BRADSHAW, PAUL y ROHUMAA, LLISA (2011): The online Journalism Handbook. Skills to survive and thrive in the digital age. Essex: Pearson.

CABRERA GONZÁLEZ, M. A. (2001): “Convivencia de la prensa escrita y la prensa online en su transición hacia el modelo de la comunicación multimedia". En Estudios sobre el mensaje periodístico, 7, pp. 71-78.

CANAVILHAS, J. (2007): Webnoticia. Propuesta de modelo periodístico para la www. Covilhà, Livros Labcom.

CEBRIÁN HERREROS, M. (2009): “Comunicación interactiva en los cibermedios". En Comunicar, 33 (17), pp. 15-24.

DÍAZ ARIAS, R. (2009): "El vídeo en el ciberespacio: usos y lenguajes". En Comunicar, XVII (33), pp. 63-71.

DÍAZ-NOCI, J. y MESO-AYERDI, K. (1998): "Desarrollo del periodismo electrónico". En Elprofesional de la información, 7 (12), pp. 4-11.

DEUZE, M. (2003): "The web and its journalism: considering the consequences of different types of newsmedia online". En New Media \& Society, 5 (2), pp. 203-230.

GREER, J. y MENSING, D. (2006): "The evolution of online newspapers: a longitudinal content analysis, 1997-2003”. En Xigen Li (Ed.): Internet newspapers: the making of mainstream medium. New Jersey: Lawrence Erlbaum Associates.

GUALLAR, J. (2008): “Prensa digital en 2007”. En Anuario ThinkEPI, pp. 102-108.

GUALLAR, J. y ABADAL, E. (2010): “The digiatal press archives of the leading Spanish online newspapers". En Information Research, 15 (1). Disponible en: http://InformationR.net/ir/15$1 /$ paper424.html.

GUALLAR, J., ROVIRA, C. y RUIZ, S. (2010): "Multimedialidad en la prensa digital. Elementos multimedia y sistemas de recuperación en los principales diarios digitales españoles". En Elprofesional de la información, 19(6), pp. 620-628. 
LARRONDO, A. (2009): Los géneros en la redacción ciberperiodística. Contexto, teoría y práctica actual. Bilbao: Servicio Editorial de la Universidad del País Vasco.

LÓPEZ, G. (2008): "La eclosión del vídeo como mecanismo de comunicación política en Internet". En Congreso fundacional de la Asociación Española de Investigadores de la Comunicación, Santiago de Compostela.

LUCKIE, M. S. (2010): The digital Journalist's Handbook. Estados Unidos: Mark S. Luckie.

MARRERO SANTANA, L. (2008): "El reportaje multimedia como género del periodismo digital actual. Acercamiento a sus rasgos formales y de contenido". En Revista Latina de Comunicación social, 63, pp. 348-367.

MAYORA, J. y EDO, C. (2014): “Evolución de la producción audiovisual en cinco cibermedios españoles". En Journal of Communication, 9, pp. 233-262.

MASIP, P. (2008): "El vídeo en los cibermedios: algunas certezas y muchas dudas". En Anuario Think EPI, 4, pp. 180-185.

MASIP, P., DÍAZ-NOCI, J., DOMINGO, D. y MICÓ-SANZ, J. LL. (2010): "Investigación internacional sobre ciberperiodismo: hipertexto, interactividad, multimedia y convergencia". En El profesional de la información, 19 (6), pp. 568-576.

MASIP, P. MICÓ-SANZ, J. LL Y MESO, K. (2012): “Periodismo multimedia en España. Análisis de los contenidos multimedia en la prensa digital". En III Congreso Internacional de la Asociación Española de Investigación de la Comunicación "Comunicación y riesgo", Tarragona.

MICÓ-SANZ; J. LL. y MASIP, P. (2008): "Recursos multimedia en los cibermedios españoles. Análisis del uso del vídeo en ElPaís.com, El Mundo.es, La Vanguardia.es y Libertad Digital”. En Tripodos, 23, pp. 89-105.

MICÓ-SANZ, J. LL. (2011): "Periodistas audiovisuales inmóviles ante el periodismo multimedia móvil". En Casero-Ripollés, A. y Marzal, J. (eds.): Periodismo en televisión. Nuevos horizontes, nuevas tendencias. Zamora, Comunicación social.

ORTELLS-BADENES, S. (2011): El infoentretenimiento en el periodismo audiovisual. La transformación del género informativo en televisión. Tesis doctoral dirigida por Andreu Casero-Ripollés. 
RINTALA, N. y SUOLANEN, S. (2005): “The Implications of Digitalization for Job Descriptions, Competencies and the Quality of Working Life”. En Nordicom Review, 26 (2), pp. 52-67.

SCOLARI, C. y otros (2008): "El periodista polivalente.

Transformaciones en el perfil del periodista a partir de la digitalización de los medios audiovisuales catalanes". En Zer, 13(25), pp. 37-60.

SALAVERRÍA, R. (2005): Redacción periodística en Internet. Pamplona: Eunsa.

VAN DER HAAK, B., PARK, M. y CASTELLS, M. (2012): “The Future of Journalism: Networked Journalism. En International Journal of Communication, 6, pp. 2923-2938. 



\title{
Video como servicio agregado en los portales de los medios impresos mexicanos
}

\author{
Claudia Alicia Lerma Noriega, Tecnológico de Monterrey, \\ Campus Monterrey, México. \\ Perfil en (1) 0000-0001-9480-9289 y en $G$ : http://goo.gl/2cY9LE
}

\begin{abstract}
Los medios de comunicación tradicionales pueden aprovechar las ventajas que les da la red cuando deciden estar en ella, sin embargo no todos las usan o las emplean de manera eficiente. Una de esas ventajas del periodismo digital es la inclusión del video generado por el mismo medio o por su audiencia. En este trabajo se puede ver cómo los diarios mexicanos que tienen presencia en Internet $56 \%$ del total de los diarios impresos) no usan el video ni aprovechan una de las redes sociales que más presencia tiene en la red: YouTube como un servicio de valor agregado para sus lectores.
\end{abstract}

Keywords

Diarios en línea, YouTube, Videos, Prensa digital, Portales.

\section{Valores agregados de los sitios web}

T OS medios nuevos y tradicionales que tienen su espacio en la red recepción de información para seguir manteniéndose en el espectro de posibilidades de medios de noticias. 
El uso del video en los portales es un vínculo que pocas entidades utilizan desperdiciando así el poder testimonial que las imágenes pueden dar a la información. En esta época en que las imágenes fijas o en movimiento despiertan el interés de los usuarios de Internet pueden ser usadas como una ventana más para comprender la realidad cotidiana y no debe pasarse de largo. Lo testimonial y el poder de la imagen en la construcción del vínculo con la realidad objetiva, un valor muy preciado en el periodismo, son las claves de esta nueva tendencia.

Los medios que piensan en crecer (y permanecer) en la red brindan posibilidades diferentes para los usuarios de los medios de comunicación tradicionales; si son bien empleados, el público puede volverse asiduo e incluso, puede crecer el número de usuarios si la ventaja es percibida por más personas que ven un aprovechamiento de la variedad de recursos.

Al usar Internet como un medio para transmitir información se puede no solo cambiar la forma y la cantidad de información transmitida, sino que también puede modificar las relaciones entre los individuos.

La televisión, la prensa, la radio y el cine pueden ser difundidos a través de la red utilizando todos los recursos que están disponibles entre ellos (multimedia); esta nueva forma de difusión de los medios tradicionales a través de una innovación tecnológica de transmisión de información le da al usuario un servicio de valor agregado (SVA) tanto al portal como al medio en su formato tradicional.

La presencia de audio y vídeo (multimedialidad) junto con la instantaneidad e inmediatez son parte de las ventajas que ofrece la red mundial; ante ello muchos medios de comunicación convencionales buscan también una presencia telemática y han desarrollado sitios que complementan la información presentada en sus respectivos canales. Lo anterior genera que el usuario dé por hecho que al navegar en la red encontrará la presencia de su medio de comunicación preferido (radio, televisión o prensa), y que en cualquier lugar y a cualquier hora podrá proporcionarle información que sea de utilidad.

Sin embargo, según López Carreño (2004) para que la combinación de los elementos que intervienen en la generación de un sitio web 
logren los objetivos de: informar, llegar a un número amplio de usuarios, que la información sea encontrada y se entienda, o que se consiga fidelidad por parte de los usuarios; hace falta seguir una serie de parámetros básicos en su confección especial para el entorno digital que son conocidos como Usabilidad Web y desarrollar una arquitectura web funcional.

Los parámetros establecidos por esta especialista en difusión de información sirven de base para el desarrollo de este trabajo en el que además de visualizar si existe un aprovechamiento del vídeo como servicios de valor agregado en los sitios web noticiosos los diferentes medios impresos mexicanos con presencia en la red y ver si están creando espacios únicos de información en la red social que por mayor uso a nivel mundial se considera como principal: YouTube.

El análisis de la presencia videográfica radica en el hecho de que la información de cada uno de estos portales está amparada por la presencia y el posicionamiento del medio tradicional.

La elaboración de este proyecto permite ver cómo se aprovechan los recursos que brindan tanto Internet como YouTube para difundir la información utilizando diversos recursos mediáticos en beneficio de los usuarios.

De acuerdo a Albornoz (2006) las empresas periodísticas cuentan con una mayor riqueza de material informativo y de apoyos que pueden ser promocionados tanto en la prensa, de la misma manera que los sitios web pueden promocionar al medio impreso; es decir, se da una complementariedad entre medios. Esta complementariedad puede ser pasada por alto por algunas empresas que cuentan con un posicionamiento amplio en el sector del entretenimiento y de la difusión de información en general. Y es que, como señala López Carreño (2004), estos sitios informativos, los portales periodísticos, conjugan dinámicamente tres elementos esenciales para su consolidación: el contenido, los productos y los servicios. Estos portales se constituyen como nuevos medios de comunicación, siendo autónomos y multimediáticos, gracias al vehículo universal que los sustenta, Internet. 
El surgimiento de este tipo de sitios se debe, entre otras cosas, a la consolidación de los portales como los principales puntos de acceso a la web por parte de los usuarios y a la necesidad que tiene el medio por estar en Internet. En este punto es importante hacer notar que dentro de este tipo de sitios se pueden encontrar productos informativos (entrevistas, especiales, suplementos) y productos documentales que no necesariamente están ligados a una noticia (agenda, guías, avisos). Estos productos documentales refuerzan al sitio informativo y le pueden proporcionar servicios de valor añadido que hagan que el usuario se vuelva consuetudinario, por otro lado, con los valores extra se puede reforzar la identidad personal, local o regional, y por tanto tienden a segmentar a la audiencia.

Guillermina Franco (2005) señala que los portales de las cadenas televisivas son una modalidad de periódico, sólo que Internet ofrece servicios que al conjuntarse con otros medios le dan un valor añadido, pero al mismo tiempo son elementos que requieren una mayor elaboración y que por tanto resultan atractivos para el lector cibernético si están bien hechos y pueden ser encontrados por ellos. Entre los servicios que se pueden dar están los boletines electrónicos, el acceso a archivos y a recursos elaborados por el propio medio como infografías, bases de datos, guías, así como servicios exclusivos para suscriptores.

López Carreño (2004) propone una clasificación de SVA en este tipo de sitios periodísticos y que engloba los siguientes rubros:

\begin{tabular}{|l|ll|}
\hline TABLA 1 & \multicolumn{2}{l|}{} \\
\hline $\begin{array}{l}\text { Servicios de Valor } \\
\text { Agregado }\end{array}$ & Tipología \\
\hline & 1. & Ayuda; \\
& 2. & Barra de navegación/Página de inicio; \\
& 3. & Buscador noticias; \\
Acceso a la & 4. & Buscador web; \\
Información & 5. & Hemeroteca; \\
& 6. & Herramientas; \\
& 7. & Mapa web; \\
& 8. & Portales verticales / Canales; \\
& 9. & Últimas noticias; \\
\hline
\end{tabular}




\begin{tabular}{|c|c|c|}
\hline Interactivos & & $\begin{array}{l}\text { Chat; } \\
\text { Foros; } \\
\text { Webmail; }\end{array}$ \\
\hline Participación & $\begin{array}{l}13 \\
14 \\
15 \\
16 \\
17 \\
18 \\
19 \\
20\end{array}$ & $\begin{array}{l}\text { Cartas al director; } \\
\text { Concursos; } \\
\text { Encuestas; } \\
\text { Envío de relatos; } \\
\text { MailNews a un amigo; } \\
\text { Página abierta; } \\
\text { Postales; } \\
\text { Sugerencias; }\end{array}$ \\
\hline Multimedia & $\begin{array}{l}21 \\
22 \\
23 \\
24 \\
25\end{array}$ & $\begin{array}{l}\text { Fotografías; } \\
\text { Gráficos interactivos; } \\
\text { Radio digital; } \\
\text { Vídeos; } \\
\text { Televisión digital; }\end{array}$ \\
\hline Personalizados & & $\begin{array}{l}\text { Alertas; } \\
\text { MailNews; } \\
\text { Mi diario; } \\
\text { Mi portada; } \\
\text { Recordatorios (eventos); } \\
\text { WAPnews; } \\
\text { Mascotas virtuales } \\
\end{array}$ \\
\hline Entretenimiento & & $\begin{array}{l}\text { Horóscopos; } \\
\text { Juegos/Pasatiempos; } \\
\text { Webcam; }\end{array}$ \\
\hline Comerciales & & $\begin{array}{l}\text { Tienda/s; } \\
\text { Viajes online; } \\
\text { Clasificados; } \\
\text { Venta de contenidos (e-contents); } \\
\text { Banca online; }\end{array}$ \\
\hline Complementarios & & $\begin{array}{l}\text { Diccionario; } \\
\text { Enlace a otros medios; } \\
\text { Móvil news; } \\
\text { Traductor; }\end{array}$ \\
\hline
\end{tabular}

Estos SVA pueden estar presentes en diversos grados dentro de un portal, o pueden ser omitidos. 
Un complemento al análisis referente a la presencia de estos SVA es enfatizar el uso multimedial en los portales informativos, específicamente el vídeo. Un análisis de este tipo permite entonces no sólo verificar la presencia de los SVA y la presencia multimediática en los portales de las periódicos generalistas de mayor presencia en México sino que también permiten verificar el empleo y la versatilidad de los recursos que estas empresas informativas presentan a sus audiencias (la impresa y la online).

\section{Definición de Objetivos}

En la actualidad puede verse lo que Albornoz (2006) llama una sinergia crossmedia entre la producción informativa de los diferentes renglones de un determinado conglomerado multimedia, lo cual da lugar a formatos innovadores y enfatiza los valores añadidos en todos los medios con la virtual ganancia para el usuario-espectador. Por ello, lo que se persigue en este trabajo es visualizar si existe una presencia de servicios de valor agregado en los sitios web de los medios impresos mexicanos especialmente de la presencia del vídeo y de un canal de difusión de información a través de YouTube.

Se definen estos medios como objeto de estudio debido a la problemática que continuamente los medios impresos de diversos países aducen con respecto a la desaparición del medio tradicional y buscan el uso de Internet para tratar de sobrevivir a la crisis. Tanto el vídeo como otros elementos multimedia pueden servir como factor para atraer lectores y muchos lo pasan por alto.

De los hallazgos de este análisis se desprenden las conclusiones que ayudarán a determinar cuáles podrían ser las ventajas que el lectorusuario de Internet encontrará respecto al medio de comunicación convencional.

Estos análisis además permitirán ver las áreas de oportunidad en la mejora del medio y acrecentar las ventajas que los mismos están teniendo; todo lo anterior con el fin de no desperdiciar recursos que podrían ser en provecho de los usuarios y de los administradores del medio. De ello se desprende el valor del análisis sugerido ya que se 
pueden hacer recomendaciones para los profesionales de la difusión de información.

\section{Metodología}

Como se ha señalado, los medios de comunicación cuentan con una presencia testimonial en Internet $y$, si lo que se persigue en este trabajo es visualizar si existe una presencia del vídeo y de un canal de difusión de información a través de YouTube, se procedió a evaluar si en el 2014 los medios impresos registrados en el Patrón Nacional de Medios (de México) está presentes dicho servicio de valor agregado.

El estudio determinó, mediante observación, si cada medio inscrito en el Patrón (y que tiene presencia en Internet) cuenta con un espacio dedicado al vídeo o tiene y promociona su canal de YouTube.

\section{Hallazgos del análisis}

De acuerdo a la observación realizada se pudo ver que la totalidad de los medios impresos inscritos en el Padrón mexicano asciende a 1278, de los cuales solo 719 cuentan con un portal web.

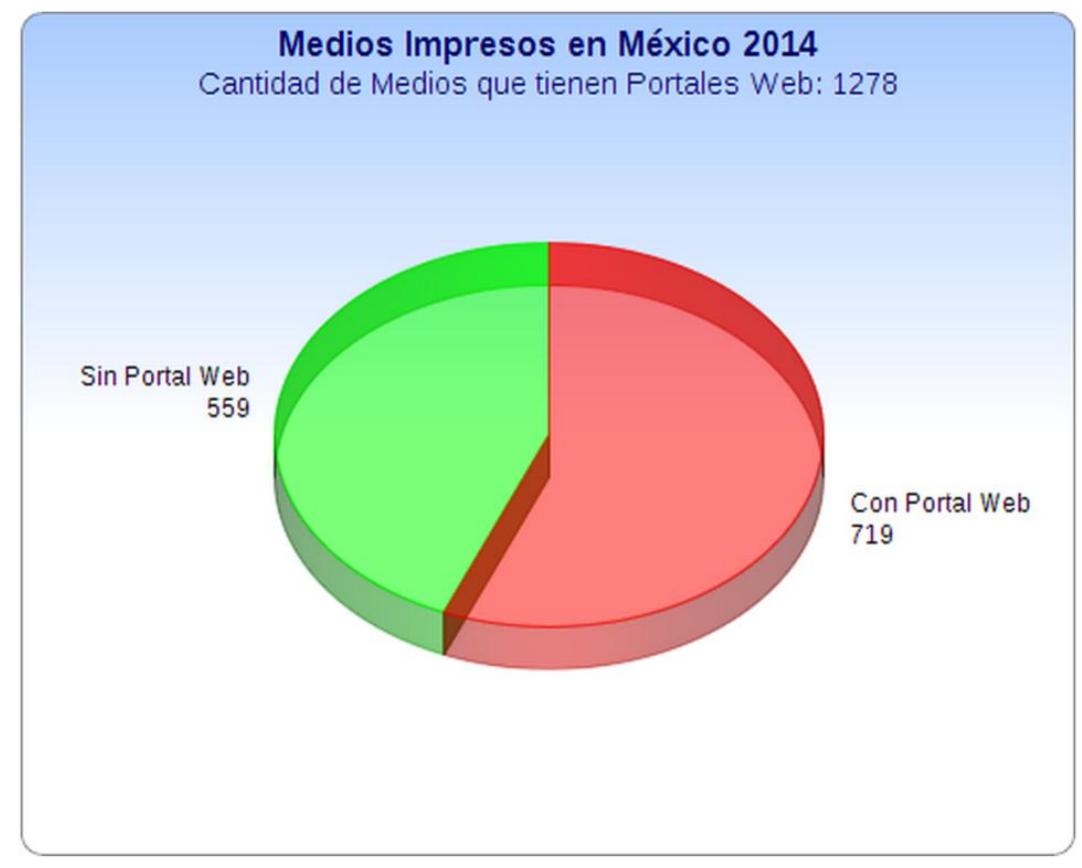

Fuente: elaboración propia 
Hay que dejar claro que hay algunos que comparten el mismo sitio independientemente si pertenecen a ciudades o entidades distintas (portales de la Organización Editorial Mexicana, Milenio, El Debate, El Diario de Sonora, AZ Diario, Contralinea y Sintesis, entre muchos otros) lo cual aminora la cantidad de oferta de diarios en línea.

En lo que se refiere al uso de los vídeos como servicios de valor agregado que deberían tener los portales periodísticos se puede apreciar que es un rubro que pasan por alto la mayoría de los sitios pues de los 719 portales solo 117 cuentan con vídeos en línea de diferentes temáticas y desarrollados ya sea por el propio medio o enviados por los lectores. Esta cantidad representa el $16.27 \%$ de la totalidad de medios impresos de México.

Por otro lado, de los 719 portales solo 164 cuentan con un canal de YouTube propio para transmitir noticias relacionadas con el material que ponen en sus portales, esto representa tan solo un $22.80 \%$ de solo aquellos que tienen un sitio en Internet, si comparáramos con la totalidad de medios impresos este porcentaje caería drásticamente.

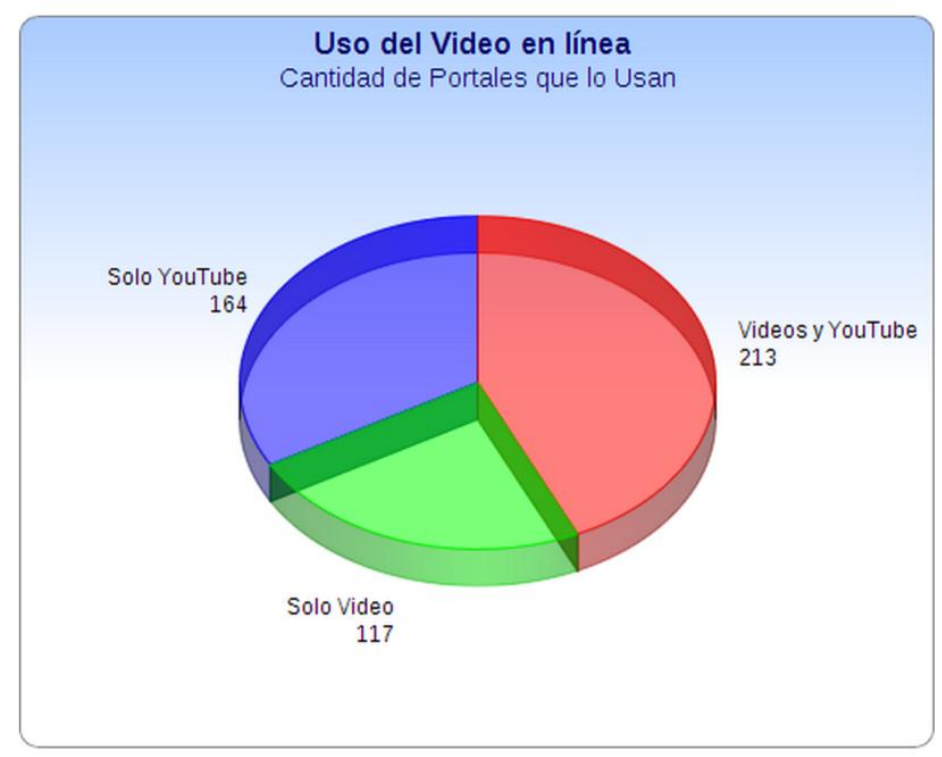

Fuente: elaboración propia

\section{Conclusiones}

Uno de los principales problemas que enfrentan los medios impresos alrededor del mundo es la lucha por la permanencia en el gusto del 
público y la disminución de lectores. Esta lucha se vuelve más complicada si los medios tradicionales no se adecuan al perfil que permiten las nuevas tecnologías y no transmiten la información con todos los elementos que ofrece la red.

El ofrecer elementos adicionales a la información impresa como vídeo, infografías interactivas, uso de redes sociales, y audio es un atractivo que pueden proporcionar para ganar más adeptos a los sitios informativos, tanto en línea como tradicionales, así es que hay que aprovechar que existen para ofrecerlos antes que lo haga la competencia y obtener así una ventaja.

En el caso de la prensa mexicana, se puede ver que solo la mitad aprovechan tener una presencia en la red (52\%), y, de ellos, muy pocos son quienes están viendo y utilizando las ventajas que pueden generarse en un medio como Internet.

Hay que hacer notar y recalcar a la prensa tradicional la idea que el usuario puede tener es que podrá encontrar abundancia de información y servicios porque los resultados del análisis demuestran lo contrario.

El análisis elaborado en este 2014 sugiere la posibilidad de hacer más evidente la necesidad de incluir en los portales periodísticos los elementos de búsqueda de noticias y de vídeos que complementen a lo presentado en los informativos televisivos y la oportunidad de abrir un canal en una red social como YouTube, que les crearía una ampliación de su marca y a tener una mayor presencia en Internet.

Este tipo de revisiones resulta especialmente importante al detectar que se ha incrementado el número de usuarios de Internet en México (51,2 millones de usuarios en 2014 de acuerdo a la Asociación Mexicana de Internet), así como la cantidad de personas que consultan información vía electrónica respecto a años anteriores, y que además son el medio que puede romper las barreras geográficas y de limitación de información.

La prensa mexicana enfrenta un reto importante no sólo por la crisis de los medios impresos sino por el desconocimiento que 
aparentemente tienen los directivos y administradores respecto a las ventajas de usar y tener presencia en la red.

Los servicios de interactividad para el usuario, opciones de entretenimiento, y complementos diversos como opciones de noticias a otros aparatos electrónicos u opciones personalizadas; son las áreas de oportunidad para la prensa mexicana $-y$ que ya muchos otros sitios periodísticos los fomentan entre su comunidad de lectores-.

Por parte del usuario también hay un desconocimiento de las posibilidades que un sitio relacionado a una cadena televisiva se pueden encontrar.

De acuerdo a los estudios realizados por la Asociación Mexicana de Internet (2014) se puede ver que los usuarios se informan a través de este medio con una mayor frecuencia en unos determinados períodos del día, por lo cual es un área de oportunidad importante para desarrollar la oferta de noticias que sean respaldadas por medio de confiabilidad reconocida por el público en cada región del país.

Un portal electrónico es un área de oportunidad para romper con las barreras geográficas, temporales y espaciales, que pone a disposición de un amplio y variado número de usuarios el acontecer social; este hecho no solo traspasa los obstáculos anteriormente mencionados, sino también los elementos de edad, distribución y relación con otros medios, por lo cual resulta esencial presentar un producto atractivo para el usuario desde el primer momento en que se enfrenta a un complemento del medio tradicional y que lo vea como una propuesta informativa acorde al avance tecnológico del siglo XXI.

\section{Bibliografía}

ALBORNOZ, LUIS A. (2006). "Los principales diarios online en español. El empleo de recursos audiovisuales y multimedia, e hipervínculos", Telos. N. 66, Segunda época. Disponible en: http://www.campusred.net/telos/perspectivaImprimible.asp?idarticu

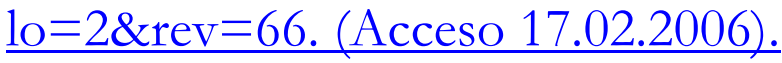


ASOCIACIÓn MEXICANA DE INTERnET (2014) "Estudio de Hábitos del Mercado en Línea en México 2014". Asociación Mexicana de Internet. Disponible en:

https://www.amipci.org.mx/estudios/habitos de internet/Est udio Habitos del Internauta Mexicano 2014 V MD.pdf. (Acceso 4.02.2015).

FERNÁNDEZ COCA, Antonio (1998). Producción y diseño gráfico para la World Wide Web. Barcelona: Paidós.

FLEMING, JENNIFER (2004). "Web Navigation". Designing the User Experience. Net library. Disponible en:http://biblioteca.itesm.mx/cgi-bin/nav/salta?cual=bases:30. (Acceso: 22.06.2004).

FRANCO ÁLVAREZ, GUILLERMINA (2005). "Los portales periodísticos españoles. El valor añadido de la información de proximidad" Telos. N 63, Segunda Época. Disponible en: http://www.campusred.net/telos/perspectivaImprimible.asp?id articulo $=2 \& \mathrm{rev}=63$. (Acceso 20.02.2006).

LÓPEZ CARREÑO, ROSSANA (2004). "Análisis taxonómico de los portales periodísticos españoles", Anales de documentación, $\mathrm{N}^{\circ}$ 7, 2004, 123-140. Disponible en:

http://www.um.es/fccd/anales/ad07/ad0708.pdf. (Acceso: 1.03.2006). 



\title{
Multimedia, multipantalla, multitarea, y emociones
}

\section{4 \\ Los videojuegos como proceso multimedia}

Enrique Morales Corral, Universidad Camilo José Cela - UTAD, Madrid, España

Perfil en 10 orcid.org/0000-0001-5886-2672

y en $\mathrm{G}$ http://goo.gl/FD9eBq

\begin{abstract}
Este artículo pretende mostrar cómo los videojuegos han desarrollado en los últimos años un proceso de incorporación en el entorno multimedia de una forma natural. Cómo han desarrollado toda la potencialidad que las nuevas culturas digitales están cultivando en la actualidad, presentando unas características particulares y únicas.

Se abordarán cuatro grandes ejes. En un primer momento se analizará brevemente la relación estrecha que siempre han mantenido el videojuego y el desarrollo de la tecnología, sobre todo de las TICs.
\end{abstract}


En un segundo apartado profundizaremos en la relación más visible: el factor económico. En un tercer apartado se mostrará brevemente la situación de la creación de esta industria cultural en España, y por último se mostrarán nuevos usos que se están dando a los videojuegos.

\section{Keywords}

Videojuegos; industria cultural; industria creativa; multimedia; TICs; comunicación.

\section{Introducción}

— STE artículo pretende aportar una serie de conclusiones y datos Lobre el porqué del éxito actual de la industria del videojuego como forma de ocio natural. Para ello se realizó una investigación mixta (cualitativa-cuantitativa) con cuatro entrevistas estandarizadas no programadas, que conformaron veintiséis códigos del discurso, con los que creó la I Encuesta Independiente de Usuarios de Videojuegos de España, con 455 respuestas completas en sólo 16 días activa durante el 2013. Se trataba de realizar un estudio inicial de la oferta del sector del videojuego, y un estudio sobre la demanda por parte de los usuarios, que nos permita ofrecer una radiografía válida de esta industria cultural.

Esta investigación original tiene como principal objetivo marcar las directrices de la demanda actual del videojuego. Se han centrado los perfiles de los usuarios españoles, sobre todo los más habituales, y se han contrastado los diferentes apartados y análisis de la investigación descriptiva. Se ha articulado la hipótesis principal, que intenta responder a por qué y cómo se ha producido este fenómeno masivo: la principal razón de que hoy en día la industria cultural del videojuego sea la más importante, en España y en el mundo, responde a una normalización masiva del uso de videojuegos como forma de ocio entre una gran proporción de población, sobre todo de menores de 35 años, que han crecido jugando, convirtiéndose en jugadores activos. Esto provoca que las desarrolladoras deban innovar constantemente, debido al gran número de jugadores y perfiles, que crece día a día. El cansancio de las viejas técnicas 
narrativas será otro factor que obligará a experimentar alimentando todo el sistema.

\section{Los videojuegos comienzan su camino}

El juego supone un proceso natural, sobre todo como elemento básico para el desarrollo, el aprendizaje y el descubrimiento en los primeros años de vida (Huizinga, 1987). Es más habitual en los primeros años de vida e infancia, pero seguimos realizándolo a lo largo de nuestras vidas, sobre todo como elemento relacional. Son muchos los ejemplos que podemos poner en la vida adulta cotidiana: deporte, cartas, dominó, parchís... Y desde hace ya algunos años debemos incorporar a los videojuegos en esta categoría porque presenta características similares (Estallo, 1995).

El camino para llegar a la invención de los videojuegos propiamente dichos empezó con la creación de las primeras máquinas recreativas para ferias ambulantes, a principios del siglo XIX. Estas máquinas son precursoras, eran ocio mecánico y tenían como objetivo despertar la curiosidad tecnológica entre el público a cambio de una moneda. Algunas máquinas usaban un sistema para, por ejemplo, dejar ver la foto de una chica sexy, o retaban a los participantes a probar su puntería con una escopeta de bajo calibre. Su construcción era muy costosa, debido a las dificultades mecánicas de la época y no existieron muchas unidades en un primer momento. Fue un éxito que llevó a inventores a intentar crear máquinas cada vez más complejas. Un segundo paso fue la invención a mediados del siglo XIX de las máquinas de pinball, con gran éxito también, que empezaron a introducirse en bares $y$ en salones recreativos donde se podían encontrar todo tipo de modelos. El tercer paso fue, a partir de los avances en la electrónica y la informática, la creación de las recreativas electrónicas, donde ya aparece el ocio electrónico: el videojuego. Allanaron el camino para la creación, a finales de los años 60 del siglo $\mathrm{XX}$, de la primera videoconsola doméstica que supuso el inicio del modelo de videojuego que entendemos hoy en día.

Pero, ¿qué es un videojuego? Según la RAE un videojuego es un dispositivo electrónico que permite, mediante mandos apropiados, 
simular juegos en las pantallas de un televisor o de un ordenador. A partir de este punto inicial podemos elaborar ya una serie de elementos importantes que hemos resaltado en esta investigación. Es importante separar los conceptos: sector del videojuego (bardware más software) e industria cultural del videojuego (software). El segundo está incluido en el primero. Son bastantes los estudios que no lo hacen provocando confusión en el lector. En esta investigación se ha tenido especial cuidado en su separación, porque hacen referencia a modelos económicos, sociales, culturales y comunicacionales que no tienen por qué ser exactamente iguales, sino que varían en función de sus particularidades propias.

El principal objetivo de este artículo es el de responder a cómo ha sido el proceso que ha llevado al videojuego al uso cotidiano en nuestra sociedad. Por qué hoy en día juegan desde niños de tres años a abuelos de noventa. La respuesta es sencilla, no así su explicación. Se ha producido una naturalización del uso del videojuego en nuestra sociedad (Morales, 2011a), ha cambiado su rol: desde una actividad marginal a una actividad normal y habitual. Este proceso se ha producido por varios factores que podemos resumirlos en cuatro grandes grupos: culturales, tecnológicos, económicos y nuevos usos. Estas cuatro categorías hacen referencia a los cuatro ejes transversales que conforman la estructura del artículo.

Un primer factor es el cultural. El videojuego fue una subcultura propiamente dicha hasta hace pocos años. Era cosa de frikis, de una minoría que pasaba horas y horas delante de un ordenador o de la pantalla del televisor, con mala reputación entre la población general que no entendía su uso (Levis, 1997). Durante mucho tiempo sólo niños y jóvenes jugaron a videojuegos porque se creaban productos sólo para ellos, creándose una base inicial de jugadores. La industria apostó por abrir mercados creando productos más generales, sencillos y fáciles de usar, buscando nuevos usuarios. Ahora juega casi todo el mundo, se ha extendido su uso entre la población general. En cierto modo la sociedad ha cambiado la forma de ver a esta práctica, aceptándola y naturalizando su uso.

Un debate interesante es el de la consideración del videojuego como elemento cultural y expresión artística por parte de la sociedad en 
general y de los propios usuarios en particular. En las entrevistas hemos visto expresiones de conformidad de ambas perspectivas que se ven refutadas con los datos de la encuesta. Ocho de cada diez usuarios reconocen al videojuego como expresión artística. De hecho, se produce un interesante debate al preguntarles el porqué. Según los usuarios hay fundamentalmente tres grandes razones: es una expresión creativa, transmite emociones y es una mezcla de artes. Estas tres razones se pueden resumir en dos, debido a que la propia definición de expresión creativa lleva implícita la capacidad de transmisión de emociones. Que sea una mezcla de artes supone un importante punto a tener en cuenta, porque puede presentar argumentos a favor y en contra sobre el reconocimiento social estable. Puede ser en contra, porque puede dar a entender que el propio medio no tiene la esencia propia adecuada como para ser reconocido algún día como arte, y puede ser a favor, porque es capaz de reunir artes reconocidos en un solo elemento, dotándolo de esencia propia. Este es el elemento clave sobre el que gira esta discusión y sobre el que debería hacerse un estudio en profundidad.

\section{Gráfico 1: Evolución por cohortes de edad de las tres} principales palabras clave que resumen mejor para los usuarios el uso de videojuegos.

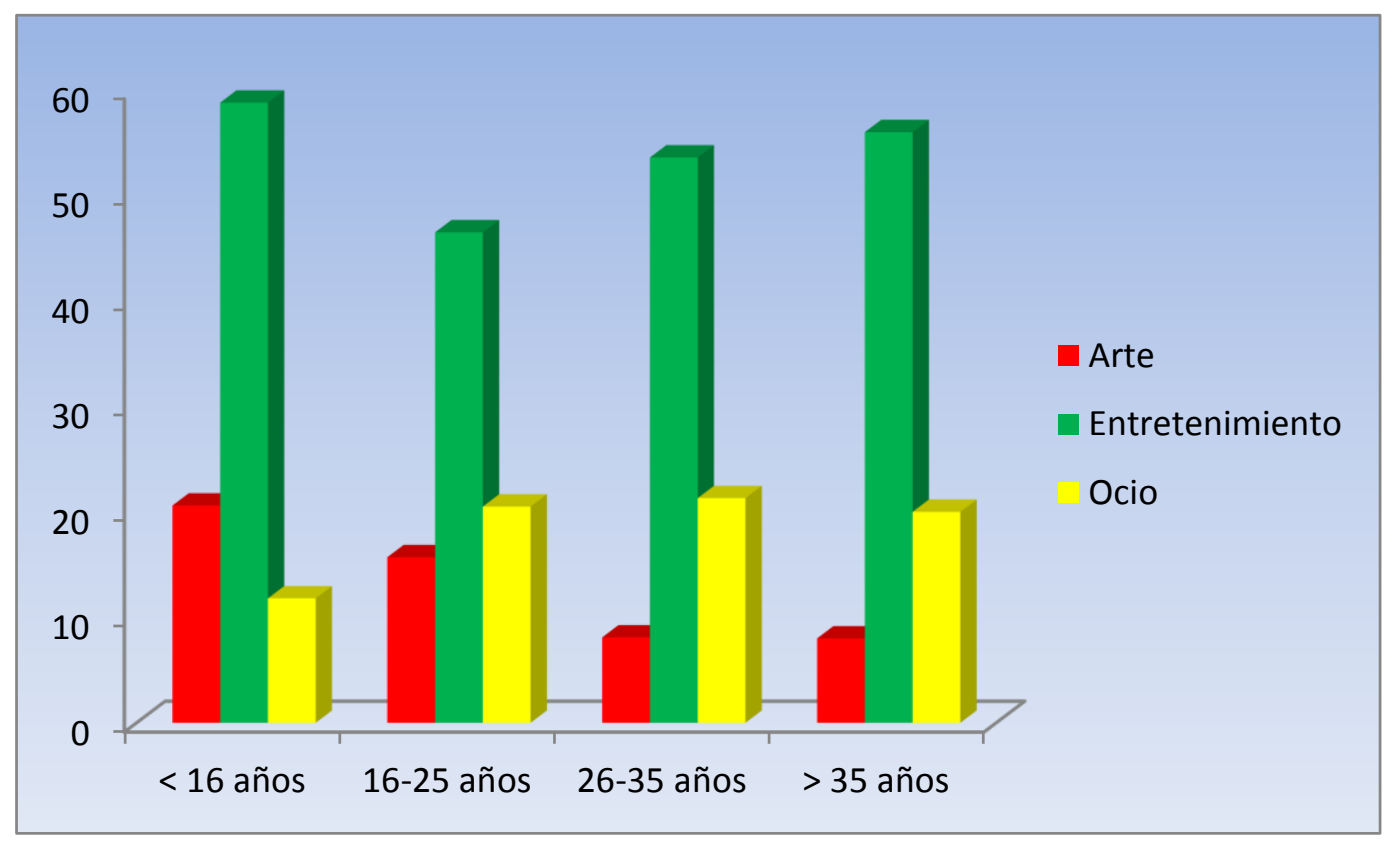

Fuente: elaboración propia 
Siguiendo esta línea argumental se preguntó a los usuarios sobre el término que más reflejase el uso de videojuegos: Entretenimiento y Ocio fueron las palabras clave más votadas, con un $51 \%$ y un $20 \%$ respectivamente, reflejando la visión lúdica que tiene ya asociada esta práctica. Es interesante ver el gráfico 1, porque refleja cómo la consideración de la palabra clave Arte disminuye con las cohortes de edad, mostrando la gran naturalización de este concepto que entre los usuarios más jóvenes tiene el ocio electrónico.

El código PEGI es el sistema que en Europa se usa para catalogar a los videojuegos en función de los contenidos, es el principal mecanismo que tienen los educadores y padres para evitar contenido no adecuado en videojuegos para menores de edad. Como podemos ver en el gráfico 2, el sistema PEGI es más útil conforme mayor es la edad de los usuarios, excepto en la cohorte de más de 35 años, la cual tiene un situación de equilibrio. Nueve de cada diez usuarios afirma conocer el sistema PEGI de calificación por edades de los contenidos en Europa, pero de estos, sólo el 57\% lo considera útil a la hora de realizar compras para menores de edad. Es decir, aún con las campañas que casi todos los años AEVI (Asociación Española de Videojuegos: http://www.aevi.org.es/, antigua aDeSe) y otros organismos realizan para poner en conocimiento de los usuarios este sistema, existe todavía un porcentaje muy alto de usuarios que aún conociéndolo no lo considera útil. Se debería modificar la publicidad sobre este sistema, apostando por nuevas estrategias, porque pueden ser de gran ayuda en la compra de productos para determinadas edades. La asimilación de esta herramienta reguladora por parte de la mayoría de la población, favorecería el cambio de opinión de sectores que todavía tachan a todos los videojuegos de violentos, cuando en realidad existen productos adaptados para todas las edades y gustos (Morales, 2011b).

Un punto importante y poco señalado por los estudios científicos sobre videojuegos, es el relevo que han tomado los estudios de desarrollo occidentales a la hora de realizar videojuegos frente a los japoneses, que habían mantenido una hegemonía creativa en los últimos veinte años. Esto ha provocado que existan productos más acordes a costumbres y realidades occidentales, y que muchos usuarios se sientan más atraídos por este tipo de productos al sentirse 
más identificados por las narrativas, siendo una de las razones de la conquista de nuevos usuarios (Gee, 2004).

\section{Gráfico 2: Utilidad del sistema PEGI según grupos de edad de los que conocen el sistema.}

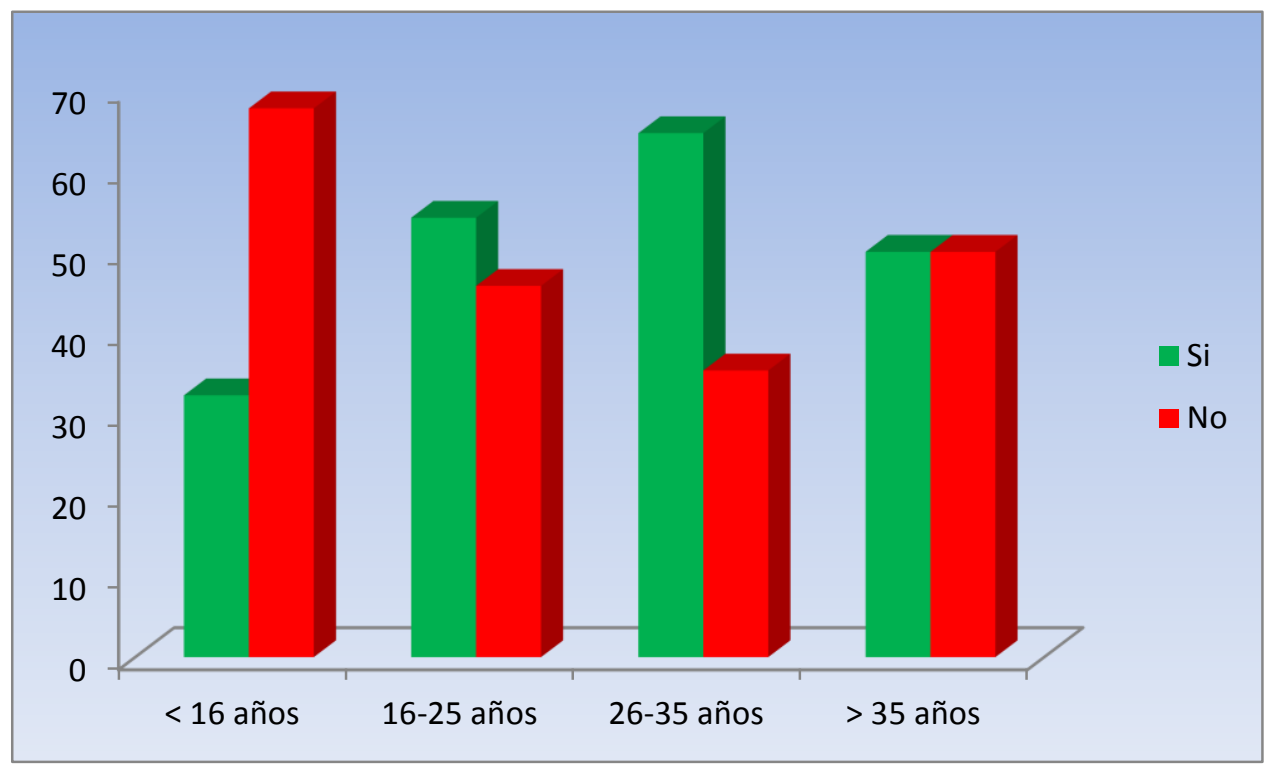

Fuente: elaboración propia

\section{Videojuegos y tecnología}

Un segundo factor es que los avances tecnológicos han favorecido que existan dispositivos de juego para todos los gustos, precios y necesidades. También han favorecido la creación de profesionales que han desarrollado nuevas temáticas, interfaces, interacciones con la pantalla... propiciando que población que nunca antes había tenido interés en probar los videojuegos lo hiciese, y a muchos les gustase. Los avances en la tecnología hicieron posible que el producto fuese cada vez más barato, pudiendo ser permitido para la inmensa mayoría de la población de primeros mundos. Era un buen regalo para hijos y sobrinos que empezaron a jugar desde edades tempranas consiguiendo una base de jugadores impresionante en muy poco tiempo, que arrastraron a padres y abuelos con juegos más sociales y grupales.

En este punto merece especial análisis la compañía Nintendo, que con sus portátiles DS-3DS, y sobre todo con la Wii y su nuevo mando que detectaba el movimiento (Wiimote), revolucionaron el 
uso de videojuegos entre la población general, debido a su manejo intuitivo y a las fuertes campañas de publicidad que lo pusieron de moda. Se creó un nuevo tipo de usuario: los casual, que demandaban juegos más sencillos, sociales e intuitivos. La creación de este nuevo tipo de usuario multiplicó la base videojugadora disparando las cifras de ventas, tanto en hardware como en software. Se podría hablar de la generación dorada, que arrastró también las ventas del resto de dispositivos y videojuegos. Una vez abierto el nuevo hobby muchos usuarios empezaron a interesarse por videojuegos más acordes a sus gustos particulares (deportes, disparos, históricos, estrategia, conducción...) abriendo el camino a nuevas compras.

Merece especial atención el hecho de que hoy en día las videoconsolas domésticas son centros multimedia totales, que cada día aumentan sus servicios, sobre todo los relacionados con las posibilidades audiovisuales. Internet también ha revolucionado al videojuego, facilitando su expansión y posibilidades. Ha creado nuevas formas de interacción entre usuario-máquina, nuevos géneros, temáticas, modelo de distribución y compra... Nueve de cada diez encuestados declaró que alguna vez había jugado a videojuegos online en alguna de las plataformas posibles. Si hacemos un análisis según las cohortes de edad, podemos observar como este porcentaje sube al 97\% para los menores de 16 años, algo lógico al hablar de nativos digitales que han nacido en la generación Google, y que su mundo casi se desmoronaría sin Internet. En las cohortes intermedias supone un $94 \%$ para los de 16-25 años, y un 89\% para los de 26-35 años. El dato más interesante es que baja hasta un $76 \%$ en los mayores de 35 años, mostrando una menor dependencia e interés de las posibilidades y servicios online.

Es importante también saber los principales problemas que se encuentran los usuarios españoles al jugar online. Para los que habían respondido que alguna vez habían jugado online, el principal inconveniente son los problemas de conexión. Para casi la mitad de los usuarios el principal problema es la conexión, y es que España no destaca por su estabilidad online. Actualmente es el principal problema, debido a que la mayoría dispone de conexiones basadas en ADSL y no en cable, mucho más estables. Recientemente Sony ha anunciado que su servicio de videojuegos streaming Gaikai se 
implementará a partir del 2015 en Europa, debido sobre todo al gran número de conexiones ADSL existentes, que no pueden garantizar correctamente el servicio.

Las videoconsolas de sobremesa siguen siendo el principal soporte para jugar a videojuegos en España, ocho de cada diez usuarios juega en ellas, seguido por el PC (56\%) y por las videoconsolas portátiles (44\%). El smartphone supone ya una plataforma de juego para el $24 \%$ de los usuarios, llegando el tablet al 9\%. Estos datos reflejan claramente el uso habitual de juego multidispositivo, una realidad en estos tiempos y que irá a más. Respecto a la plataforma de juego mayoritaria: para la mitad de los usuarios la videoconsola doméstica es su principal plataforma de juego, el PC es para el $27 \%$, las videoconsolas portátiles representan el $15 \%$ y un sorprendente $6 \%$ para los smartphones, dejando el porcentaje de los tablets en un 1\%. En los próximos años veremos cómo estos dos últimos porcentajes subirán, en detrimento del resto de opciones, debido al cambio de dispositivos de juego que ya se está produciendo, sobre todo desde las videoconsolas portátiles a los smartphones. En la feria de videojuegos Tokyo Game Show 2013, la tercera más importante del mundo, dos de cada tres nuevos videojuegos presentados eran para smartphones y tablets, reflejando esta tendencia.

El sector del videojuego siempre ha sido muy dependiente de las innovaciones tecnológicas. La renovación en las generaciones de videoconsolas así lo atestigua. En el panorama actual, en el que los smartphones y tablets están irrumpiendo con fuerza en el mercado, se inclina todavía más la balanza hacia la búsqueda del nuevo gadget o tecnología revolucionaria con la que vender soportes y videojuegos. Bajo este prisma se preguntó a los usuarios qué tecnologías creían que estarían presentes en el mercado de los videojuegos en un intervalo de diez años. Las dos respuestas mayoritarias, con tasas de respuesta de dos de cada tres usuarios, son que dominarán los Gráficos hiperrealistas y que habrá más Conectividad online. Algo bastante plausible, ya que ya hoy en día se podría argumentar que estos dos factores forman parte de las estructuras presentes de la actual generación, y que se verán potenciadas todavía más en la nueva que estrenamos a finales del 2013. Como tercera opción más votada, con casi la mitad de tasa de respuesta, los usuarios señalaron la tecnología 
Videogame streaming, que supone jugar a videojuegos alojados en servidores desde una pantalla, un YouTube para jugar, ejemplos actuales son Onlive o Gaikai. Esto sugiere una espera ansiosa de una gran parte de los usuarios hacia este tipo de modelo comercial en los videojuegos, ya sea mediante subscripción de catálogo o temporal. No hay que olvidar que el perfil mayoritario de usuario que ha contestado la encuesta corresponde a jugadores hardcore, que juegan más de cinco horas a la semana, y que este modelo comercial parece especialmente orientado hacia su perfil. La cuarta opción refleja un interés por un 3D más real, debido a los resultados desiguales actuales, y que no ha sido explotado en todo su potencial todavía. Por último, con porcentajes superiores al 30\% encontramos la incursión de Gafas de inmersión 3D y la Realidad virtual al estilo Matrix como herramienta de interfaz habitual.

\section{El factor económico en los videojuegos}

El tercer factor son los aspectos económicos. El videojuego heredó inicialmente el modelo comercial de las máquinas recreativas de pinball, evolucionando a partir de ahí hacia modelos propios, aprovechándose de los desarrollados por otras industrias culturales. El modelo de distribución retail, de venta de un videojuego por caja, nace con el inicio de la primera videoconsola doméstica creada por Ralph H. Baer en 1968, y sigue activo en la actualidad. Poco a poco el modelo de distribución digital irá imponiéndose frente al retail, debido a los grandes beneficios que aporta, tanto al usuario como al distribuidor o desarrollador (comodidad de compra desde casa, catálogo, rapidez de acceso...) siempre que baje el precio. Ya en las entrevistas, se argumentó que sería necesaria una bajada significativa del precio para que apostase definitivamente por este tipo de distribución, debido a la pérdida económica que supondría la venta de segunda mano de sus juegos físicos usados.

Podemos observar, en la actualidad, seis submodelos dentro de la distribución digital de videojuegos: online download (distribuye videojuegos por descarga digital online), online casual (utilizan el navegador de Internet o las redes sociales como soporte de juego), 
MMOs (videojuegos donde un gran número de usuarios pueden participar al mismo tiempo en un mundo virtual online), mobile games (específicamente diseñados para smartphones y tablets), social games (diseñados específicamente para redes sociales, este modelo está incluido en online casual, pero por sus características particulares se crea una categoría propia) y cloud gaming (videojuegos para jugar mediante tecnología streaming). Todo este grupo de modelos comerciales no hacen sino expandir las posibilidades de un sector que no parece conocer la actual crisis que estamos padeciendo (Morales, 2012). Su gran capacidad de fagocitar modelos comerciales es una de sus grandes virtudes pero también puede ser una debilidad, al complicar los mecanismos de retribución sobre los productos que ofrece. Por el momento vivimos una transición evidente que se consumará en los próximos años, dejando solo el modelo retail para nostálgicos, packs y ediciones especiales.

Las nuevas plataformas de juego móviles (smartphones y tablets) presentan modelos de distribución en grandes portales (Google Play, Android Marquet, AppStore...), y nuevos géneros de videojuegos especiales para estos dispositivos, aprovechando sus opciones táctiles. Otro aspecto a destacar son las tendencias de nueva financiación como el crowdfunding o micromecenazgo, que están ya siendo utilizadas por estudios pequeños y medianos para desarrollar proyectos sin la ayuda de productoras. $\mathrm{Al}$ involucrar directamente, mediante pequeñas aportaciones económicas, a los usuarios consiguen una base fiel, implicados en el desarrollo de producción, con acceso a información de todo el proceso. Puede ser una fuente importante de financiación en el medio y largo plazo para proyectos rechazados por las grandes productoras o para estudios que quieren ser independientes $y$ depender sólo de la opinión de sus usuarios. Seguramente veremos en los próximos meses o años un sello de financiación colectiva a modo de medalla de producto, como esencia de valor añadido, ofrecido al margen de las grandes productoras y distribuidoras. Un sello indie, que ofrezca videojuegos más arriesgados (temas, interfaces, dispositivos de juego...), como ya sucede en la música o el cine que terminará por ponerse de moda olvidando su esencia primigenia. $O$ incluso que grandes productoras prueben este sistema de financiación para 
productos más arriesgados, buscando innovación con menor riesgo de inversión.

EEUU es el mayor mercado del mundo, tanto en producción como en consumo. Europa ha subido mucho en producción en los últimos años y la crisis ha provocado fuertes bajadas en el consumo. China es un mercado emergente donde las videoconsolas han estado prohibidas mucho tiempo (a excepción de la DS), porque corrompen a los jóvenes, aunque parece que se abrirá pronto al resto del hardware. $\mathrm{Su}$ mercado está formado sobre todo por juegos online para PC, destacando los modelos free to play y de subscripción. Es irónico que en el país donde se fabrican casi el 100\% de los dispositivos de juego estén prohibidos. El mercado español goza de una salud envidiable con cifras impresionantes de consumo. Es el cuarto país por facturación en Europa y sexto del mundo, pero la creación es de apenas el 3\% de lo consumido. Hay un gran desequilibrio entre producción y consumo que debería intentar compensarse en los próximos años. La creación del sello Games from Spain, supone un gran acierto institucional con el fin de asegurar una presencia de las empresas españolas de desarrollo (sobre todo pequeñas y medianas), en las principales ferias internacionales, que sin esta iniciativa, impulsada por el ICEX y la Academia de las Artes y las Ciencias Interactivas, no hubiesen podido presentar sus productos por medio mundo.

\section{El sector de creación de videojuegos en España}

El sector del videojuego puede convertirse en estratégico en los próximos años en España, donde hay grandes profesionales, grados específicos y abundancia de personal capacitado en paro. Si existiese voluntad política con planes específicos de ayuda empresarial podríamos levantar un sector productivo importante. Los profesionales españoles están muy bien considerados en el extranjero teniendo que emigrar la mayoría por falta de oportunidades nacionales. Actualmente existen varias iniciativas propuestas desde el Ministerio de Industria como parte del nuevo plan de impulso de la economía digital y los contenidos digitales (Boix - Lazzeretti, 2012), 
en el que el sector del videojuego español puede participar. Se divide en tres grandes ejes: contenidos digitales, adaptación del régimen de derechos de autor y programa de reutilización de la información del sector público. Así mismo, se pretende favorecer la participación de inversores informales privados, los llamados business angels. La diferencia de este sistema frente a los de capital-riesgo es que no se ofrece ningún tratamiento fiscal específico, siendo su tributación similar a la de cualquier inversión mobiliaria. Se trata de que los inversores no sólo aporten capital inicial sino también conocimientos empresariales y contactos.

La encuesta ofreció interesantes datos sobre el consumo medio de videojuegos en España, sobre todo para los jugadores más habituales, los hardcore, que representan a casi ocho de cada diez encuestados. Son consumos muy altos. El 30,99\% gastó más de 100 euros en el primer cuatrimestre, el 31,87\% entre 50 y 100 euros, y sólo un 25, $71 \%$ menos de 50 euros (ver gráfico 3). Estamos hablando de que casi uno de cada tres gastó más de 150 euros durante el último año, y que también uno de cada tres más de 300 euros. El perfil medio que más gasta es el de un hombre, de entre 26 y 35 años y que es jugador muy habitual o hardcore.

\section{Gráfico 3: Gasto medio reconocido por el usuario entre los meses de enero-abril.}

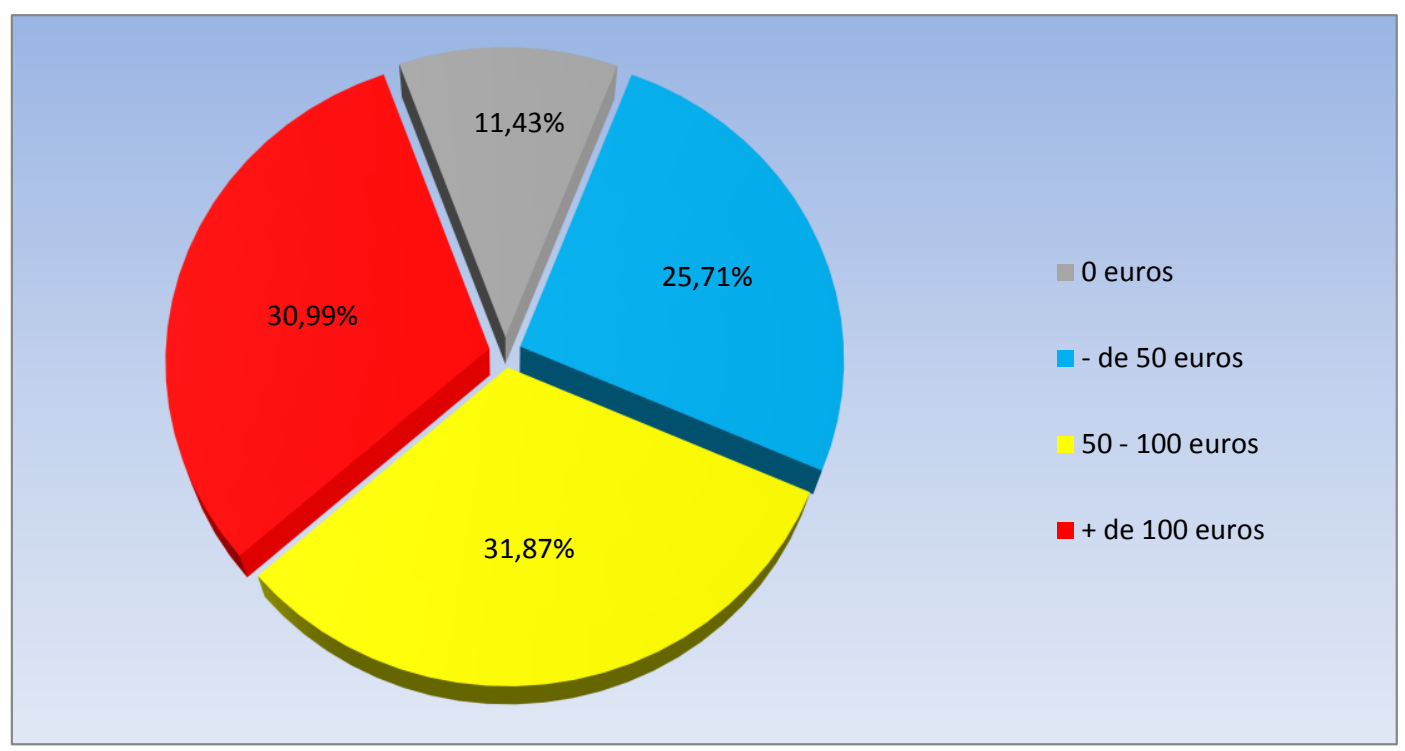

Fuente: elaboración propia 
Hasta fechas muy recientes era difícil encontrar datos secundarios que tuviesen en cuenta las compras online de videojuegos. Casi tres de cada cuatro encuestados afirmaron haber comprado videojuegos de descarga digital online en alguno de sus dispositivos de juego. Este porcentaje baja sensiblemente a casi el $62 \%$ para la franja de edad de menores de 16 años. En este caso suponemos que la falta de acceso a dinero propio y a los métodos habituales de pago en este sistema (tarjeta crédito-débito, PayPal...), para la compra online suponen la principal razón para este descenso significativo de más de diez puntos respecto a la media de los encuestados. Si analizamos este dato en función del tipo de jugadores este porcentaje de compra online baja a casi un 53\% para los jugadores casual y aumenta a un $78 \%$ para los hardcore, corroborando que este tipo de jugadores está más habituado a este tipo de transacciones.

Es interesante analizar qué mueve a los usuarios a decantarse por este sistema de compra frente al tradicional retail, un aspecto poco profundizado en los estudios consultados. A la hora de realizar compras digitales de videojuegos los usuarios se decantan sobre todo por la opción de que el producto que quieren está solo en ese formato (43\% de tasa de respuesta). En este punto es importante señalar que todos los videojuegos para smartphones y tablets tienen esta distribución, no existe el retail. Creemos que esta es la principal razón de la alta tasa de respuesta en esta categoría, pero también existen videojuegos para videoconsola y PC con este formato, donde destaca la plataforma de venta digital Steam para PC, que en poco tiempo ha conseguido un catálogo de más de dos mil títulos y más de cuarenta millones de usuarios en todo el mundo. En el caso de videojuegos con ambos tipos de distribución los usuarios prefieren todavía el tradicional modelo de venta en caja (retail) porque no hay diferencias significativas de precio. Solo uno de cada cuatro argumentó la categoría Ofertas y uno de cada cinco Mejor Precio. Como bien se señaló en las entrevistas, hace falta una bajada significativa en los precios de los videojuegos de descarga digital para que los usuarios se decidan por este formato dejando de lado el tradicional modelo retail.

El sector del videojuego cada vez invierte más en publicitar sus productos en los medios tradicionales como parte de campañas tradicionales de marketing. El negocio se incrementa, la base de 
usuarios es mayor favoreciendo mayores campañas de publicidad. Por otro lado, cada vez hay más anuncios de productos dentro de los videojuegos, debido a su gran penetración entre la población y a su mayor tasa de recuerdo, por la gran atención que debe tener el usuario al jugar. En los próximos años veremos mucha más publicidad dentro de los videojuegos como parte de la estrategia económica de muchas compañías. Para los juegos de producción barata o que se ofrezcan gratuitamente será su modelo de negocio, y para las producciones más caras una forma de recuperar más rápidamente la inversión.

Otro sector importante es el tema de la piratería. Es un problema grave pero que requiere de medidas no punitivas para los usuarios, porque estas refuerzan el propio sentido de la piratería. A día de hoy se piratean videojuegos porque generalmente es más barato, más fácil, más cómodo y más rápido que conseguir el mismo contenido de forma legal. Casi nueve de cada diez usuarios españoles consideran que si bajasen el precio los videojuegos se piratería menos. Si el equilibrio coste-producto fuese más ajustado, los usuarios no piratearían tanto. Existe también la creencia de que no llega suficiente dinero para los desarrolladores: si las políticas de retribución fuesen más transparentes los usuarios verían como son recompensados sus creadores favoritos. Los usuarios se quejan de que creen que no llega suficiente dinero de la venta de videojuegos a sus creadores, quedándose gran parte de los beneficios las distribuidoras. De esta respuesta se desprende un gran desconocimiento del modelo comercial por parte de los usuarios consultados. Los distribuidores son parte fundamental en todo el proceso del sector. Incluso si no hablamos del modelo retail, y nos centramos en el online, se requiere de una adecuada campaña de marketing y de posicionamiento web, trabajo que suelen realizar las distribuidoras. Lo que sí podemos comentar es que el usuario suele echar la culpa de los altos precios de los videojuegos más a las distribuidoras que a los desarrolladores, casi dos de cada tres usuarios señalaron que se debería evitar intermediarios (del consumidor al estudio de desarrollo).

La distribución digital limita más fácilmente la piratería al no haber disco físico de por medio susceptible de copia. El cambio hacia los modelos de distribución digitales comenzó ya a mediados de la 
década pasada, pero no ha sido hasta fechas muy recientes que está empezando a funcionar. La aparición de las nuevas videoconsolas de sobremesa a finales del 2013 aceleró todavía más este proceso, donde la filosofía de que los videojuegos dejan de ser productos para convertirse en servicios supondrá una revolución en todo el sistema comercial. Es sólo cuestión de tiempo que todos los videojuegos se asocien a cuentas de usuarios, como ya viene haciendo la plataforma Steam para PC y los portales de videojuegos para smartphones y tablets, añadiendo valor añadido y opciones sociales, que los juegos pirateados nunca podrán ofrecer. Se trata de que merezca la pena la compra legal, no sólo por el producto en sí, sino por las posibilidades que ofrece la plataforma de venta. La experiencia de juego se incrementará haciendo más factible la creencia de un justo equilibrio entre coste-beneficio. Si a esto le unimos sencillez, rapidez y seguridad en la compra, la fórmula funciona por sí sola.

\section{Nuevos usos para los videojuegos}

Como cuarto factor determinante el videojuego está siendo también naturalizado debido a los nuevos usos que se están realizando. Los videojuegos se están utilizando ya como recurso didáctico de apoyo en asignaturas de primaria y secundaria (Bishop, 1998 y Cuenca Martin, 1988), por su gran aceptación entre niños y jóvenes en varios programas educativos (Gros, 2008), que facilitan la disposición a contenidos programados. Podríamos conseguir que los niños aprendan sin que se den cuenta. El uso en todo tipo de simulaciones es ya común desde hace varias décadas (Abt, 1970), porque son mecanismos de aprendizaje más baratos y seguros (aviones, coches, barcos, naves espaciales...). También destaca su uso en todo tipo de entrenamientos militares, para publicidad (adgames), en investigación médica (Foldit), rehabilitación física y mental, para marketing... la lista crece día a día.

Dos aspectos importantes, y que aparecieron en dos de los códigos experimentales testados en las entrevistas y trasladados a la encuesta de usuarios fueron: la relación entre videojuegos y los valores de igualdad de sexo, y la relación entre los videojuegos y los medios de 
comunicación generalistas. El primero de ellos reflejó que los usuarios creen que los videojuegos no reflejan bien los valores de igualdad. Tradicionalmente ha sido un producto creado por hombres para hombres. Hoy en día esto comienza a cambiar, siendo el público femenino uno de los que más ha crecido en la última década. Cada vez hay más productos específicos, con características particulares. La generalización de los usuarios ha propiciado este cambio de tendencias, que continuará en los próximos años, e incluso aumentará, conforme se vayan incorporando creadoras de videojuegos a un sector dominado tradicionalmente por hombres. La diversificación y especialización de productos no acaba sino de comenzar. El conflicto es evidente, y hacen falta estudios sobre las relaciones entre los valores de igualdad en los videojuegos porque brillan por su ausencia.

Quizá el sistema PEGI debería de establecer una categoría propia para esta problemática, con el fin de prevenir a padres y educadores de contenidos no adecuados para menores. Deberían mostrar un valor que hoy en día debería ser ya casi universal en una sociedad avanzada como es la española: la concepción social de igualdad entre sexos. Los videojuegos dirigidos a menores deben cuidar especialmente este tipo de conductas, debido a que son ya parte importante del ocio natural. Sólo desde la prevención y la visibilidad de que hay un problema podremos atajar en un futuro conductas no adecuadas. Dentro de los pictogramas del sistema aparece Sexo y Discriminación, pero leyendo su definición, hace referencia a otros factores (escenas de tipo sexual o discriminación por raza), siendo inútiles para la labor aquí descrita y demandada. Desde este estudio se demanda una categoría propia que de visibilidad al problema.

El segundo aspecto es cómo han tratado y cómo tratan los medios generalistas las noticias referidas a videojuegos. Existe una opinión aplastante de que no lo hacen bien. La explicación se basa en una mala prensa tradicional y una falta de interés entre los directores de informativos que deciden qué es noticiable y qué no. Esto también irá cambiando, conforme usuarios activos lleguen a puestos redactores y cubran a esta representación cultural con la importancia que se merece. Otra explicación es que el público objetivo de los medios 
tradicionales no está interesado en estos temas, situación que irá cambiando con el tiempo.

\section{Conclusiones}

Tras el estudio detallado de la oferta del sector del videojuego y el estudio original sobre la demanda por parte de los usuarios, debemos concluir la gran capacidad que tiene este sector para adoptar nuevas estrategias comerciales y temáticas solicitadas por los usuarios. Es muy habitual que logren cambiar las políticas comerciales de las grandes empresas. Un ejemplo reciente son los cambios de estrategia que ha realizado Microsoft para el lanzamiento a finales del 2013 de su nueva videoconsola de sobremesa, Xbox One. Microsoft pretendía implantar una serie de medidas para integrar los juegos a una cuenta de usuario, requerir conexión online permanente... vamos, un Steam pero en videoconsola, que no fueron bien acogidas por la gran masa usuaria. Por lo que cambiaron sus políticas hacia un modelo de transición más suave que el que pretendían. Porque no nos engañemos, el futuro de los videojuegos es ese, nos guste o no. Será un modelo que veremos en pocos años y que reducirá la piratería significativamente. Pero para que sea aceptado tienes que dar valor añadido y lograr convencer a los usuarios de que los videojuegos van a dejar de ser producto para convertirse en servicio. No vamos sólo a tener el videojuego, vamos a tener una red social asociada al producto, ítems exclusivos, logros, notoriedad por uso, acceso a ofertas exclusivas, facilidad de pago, opciones en la nube, audiovisual de calidad, integración con aplicaciones de smartphones y tablets... Un sinfín de nuevas opciones que proyectarán a este sector a crear sinergias con otros, ofreciendo servicios, no productos.

En definitiva, los videojuegos suponen en la actualidad el principal sector del entretenimiento cultural mundial. Es la industria cultural con mayores cifras de ventas y usuarios, creciendo cada día. La principal razón de este fenómeno es que se ha producido una naturalización del uso de videojuegos en nuestra sociedad, existe ya una cultura del videojuego como forma de ocio normal. La gente juega porque le gusta y seguirá jugando. Los temas, las interfaces, los 
dispositivos, la distribución... irán cambiando con el tiempo, pero lo que nunca cambiará son las ganas de echar una partida y divertirse con tu videojuego favorito, ya sea sencillo o complicado, largo o corto, en tu televisión o en tu smartphone... la gente seguirá jugando.

\section{Bibliografía}

ABT, C. (1970). Serious Games. Nueva York: Viking Press.

BISHOP, A. (1998). "El papel de los videojuegos en la educación matemática". Revista de didáctica de las matemáticas, 18, pp. 9-19.

BOIX, R., LAZZERETTI, L (2012). "Las industrias creativas en España: Una panorámica". Investigaciones regionales 22, pp. 181206. Disponible en:

http://dialnet.unirioja.es/servlet/articulo? codigo $=3911846$ (Acceso 15.02.2015).

BUSTAMANTE, E., ZALLO, R. (Coord.) (1988). Las industrias culturales en España. Madrid: Akal Comunicación.

CUENCA LOPEZ, J. M., MARTIN CACERES, M. (2011). "Historia y videojuegos: Una propuesta de trabajo para el aula de $1^{\circ}$ de ESO". IBER: Didáctica de las Ciencias Sociales, Geografía e Historia. ISSN 1133-9810, No 69, pp. 64-73.

ESTALLO, J. A. (1995). Los videojuegos: juegos y prejuicios. Barcelona: Planeta.

GAITAN MOYA, J. A., PIÑUEL RAIGADA, J.L. (1998). Técnicas de investigación en Comunicación Social. Madrid: Síntesis.

GEE, J. P. (2004). Lo que nos enseñan los videojuegos sobre el aprendizaje y el alfabetismo. Málaga: Aljibe.

GROS, B. (2008). Videojuegos y aprendizaje. Barcelona: Graó.

HUIZINGA, J. (1987). Homo ludens. Madrid: Alianza.

LEVIS, D. (1997). Los videojuegos, un fenómeno de masas. Barcelona:

Paidós de Comunicación.

MORALES CORRAL, E. (2011a). "Los videojuegos: apostar por la cultura multimedia”. En BUSTAMANTE, E. (Coord.). Informe sobre la cultura española y su proyección global. Fundación Alternativas, Madrid: Marcial Pons Ediciones Jurídicas y Sociales, pp. 133-152. 
MORALES CORRAL, E. (2011b). "El videojuego y las nuevas tendencias que presentan al mercado de la comunicación". Revista Disertaciones, V. 4, No 2 julio-diciembre, pp. 36-54.

Disponible en:

http://erevistas.saber.ula.ve/index.php/Disertaciones/article/v iew/3464/3366 (Acceso 15.02.2015).

MORALES CORRAL, E. (2012). "El reconocimiento institucional español de los videojuegos como industria cultural: propuestas para crear industria". Derecom, No 11, septiembre-noviembre, pp. 17-33. Disponible en: http://derecom.com/numeros/pdf/morales.pdf (Acceso 15.02.2015).

PIÑUEL, J. L., LOZANO, C. (2006). Ensayo general sobre la comunicación. Barcelona: Paidós. 


\title{
Multitarea, Multipantalla y Práctica social del consumo de Medios entre los jóvenes de 16 a 29 años en España
}

Gemma Teso Alonso, Universidad Complutense de Madrid, UCM, Madrid, España

Perfil en (1) http://orcid.org/0000-0001-9852-0255

y en 6

José Luis Piñuel Raigada, Universidad Complutense de Madrid, UCM, Madrid, España

Perfil en (1) http://orcid.org/0000-0003-1354-0770

y en $G$ http://goo.gl/QKDfoQ

\begin{abstract}
En la actualidad, los jóvenes constituyen la franja de público que menos hace uso de los Medios de Comunicación Social (MCS) convencionales y más emplea las Tecnologías de la Información y Comunicación (TIC); A medida que todos los MCS se han integrado ya en Internet conformando un nuevo ecosistema comunicacional (Jenkins, 2009), los jóvenes a través de la Red acceden a determinados discursos producidos y/o vehiculados a los Media y a las corporaciones mediáticas (discursos-fuente informativos, de opinión, de divulgación, publicitarios y, sobre todo, discursos de ficción: videojuegos, films, series, etc.). Como indican diversas encuestas, hay evidencia empírica de que la principal fuente de conocimiento científico para los jóvenes radica, además de en la fuente educativa, en los discursos provistos sobre todo por los MCS y por las
\end{abstract}


multinacionales mediáticas, accesibles en distintos soportes o plataformas (Lopera, 2013, Meira, 2013).

En este texto se presentan y se discuten datos sobre la práctica social del consumo de Medios por parte de los jóvenes, la cual se caracteriza hoy día por ejercitarse en el marco de conversaciones virtuales mantenidas entre iguales a través de las redes sociales, sirviéndose de la "multitarea" y el uso de múltiples pantallas (TV, móvil, tablets...). Los datos empleados proceden de estudios sobre consumo audiovisual de audiencia juvenil y de una encuesta realizada en el marco de la tesis doctoral titulada "Discursos mediáticos, representación del cambio climático en los jóvenes y cambio social" cuya autoría corresponde a Gemma Teso Alonso, con la dirección de José L. Piñuel y Rogelio Fernández.

\section{Keywords}

Multipantalla; Consumo de Medios; Redes Sociales; Jóvenes.

\section{Introducción: algunos datos sobre consumo de multipantallas y rasgos socio demográficos de los usuarios}

A L conectarse al mundo a través de una pantalla "audiovisual" van cambiando. Mientras la pantalla que ocupaba antes el escenario central del hogar, antes llamada "de sobremesa" es cada vez más grande y de formato más panorámico y espectacular (hasta de 82" pulgadas en la actualidad), otras se van tornando cada vez más ligeras y transportables como es el caso de las pantallas del ordenador portátil, las tablets y la del teléfono móvil. Si se comparan el número de los usurarios que simultáneamente se reúnen para disfrutar de un mismo relato, encontramos que los dispositivos de mayor tamaño se destinan a convocar a grupos formados por un mayor número de personas, mientras que aquellos dispositivos más pequeños se acomodan a la medida de las posibilidades de cada individuo (posibilidades de manejo/operatividad, el tiempo personal de dedicación y la disponibilidad de cualquier espacio que haga posible un aislamiento mínimo, dando lugar a lo que conocemos como dispositivos en movilidad). 
Pero estos escenarios (que en la Figura 1 se pueden ver integrando hoy en diversas proporciones el equipamiento doméstico), no se ponen exclusivamente al alcance de forma simultánea, secuencial y directa conforme a parrillas de programación, sino a la carta y brindándole al usuario la posibilidad de penetrar en ellos para intervenir interactuando y contactar así con cualesquiera otros actores del relato y cualesquiera otros agentes consumidores, intercambiando opiniones y mensajes audiovisuales en una conversación de discurso poliédrico y en forma de red (red de amigos, de followers, de conversadores...). La disponibilidad de estos discursos multipantallas, requiere sin embargo de una industria tanto más compleja en la producción de servicios (conexión, trasmisión de datos, etc.), cuanto más sencillo e individual resulte ese escenario en su accesibilidad, operatividad y familiaridad de consumo para el usuario. La industria informática, la red de Internet, la telefonía móvil, la capacidad de gasto en equipos y en suscripción, etc. constituyen la infraestructura imprescindible, cuyo éxito empresarial y de oportunidades de mercado se incrementa exponencialmente con el consumo del espectáculo audiovisual que brindan esos escenarios tan próximos y personales.

Y ¿para qué se usan y cómo tales pantallas, tales aparatos, mientras se ve la televisión? Gracias a la convergencia de los medios de comunicación convencionales dentro de las redes sociales, asistimos a nuevas formas de consumo de los contenidos mediáticos, es decir, al denominado consumo social (González-Neira y Quintas-Froufe, 2014).

Tanto el consumo de contenidos de radio y televisión a través de las redes sociales, como las posibilidades de que la audiencia pueda interactuar entre sí y con los emisores intercambiando opiniones escritas y mensajes audiovisuales en una conversación polifónica y extendida como una malla tejida de amigos, de followers, de conversadores, ha dejado obsoleto el paradigma de consumo tradicional. El informe citado de Cocktail Analysis en el gráfico que se ofrece en la figura 2, ilustra magistralmente qué tipos de dispositivos en movilidad se emplean al tiempo que se ve la televisión, permitiendo el acceso a las redes sociales y diversidad de 
tareas de interacción produciendo un discurso social paralelo en torno a los contenidos emitidos.

\section{Figura 1.}

Equipamiento tecnológico en el hogar

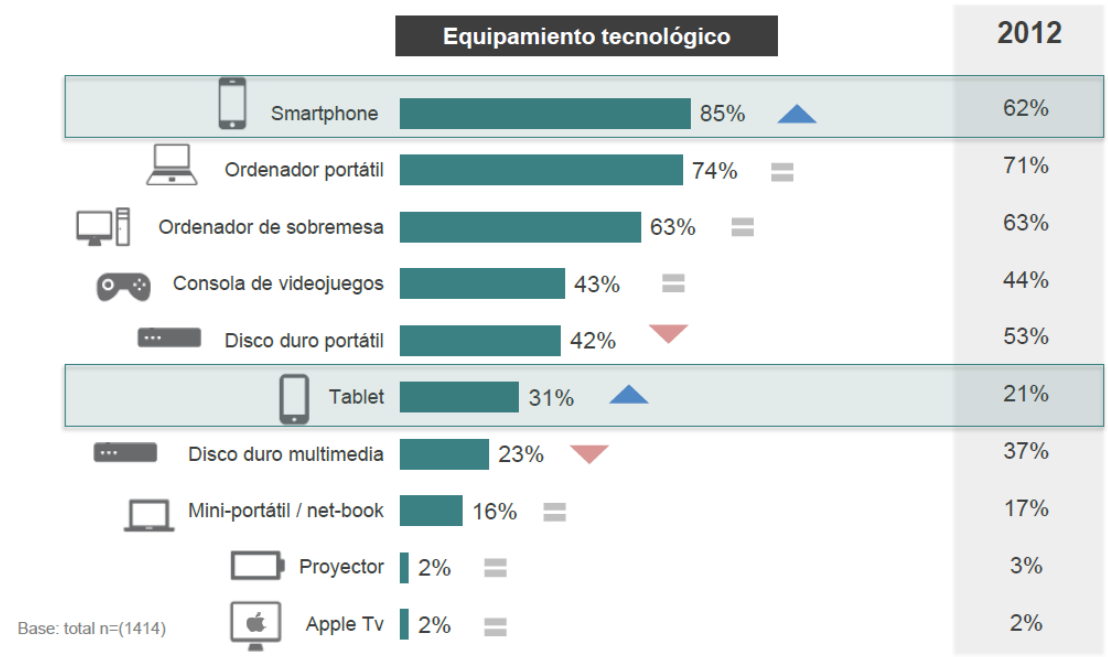

Los dispositivos en movilidad son los únicos que crecen en penetración Fuente:CocktailAnalysis, $2013^{15}$

\section{Figura 2}

Actividades de cada dispositivo mientras ve televisión

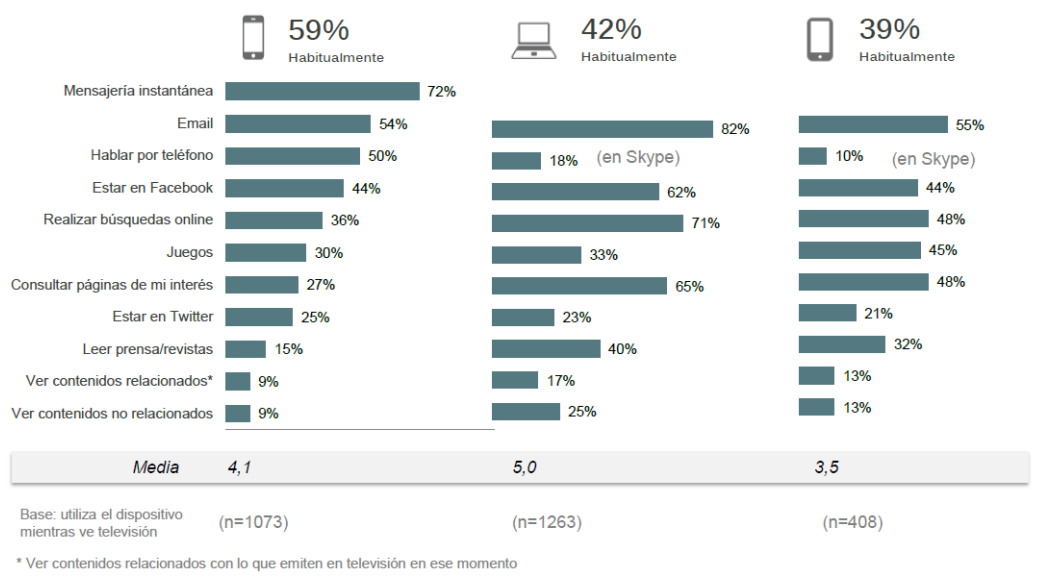

Diferentes dispositivos de interacción se traducen en diferentes usos concurrentes Siendo el ordenador el que ofrece mayor amplitud frente a Smartphone y Tablet.

Fuente: Cocktail Analysis 2013

${ }^{15}$ COKTAIL ANALYSIS. Televidente 2.02013 (VII Oleada). Informe público disponible en:

http://www.slideshare.net/TCAnalysis/informe-publico-televidente$\underline{11102013}(02-11-2014)$ 
Finalmente, tomando igualmente datos del Informe de Televidente de 2013 de Cocktail Analysis puede además apreciarse que la televisión se ve cada vez más a la carta, como habíamos anunciado al principio, y que además, no sólo es una práctica habitual entre los más jóvenes, sino que también la van incorporando a sus hábitos los más adultos mediante descargas o streaming, como se muestra en la Figura 3.

\title{
Figura 3
}

\section{Evolución de descargas y streaming}

\begin{abstract}
El cambio en el uso del numero de usuarios de descargas y/o streaming ha sido muy intenso:
Si caía 8 puntos en el 2012 por el cierre de Megaupload, en el 2013 no solo se ha recuperado, sino que ha llegado a crecer 17 puntos.
\end{abstract}

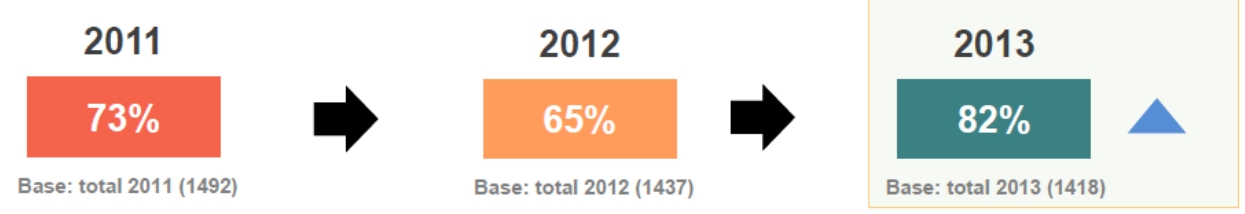

Este aumento se concentra en los perfiles de mayor edad:

\begin{tabular}{|l|l|l|}
\hline $\begin{array}{l}\text { \% descarga y/o } \\
\text { streaming }\end{array}$ & 2012 & 2013 \\
Hasta 25 años & $87 \% \rightarrow 93 \%$ \\
De 26 a 35 años & $79 \% \longrightarrow 87 \%$ \\
De 36 a 45 años & $55 \% \rightarrow 78 \%$ \\
De 46 a 55 años & $47 \% \longrightarrow 66 \%$ \\
\hline
\end{tabular}

Los perfiles de menos de 35 años siguen estando a la cabeza en la búsqueda de contenidos de su interés vía internet.

Son los más adultos, que el año pasado habían abandonado estas prácticas como consecuencia de la mayor dificultad en el acceso, los que más se han incorporado en mayor medida a esta pauta de uso habitual en la búsqueda de contenidos de interés.

Fuente: Cocktail Analysis 2013

\section{Una cuestión a ser planteada: la redes sociales como "lugar de encuentro" entre Medios y audiencias}

Conviene plantearse a este respecto cuáles son las tendencias más relevantes que en los últimos años ha experimentado lo que podría llamarse el "lugar social de encuentro". El nuevo "lugar social de encuentro" se caracteriza en efecto por localizarse virtualmente a través de Internet, donde los Medios se ubican para acercarse "personalmente" a sus audiencias y donde las audiencias, hasta ahora dispersas, se reúnen para "estar en contacto". Y este contacto ya no se hace disponible convocando a las audiencias a las horas que fija 
una parrilla de programación, sino brindándoles sus contenidos “a la carta”.

Así, a diferencia de los tradicionales "lugares sociales de encuentro" físicamente localizables en una territorialidad socialmente construida con antelación al propio ejercicio de "llegar y encontrarse", o temporalmente ubicada a horas precisas del día, el encuentro virtual en la redes sociales carece de toda proximidad física o temporal a la que, por supuesto, renunciaban hasta ahora los medios para acercarse a sus audiencias y las audiencias para acercarse a los Medios. Hoy el encuentro entre Medios y Audiencias en las redes sociales se urde por medio de la conversación virtual gracias a la multitarea facilitada por el manejo simultáneo de diversos dispositivos y pantallas. Pero sobre todo, gracias a las redes sociales que constituyen hoy un espacio virtual donde se exhibe el valor simbólico del perfil o identidad virtual del usuario siempre en construcción. $\mathrm{Y}$ en este empeño, la práctica social del periodismo le brinda al sujeto recursos y habilidades de socialización, abriéndole ventanas a la percepción de la realidad social frente a la cual, el contacto, la red de amigos y el reconocimiento del "sí mismo" se torna en asidero vital de seguridad y permanencia. Podemos citar como antecedentes, en lo que respecta a los procesos de percepción social del acontecer y sus quiebras (noticias), estudios realizados en torno a la incertidumbre por Ulrich Beck, 1998 y 2002; Lozano Ascencio, 2002 y 2003; Gil Calvo, 2003, y diversos trabajos realizados en torno a la construcción social de la realidad, por Berger y Luckmann, 1976; Gergen y Warhus, 2003, etc. Y por lo que respecta al contexto de las nuevas relaciones sociales urdidas por el uso que tanto los medios como las audiencias hacen de las denominadas redes sociales, podemos citar a Johnson, S. 2003, Castells, M. 2001, y Ontalba-Ruipérez, J. 2006. El propio Manuel Castells, en la entrevista publicada el 4 de agosto de 2013 en el Blog de Sociología y actualidad denominado Ssociólogos, afirmaba que "la sociabilidad real se da hoy en Internet". ${ }^{16}$

${ }^{16}$ Entrevista completa disponible en: http://ssociologos.com/2013/08/04/manuel-castells-la-sociabilidad-real-se-dahoy-en-internet/ (02-11-2014). 
Nos planteamos así que Medios y audiencias usan las redes sociales creando hoy día un nuevo "lugar social de encuentro" caracterizado por su ubicación virtual en Internet, donde los Medios se aproximan "personalmente" a sus audiencias y donde las audiencias, hasta ahora dispersas, se reúnen para "estar en contacto" o "estar atentos" y como amigos o seguidores (followers) conversar. Unos y otros se presentan, se siguen y persiguen, se intercambian opiniones, imágenes, vídeos, y tejen sus relaciones sin los riesgos del contacto próximo y precaviendo la intimidad. Así, ya es casi viejo (2011) el que los Medios de Comunicación se hagan presentes en las redes sociales (Facebook, Twitter, YouTube...), como puede comprobarse en el informe publicado en el 2011 por el Gabinete de Análisis Demoscópico (GAD3) y titulado "Medios de Comunicación en Redes Sociales".

\section{Figura 4}

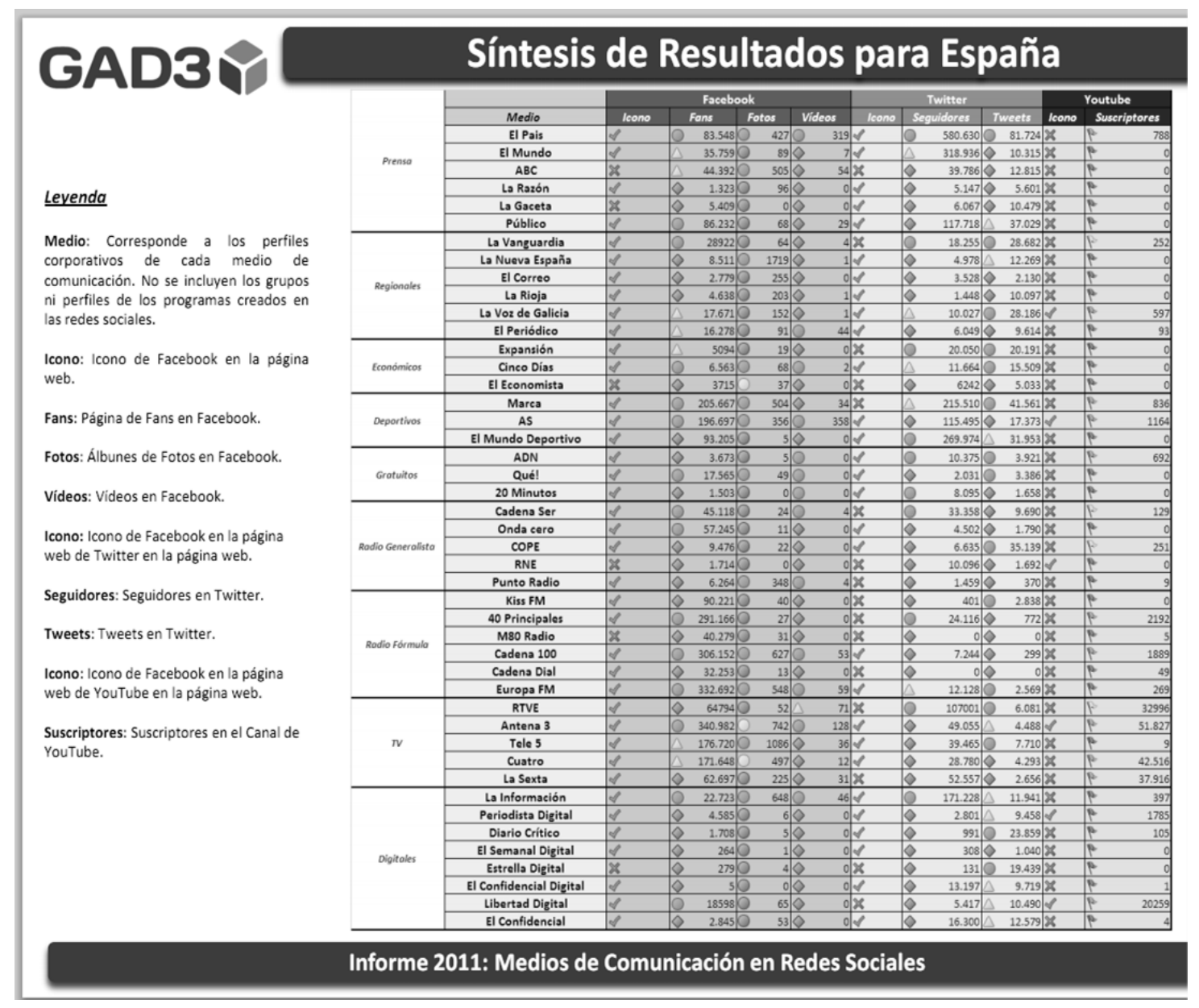

Fuente: Informe 2011, Medios de Comunicación en Redes Sociales, de GAD3 (Gabinete de Análisis Demoscópico). 
En esta tabla puede cotejarse cómo, por ejemplo, El País proyectaba su liderazgo en las redes sociales, siendo Twitter donde tenía más seguidores, más de 580.000. El Mundo mantenía también su segunda posición, con más de 350.000 seguidores, mientras Público, era líder en Facebook con más de 85.000 fans, superando a El País y a ElMundo en esta red social. Entre los diarios regionales destacaba La Vanguardia en Facebook, seguido de La Voz de Galicia. Respecto a la prensa económica, Expansión era líder con 25.000 seguidores.

Por su parte, las audiencias se sirven de las redes sociales acudiendo primordialmente a ellas para encontrarse con sus iguales (usuarios de perfiles afines) para afianzarse en la relación, por una parte, y compartir su conocimiento y opinión del entorno y de lo acontecido, por otra. Los programas de televisión que se están viendo en ese momento o que se han visto recientemente, son objeto de comentarios en las conversaciones virtuales casi tan importantes como el resto de contenidos compartidos por los usuarios relativos a intercambios de fotos y expresiones, o sobre las cosas que se están realizando mientras se mantienen conectados (ver figura 5) .

\section{Figura 5}

\section{Tipos de contenidos sobre los que se realizan comentarios en plataformas sociales}

Tipos de contenidos

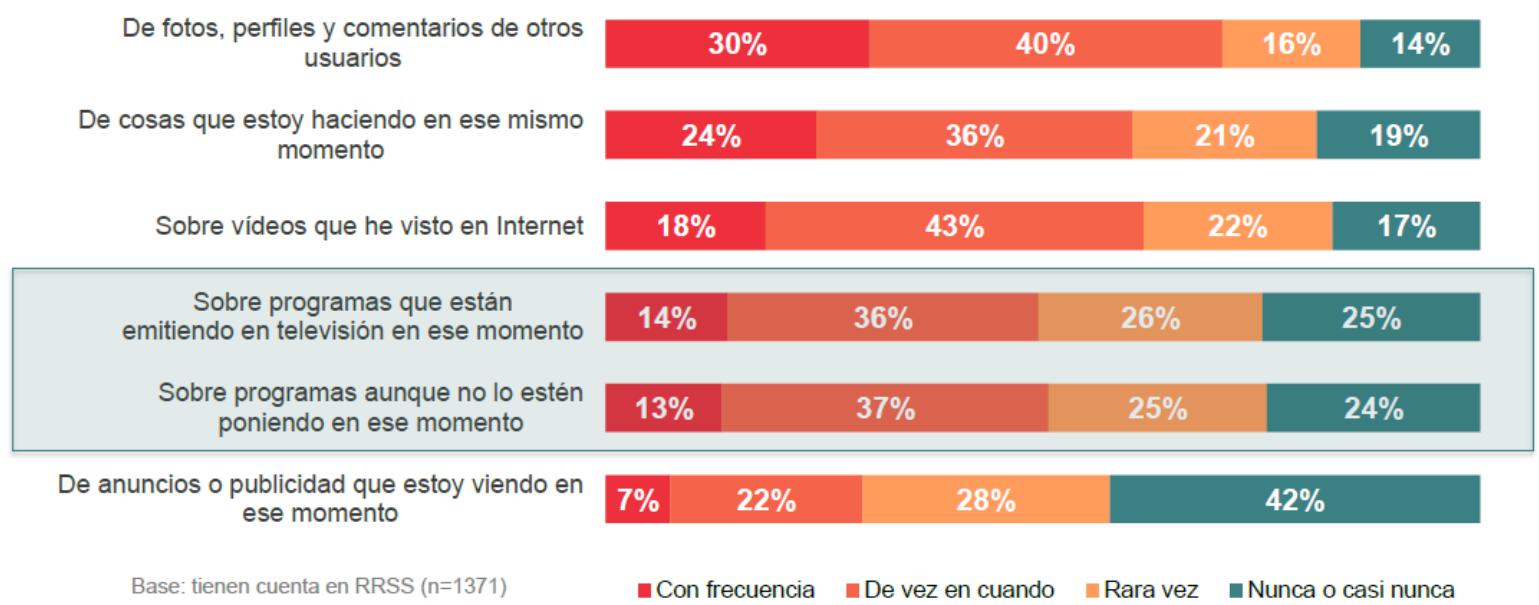

Fuente: Cocktail Analysis, 2013 
Una plataforma especialmente singular entre la juventud es YouTube, que se ha convertido en uno de los canales preferidos por los jóvenes para el consumo audiovisual de contenidos producidos al margen de los medios convencionales. Según el último EGM, YouTube es la web más visitada de España, con 20.431.000 visitas mensuales, lo que podría considerarse como el cuarto canal más visto. Y en este canal, los jóvenes youtubers se están afianzando como los nuevos creadores de contenidos, logrando en muchos casos monetizar su trabajo en cantidades que pueden alcanzar incluso los 3000 euros mensuales cuando logran superar los 50.000 suscriptores. Los youtubers con más seguidores pueden generar entre medio millón y cinco millones de euros al año, tal y como explicaba al diario El País Toni Garrido, de la empresa Marker Studios en España, dedicada a producir y distribuir contenidos de YouTube ${ }^{17}$.

Definitivamente, el "lugar de encuentro" al que concurren los Medios de Comunicación se llena de contenidos cada vez más vinculados a las relaciones interpersonales que sus usuarios tejen durante las conversaciones virtuales entre iguales.

\section{Una encuesta a jóvenes de 18 a 29 años, de seguimiento monitorizado en el aula, sobre uso de Medios de Comunicación}

Es en el contexto descrito donde radican las preguntas y respuestas de una encuesta sobre uso de Medios de Comunicación, aplicada a una muestra de 756 alumnos de primeros cursos de universidad y de Formación Profesional, grado superior, en el marco de la tesis doctoral titulada Discursos mediáticos, Representación del Cambio Climático en los jóvenes y Cambio Social.

La encuesta aplicó un cuestionario on line, de cumplimentación "tutelada", es decir, realizado en los centros educativos y durante el horario lectivo, contando con la presencia de un profesor responsable

\footnotetext{
${ }^{17} \mathrm{La}$ entrevista forma parte del artículo titulado "De mayor quiero ser youtuber" publicado en la edición impresa del diario El País el sábado 15 de noviembre de 2014.
} 
que previamente había tenido conocimiento del contenido y las posibles incidencias que pudieran tener lugar.

A priori se optó por una muestra probabilística y un muestreo por áreas o conglomerados (Gaitan, Juan A. y Piñuel, José L. 1998:153) ${ }^{18}$. Teniendo en cuenta que las variables de corte que definen el público objetivo de la encuesta eran la edad (16 a 29 años) y el nivel educativo ya señalado, se consideró la opción más eficaz practicar la encuesta atendiendo a las estructuras naturales en las que se agrupan los individuos atendiendo a las citadas variables y que no son otras que las aulas, en las que se agrupan los jóvenes atendiendo a la edad y etapa educativa.

El grado de heterogeneidad de este universo es alto, ya que la encuesta ha sido practicada a grupos de jóvenes de varias comunidades autónomas del estado español, atendiendo así a las diferentes singularidades identitarias, lingüísticas y culturales existentes en las diversas Comunidades Autónomas representadas en la muestra. Esta heterogeneidad propia de España, compensó la posible homogeneidad existente en los grupos de estudiantes. Las Comunidades Autónomas participantes fueron: Madrid, Cataluña, Galicia, Andalucía, País Vasco, Valencia y Castilla y León.

Pues bien, en aquella encuesta el primer dato relevante para nuestro propósito fue confirmar cómo los jóvenes valoraron de 1 a 5 los diversos medios de comunicación preferidos durante su tiempo de ocio, y como puede advertirse en la Figura 6, destacan las redes sociales y el acceso on-line a la televisión y a las páginas web. Que la televisión TDT se aproxime al valor 4 y que la televisión por Internet (TV IP), no alcance el valor 3, demuestra el uso de la multitarea y la multipantalla.

\footnotetext{
${ }^{18}$ Sobre una muestra probabilística, se calculó el tamaño de la misma para un universo infinito y teniendo en cuenta los siguientes parámetros: valores "p" y "q de un 30/70 ( $p+q=100)$ y límite de error de un $+-5 \%$. El tamaño de la muestra resultante fue de 756 individuos.
} 
Figura 6

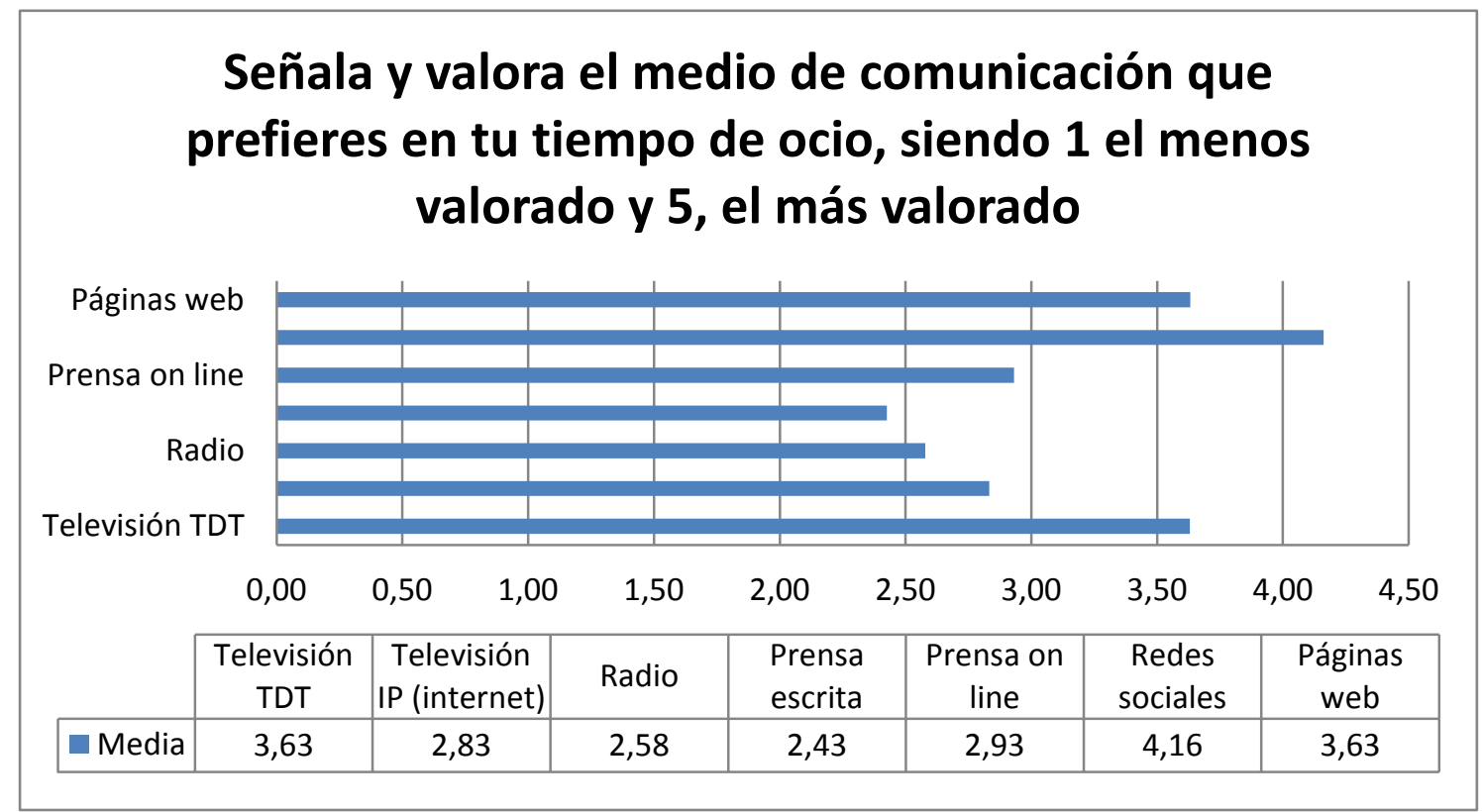

Fuente: elaboración propia

Y si se preguntaba por el número de horas dedicadas a prestarle atención a estos mismos medios, resalta cómo (ver Figura 7) las redes sociales reciben más de tres horas de dedicación, más de dos horas las páginas web y casi dos horas la televisión TDT, confirmando así los datos anteriores.

Figura 7

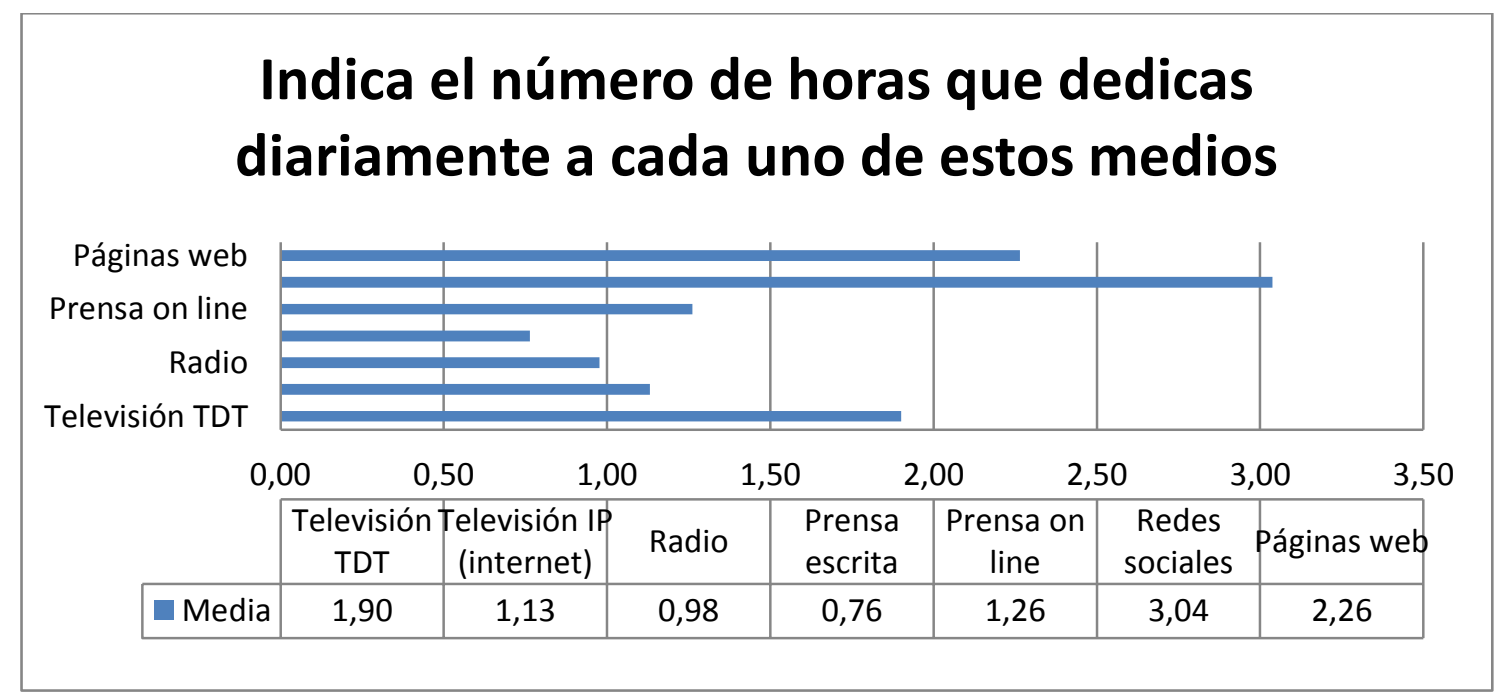

Fuente: elaboración propia 
Y como las redes sociales aparecen de forma tan relevante, se preguntó cuáles eran las más usadas. El resultado se muestra en la

\section{Figura 8}

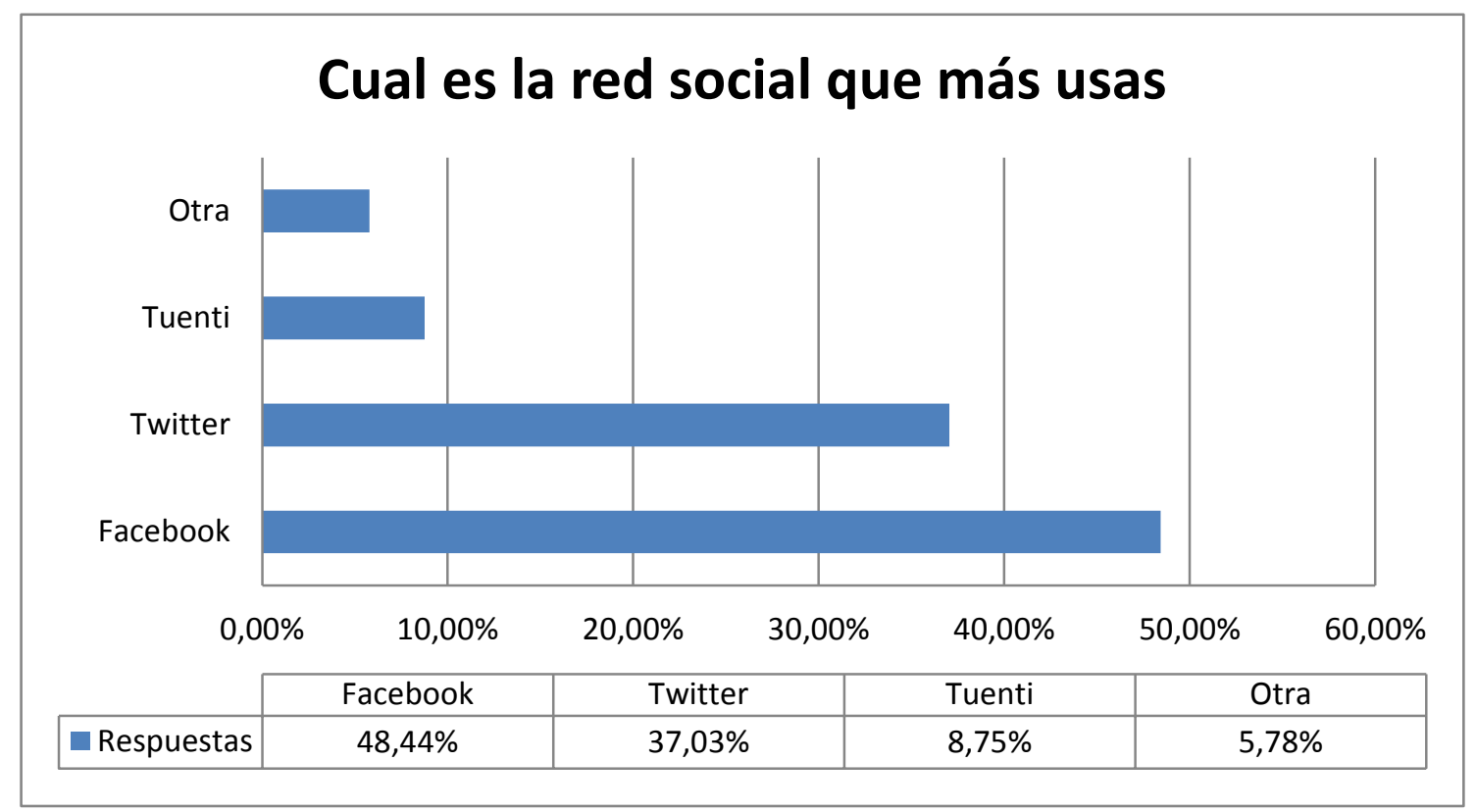

Fuente: elaboración propia

Finalmente, y dado que la encuesta se hizo en el marco de una investigación sobre las representaciones sociales del cambio climático entre los jóvenes españoles, consideramos relevante el perfil de las respuestas a la pregunta sobre la fuente más rica o más abundante de información científica, que en aquel caso era el cambio climático, pero que puede ilustrar en general la calidad con que los jóvenes apreciaban sus fuentes de información científica.

Y los resultados se muestran en la Figura 9. En ella se advierte cómo esta información procede sobre todo de Internet, pero también de la televisión y de las redes sociales, atribuyéndoles casi tanta importancia como al profesor en el aula y a las revistas especializadas, mientras que la prensa, la radio, así como los amigos y familiares reciben las apreciaciones peores como fuentes de información. 


\section{Figura 9}

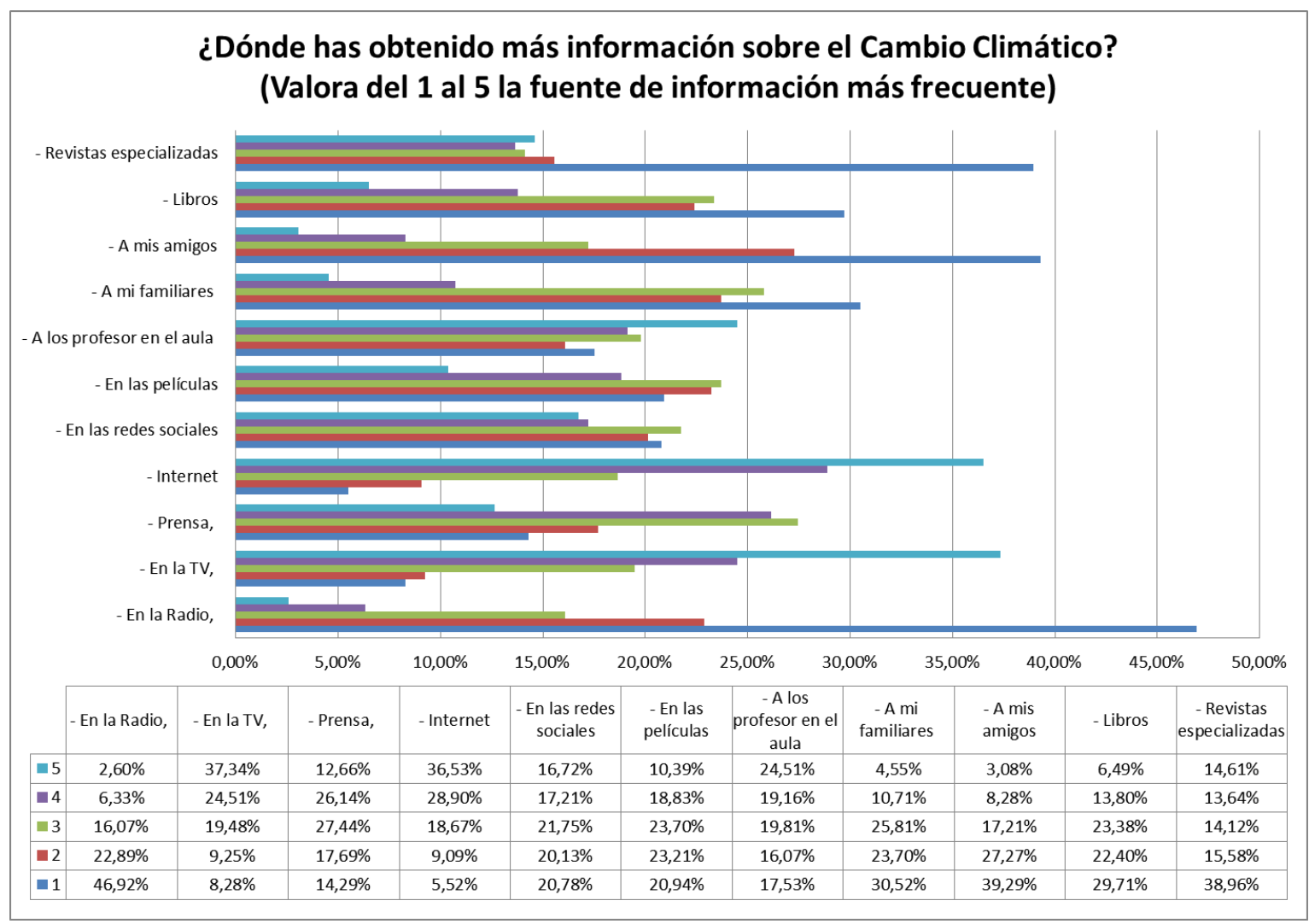

Fuente: elaboración propia

\section{Conclusiones}

Tras la exposición precedente de datos, puede haberse comprobado que todos ellos, aun cuando procedan de fuentes e investigaciones distintas, coinciden en ofrecer un perfil del consumo audiovisual que de manera primordial en la juventud se realiza utilizando simultáneamente diversos dispositivos convergiendo con la pantalla de la televisión, y que su consumo, preferiblemente a la carta y sin seguir parrillas de programación temporalmente ubicadas, se articula siguiendo el curso de conversaciones virtuales cuya sinergia secuencial se teje en las redes sociales. Ello puede hacer comprender fácilmente el interés de los Medios de Comunicación por intervenir en las redes sociales al encuentro de sus audiencias, compitiendo entre sí por ganar la confianza de sus seguidores (followers), y sobre todo incentivando el crecimiento del tejido de las conexiones, de la malla virtual, de las redes sociales, y de los contenidos cuya espectacularidad 
mejor pueda alimentar las conversaciones como los dispositivos más eficaces para incrementar la sociabilidad.

\section{Bibliografía}

BECK, U. (1998). La sociedad del riesgo. En camino hacia otra sociedad moderna. Barcelona: Paidós.

BERGER, P.L. y LUCKMANN T. (1976). La construcción social de la realidad. Buenos Aires: Amorrortu.

CASTELLS, M. (2001). La era de la información: economía, sociedady cultura. Madrid: Alianza Editorial.

THE COKTAIL ANALYSIS. "Televidente 2.02013 (VII Oleada)". Informe Público. Disponible en: http:/ /tcanalysis.com/blog/posts/el-62-de-los-internautas-usaotro-dispositivo-a-la-vez-que-la-television-de-manera-habitual (Acceso 14.03.2015)

CRESPO, K. (2006). "Comunidades virtuales y construcción de conocimientos". Disponible en:

http://portal.educ.ar/debates/educacionytic/debate/comunida des-virtuales-y-construccion-de-conocimientos-.php. (Acceso22.02.2008).

CROVI DRUETTA, D. (2006). Educar en la era de las redes: una mirada desde la comunicación ( $1^{\circ}$ ed.). México: UNAM Facultad de Ciencias Políticas y Sociales; SITESA.

GAITAN, J. A. y PIÑUEL, J. L. (1998). Técnicas de Investigación Social en Comunicación. Elaboración y registro de datos. Madrid: Ed. Síntesis.

GERGEN, K. y WARHUS, L. (2003). "La terapia como una construcción social: dimensiones, deliberaciones y divergencias". Revista Venezolana de Psicología Clínica Comunitaria, 3, pp. 3-44.

QUINTAS-FROUFE, N. y GONZALEZ-NEIRA, A. (2014). "Audiencias activas: Participación de la audiencia social en la televisión". Comunicar no 43, pp. 83-90.

JOHNSON, S. (2003). Sistemas emergentes: o qué tienen en común hormigas, neuronas, ciudades y software ( $1^{\circ}$ ed.). Madrid: Turner

ONTALBA-RUIPÉREZ, J. (2006). Las comunidades virtuales como herramientas para la socialización del conocimiento tácito. Huelva: Book Chapter. 
PIÑUEL, J.L. y LOZANO, C.H. (2006) Ensayo general sobre la Comunicación. Barcelona: Paidós.

PIÑUEL, J.L. y LOZANO, C.H. (2007) "Incertidumbre y comunicación. Dominios de supervivencia y estructuración del acontecer". Diálogos de la Comunicación, nº 75 FELAFACS. Lima, Perú.

PIÑUEL, J.L. y LOZANO, C.H., TESO ALONSO, G. (2015). Discursos mediáticos, Representación del Cambio Climático en los jóvenes y Cambio Social. Tesis doctoral. Universidad Complutense de Madrid.

VARIOS (2013). "El 46\% de los españoles navega con sus tabletas mientras ve la televisión". Disponible en: http://www.puromarketing.com/12/18593/espanolesnavegan-tabletas-mientras.html 



\title{
Emociones: importancia y fundamento en los contenidos televisivos
}

\author{
María José Labrador, Universidad Mayor, Santiago, Chile \\ Perfil en $(1)$ y en $\widetilde{G}$
}

\begin{abstract}
En el análisis sobre las plataformas digitales, el futuro de la televisión y la proliferación de canales, frecuentemente se olvida qué es lo que se constituye como sustancial para el funcionamiento de la televisión y sobre lo cual debemos focalizar nuestra atención: los contenidos. Este trabajo presenta como objeto de análisis la dimensión emocional en la televisión en sus diferentes manifestaciones: a través de sus contenidos, personajes, características del relato televisivo y lenguaje audiovisual (imágenes, códigos de iluminación, edición, y efectos sonoros entre otros), para lo cual se ha considerado fundamental integrar a la disciplina de la Comunicación, otras áreas del conocimiento como la Psicología y la Antropología Filosófica que abordan dicha materia desde su raíz más profunda.

El estudio que aquí se presenta en una primera etapa, a través del método reflexivo aborda los fundamentos de la dimensión emocional, profundizando en el conocimiento de las emociones, su influencia en la conducta humana y el planteamiento de los contenidos televisivos en clave emocional, entre otras perspectivas. Esta investigación se encuentra actualmente en una segunda etapa de análisis con una
\end{abstract}


metodología cuali-cuantitativa sobre emociones y contenidos infantiles televisivos.

A partir de lo anterior, se propone el uso de ciertas habilidades y aspectos que se pueden implementar en la creación de los contenidos televisivos y multiplataforma. Se pretende también avanzar en el debate para definir posibles directrices que orienten por un lado a la industria de la comunicación a buscar un acercamiento hacia la innovación en dicho tema y la calidad que agrega valor a la marca de cualquier canal y, por otro, conocer y valorar a las audiencias infantiles en su calidad de inteligentes, selectivas, criticas, interactivas y globalizadas.

\section{Keywords}

Televisión; infancia; emociones; consumo; contenidos

\section{Las emociones: importancia y fundamento en la infancia y los productos audiovisuales dirigidos a ella}

— L título nos sitúa frente a un desafío que involucra a diversas 1 áreas del conocimiento y por tanto reviste fundamental importancia abordarlo desde la fundamentación de la dimensión emocional en su raíz más profunda con la finalidad de poder aplicar ese conocimiento al respecto a la educación en medios -entendida como diálogo- lo que debería tener como consecuencia, a corto y medio plazo, un doble proceso. En primer lugar, la formación de una conciencia crítica y participativa de las audiencias jóvenes en relación al análisis de los contenidos y especialmente al conocimiento de cómo se abordan las emociones en la televisión en sus diferentes manifestaciones: las características del relato televisivo y lenguaje audiovisual (imágenes, códigos de iluminación, edición, y efectos sonoros entre otros) y su influencia en su desarrollo cognitivo, social, familiar y por supuesto emocional. En segundo lugar, la progresiva aceptación, por parte de los medios, de un compromiso profundo con la educación y el planteamiento de las emociones en los contenidos, productos audiovisuales o multimedia de forma innovadora y positiva.

A través de una línea de investigación abierta en torno al tema, 
hemos abordado la dimensión emocional desde tres ámbitos del conocimiento, por tanto recogeremos el trabajo que hemos realizado junto con otros investigadores (Labrador y Rebeil: 2013) intentando resumir de la forma más concreta posible los aspectos que nos convocan en este apartado.

La integralidad de las facultades humanas deja clara la interdependencia de las facultades de la persona en la acción. En esta, la estructura superior (intelecto y voluntad) interactúa con el fondo vital y el endotímico - con sus vivencias pulsionales, emocionales y estados de ánimos persistentes-. Tal comprobación avala el estudio de Goleman (1997) que afirma que más del 90 por ciento de nuestras conductas son emocionales en su primer momento; sin embargo, es evidente que un ser racional y libre como es el humano, en su realización está llamado a orientarlas -no reprimirlas- con el conocimiento y el querer libre (actualizados ambos por lo que es propio a cada uno: posesión del conocimiento de los seres que permita ver el bien real, que será siempre favorecedor del desarrollo individual de la estructura de la persona humana).

Las emociones son uno de los tres componentes-naturales del fondoafectivo-sensible de la persona. Se originan en las tendencias o fuerzas sensibles naturales del hombre (instintos en el animal), y a su vez, influyen en los estados de ánimo persistentes. La capacidad emocional en la persona es, en la acción humana, anterior a la intervención del intelecto y de la voluntad. Los estudios vinculantes evidencian que el desarrollo de las emociones se realiza en el encuentro del sujeto actuante con el mundo circundante real e inmediato; por lo tanto, son la raíz de la acción del ser humano en condiciones normales y más aún en las anormales, en las que no es posible exigir la intervención de la razón. (Vidal, 2013).

En el esquema 1 presentamos el esquema de la estructura de la persona.

El esquema 1 muestra a la persona -a cada uno de nosotros- en una triple estructura que contiene todo su sí mismo, su yo personal, su aseidad, su yoeidad de criatura. Los tres aspectos -como la experiencia lo demuestra- están íntimamente unidos en la persona a modo de 
coprincipios (inseparables). Es inimaginable suprimir uno de aquellos y hablar de persona humana.

\section{Esquema 1. Estructura de la persona}
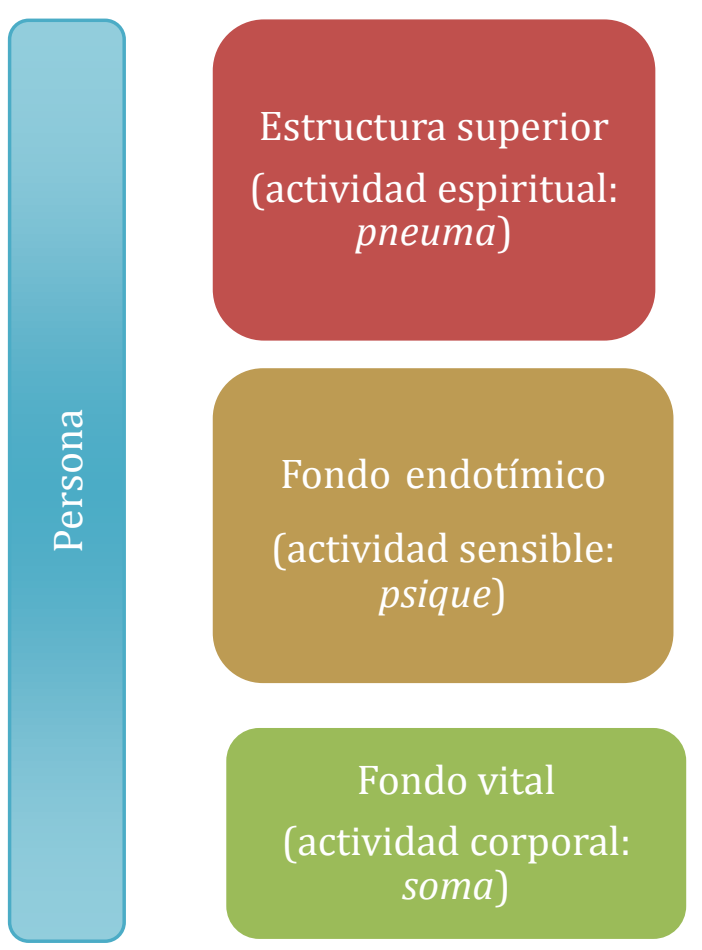

- Intelecto

- Voluntad

- Tendencias o pulsiones

- Emociones

- Estados de ánimo

- Procesos fisiológicos

Fuente: Lersch (1966: 77-484)

El fondo vital contiene las facultades orgánicas, lugar de toda actividad corporal, somática. Es la constitución anatómica, histológica, fisiológica, etc., del individuo, una realidad basal para la existencia de las otras dos estructuras (lo que no significa que la persona no existe si hay daños o deterioros físicos en la corporeidad).

El fondo endotímico es el lugar donde radican las facultades sensibles o anímicas de la persona (psique), a partir de las que se origina la actividad afectiva sensible, es decir, donde se originan las tendencias o pulsiones, las emociones y los estados de ánimo (ámbito de la persona al que nos referiremos más ampliamente después, por su relación con las emociones). 
La estructura superior es la contenedora de las potencias espirituales propiamente dichas -intelecto y voluntad- que definen como tal al ser humano y posibilitan el ejercicio de la libertad.

En esta, la estructura superior (intelecto y voluntad) interactúa con el pujante fondo vital y el endotímico - con sus vivencias pulsionales, emocionales y estados de ánimo persistentes-. El estudio de Goleman (1997) evidencia lo dicho: el autor reconoce que más del 90 por ciento de nuestras conductas son emocionales en su primer momento. Sin embargo, es evidente que el hombre, por su condición racional y libre, está llamado a orientar -no a reprimir- sus emociones en el actuar, auto conduciéndolas hacia algo superior a sólo sentir. La condición para hacerlo es la posesión amable del conocimiento de sí mismo y de la realidad humana, que le permitirá ver y aceptar el bien real -no sólo emocional-. Este se descubriría como tal, al observar la aportación al desarrollo indiviso a la estructura de la persona humana, no a una parcialidad de aquella.

Lersch distingue tres grandes grupos de emociones (Lersch, 1966: 194-256) - de la misma manera que distingue tres grupos de tendencias o pulsiones-, con el fin de poner en evidencia las relaciones profundas entre los diversos aspectos de la dinámica anímica. Esto no quiere decir que cada emoción deba ser referida a un grupo de tendencias anímicas exclusivamente, sino que se trata de acentuar el tono o cualidad fundamental por la que una emoción corresponde a una determinada tendencia. Conviene recordar que, a nivel emotivo, de la misma manera que en todas las realidades anímicas, las emociones se manifiestan en un fluir constante y es difícil determinar con precisión sus contornos. Son fugaces y difusas, por lo que presentan obstáculos para su descripción individualizada. Según Lersch, en cada emoción habría que distinguir dos facetas, que se ensamblan complementándose: una hace referencia al estado actual del ánimo, es decir, al colorido o tonalidad endotímica o cualidad. La otra alude a la emoción propiamente dicha.

La profundidad de una emoción se capta por el mayor territorio anímico que abarca y recibe de aquella superficie su colorido y matiz. La vivencia será superficial si, por ejemplo, al oír una música o una noticia su contenido nos entra por un oído y nos sale por el otro; sin embargo, esa misma audición puede hacernos experimentar una 
transformación: nuestros pensamientos toman una nueva dirección y toda nuestra vida pasada y la futura adquieren una nueva luz (profundidad emocional).

El colorido (o cualidad) y la profundidad son dos direcciones que hacen variar las vivencias emocionales. Cada emoción se caracteriza por el grado en que son vivenciados los componentes tendenciales o pulsionales (Lersch, 1966: 1942).

Las emociones propiamente dichas se manifiestan a través de los signos siguientes:

- Interrupción del ritmo regular psicosomático.

- Sensación de trastorno corporal, especialmente la parte regulada por el sistema nervioso vegetativo: susto, excitación, pavor (común con los animales); horror, entusiasmo, indignación, cólera (propias del hombre).

La respuesta emocional en la acción humana es anterior a la intervención del intelecto y de la voluntad. Los estudios vinculantes evidencian que el desarrollo de las emociones se realiza en el encuentro del sujeto con el mundo circundante real e inmediato (unwelt). Por tanto, son la raíz de la actuación del ser humano en condiciones normales (y más aún en las anormales, en las que -en muchos casos- no es posible exigir la intervención de la razón. En consecuencia, reconocemos que el primer paso de toda conducta es emotivo o emocional (e-movere), debido a un movimiento-afectivosensible del sujeto, en respuesta a la percepción que surge en su relación con otro y el mundo. Lersch distingue tres grandes grupos de emociones (Lersch, 1966: 194-256) -de la misma manera que distingue tres grupos de tendencias o pulsiones-, con el fin de poner en evidencia las relaciones profundas entre los diversos aspectos de la dinámica anímica. Esto no quiere decir que cada emoción deba ser referida a un grupo de tendencias anímicas exclusivamente, sino que se trata de acentuar el tono o cualidad fundamental por la que una emoción corresponde a una determinada tendencia. La base de la distinción son las cualidades axiológicas objetivas, el colorido endotímico y la configuración emocional. 


\section{Emociones de vitalidad}

-Dolor, placer, aburrimiento.

- Saciedad y repugnancia.

- Asco físico y psíquico.

- Diversión y fastidio.

-Alegría y aflicción.

\section{Emociones del yo-individual}

- Conservación del individuo:

- Susto, agitación, temor, confianza, desconfianza.

- Del egoísmo, deseo de poder, necesidad de estimación:

- Contento, descontento, envidia, celos, triunfo y derrota, halago, agravio.

- Del impulso vindicativo:

-Desquite, alegría por daño ajeno, gratitud.

-De autoestimación:

Emociones transitivas

-Emociones del destino:

-Esperanza, temor del futuro, resignación, preocupación, desesperación.

- Emociones dirigidas al prójimo:

- Convivencia; simpatía y antipatía; estima y desprecio del prójimo; respeto, burla.

- Del sentimiento compartido:

-Amor al prójimo (amistad, familia).

-Erótico, humano.

-Alegrarse con otros.

- Compasión.

- Odio a los semejantes.

- Emociones de las tendencias creadora y cognoscitiva:

- Alegría de crear

- Sentimientos noéticos

- Emociones de las tendencias amorosas y morales:

- Amor extra humano a las cosas

- Sentimientos normativos

- Emociones de las tendencias trascendentes:

- Sentimientos artísticos

- Sentimientos metafísicos.

- Sentimientos religiosos

- Cordialidad y conciencia sensible.

Enseguida se esquematizan las emociones contenidas en cada clasificación, éstas han sido estudiadas de forma particular y 
posteriormente se ha planteado el desarrollo de variadas habilidades en los diversos contenidos televisivos para la infancia. ${ }^{19}$

En la perspectiva neuropsicológica y del campo de la salud, la conducta emocional ocupa un lugar preponderante en nuestra sociedad. El estudio de las emociones en los niños, jóvenes y adultos es objeto de intenso interés en la comunidad mundial. Desde diferentes puntos de vista, como el psicológico, el neurológico, y otros, conocemos qué son las emociones, cómo afectan a la persona para llevar a cabo su proyecto de vida y la importancia del desarrollo y manejo emocional en todos nuestros ámbitos de acción para vivir con calidad de vida. Las investigaciones en el ámbito de la inteligencia y las emociones han llevado a los investigadores a realizar estudios neurológicos para encontrar respuestas científicas a las interrogantes que se plantean hoy en día.

Desde William James, Cannon-Bard (1927), Schachter-Singer, LeDoux (2000), Ekman (2003), hasta Damasio (1999), en la actualidad, entre otros filósofos, psicólogos, neurólogos y estudiosos del tema, relacionan la vida emocional con los sentimientos y emociones de diferentes características. Estos términos indican una mayor duración y menor intensidad en el caso de los sentimientos; menor duración y mayor intensidad en las emociones, con repercusiones en nuestro organismo. La modularidad cerebral (la relación entre cerebro emocional y cerebro racional) se expresa mediante un complejo juego de interacciones. Los módulos interaccionan entre sí, para bien o para mal. Ekman escribe en EmotionsRevealed (2003) que "las emociones determinan la calidad de nuestras vidas". Se dedica desde hace cincuenta años al estudio de las emociones por medio del reconocimiento de estas en el rostro, en distintos pueblos y culturas. Su maestro y primer mentor, Tomkins (1962), escribía algo emparentado con ese concepto de calidad: "las emociones motivan nuestra vida".

Rizzolatti y Craighero (2004) muestran la existencia de neuronas

\footnotetext{
${ }^{19}$ Se sugiere leer el capítulo 1 "Antropología de las emociones", de la Dra. Carmen Vidal, autora de dicho texto en Labrador, Rebeil 2013, La dimensión emocional del discurso televisivo, Valencia, Tirant lo Blanch.
} 
"espejo" (mirrorneurons) que permiten la detección de las emociones y posibilitan imitar las emociones de quienes nos rodean, lo que se vuelve un punto fundamental de estudio en cuanto su aplicación al público televidente frente a los contenidos televisivos. De esta forma y porque existe esa red neuronal, se observa la expresión y detección de las emociones desde muy temprano en la vida.

Dichos estudios facilitan la comprensión de los sentimientos y emociones que favorecen el desarrollo armónico de la personalidad o, por el contrario, pueden provocar desórdenes psicológicos de la infancia, la niñez y la adolescencia, de consecuencias negativas para el ámbito familiar, escolar y social. Aportar ideas y procedimientos para mejorar y desarrollar de forma más óptima los estados y procesos emocionales, a través de un soporte mediático como la televisión actualmente inmerso en un gran cambio- puede suponer una gran ayuda para disfrutar de una industria programática que incentive interesantes y novedosos contenidos, de una mejor calidad de vida, así como de una mejoría de la sociedad, respectivamente. (Martín, en Labrador y Rebeil, 2013: 3-5).

\section{Las audiencias y la nueva forma de consumir televisión}

En Chile el número de televisores por hogar ha aumentado con un promedio de 2.7 aparatos por vivienda, lo que representa un crecimiento sostenido aunque no explosivo en comparación a los 2.4 de 2008. Muchos de esos nuevos televisores son instalados en las habitaciones de los menores, lo que genera un doble efecto. Por una parte la cantidad de minutos a los que están expuestos aumenta, pero también la posibilidad de que se expongan a contenido no adecuado a su edad, si es que no existe un control adecuado por parte de los padres.

La televisión abierta sigue siendo el principal medio de información, y uno importante de educación, cultura, entretención y compañía para la ciudadanía. Los noticiarios, películas, reportajes y programas culturales, son los contenidos mejor evaluados. Por su parte, los programas más criticados por su contenido fueron precisamente los programas infanto-juveniles, donde un $70 \%$ cree que en ellos se 
muestra una imagen superficial de la juventud y en donde se erotizan gran parte de sus contenidos.

En la actualidad el grupo entre 8 y 10 años es difícil de clasificar, porque muchos son sujetos activos que en algunos casos se comportan como adolescentes y no como niños, lo que parece ir de la mano con un contacto temprano y frecuente con los medios de comunicación masiva. ${ }^{20}$

La última encuesta del CNTV arrojó que los niños tienden a ver contenidos que no están dirigidos a ellos. Reconocen que tienen cierto grado de libertad para ver los programas que quieren pese a las advertencias de sus padres. ${ }^{21}$ Esta situación de independencia que se da en muchos hogares, contrasta con la declaración de los padres encuestados, que afirman que controlan, restringen y evitan que sus hijos pequeños se expongan a contenidos inadecuados para su edad.

La insatisfacción de los padres por el contenido en la televisión abierta disiente con la opinión que tienen respecto de la televisión pagada, donde un $85 \%$ se encuentra satisfecho con la oferta, siendo la variedad el principal impulsor de este sentimiento. ${ }^{22}$ El pequeño grupo que se muestra insatisfecho lo hace porque cree que en ciertos espacios se emite contenido de mucha violencia.

Se observa también, que el creciente desplazamiento de la audiencia infantil desde la televisión abierta hacia la sintonía de los canales de cable es cada vez más claro. Los datos de Ibope Media para varios países de esta región arrojan que canales como Cartoon Network, Nickelodeon, Discovery Kids, Jetix, Disney Channel, ocupan los primeros lugares en el total de la sintonía del cable; incluso ya hay ciertas horas en algunos días de la semana (sábado y domingo por la mañana) en que la sintonía total de la televisión por cable supera la sintonía de la televisión abierta por el peso de la audiencia infantil. ${ }^{23}$ Incluso algunos han comenzado con una sub-segmentación orientándose sus parrillas

\footnotetext{
${ }^{20}$ Informe 8/13: los Tweens Chilenos, Consejo Nacional de Televisión, 2003.

${ }^{21}$ Séptima Encuesta Nacional de Televisión, Consejo Nacional de Televisión, 2011.

${ }^{22}$ Ibid.

${ }^{23}$ Fuenzalida, V., Los niños y la televisión en Revista Chasqui, disponible en web: http: //www.chasqui.comunica. org/content/view/455, con fecha 20.07.12.
} 
programáticas hacia nichos más pequeños: Dicovery Kids para menores de seis años y otros hacia edades mayores como Nickelodeon, Jetix y Disney.

La televisión abierta no se ha quedado atrás y en diferentes países de Europa se pueden encontrar productos específicos para menores. En Alemania, la televisión pública creó el Kinder Kanal, que transmite desde las 06:00 hasta las 21:00 hrs; mientras que RTL - canal privadose lanzó con Super. La BBC en su oferta digital tiene canales segmentados para niños y France Telévisions también se ha sumado a esta tendencia. ${ }^{24}$ De este modo los canales infantiles de pago y de televisión digital incrementan sus cuotas de pantalla, siendo los de pago los que mayor porcentaje de niños concentran consiguiendo así un mayor índice de afinidad con el público de entre 4 a 12 años.

Las transformaciones tecnológicas también han generado cambios en la forma en que los menores ven televisión. Para muchos el prender la televisión es un hábito y una costumbre casi instintiva, más que una preferencia. Sienten que los acompaña mientras realizan otras actividades, siendo la principal, el computador. La mayor cantidad de horas las destinan a Internet y muchas veces desde esa plataforma, acceden a contenidos audiovisuales (Disney, Nick, etc.). En la actualidad un 55\% del total de contenido que se consume en la web es video y el pronóstico para los próximos años es que continúe en aumento. ${ }^{25}$

Este hábito demuestra que las generaciones más jóvenes han incorporado un uso convergente de pantallas, en el que se comienzan a eliminar barreras restrictivas de consumo en forma y fondo. De este modo muchas empresas se han visto obligadas a modificar sus estrategias. La tendencia actual muestra una mayor orientación a la creación de marcas más globales que proporcionen nuevas oportunidades. Ya no se puede pensar en un producto sólo para televisión sino que se deben idear desde un comienzo productos exportables a diferentes soportes.

Pero estas acciones también apuntan al esfuerzo de las grandes

\footnotetext{
${ }^{24}$ Ibid

${ }^{25}$ Cisco Visual Networking Index: Forecast and Methodology, 2011-2016
} 
corporaciones por reforzar la reputación a través de las relaciones que establecen con sus públicos en sus distintos ámbitos. ${ }^{26}$ Esta nueva forma de explotación comercial (videojuegos, DVDs, música, etc.) se constituye como un camino adicional de rentabilizar los contenidos, además de ser un apoyo adicional a las herramientas de marketing más tradicionales. ${ }^{27}$

\section{Valoraciones ante los cambios en el escenario televisivo}

Particularmente en los últimos años la televisión ha experimentado procesos de fragmentación de audiencias y diversificación del consumo cultural. En variadas investigaciones y estudios se observa que la televisión sigue siendo el medio dominante para los jóvenes, aunque cambia el modo de verla.

La actual generación de adolescentes de Argentina, Brasil, Chile, Colombia, México, Perú y Venezuela puede comunicarse, estudiar y divertirse por medio de una pantalla, bien sea la televisión, la computadora, el celular, los videojuegos o Internet. Sus modos de comunicación y su manera de entretenimiento han evolucionado; hoy son capaces de vivir dentro de la virtualidad. (Bringué, X., Sádaba, Ch., 2010).

Es interesante destacar cómo en algunos países el perfil de creador de contenidos de los niños y niñas es llamativamente alto. En Chile por ejemplo el 50,3\% de los adolescentes tiene su propio blog, donde vuelca sus emociones, la información y los contenidos que le parece adecuado poner en el ámbito de Internet (ibíd.).

Por otra parte se observa también en países como Estados Unidos que la atención de los jóvenes entre 8 y 18 años a los medios de comunicación social sigue en aumento de seis a siete horas diarias aproximadamente (Kayser Foundation Family, 2010).

Una preocupación que se recoge de los resultados de la primera

${ }^{26}$ Cfr. Melgarejo I., Rodriguez M.M., La creación de imagen de marca en los canales infantiles politemáticos de televisión. En MHCJ No 3 -2012, art. 3-28, pp. 37-54.

${ }^{27}$ Dunlap, B., El poder de la mercancía, Revista TV Latina, WSC INC, enero 2006, disponible en web http://www.tvlatina.info/, visitada el 03.11.06. 
investigación citada, y que se constituye como un aspecto de fundamental en el análisis de las respuestas emocionales de las audiencias -tanto hacia los contenidos como en su entorno familiar, educativo y social-, radica en la consolidación de la cultura del dormitorio o la realidad de unos adolescentes que viven en un hábitat propio, aislado de la vida familiar y en muchas ocasiones equipado para abrirse de forma global a un universo interactivo; y el acceso en solitario a las pantallas como la forma más habitual de uso y aprendizaje.

Las oportunidades actuales no sólo se generan con la aparición de nuevos dispositivos de digitalización de los contenidos y las señales, sino también con la creación de contenidos que no pierdan de vista los compromisos y responsabilidades para la nueva ciudadanía. La programación infantil en el futuro inmediato con el surgimiento de nuevos canales - públicos y privados- debiese aumentar, esto generará una mayor competencia producto de una mayor fragmentación, que se traducirá en una mayor disputa por conseguir televidentes. Esa lucha debiese traducirse en una mejora de la calidad de lo que se emite y se produce teniendo como elementos fundamentales el conocimiento de los procesos neuropsicológicos de las actuales audiencias, la dimensión emocional y los contenidos planteados en clave emotiva.

La televisión digital entendida como oferta audiovisual se presenta cada día más pujante, independientemente de sistemas tecnológicos y de difusión de la señal. Su desafío consiste en convertirse verdaderamente en una plataforma que logre tener una variedad de contenidos que persigan sistemáticamente la calidad, generando contenido de significativa importancia para las audiencias. Las oportunidades que tienen actualmente los canales con las redes sociales sin duda se constituyen como un foro muy útil para escuchar y valorar la opinión de las nuevas audiencias a través de las redes.

A raíz de estos cambios en los hábitos de consumo de los usuarios, Twitter y Nielsen presentaron su herramienta para medir audiencias sociales conjuntamente. "Nielsen Twitter TV Rating" la que medirá la audiencia total de televisión según su participación en Twitter. En la medición de esta actividad social se incluirán tanto los tuits de las personas que comentan sobre un determinado programa de televisión 
como aquellas que están expuestas a sus comentarios.

En este nuevo escenario, los responsables de las cadenas manifiestan extremo interés por las audiencias activas. La tendencia de este fenómeno, conocido como Social TV, va cada en día en aumento. Consiste en mirar la televisión mientras se interactúa en redes sociales. De esta manera, los usuarios pueden no sólo interactuar con otros usuarios e intercambiar puntos de vista sobre los contenidos de un programa en particular, sino también con los conductores y, en algunos casos, hasta con los personajes de un show. Según el último estudio de Ericsson (2012) el crecimiento de la Social TV ha sido constante: el $68 \%$ de usuarios a nivel mundial ve televisión mientras navega y discute sus contenidos a través de redes sociales.

La televisión social podría representar una estrategia de la televisión convencional para que los usuarios logren un grado más profundo de involucramiento o engagement con su programación. La idea de tener de cerca a competidores tan fuertes como la televisión on demand, ha obligado a los medios a buscar alternativas que prolonguen y amplíen la experiencia de disfrutar un programa o una serie de televisión.

\section{Consideraciones finales}

Podemos afirmar que es importante cultivar en las audiencias infantiles los hábitos de la mente, el desarrollo de habilidades neuropsicológicas y de la afectividad, que junto con los referentes de valores familiares, personales y educativos, harán posible el desarrollo integral y armónico de la personalidad.

$\mathrm{Al}$ respecto, en el ámbito mediático, conviene destacar que estudios recientes abordan diversas perspectivas sobre la calidad en contenidos de televisión para la infancia desde dicha premisa. Estos plantean que la calidad en la televisión infantil como promotora del desarrollo de la inteligencia en el niño implica, necesariamente, admitir que la interacción entre el niño y la televisión en relación al tiempo de consumo, a la jerarquía que el aparato tiene en el hogar y su impacto en los procesos cognitivos y emocionales, así como las pautas de comunicación, actitudes y valores que el niño aprende de la televisión, no pueden limitarse a los aspectos verbales, ciertos aprendizajes, 
producciones exitosas y por tanto, valoración de influencias y efectos. Sino que es crucial admitir y destacar un nuevo tipo de relación que en la actualidad se da en forma simultánea al proceso de socialización: la relación del niño con los contenidos televisivos, multiplataforma y sus emociones. Esta relación ha pasado a formar parte integrante de su vida cada vez con mayor frecuencia e intensidad caracterizando su desarrollo por lo que, a nuestro juicio, debe convertirse en un medio eficaz para promover el desarrollo de habilidades de pensamiento.

Es posible desarrollar en los contenidos de diversas formas, habilidades que se plantean sobre la base de la inteligencia emocional. Algunas de estas son la habilidad para usar el pensamiento lógico, habilidad para la búsqueda del pensamiento crítico, habilidad para resolver problemas, habilidad para el control de impulsos, habilidad de motivación, habilidad para la asertividad, habilidad interpersonal y de empatía, habilidad de inspiración e imaginación, habilidad musical.

Paralelamente, los centros educativos han de tomar conciencia de promover el desarrollo emocional de sus alumnos, pues esto favorece el aprendizaje, la maduración y el bienestar personal, avanzando de este modo hacia la autorrealización y la convivencia.

La educación emocional se presenta como un recurso para potenciar la percepción positiva que la persona debe tener de sí misma, de una capacidad de obrar y confiar en su propio juicio, de ser capaz de reconocer sus inclinaciones, tanto positivas como negativas, de estar abierto a las necesidades de los demás. En una palabra: conseguir el equilibrio cognitivo-afectivo-conductual necesario para enfrentarse a las necesidades de este mundo global, desde el ejercicio responsable de su libertad.

Desde la comprensión de las emociones y de la fuerza de la experiencia audiovisual, se puede impulsar la educación emocional. Es un reto muy interesante y de gran alcance personal, familiar y social. 


\section{Bibliografía}

BRINGUE, X., SÁDABA, CH. (2010). La generación interactiva en Iberoamérica. Niños y adolescentes ante las pantallas. Foro generaciones interactivas. Fundación telefónica.

CANNON, W. B. (1927). The James-Lange Theory of Emotions: A Critical Examination and an Alternative Theory. American Journal of Psychology (39).

DAMASIO, A.R. (1999). The Feeling of What Happens. New York: Harcourt.

EKMAN, P. (2003). Emotions Revealed. Nueva York: Times Books.

GOLEMAN, D. (1997). La inteligencia emocional. Buenos Aires: Javier Vergara.

KAISER FAMILY FOUDATION STUDY. (2010). The lives of 8 to 18 year -olds. January 2010

LABRADOR, M.J, REBEIL, M.A.(Coords) (2012). La dimensión emocional en el discurso televisivo, México: Tirant Lo Blanch.

LEDOUX, J.E. (2000). Emotion circuits in the Brain. Annual Review of Neuroscience (23).

LERSCH, PH. (1966). La estructura de la personalidad. Barcelona: Ciencia.

MARTÍN LOBO, P. (2013). Bases neuropsicológicas de la emoción En Labrador, MJ y Rebeil, MA. La dimensión emocional en el discurso televisivo, México: Tirant Lo Blanch

RIZZOLAT'TI, G., CRAIGHERO, L. (2004). The Mirror-Neuron System. Annual Review Neuroscience (27), pp. 169-92.

TV AND VIDEO (2012). And analysis of evolving consumer habits. Ericsson consumer insight summary report, August 2012.

TOMKINS, S. (1962). Affect. Imagery. Consciousness (Vol1). New York: Springer Publishing Co.

VIDAL MONTECINOS, C. (2013). Acercamiento antropológico filosófico a las emociones humanas En Labrador, MJ y Rebeil, MA. La dimensión emocional en el discurso televisivo, México: Tirant Lo Blanch. 


\title{
ENGLISH VERSION
}

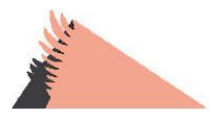 \\ Prologue

\section{Digital Media. A New Communicative Context}

Maria Jose Arrojo and Jose Luis Piñuel

T $\mathrm{N}$ recent years, due to the support of the technological 1 innovations, the creativity developed in the field of digital media has caused impressive communicative changes, which have not precedent in Western societies. These communicative changes can be noticed in six main aspects: (i) communicative contents, (ii) programming strategies, (iii) production processes, (iv) distribution mechanisms, (v) financing routes, and (iv) the use made by the audience of these communicative contents.

These impressive changes require a deep research to find out the communicative designs that underly these communicative innovations. In addition, the research should clarify the aims, processes and results of these new designs. This research is particularly important because it is the only way to make scientific contributions to the field of digital media. The outcome of the 
research should allow us to predict the possible future, including new problems, and to prescribe patterns of action to solve those problems within the communicative environment.

Moreover, because the communication sciences are applied sciences, one of the roles of these sciences is to find solutions to specific communicative problems. This objective of these applied sciences is the basis for a subsequent application of these sciences by professionals of any digital media. The thorough understanding of these emerging communicative phenomena is the necessary step to develop action protocols for the professional. These practical protocols should be more accurate than those resulting from the mere intuition of professionals.

In order to study of these communicative phenomena from a dual perspective -structural and dynamic- this volume comprises two different sections, entitled "From YouTube to specialized web pages as new content portals" and "Multimedia, multiscreen, multitask, and emotions". In these sections are addressed the issues pointed out: communicative contents of the new digital media, programming strategies in these media, production processes introduced with then, new distribution mechanisms open up with them, new financing routes that have appeared with them, and the use that the public makes of these communicative contents.

"From YouTube to specialized web pages as new content portals," which embraces the first part of this volume, has three chapters. In the first chapter, Maria Jose Arrojo analyzes this new communicative realm from a new perspective: communicative sciences as applied sciences of design. This approach deals with the communicative aims of the platform YouTube, the processes that are carried out to achieve those aims and the results that eventually are obtained. This way of research to analyze the communicative innovation introduced by the platform also considers a triangulation between content producers, users of such contents, and the advertising environment.

In the second chapter, entitled "Video News: Trends in the Digital Press. The Case of The Guardian and the Scottish Referendum Coverage", Sara Ortells analyzes the internal and external features that characterize video news hosted in specialized web pages as new 
communication formats. Thereafter, in the third chapter - "Video as added value ar Mexican print media website" - Claudia Alicia Lerma studies the use the Mexican print media is making of the two platforms previously mentioned: YouTube and specialized web pages. This analysis allows us to know the degree of adaptation of traditional mass media to the new digital environment in a specific geographical area.

"Multimedia, multiscreen, multitask and emotions" includes three papers that form the second section of this volume. Thus, in the fourth chapter - "Video games as multimedia process" - Enrique Morales identifies the main elements that characterize videogames as unique communicative realities. In this chapter, the author makes explicit four essential aspects of a multimedia communication environment: (1) technological development; (2) technological factor; (3) the sphere of the production of cultural content; and (4) the audiences' use of this content.

This last aspect, the audiences' use of the content in a multimedia environment, is the core idea within the other two chapters of the second section in this volume. Thus, the paper "Multitask, multiscreen and social practice of the use of Media among young spanish people between the ages of 16 to 29 years old", written by Gemma Teso and Jose Luis Pinuel, focuses on the analysis of the consumption of audiovisual content among young people. Also, this fifth chapter discusses how new communicative advances determine and shape their social relationships.

Meanwhile, in "Emotions. Importance and basis in the TV contents", which is the sixth chapter, Maria Jose Labrador focuses on a more specific target. His discusses the children and the importance of emotions in the consumption process of audiovisual content. Labrador concludes her chapter with a study on new forms of audiovisual consumption, which allows for laying the basis for the industry so that it can produce digital audiovisual content specifically created for children.

An important feature of this book is to be bilingual. The papers are presented in both Spanish and English versions. This can contribute to spreading further these studies and to catch the attention and 
interest of international academic circles. This interest is due to the novelty of the topic as well as the theoretical and methodological proposals formulated in this volume. This study allows for delving into new communicative processes and contents in a digital and multiscreen environment. 


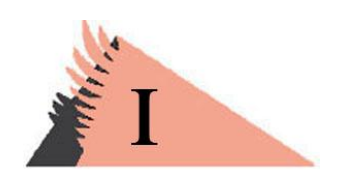

\title{
From YouTube to specialized webpages as portals of content
}

YouTube considered as new communicative phenomenon. Analyse of aims, processes and results from the perspective of Applied Science of Design
\end{abstract}

\author{
María José Arrojo Baliña, University of A Coruña, Spain \\ Profile in orcid.org/0000-0002-2385-5461 \\ and in $\mathrm{G}$ htp://goo.gl/cYhcD0
}

\begin{abstract}
This paper discusses the communicative change introduced by YouTube in three main aspects: 1) the content posted in this platform; 2) the production processes of the content; and 3) the role of the citizen in the new content. This analysis is done from the perspective of Applied Sciences of Design, understanding that
\end{abstract}


communication phenomena have specific aims, which seek to achieve by means of processes, to reach finally concrete results.

To undertake this study, the proposed hypothesis involves a triangulation among content producers, users and the advertising environment. This triangulation is performed taking into account the internal and external aspects of the analyzed phenomenon. The internal dimension concerns the design that guides the communicative phenomenon, leading to exceeding the mere sociological sphere of the users; and the external component analyzes the weight of the technology in this new communicative scenario and the actual use by citizens.

To test the initial hypothesis, an empirical study is carried out, to analyzed the evolution of YouTube contents, with a greater number of followers and views worldwide, during the first half of 2014.

\section{Keywords}

YouTube; Multi Channel Network; Sciences of Design; Audiovisual content; Communication

\section{Introduction}

X $\mathrm{HICH}$ is the innovation provided by YouTube? What are its contributions according to communicative aims, processes and results reached up to this time? These are the two questions to contemplate. To carry with this out, the newness that YouTube introduces as a communicative phenomenon it is being analysed here. This characteristic is investigated according to three main points: novelty respect to the programming and distribution of audio-visual content; (ii) the contribution to the communicative system that media content producers make thanks to this platform; and (iii) the contribution to this platform that users do be an active part of the communicative phenomenon.

As theoretical framework, the test considers that Communication Science, as Applied Science of Design, can analyse the communicative aims, processes and results of YouTube. This means they are science what are searching for the resolution of concrete 
problems in the communicative environment. In this case, the new communicative phenomenon of YouTube solves several communicative problems and open new prospects. The existence of concrete communicative designs, what have aims, developing processes and expected results, is the baseline in the Applied Science of Design (Arrojo, 2012).

As well as analysing the already known phenomenon of YouTube, the Applied Sciences of Design let notice the artificial aspect of the communication. As in YouTube, there are three consecutive aspects to consider: a) the agents have new objectives that strengthen communication and appear in the designs; b) these agents use certain processes to achieve the goals; and c) the agents obtain some concrete results that can be empiric evaluated. In this case, we can say that Communication Science adjusts to the criteria of Design Science because they strengthen the human chances to communicate through these patterns (Gonzalez, 2007b).

\section{YouTube phenomenon according to its context: The new communicative uses in the digital environment}

Regarding the digital environment, nowadays there is a constant adaptive change in the communicative designs of the companies, which concerns to its aims, processes and results. As well as the interest in the new contents, the influence of the kind of technological support is very big. In this way, it has been a communicative evolution without precedents thanks to the new contents to transmit and the technological advances. This can be appreciated in five aspects of the digital environment: 1) there are changes in the languages used by the contents managers; 2) there are new programming politics; 3) the role of the users is changing; 4) there are new types of distribution of media contents; and 5) new commercial flows are appearing.

\subsection{Initially aims and development}

In this new scenery appears YouTube. It is a communicative phenomenon that begins linked to technological progress. It 
promotes new communicative aims, whose goals reach unsuspected levels. YouTube appears in February 2005 as a lodging website for online videos. Three former employees of PayPal company (Chad Hurley, Steve Chen and Jawed Karim) created this service to reach three main goals: I) Communicative object was to provide people all around the world a tool to see and share their videos for free. II) The social goal was to create a new environment for social relationships, mediated through screens (computers, tablets, etc.). III) The commercial purpose was the sale of advertising space and specific agreement with companies engaged with the cultural production: film producers, television, recording firms, etc. (Perez Rufi, 2011: 149).

The newness in the communicative, social and commercial purposes, together with the initial success of the platform, attracted the investment of groups like Time Warner and Secuoia Capital. A year after the start-up of the project, in 2006, Google acquired the company for 1.65 billion $\$$ in stock, being one of the most commented issues about websites' acquisitions (Snickars and Vonderau, 2009). During these years, the number of users, as well as producers and watching-video hours in this platform has done nothing more but increasing. To explain the reason of the success it is necessary to pay attention to the combination of several causes. a) Opportunity to give an answer to a concrete communicative need that appears because of the development of Internet uses and cultural reasons. b) Low cost of the technology used to product audio-visual contents (cameras and video-edition systems). In this way, more people have the opportunity to become producers of their audiovisual contents. c) The beginning of a cultural change: the desire to increase the spreading of some types of communicative contents. Now it is possible to share the videos with close people as well as anyone wishing to enjoy the viewing.

The possibilities of media contents' production are being democratized, coinciding with social change in the relationship with the information and with the communicative contents in general. There is an explosion of the "web 2.0", a term coined by Tim O'Rilley and Dale Dougherty (2005). The web 2.0 is a way to understand the Internet, based in the users' communities $^{28}$. This

\footnotetext{
${ }^{28}$ Through the management of software tools the user promotes that "organisation and flow of information depend on the behaviour of people
} 
"social change", where the methodological individualism has a big role, it is reflected on a kind of people: the so called millennial. These agents have grown in a culture that is progressively leaving the hierarchical communicative structure that was the dominating in the conventional communicative model, where only a few individuals nurtured the ideas of the passive spectators. (Garcia Cay and others, 2013). The development of this participatory culture referred as something external to the platform has favoured that society adopts platforms like YouTube and contributes to their fast evolution (Jenkins, 2007).

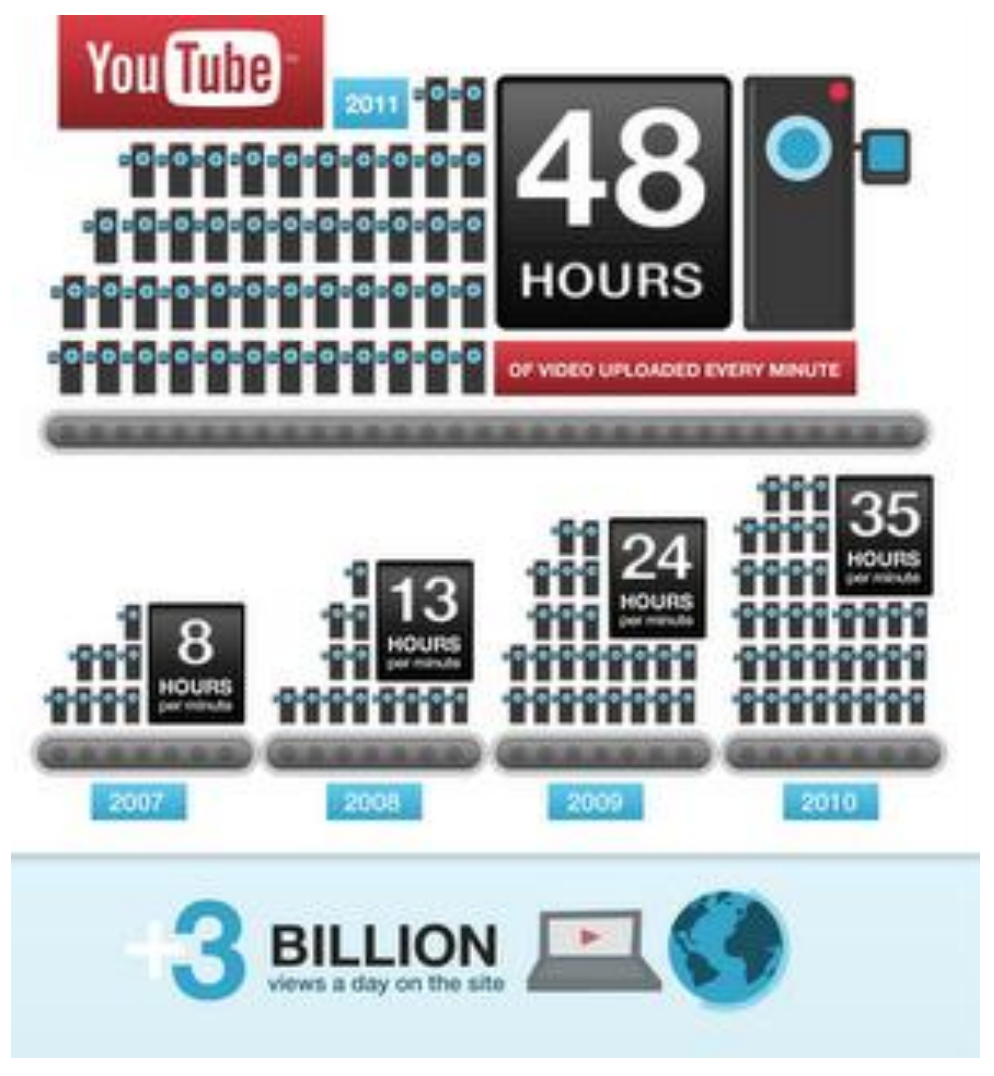

YouTube has become a new communicative phenomenon with an own entity. The site has 1 billion unique users all around the world, settled down in 61 countries (Parejo, 2014). It is the most important online video-platform of the world attending to both the number of

accessing to it, by allowing not only much easier and more centralized access to the contents, but also their own participation in the contents' classification as well as their construction, using ever more simple and intuitive tools (De la Torre, A., 2006). 
users and the quantity of contents. The volume of visitor traffic ranks YouTube as the third most visited website on the Internet, behind Google and Facebook (Alexa Internet, Inc., 2014). Along the time, YouTube has exceeded its initially expectations -a platform to see and to share videos - up to become a social network. In fact, some new functions have been added to this new entity: sharing, creating and commenting all kind of media contents.

Starting from the initial goals and its development along the time, there are some characteristics in YouTube to underline: i) As audiovisual communicative platform arises from the creativity in the design of new communication ways -with a direct character and easily accessible-, using the technological tools to make viable its objectives and processes. ii) Its designs have a clear accessibility to the contents, and there is an active in the real-time participation of users -being this individual or institutional consumer-, thanks to the new technological developments. (iii) Processes of this communicative activity are new in two ways: according to the relationship with the platform itself and respecting to the social interactions that it promotes. (iv) To get a communicative activity more participative, the platform is organized as a for-profit commercial entity, with a transcultural and purely international projection. These characteristics offer an innovative communicative ontology that goes beyond the simple entertainment, up to the point that some theorists considerate it as a new communication medium.

\subsection{Introducing changes}

To this unprecedented change in the field of communication, first of all, there are two interdependent elements: new communicative designs and new technological formats. Those elements complement each other to increase the communicative distribution and consumption channels. Secondly, there are new communicative relationships: users become now active agents because they create their content: they are not only content with consumption of given contents (Levinson, 2012) but also they are co-authors of these contents (Reno, 2011). Thirdly, users have the opportunity of becoming "prosumers" (agents that produce contents while they are 
consuming them). This means, they change their role: now they can become valuable partners for the professional (Merino, 2013: 254).

Going into detail about the changes in YouTube in the communicative context can be observed -in my opinion- three complementary perspectives about the internal change. They have to do with the design guiding the own phenomenon. Firstly, it is necessary to study everything related to the aims: the content's programming in YouTube and its possible production and distribution channels. After this, the processes can be analysed: the changes in the processes of contents' production available on YouTube. Finally, also the results and the citizen's role regarding this new content in this emergent context can be evaluated.

That it means that there is a new communicative dynamic introduced by YouTube, which concerns aims, processes and results in an initially artificial area with a clear social projection. This first element of this hypothesis -the existence of a triple change in the communicative dynamic introducing by YouTube- can be proved empirically. If we admit that YouTube is a complex system, then it is possible turning to the factors' sobriety or parsimonious factors to cover this communication system ${ }^{29}$.

\subsection{Current aims and its agents}

The aims of YouTube are changing gradually. This change is only possible to continue with the help of youtubers and a wide audience.

\footnotetext{
${ }^{29}$ The study of factors' sobriety takes place in the area of Complexity Science, such as in the case of Communication Science respecting to Applied Science of Design. Herbert Simon was the first to search in the area of Artificial Science.

To learn more about this: GonZALEZ, W. J., "Las Ciencias de Diseño en cuanto Ciencias de la Complejidad: Análisis de la Economía, Documentación y Comunicación", en GonZALEZ, W. J. (ed), Las Ciencias de la Complejidad: Vertiente dinámica de las Ciencias de Diseño y sobriedad de factores, Netbiblo, A Coruña, 2012, pp. 7-30; and GonZALEZ, W. J., "Complejidad estructural en Ciencias de Diseño y su incidencia en la predicción científica: El papel de la sobriedad de factores (parsimonious factors)", in GONZALEZ, W. J. (ed), Las Ciencias de la Complejidad: Vertiente dinámica de las Ciencias de Diseño y sobriedad de factores, pp. 143-167.
} 
To keep growing it is necessary to look for new audiences, which means becoming more professionalized. The Multi-Channel Networks (MCN) are presented as key-elements in this new scenery, something that can be observed empiric through the information we have. There is an evolution of contents, which have increased a bigger number of followers and views in YouTube between January and September 2014 in the whole world. Besides, this analyse allows to illustrate some aspects of these mentioned changes, already observed empirically. These changes force to modify some current objectives of the platform and the agents who are involved in it.

1) Immediacy is still the communicative aim of YouTube: it seeks to facilitate people everywhere can share and see videos, but not always for free. YouTube has begun to introduce pay channels and is bringing closer to the industry to increase the quality of contents. There is a clear evolution in the offered contents, which implies a change in the concept of "programming". 2) The social objective making public the creative talent in audio-visual form - is still one of the most distinctive features of the identity of this platform. But there is an increasing professionalization of YouTube ${ }^{30}$. 3) The business objective - getting benefits through the use of the platform - brings new consequences to the communicative field of YouTube. a) Internal consequences: the platform structure is affected by an own, characteristic and original business model: there is a direct relationship between the producers and the trademarks. b) The external consequences allow build business models that are complementary to existing ones in the media industry.

New agents emerge, who spring already linked to a new culture in the Net. It is about the Multi-Channel Network (MCN). They are companies that are specialized in intellectual production rights management. They have the ability to manage the creative talent, making it visible for users, and represent them in the commercial companies. MCN are becoming increasingly important. They set themselves up as an intermediary in this new area, a fact that is

\footnotetext{
${ }^{30}$ The creation and spreading of audio-visual contents is no limited to broadcast agents, but there is already an expertise about which are the keys to reach that a content empathises with audience to generate a fan community around a brand.
} 
already affecting the internal structure of the relations in the platform. The initially completely horizontal model of organisation and communicative spreading starts to organize in a hierarchy ${ }^{31}$.

\section{The contribution of YouTube to the new systems of audio- visual programming and distribution}

There is necessary to limit the contribution of YouTube to the new systems of programming and distribution, but the key is not the fact that more than 100 hours of content are uploading every minute, and there is a registered consume of 6 billion watching hours per month ${ }^{32}$. These data - the volume of consuming and generation of media content - just indicates an external factor: they point out something that it was out of reach for a TV broadcast company. Neither the existence of three types of agents, that is producers, users and publicists, is the key.

The real contribution of this platform is implicit in its objectives: they modify the level of present relationships in the traditional media model, and this affects the programming and production of media contents. YouTube launched a new design for the distribution and programming of audio-visual content that allows to the agents viewing and sharing videos without requiring an own virtual space with own technology (Mier and Porto-Reno, 2005: 208). The YouTube design -Broadcast yourself- looks for the person as a protagonist in the video creation as well as in the experience as a user.

The game rules are easy, direct and clear to understand. The economical earnings will be established by the size of the viewers'

\footnotetext{
${ }^{31}$ At the same time that the number of producers who wants to become professional grows and the conventional industry is discovering a niche business in this new area, there are appearing new relations between agents, who change their roles representing one each other and vice versa -internal factors- and make necessary to the conventional industry to look for complementary business models -external factors-.

${ }^{32}$ According to the data that were provided by YouTube (youtube.com, access in $6 / 11 / 2014)$.
} 
community ${ }^{33}$ regardless of the content has been created by professionals or amateurs. The bigger is the community; the bigger will be the volume of economical earnings for the content's producer. ${ }^{34}$ In other words, YouTube is a platform for consuming media contents, but a conversation and meeting place for people with similar tastes and concerns too. The main challenge facing the contents producers in this platform is how to be discovered, viewed and followed by the YouTube users ${ }^{35}$.

In the traditional TV, much more simple respecting to the volume of contents and actors, the programmers are in charge to make that the content is accessible or reachable. With YouTube, there is a new communicative order: the new programming forms allow discovering the content. They are based in two key elements: 1) search systems, and 2) the action of agents through the community ${ }^{36}$.

${ }^{33}$ Attending to the official data provided by the own platform (Parejo, 2014) $60 \%$ of view traffic in a YouTube channel comes from different countries to the place where the content was generated. Translated to marketing terms, the exportation of media contents represents $60 \%$.

${ }^{34}$ In 2007 YouTube started up a partner program that allows the uploader earning money if the content gains recognition between the community (understanding "recognition" as viewing number). Partner may refer to any person who has the distribution and the copyright of the contents to be published online (Larrañaga and Ruix, 2009: 122).

According to estimates by Credit Suisse, in 2013 the standard marketing cost per 1000 pieces of advertisement viewed in YouTube (Cost Per Mille CPM) was approximately 8 (CNN Expansión, 2014). However, some publicists in the Net claim to be able to get sponsors for $25-40 \$$ per CPM with pre-roll or inserted advertising in the video (Fullscreen, 204).

${ }^{35}$ According to Alexa.com (2014) YouTube is already the second most visited browser in Internet, behind Google. It is a global space, where people from 61 different countries interact in 72 languages and generate contents on a collaborative way.

36 1) Searching systems contribute to keep an order and structure in the platform. They are not innocuous, but they determined by criteria establishing by the own platform, and they are based in a structure of categories and in semantic and quantitative criteria. (i) Categories system: YouTube provides 15 different types of categories to choose when hosting the media contents. This allows mediate between an internal structure and classify the contents, in such a way that generates an order in all this universe of videos. (ii) Search engine. The platform allows working with two different search systems: the first one is 


\subsection{Novelty provided by content producers in YouTube}

In the structure as well as in the languages, the newness in the relation and programming processes has a direct effect in the producers and the own contents. Nowadays it is possible to distinguish between 4 categories of content producers in YouTube: 1) amateurs, who are satisfied unleashing their creativity either generating ex-novo material or using content previously produced by others; 2) the amateurs who want to become professional; 3) professional companies that emerge linked to YouTube; and 4) the conventional industry, which finds in the internet a platform to bring closer its contents to complementary publics.

Observing the ranking of the 12 most viewed channels of YouTube in the world between January and August 2014, there appear contents produced by the three first categories. There are seven channels with musical content, which has been produced by professional industries arise from the digital environment. The other channels, which are currently the most viewed in YouTube, are becoming more professional thanks to a new kind of companies emerging to represent and give them technical assistance.

based in the semantic search, attending to the tags or metadata given to the video; the other one is based in the previously viewing number of the video and in the viewing time. That means, the search results will be ordered in decreasing size attending to the traffic volume of the contents. Thereby, the search results combine these two criteria; and iii) recommendations. The registered users, when they bookmark a video as favourite or subscribe to a determined channel, are giving enough information to the platform so that this recommend them similar contents.

2) Respecting to the intervention of agents through the community. There are users who only consume videos yet. Opposite to these there is another kind of active users that is becoming opinion leader. The fact that users can comment the videos and express their opinions make possible that users with more social reputation (here and in other social networks) become opinion leaders. With their suggestions about contents these agents that are more active assume in part the role-play of a conventional programmers. They are individuals with ability to have influence around them. 


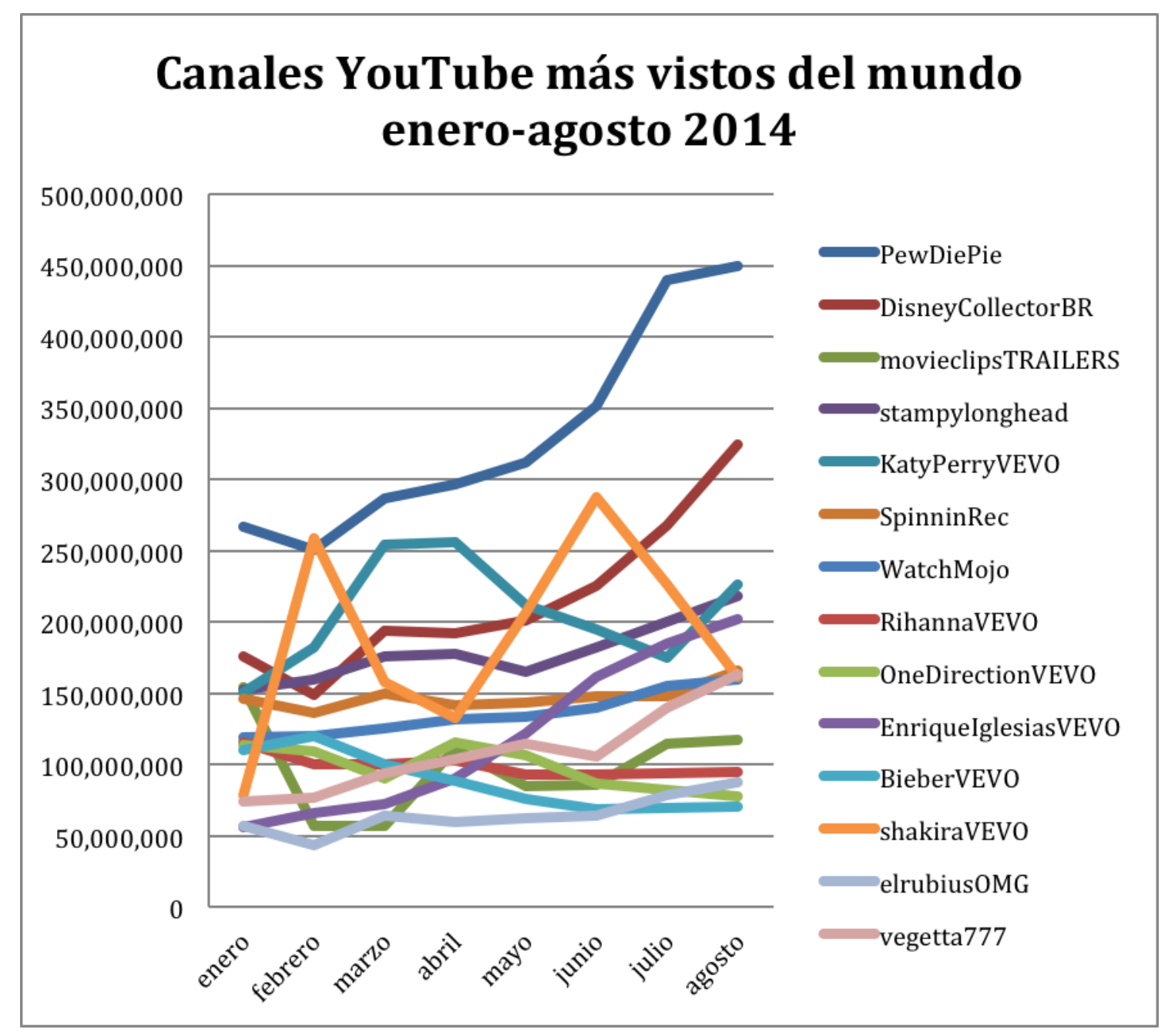

Source: compilation by the author based in the data obtained from YouTube in its different channels

That means: a) conventional industry has not found a highlighted space in this new communicative environment yet, and b) that in this digital scenery is emerging a new category of agents that are becoming increasingly significant. It is the Multi-Channel Network $(\mathrm{MCN})$ of YouTube. It is defined by companies or organisations created to intercede in this environment full of creators, audiences and advertisement. These are the agents who are called to bring order thanks to their expert knowledge about the new model of design, which is setting up in YouTube. The main novelty of these production companies is that they are firms genuinely digital, which develop or help to develop channels about all kind of categories (music, lifestyle, plays, sports, news, children, education). They connect directly the contents with the audience and the economical agents. 
What is doing the conventional industry in this field? Right now it is developing two different and complementary strategies: (i) use YouTube as a springboard for making its contents known in the digital environment and (ii) it is trying to gain prominence in YouTube by buying or acquiring shares of these new Networks. The goal of the conventional industry is obtaining benefit from the knowledge that these new agents have about the digital area to create specific contents with them for YouTube. They want to reach an audience, which is no more interested in discovering their contents. These new firms offer technological solutions to position the contents and the channels in YouTube too; they provide support services for the contents' right management of the third party to use them in the net (Tubefilter, 2012b), and they gather an expert knowledge about the audience behaviour in a new communicative environment in order to find the global consumption demand.

\subsection{Users' contribution in You'Tube: From passive consumers to interactive agents}

When YouTube emerges, the main characteristic of the Web 2.0 is that a part of the users wants to leave being passive spectators and wishes to take part in an active way in the communicative process (Cabrera, 2010). This participation materializes by producing contents (texts, photos, videos) or simply by bringing opinions (forums, surveys, chats) or by recommending contents through a sharing or subscribing system. But not all the agents are active in YouTube.

Patricia G. Lange identifies five different users types. (i) Old participants. People who some time ago were active in YouTube but now they have their counts open just to comment or view some videos. (ii) Occasional users. The most of cases they do not have an account. They access to the platform to search for something concrete or because somebody sent them a link. (iii) Active users. They have an account, normally they comment videos of other people, and sometimes they upload their videos to the platform. (iv) Youtubers. People involved in the platform. They usually generate contents, take part in discussions, establish a strength compromise with the platform and normally spend at least an hour a day in 
YouTube. (v) YouTube celebrities. They are youtubers who achieved the success with their contents. They become opinion leaders and agents with a big influence in the YouTube environment through their videos, comments, newsletters and other ways of interaction. (Lange, 2007: 4).

Because of the variety of users' behaviours it is necessary to ask which is the reason that pushes them to go ahead anyway to create contents or interact with them and why they become fans. There are several reasons, attending to social, cultural as well as aesthetical criteria, to answer such questions properly.

1) Respecting to social criteria, it has to do with the construction of an identity in the Net. Depending on the channels that a person follows, on the contents that this individual recommends or on the comments he does, he is building a virtual personality that sometimes, can be the opposite to the real ones ${ }^{37}$. Through this identity the person can feel like part of a community and become opinion leader, that means, he is a source of information to follow other people (Lange, 2008) ${ }^{38}$. 2) Regarding the cultural criteria, the open structure of YouTube, combining with the social networks, allows that people make public things they think are valuable. 3) Besides, there are some historical criteria, which make these people feel like active agents communicating something that can have relevance in the History. 4) In this way, there is an aesthetical component too: they become fans of some content because of its beautiful, harmony or balance.

Once that the behaviour of a fan community on Internet can be predicted, then it is possible to prescribe which characteristics must have the contents and the communicative strategy to the channels

\footnotetext{
37 "People don't just subscribe because they want to get the content, they subscribe because they want to be a subscriber. They want to be able to say Oh yeah, Vice totally, I'm subscribed like I've already seen all their stuff. I'm as cool as Vice. That's what's it about, it's about them" (Stevens, 2014).

${ }^{38}$ Related to this there is a clear identification element. Why have such success youtubers games' channels? Actually, it is imported a real model that can be used as guide about behaviour and identification. Behind this underlies a descriptive model "I could do it too".
} 
achieve the success in this new digital scenario ${ }^{39}$. Respecting to the contents, the design of the communicative strategy is based in some common elements, which are established once there is an expert knowledge about the technological (working of the Google browsers) and social side of the Net (types of users and their behaviour in the digital environment). After a first period observing the communicative phenomenon, it is possible to identify the elements that are necessary and adequate to make the communicative strategy a success.

\section{Scientific characterisation of the new communicative phenomenon of YouTube: aims, processes and results}

After a first observation period of the communicative phenomenon that concerns to us, it is possible to establish a basis for a second task: the scientification of some emerging professional practice (Niiniluoto, 1993 y 2014). It is about extracting from some professional instructions some criteria, accepted for the aims and the processes, which can conduce to the searched results. In actions like this it can be seen how Communication Sciences are applied science because they solve concrete communicative problems and work with predictions and prescriptions. To achieve this scientification's purpose that allows getting operative solutions to concrete problems this science has to investigate the communicative phenomenon. In the case of YouTube, it is to be conscious that the problems' resolution it is conditioned by the newness of the own communicative phenomenon and by the environment where this is being developed.

In this context, the Communication Sciences must be able to identify the communicative objectives searched by the agents and the designs that are underlying in the communicative models (with their aims,

\footnotetext{
${ }^{39}$ About the prediction and prescription in Design Science, cfr. GONZALEZ, W. J., "Análisis de las Ciencias de Diseño desde la racionalidad limitada, la predicción y la prescripción”, in GONZALEZ, W. J. (ed), Las Ciencias de Diseño: Racionalidad limitada, predicción y prescripción, Netbiblo, A Coruña, 2007, pp. 3-38. GonZALEZ, W. J., "Prediction and Prescription in Economics: A Philosophical and Methodological Approach", Theoria, v. 13, n. 32, (1998), pp. 321-345.
} 
processes and results). From this moment is already possible to establish the scientific investigation methods. First of all it is to predict the evolution of the new phenomena through the use of models about the possible future, and then they must offer prescriptions to act, it means, they have to give instructions to help to solve concrete problems (Gonzalez, 2007c).

\subsection{The new theoretical context: Communication Sciences as Applied Science of Design}

The theoretical framework has to be connected to the studied phenomena. In this context the communication, generally, and YouTube, particularly, emerge as an international phenomenon, which is shaped by aims, processes and results. These three elements are characteristic in the field of study of Design Sciences and strengthen the human possibility through the resolution of concrete problems. To foster the human possibilities, the communication uses technological items as support for the transmission, distribution, production and storage of media contents, being all they components of Artificial Science. (Arrojo, 2007). That is, to achieve innovation in the new communicative environment it is necessary that exists the appropriate technology in the processes.

(i) There is a social component - the agents' actions in a social net going with the artificial design. This duality of the Communication Sciences - social and artificial - gives complexity. (ii) There are both a structural as a dynamic side because the communicative design is always in evolution. (iii) This design has two concrete aims, fixed by the own goals of the communicative agent. After this, the viability depends on a processes' series, which have a contextual component: they will depend on the available media in a concrete social, economical, technological, political and legislative environment. These processes are used to achieve some results, which accomplish new objectives, even more sophisticated. These results must be based on the initially fixed goals, which are oriented to expand the existing human possibilities. These designs, with their aims, their followed processes and the obtained results are the field of study of Artificial Science, concretely of Applied Sciences of Design. (iv) The high 
dependence level on other technologies is another complex element of these disciplines.

\subsection{The methodological perspective to study the new communicative phenomenon: the factors' sobriety (parsimonious factors)}

From Communication Sciences, it is possible to study the start, configuration and limits of the web 2.0 and concretely, the emergence of YouTube, which produced a big change in the scene respecting to the existing communicative designs. There is a big novelty regarding the processes of a relation between the agents: It is establishing a horizontal relation between creative talent and the users who interact with this contents. Now there are bidirectional relationship's streams.

Not all users are willing to explore to the maximum this possibility, and there are people who are satisfied just using the platform as a simple window display to watch videos. But the processes of participation between agents (the "external" aspect) have caused structural changes in the communicative model (the "internal" aspect). In this way, the level of direct and bidirectional conversation between producers, users and trademarks has forced the agents to change their aims and their processes of production and programming.

The methodological analyse of Media Sciences must pay attention to these elements, classified as complex, to its configuration as Design Science, which wants to give a solution to concrete communicative problems in a dynamic environment. For this reason and according to the objectives to achieve first of all it is necessary to identify the design that is behind the new communicative phenomenon. Being in continuous evolution, the designs are supported by professional criteria that try adapting to the variable environment, as the appearance of YouTube in its time and its posterior evolution. From this, research is required to bring into scientific terms the observed behaviours and set out some guidelines for action in the future, which are happening in a changing environment. Afterwards, it is necessary 
to identify the sobriety of factors (parsimonious factors): the necessary and enough elements that range over the communicative system.

The communicative objective of YouTube is the first thing to take into consideration in order to identify the sobriety of factors: it was created to find contents in the distribution platform in an accessible way. After an observation period it is possible to identify the structural elements that the audio-visual contents must have to expedite their view in this environment: (i) the topic must be clear; (ii) it is aimed at a well-defined target; (iii) they are easy to share; iv) each piece must be accessible to be understandable by itself; and (v) they must promote the interactivity with the users through a direct conversation reflected in the own contents ${ }^{40}$.

These five elements are widespread to all successful contents in YouTube. They must be considerate as necessary to establish a successful creative strategy. A) That confirms the hypothesis about the existence of a new communicative model, and b) in this new model people receive the communication in a better way when it is immediate, focused and interactive. But the communicative change introducing by YouTube is so deep that affects the own concept of programming too. So that users can discover the contents and interact with them, it is necessary to bring internal order in the own system's structure, so that it allows the appearance of new programming elements adapted to the specific characteristics of the platform. These new elements are dynamic, and they are evolving with the own development of YouTube.

The internal order in the structure is achieved through the categories where the channels are included. From this, the dynamic elements that define the new programming rules in the platform are four: 1) the search algorithms established in the robots of YouTube; 2) the contents that the platform recommends thanks to the data provided by the user through the Internet browsing and the interaction with the platform; 3) the opinion leaders' referrals in the digital

\footnotetext{
${ }^{40}$ To achieve this interactivity sometimes producers use additional tools to the own environment of YouTube, such as other kind of social networks, videoblogs, etc.
} 
environment; and 4) the strategies implemented by the new mediating agents $(\mathrm{MCN})$ to achieve contents "worth discovering" for the users.

Respecting to the external factors that have to do with the users and de social environment where they take place, there are also some changes. In YouTube environment, it is possible to have a direct relation with the source, with the producer. A simple user can even become a prosumer: he is generating content while he is consuming it. In this context, youtubers must feed back their contents with the contributions of other citizens. That means a dynamic interaction in the aims, processes and results respect to what design's professionals do.

\subsection{Expecting results about the communicative phenomenon in medium and long term}

Behind YouTube design, with the communicative phenomenon and its social component, there is a firm not only with communicative and social purposes but also with some business objectives. There are three factors fighting over, which have an impact on the expecting results in a medium and long term: the communicative, the social and the business factor. The three of them contribute to the updating of the communicative model of YouTube along the time while there is an increasing knowledge about the role of every agent and about the possibilities that the own model propitiates itself. Once the model has been already consolidated the next objective is making it even more attractive so that it achieve to expand its scope.

After a first observation period of the phenomenon, the Communication Sciences understood as Applied Science of Design, can apply scientific terms to the until now considered as simple professional, social and business (with its technological component) training. The expert knowledge that already exists about YouTube helps to predict the future and then do the prescription of the phenomenon, that is, to guide what is possible to do. After delimiting the accessible future, these guidelines must show the steps to take to extend this communicative phenomenon. Once the succession between prediction and prescription has been made, results must be 
observed to know what it works and what it does not work in this real field.

Then, again, the expected results can be predicted (the prediction): how the platform is expecting to evolve, by the currently available information, to provide the right prescriptions to solve the raised issues. To my mind, that would be reflected as follows:

(i) YouTube will continue the evolution, which started some years ago, from video platform to social network, until becoming in a communication media itself, because of the volume of contents and the agents implying in its community.

(ii) There will be a growing space in the platform for new producers who become professionals.

(iii) The successful of YouTube has already a pull effect to other companies that have emerged in its environment. The universe of online platforms will be increased to bring a new media ecosystem much more complex than the current one.

(iv) To continue with the expansion in an environment of new competence YouTube needs to raise the age group (above and below). To achieve this, it is necessary to extend the contents' segment. The platform will evolve from a culture of the ephemeral towards other contents more professional, which satisfy the demands of a more adult audience.

(v) If this qualitative leap is possible, a premium model of payment contents will be developed.

(vi) There will be an evolution of the type of user, who will change from a more generic user to a more specialized one.

(vi) The international coverage will continue increasing. For this, it is essential to improve the subtitle system of contents. 


\section{Closing remarks}

YouTube has helped the development of a new audio-visual model, which is only possible in a socioeconomic and culturally developed environmen $\mathrm{t}^{41}$ that demands a new kind of communicative dynamics, represented by the culture of the web 2.0 and where the rationality is oriented towards something virtual. There are some realities that cannot be explained in the traditional media model, as the fact that users develop an own virtual personality attending to their behaviour in the platform. In a natural environment, the human being has its personality but in a social environment the identity is given by the social approval and recognition, and in a digital environment, through the social networks, it is possible to create a new reality: the individual is how is based on the perception through a screen.

In this new model the person, unless in an apparent way, is the centre of the communicative process. This person has access to a new environment to express freely, with the same opportunities that any other agent, to choose what contents wants to consume and to decide what level of interactivity wants to develop with other people. The individual action of each agent allows build virtual communities, without geographical boundaries, through a clear technology, and whose goal is to enable a global and immediate interconnectivity.

This scenery, apparently democratic and with a horizontal structure, is based in a communicative design, which has developed some dynamics of internal use in the processes (fixed by the own platform or by the new agents who appear in this new ecosystem) that are establishing a new hierarchical order, very different to the one which rules in the conventional media system.

These hierarchies are given by the expert knowledge about the behaviour of the individuals in the new environment. This expert

\footnotetext{
${ }^{41}$ In order to a model with these characteristics can be developed, it is necessary, on the one hand, to have enough technological resources (software, hardware and connection availability). On the other one it is necessary having free time to devote to the leisure and creativity's expression. This free time is only possible when the basic subsistence needs are satisfied. That means, in the most developed societies from a social and economical point of view.
} 
knowledge has several criteria: kind of contents which are consumed, narrative characteristics of the most consumed contents; the most demanded and effective typology and interaction levels; viewing time.

In the current situation there are two kinds of agents who have this expert knowledge: i) the own platform, through search algorithm and large-scale data analysis; and ii) new professional agents who were already born in this digital environment and manage the new uses, the new languages and the new work dynamics in this field.

The traditional media sector needs an active agent in the new environment. At this moment, the sector understands Internet as an extension of its conventional business model and has begun tapping into by creating channels in YouTube. In this way, it achieves to rise the exposition time of its contents, to create a trademark around them and that more people discover them. However, in the medium term, his role in the new scenario must be more active if he does not want to lose importance into the industry.

Since 2010, it has been appearing a new type of companies, specialized in intellectual property rights management of the contents. Its goal is that new users can use the professional contents and express with them their creative content. That means a change in the business mentality without precedent. The conventional industry has begun to understand that users want to interact in an active way with their contents and that this fact feeds back them. A clear example is the film "Frozen", from Disney factory. In this case, the major allowed that people use the images and the audio of the film without restrictions. That contributed to the creation of thousand videos about the film topic with million views all around the world.

The traditional sector will not lose importance so long as it develops complementary programming politics on the internet. They must be proceedings that allow that their contents can be discovered by a new kind of user with very different behavioural patterns respecting to the conventional ones. For this reason, the conventional industry needs to gain new creative talent, experts in new languages and new narratives of the media area. This verified reality let us predict that the Multichannel Networks will have an increased presence in the media sector. 


\section{Bibliography}

ALEXA INTERNET, INC. (2014). Top sites. The top 500 sites on the web. The web information company. Retrieved from: http://www.alexa.com/topsites. (Access 12.10.14).

BURGESS, J., GREEN, J. (2011). YouTube: online video and participatory culture. Cambridge: Polity Press.

CARLOSS, A. (2014). "The power of Choice". Conferencia del Global head of enterteinment Youtube USA, in Mipcom 08.04.2014. Retrieved from:

https://www.youtube.com/watch?v=GrpolzBsdq8. (Access 10.2.2015).

CNNExpansión.com (2014). Vevo busca seducir a usuarios de YouTube. Retrieved from:

http://www.cnnexpansion.com/tecnologia/2014/05/01/vevodesea-seducir-a-usuarios-de-youtube. (Access 10.12.2014).

CHENG, X., DALE, C., LIU, J. (2007). Understanding the characteristics of Internet short video sharing: YouTube as a case study. Retrieved from: http://arxiv.org/pdf/0707.3670.pdf -(Access 09.12.2014).

DE LA TORRE, A. (2006). Web Educativa 2.0. Revista Electrónica de Tecnología Educativa. $\mathrm{N}^{\mathrm{o}} 20$, january. Retrieved from:

http://www.uib.es/depart/gte/gte/edutece/revelec20/anibal20.htm - See more at: http://www.nosolousabilidad.com/articulos/web20.htm\#sthas h.fYFeQow7.dpuf. (Access 10.12.2014).

ERTIVI, M.C., LEÓN, B. (2014). La comunicación de la ciencia a través del video online: contenidos populares en Youtube. In SIERRA, J. and RODRIGUES D. (coord.) Contenidos digitales en la era de la sociedad conectada. Madrid: Ed. Fragua, pp. 129-146.

FÍAS, A. (2014). El País

http://politica.elpais.com/politica/2014/11/14/actualidad/141 5995907 985209.html. (Access 10.12.2014).

FULLSCREEN (2014) https://www.fullscreen.com/es/artists-andcreators/ (Access 10.12.2014).

GALLARDO, J. (2010). La televisión tradicional quiere gobernar Internet. El fenómeno YouTube España. Euro Editions.

GARCÍA CAY, GARCÍA PEÑA, M., KENDALL LÓPEZ, L.G., LIMA FLORIDO, C.I. (2013). Youtube: la clave de los canales 
con mayor número de suscriptores en España. In PEREZ RUFI, J.P. (Coord.) Industrias audiovisuales: producción y consumo en el s. XX (pp. 6-28). Málaga: Universidad de Málaga.

GONZALEZ, W. J. (2012a). "Las Ciencias de Diseño en cuanto

Ciencias de la Complejidad: Análisis de la Economía, Documentación y Comunicación". In GONZALEZ, W. J. (ed), Las Ciencias de la Complejidad: Vertiente dinámica de las Ciencias de Diseño y sobriedad de factores. A Coruña: Netbiblo, pp. 7-30.

GONZALEZ, W. J. (2012b) "Complejidad estructural en Ciencias de Diseño y su incidencia en la predicción científica: El papel de la sobriedad de factores (parsimonious factors)". In GONZALEZ, W. J. (ed.), Las Ciencias de la Complejidad: Vertiente dinámica de las Ciencias de Diseño y sobriedad de factores. A Coruña: Netbiblo, pp. 143-167.

IAB MÉXICO (Interactive Advertising Bureau), Millard Brown and Televisa (2013). Estudio de consumo de Medios entre internautas mexicanos. $5^{\text {a }}$ edition. Retrieved from: http://boletines.prisadigital.com/Estudio $\% 20 \mathrm{de} \% 20$ consumo $\% 20 \mathrm{de} \% 20$ medios $\% 20 \mathrm{en} \% 20 \mathrm{Mexico}$.pdf. (Access 10.12.2014).

KIM, J. (2012). The intitutionalition of YouTube: From user generated content to professionally generated content. Media, Culture \& Society, 34 (1), pp. 53-67.

LANGE, P. (2007). Commenting on Comments: Investigating Responses to Antagonismo on YouTube. Retrieved from: http://anthropology.usf.edu/cma/Lange-SfAA-Paper2007.pdf. (Access 09.12.2014).

LANGE, P. (2008). Publicity Privete and Privately Public: Social Networking on YouTube. Journal of Computer-Mediated Communication (13), pp. 361-380.

MIER, C., PORTO-RENÓ, D., (2009). Blogosfera y YouTube como espacios para la exhibición de productos audiovisuales interactivos. Palabra Clave, V.12, n.2, december, pp. 207-214.

O'RILLEY, T. (2005). What is 2.0? Design Patterns and Business Models for the Next Generation of Software. Retrieved from: http://www.oreilly.com/pub/a/web2/archive/what-is-web20.html. (Access 14.01.2015).

LARRAÑAGA, J., RUIZ, A. (2009): "El modelo de negocio de YouTube”. In Icono 14, no 12, pp. 109-131 Retrieved from: 
http://www.icono14.net/ojs/index.php/icono14/article/viewF ile/336/213. (Access 14.01.2015).

MAKERSTUDIOS www.makerstudios.com

PAREJO, M. (2014). Conference at "Máster de Producción y Gestión Audiovisual", may, A Coruña, Spain.

PEREZ RUFI, J.P. (2011): "YouTube ya no es "tu televisión": cultura colaborativa y red comercial en el video online". In Revista Comunicación, $\mathrm{n}^{\circ}$ 9, Vol. 1, pp. 146-162. Retrieved from: http://www.revistacomunicacion.org/pdf/n9/monografico/M 11.-

YouTube ya no es tu television cultura colaborativa y red comercial en el video online.pdf. (Acceso 14.01.2015).

RIPERT, D. (2014): How to build a sustainable audience on YouTube. Conference at Mipcom, Cannes, 9.04.2014. Retrieved from: https://www.youtube.com/watch? $\mathrm{v}=\mathrm{iV} 8 \mathrm{~s} D D L Z B 2 k$. (Access 16.01.2015).

REALINREAL (2014). Retrieved from: http://www.reelnreel.com/watchmojo-youtube-mcn-successstrategy-overview/ (Access 14.01.2015).

SNICKARS, P. y VONDERAU, P. (eds.) (2009). The YouTube reader. Estocolmo: National Library of Sweden. Retrieved from: http://www.kb.se/dokument/aktuellt/youtube reader inledni ng.pdf. (Access 14.01.2015).

STEVENS, M. (2014). How to build a sustainable audience on YouTube. Conference Vsauce in Mipcom, Cannes, 09.04.2014. Retrieved from: https://www.youtube.com/watch?v=iV8sDDLZB2k. (Access 14.01.2015)

STRANGELOVE, M. (2010). Watching YouTube: Extraordinary videos by ordinary people. University of Toronto Press.

SUSTER, M. (2013). Why the Media has been Wrong about YouTube Networks. Retrieved from: http://www.bothsidesofthetable.com/2013/09/15/why-themedia-has-mostly-been-wrong-about-youtube/ (Access 22.02.2015).

TUBEFILTER (2012). http://www.tubefilter.com/2012/10/15/zefr-movieclipsbrand-copyright-youtube/ 
TUBEFILTER (2012, b). http://www.tubefilter.com/2012/10/15/zefr-movieclipsbrand-copyright-youtube/

YOUTUBE.COM https://www.youtube.com/yt/press/es/ ZEFR (2014) www.zefr.com 


\title{
Video News: Trends in the Digital Press. The Case of The Guardian and the Scottish Referendum Coverage ${ }^{42}$
}

Sara Ortells-Badenes, Universitat Jaume I (Castellón), España

Profile in

and in $\mathrm{Gttp}: / /$ goo.gl/3pRNfm

\begin{abstract}
Video contents are more frequently use by digital media to report the news. Despite video-news have gained weight within the information supply; the vast majority of these pieces come from press agencies. However, recent studies reveal that self-production videos -produced by the media itself to be consumed through the web- are also experiencing a gradual rise. This paper analyses the concrete case of The Guardian -its digital version- and the use of self-production videos to cover the Scottish Referendum, a political issue included in the medium agenda. The analysis conducted in this chapter is focused in the study of the stylistic features of these self-production videos. The aim is to determine the characteristics defining these pieces of news. The main results reveal that the British newspaper prefers including reports having citizens as a main source, making the reporter appear on the screen all the time and using a careful
\end{abstract}

${ }^{42}$ This research is part of the R\&D Project with reference (P1·1A2013-12) funded by Universitat Jaume I -Plan de promoción de la investigación 20142016. 
aesthetic. These characteristics could be easily tied to the infotainment phenomenon.

\section{Keywords}

Digital press; self-production videos; Scottish Referendum; The Guardian; online videojournalism

\section{Introduction}

$\mathrm{M}$

ASS media are going through a crisis, which generates the urge of making a series of changes within the management and production of news contents. In the case of press, the current scenario, together with the full establishment of Information Technologies has a double effect: on the one hand, it boosts the creation of pure players media and, on the other hand, it also favours traditional newspapers to integrate Internet among their strategies. They create news portals that not only become a distribution platform to disseminate their offline news, but become also a key factor to reshape their business model. Nowadays, this effort to make profitable and boost their digital version is translated into a rising trend of producing news contents to be consumed exclusively through the web.

These cybermedia share some features that make them different from hardcopy newspapers, both in producing the news and consuming them. Following the proposal of different authors (Diaz-Noci y Meso-Ayerdi, 1998; Deuze, 2003; Salaverria, 2005; Larrondo, 2009; Guallar \& Abadal, 2010; Masip, Diaz-Noci, Domingo \& Mico-Sanz, 2010) these are the characteristics of online media: hypertextuality, interactivity, multimediality, updating, personalization and documentation. These characteristics make these media unique as they have the chance to combine different types of content and, moreover, integrate the possibility of interaction with the audience.

Precisely, given the particularity of these online media, their establishment is linked to the redefinition of journalists' professional profiles -now multi-skilled and able to work simultaneously for different formats (Rintala \& Suolanen, 2005; Scolari et al., 2008; MicoSanz, 2011)- and contents as well. Despite it is true that text and 
pictures still have a major weight (Marrero Santana, 2008; Guallar, Rovira \& Ruiz, 2010), each time infographics but, especially, videos are gaining relevance (Masip \& Micó-Sanz, 2008; Mayoral \& Edo, 2014). In this online scenario all media, traditional and digital, compete in the same conditions as, by using multimediality, they can produce information using texts, pictures, infographics and videos. This changes the conception of media's offer, finishing, for instance, with the traditional idea that only television can broadcast video news; as nowadays any media in its digital version can include this element to enrich its information (Guallar, Rovira and Ruiz, 2010).

This research is focused on the analysis of how the British newspaper The Guardian uses video news in its digital version to cover the Scottish referendum hold on $18^{\text {th }}$ September 2014. The aim of this study is to analyse the strategy followed by this medium to report this topic -included in the agenda- by using video news. A quantitative analysis method has been used to check the volume of video published, their origin (produced by the media or coming from other sources) and their features. Main results reveal that, as in the Spanish case, self-production videos are still reduced but present a greater quality than those coming from other sources.

\section{The use of videos in the digital media: a rising trend}

The integration of video in the digital media has been gradual. Despite the more advanced traditional media launched their digital version at the beginning of 2000 (Greer \& Mensing, 2006), it was not until 2007 when the presence of video began to be really relevant (Guallar, 2008). Nowadays, the use of videos is more and more important in online media. In fact, it turns out to be very frequently to find this type of news at the newspapers' front page (Mayoral \& Edo, 2014).

The rise of this news type is linked to the constant evolution that Internet contents are experiencing. Unlike pure players, traditional media have had to adapt their consolidated models to the 2.0 environment. The integration of video news is slowly because the development of these media is also gradual. Cabrera-Gonzalez (2001) 
distinguishes four stages to explain the progress of this process: a) facsimilar, b) adaptation, c) digital and d) digital multimedia. In the first stage, the facsimilar, the contents published by the digital version of the traditional media was only based on cloning the contents published by their paper version. In the second stage, adaptation, these contents began to be minimally versioned for the web. The two last stages, digital and digital multimedia, are characterized for disseminating contents exclusively designed for the cybermedia, including all type of multimedia contents to enrich their news. This last stage -which we are living right now- has also been called social multimedia as, a part from multimedia contents, media also boost the use of social networks in order to disseminate their contents and interact with their audience. In this very last stage is when the use of video has been boosted.

There are different factors justifying why the rise of video has emerged right now. Lopez (2008) indicates three main reasons: a) new lightweight techniques to compress video frames conserving its quality and, thus, becoming easier to be distributed; b) the decrease in the price of Internet access for users and the increase of data download speed improving the consumption of these news and; c) the decrease of the price of the technological equipment used to produce this kind of news.

All these advances favour the proliferation of the use of videos by cybermedia. Although it is true that their presence has risen remarkably in the last years, media have used different techniques to integrate video among their contents. Mico-Sanz \& Masip (2008) distinguish four main trends within the Spanish scenario:

1. News portals of audiovisual media that, a part from offering video-news, also integrate other multimedia resources.

2. Newspapers that begin to integrate video among their contents, although text prevails over other news formats.

3. Cybermedia that create TV channels linked to their publication.

4. Newspapers that shift and abandon text news to become video containers.

Regarding to the kind of contents, there are unlimited possibilities. Following the proposals of Lopez (2008) and Bradshaw \& Rohumaa 
(2011) these are the most common types of video that can be found in cybermedia:

a) News clips: Pieces of news normally coming from news agencies, traditional media or Youtube. They are normally presented embedded as a part of a report combining text and video.

b) Video news: complete VTR's that, a part from using images, also includes voice over, interviews and infographics that help to illustrate the information. They are self-produced by media.

c) Video guides: videos that teach users different things such as handicrafts, recipes or how to use electronic devices.

d) Vblogs: a blog designed inside the cybermedia that only includes videos.

e) Streaming: live broadcasting of an event.

f) Complete shows produced exclusively to be broadcasted through Internet.

Although the use of video on online media keeps on rising, showing a remarkable sensitivity for the use of these contents, it is curious to highlight that recent researches show that the use of self-production videos is still limited, less than 1 video out of 3 , becoming news agencies videos those with a major presence (Mayoral \& Edo, 2014).

\section{Video features in the digital media}

Online videojournalism must not be understood as "television on the web" (Brasdhaw \& Rohumaa, 2011: 106). Videos produced for cybermedia must not also be associated to low quality or amateur quality contents. Despite the way of telling the stories and the contents are similar to those broadcasted by television, videos produced for Internet have their own features, some so specifics as their interactivity. Thus, the difference is not rather on the production process but in the way of telling the news. Having more flexible deadlines in the digital newsrooms promotes the production of longer videos and also allows introducing documentary characteristics when producing the video news (Bock, 2012). This can also stimulate the creation of new formats allowing telling stories in a 
more appropriate way for the digital environment. In fact, Bock states that the use of alternative narratives contrasting with the traditional way of reporting the news on television, motivates videojournalists to be considered more trustworthy and serious than TV journalists.

The scarce self-production of contents is translated into publishing videos edited, generally, in a basic way (Masip, 2008). The most common is to find videos only including images -with no other type of contents- or soundbites coming from press conferences. These contents are conceived as elements that support the text of the information, contextualize the events or show information difficult to describe (Masip, Mico-Sanz \& Meso, 2010; Mayoral \& Edo, 2014). Additionally, the quality of these contents is directly linked to the purpose the journalist want to achieve with it. In the case of live blogs or live chronicle (Salaverria, 2011) immediacy prevails, so, these pieces of news are not expected to have a careful image; as informative value prevail over image quality. On the contrary, in the rest of publications quality and longer length will prevail (Bradshaw \& Rohumaa, 2011).

There is no consensus regarding the stylistic features that should be followed in order to succeed on Internet. Television is a mass media while the consumption of Internet contents is individual and interactive, so, the language and images should be adapted to this scenario (Cebrian Herreros, 2009; Bradshaw \& Rohumaa, 2011). In fact, there is not also guidelines establishing the length of these videos. It is considered to be a phenomenon that impulse a format imposing a new audiovisual narrative based on fugacity, the compulsive consumption of small news pills and brevity (Diaz Arias, 2009). Some researchers advice that videos should not last more than three minutes (Luckie, 2010; Masip, 2008), although they maintain that the importance of the topic will be the last setting the length of the video (Bock, 2012).

There is neither a consensus regarding the topics, as any information can be narrated using a video. However, some researchers state that despite citizens use videos more frequently as a main source to keep informed (Van der Haak, Park, y Castells, 2012), because they seem to be more attractive (Canavilhas, 2007), media must correctly select which topics will be reported by using a video. They will also have to 
boost the distribution of these contents, as lots of economic and human resources are needed to produce them (Luckie, 2010).

\section{Method}

A quantitative analysis method has been designed to achieve the goals of this research. The online version of the British newspaper The Guardian has been chosen as the sample of the case of study. The aim of this project is to analysis the strategy followed by this medium to integrate video in its digital version. It has been selected a period including the coverage of a scheduled topic. By selecting such a topic we ensure that its video coverage can be planned in advanced, so we can check if this planning includes assigning human and technical resources to self-produce video news. The period covers from $15^{\text {th }}$ to $19^{\text {th }}$ September 2014. The Scottish referendum was hold on $18^{\text {th }}$ September. This period of time has been selected in order to analyse the previous and later coverage of the voting day. 281 pieces of news have been analysed.

In order to carry out this research we have designed an analysis model to study all the news published on the web. This research has been done in two steps. In the first stage, the 281 news included in the original sample have been analysed searching for those containing videos. 38 pieces of news have been found using audiovisual contents. An analysis model has been also designed to study those videos. This model is formed by 60 different variables divided into 4 main groups:

1) Position and origin. This will determinate if this is a selfproduced video or coming from other source (press agencies, other media, official press conferences, political speeches...). They will also be classified depending on their position within the news (video presented as an independent news or combined with text).

2) News format. After doing a preliminary analysis the following categories have been selected: report, infographics report, sounbite and no comment. Moreover, a category named 
"Others" has also been included in order to classify those videos that do not suit the previous proposals.

3) Stylistic features. Different variables are included: length of the video, lead-ins use, linking the video to the media repository, use of open and close credits or infographics of the media itself, use of voice over or music. Moreover, this section also includes the analysis of the techniques used to boost audience's interaction by giving the possibility to share the contents in social networks or leave comments.

4) Type of sources. These are the different sources taking into consideration: politicians, citizens, experts and journalists.

\section{Results}

\subsection{Formulas to present the videos}

281 pieces of news have been published by the online version of The Guardian during the analysed period. All of them are part of a special issue created ad hoc to cover the Scottish referendum called Scottish Independence Blog. Despite the huge volume of news production only $13,5 \%$ of the news (38 in total) contain videos to enrich their information, 6 self-production videos and 32 coming from other sources.

The data obtained from the analysis let to determine that The Guardian combines the use of too different strategies to integrate videos in their publication depending on the importance given to the information. In the cases that video becomes a video news, that is to say, when it contains all the information, it is be presented in an independent way, becoming a single post in the blog. The $63 \%$ of the broadcasted videos (24 in total) have been presented as independent video news, redirecting readers to the media repository to watch them (Graphic 1). All the self-produced news, 6 in total, have been presented as independent video news. It has been done in this way, possibly to focus the attention on the video and, in this way, boosting its view and resulting distribution by using social networks. 
Only in 39\% of the cases, 14 in total, video is conceived as an element supporting the information text and it is embedded in the publication including both text and audiovisual material. This type of videos broadens or contextualizes the event or, even, shows information difficult to describe (Mayoral \& Edo). Moreover, unlike independent video news, in this case only $57 \%$ of the reports, 8 in total, are linked to the video library of the medium. The rest of videos, 6 in total, are hyperlinked to their original source, Youtube.

\section{Graphic 1. Position of the video}

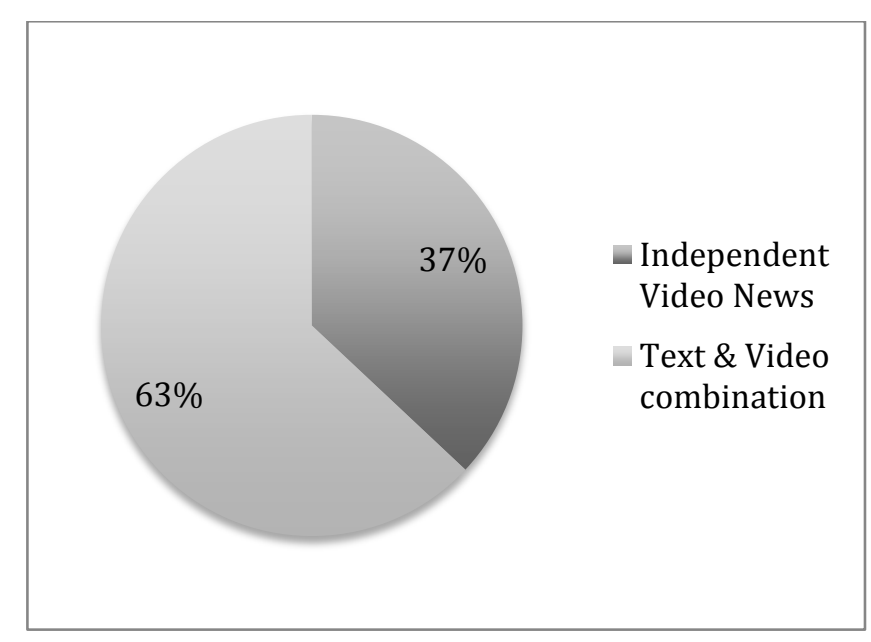

Author's compilation based on survey

\subsection{Videos' origin}

The Scottish referendum coverage is included in the long term planning of The Guardian. In fact, the special blog Scottish Independence Blog started regularly publishing post about this topic on $1^{\text {st }}$ May 2014. Despite this topic is scheduled in the agenda, during the analysed period, only 6 self-produced audiovisual reports $(15,7 \%)$ have been published by the online version. It is important to highlight that all the self-production video news were published between $15^{\text {th }}$ and $17^{\text {th }}$ September, the previous days of the voting. No self-production video was included the day of the referendum or the day after. Therefore, as the analysis of the Spanish case show (Mico-Sanz \& Masip, 2008; Lopez, 2008; Mayoral \& Edo; 2014) self-produced video news are still limited in The Guardian as well. 
The remaining $84,3 \%$ of the videos (30 in total) comes from other sources. The $80 \%$ of these contents have been supplied by news agencies as ITN or Reuters; the $13 \%$ by TV stations as $B B C$ or Skynews; and only a 6\% come from citizens or file images (Graphic 2). Unlike the publication of self-production video news, in this case, most of the videos have been published the previous day of the voting (1 $17^{\text {th }}$ September: 8 videos), and the day after $\left(19^{\text {th }}\right.$ September: 12 videos). So, nowadays, videos coming from press agencies are still the main resource to obtain videos for cybermedia.

\section{Graphic 2. Video's origin}

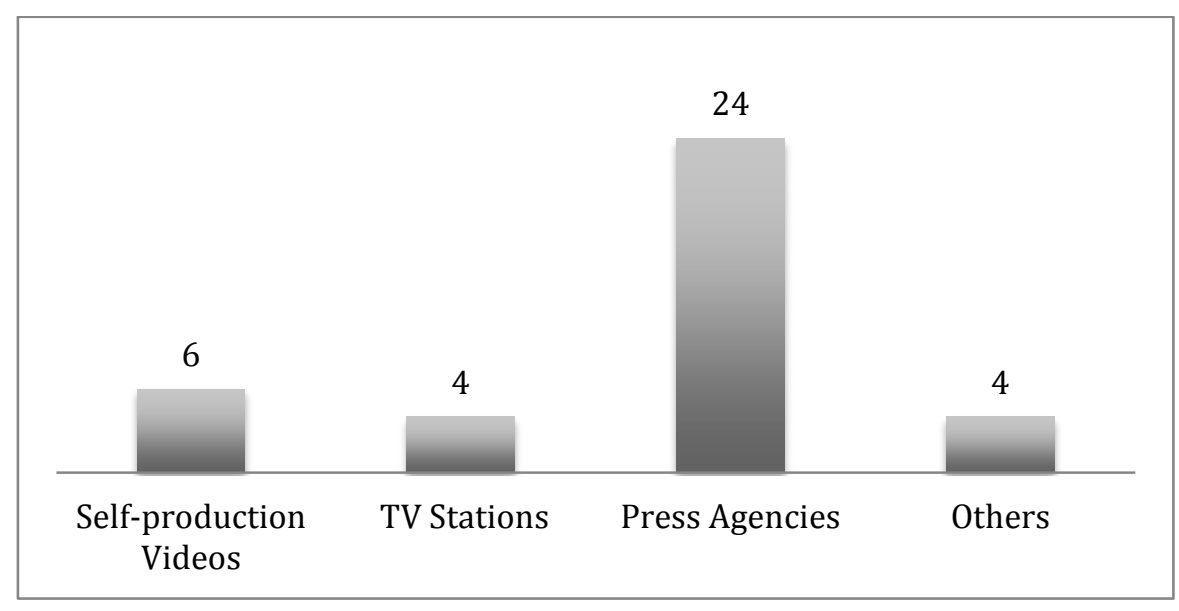

Author's compilation based on survey

\subsection{Video features: news formats}

Regarding the news format use in each video, there are remarkable differences between self-produced pieces and those coming from other sources. All self-production video news are produced as a report. Five of them are edited by using real images while one of them is edited only using infographics. The length of these audiovisual contents varies from 02:39 minutes to 09:21 minutes.

When videos come from other sources different news formats can be found. The main relevant data is that during the analysed period no report format has been used by these external sources. In this case, the news format used more frequently is soundbite 22 videos 
$(68,7 \%)$. The $54,5 \%$ of theses soundbites (12 in total) comes from interviews, the $40,9 \%$ (9 in total) comes from press conferences and, the remaining 4,5\% (1 video) from spontaneous interviews. No comments, videos just edited with images and ambient sound, represent the $12,5 \%$ of the news coming from other sources, while the videos classified as "others" -including pieces of programmes and TV series- reach a 18,7\% (Graphic 3). In these video news, only real images have been used to produce them. There are no infographics elements. Their length varies from 00:49 seconds to 04:25 minutes. In the analysed period they have included a link to a complete episode of a TV series lasting 27:27 minutes.

\section{Graphic 3. Total use of each news format}

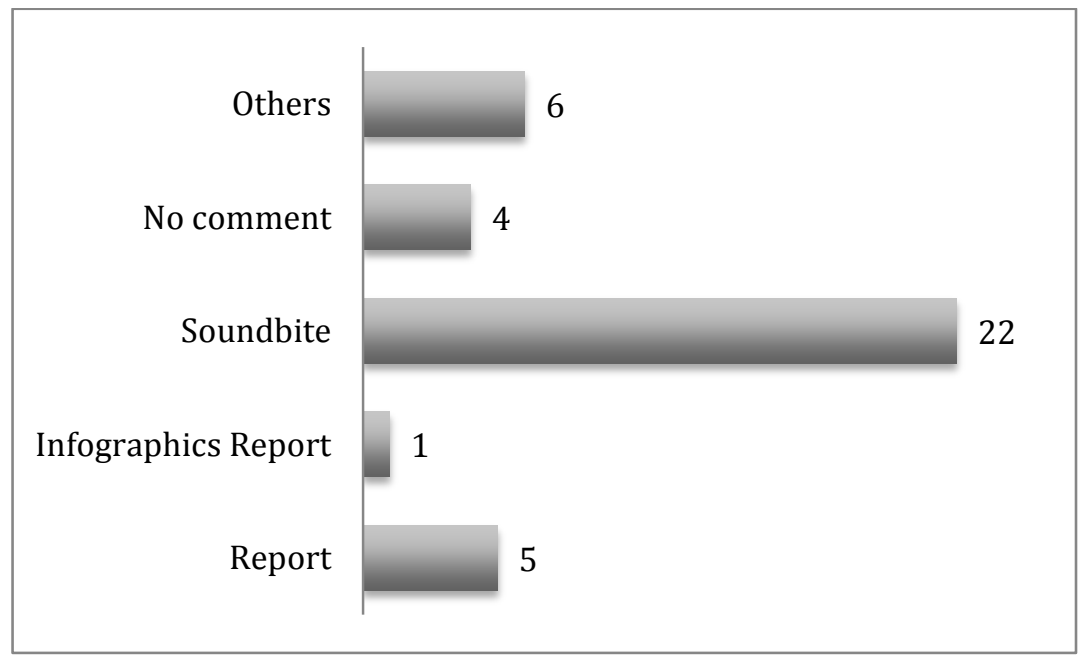

Author's compilation based on survey

\subsection{Video features: stylistics characteristics}

Self-production videos share a series of presentation and editing characteristics that contribute to the creation of the corporate image of the medium. They always come together with a lead-in introducing the topic. Moreover, all of them are preceded by the opening credits of The Guardian. This is a three-seconds opening and close credits that frame the whole information. Except for a report, which uses no credits, they all use the corporative infographics. 
Concerning the stylistic editing features, these video news have been produced following a careful editing method, using, in most cases, characteristics linked to the documentary genre: use of different shot scales, combination of recording technics (steady or hand-held filming), shots lasting more than three seconds, use of voice-over to structure the information or use of music to make the video more dynamic.

So, data reveal that self-production video news for the online version of The Guardian are characterized by needing a previous planning and pre-production as the reports analysed has a high quality both in editing and content.

It is quite different when talking about the features of other sources videos. It is important to notice that as their origin is completely different, there are no share features contributing to reinforce the corporative image of The Guardian. Their original sources will assign the style of each video news. $65 \%$ of them (21 in total) come together with a lead-in. The $75 \%$ (24 in total) include the corporative opening and close credits of The Guardian. 53\% use no infographics (17 in total), 37\% (12 in total) use The Guardian's corporative infographics and, only a $9 \%$ (3 in total) come with their original credits.

Two technics have been detected to film the images: a) images produced through live connection coming from institutional signal and, b) images filmed hand-held. These videos have been edited by using a basic edition system, just cleaning the beginning and end of the video. Producing this type of news does not imply a creative process as they are published almost in the same way they are received from the original source. These videos use no voice-over or music. Therefore, the abundance of other sources videos is characterized by using a simple editing, not needing to be planned in advance and not contributing to the creation of the corporative image of the medium.

Regarding interactivity, a special feature of cybermedia, there are no differences between self-produced videos and other sources news. The Guardian always uses the same strategy. All videos can be share through Twitter, Facebook, Google+, inShare and mail. Moreover, users can leave comment in all news. 


\subsection{Information sources}

Data reveal that there are also differences in the type of information sources used by self-production video news and those coming from other sources. Videos produced exclusively by The Guardian are characterized for mainly use citizens as information sources. Each video, except for the one produced with infographics material, contains the point of view of citizens, and just one of them also includes the voice of a political actor. These videos want to show voters' opinion. Moreover, in this type of self-produced videos, journalist gains relevance and become a co-protagonist of the information. The journalist appears on the screen while doing the interviews, and in four videos also performs a speech.

The use of informative sources by those videos coming from other sources is characterized by the prevalence of the use of political actors sources representing the $93,8 \%$ of the consulted sources as they appear in 29 videos. Expert sources achieve a 6,2\% (appearing in 3 videos) (Graphic 4). For the analysed period no citizen sources were included. Moreover, in these videos journalist disappear completely, as the informative weight is focused on sources and information.

Graphic 4. Informative sources type used by the different videos

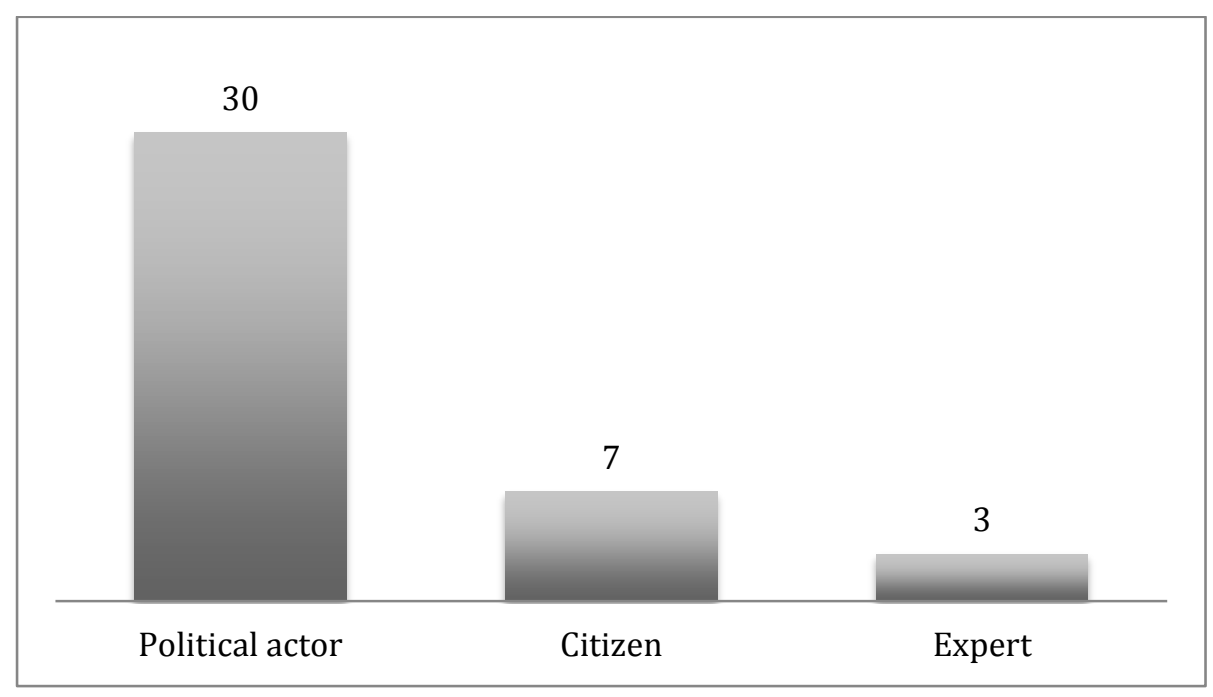

Author's compilation based on survey 


\section{Discussion}

Results reveal that like in the Spanish case, the use of video is significant in the digital version of The Guardian. It also verifies that videos coming from press agencies are still the main source to get this kind of contents. Despite self-produced video news has still a minor representation, it is important to highlight that they are high quality reports that can become a key factor to distance from the competitors. These videos are longer than those broadcasted by traditional TV, as they rarely exceed from two minutes. These videos also adopt some characteristics typically used by the documentary genre. They present original and exclusive topics narrated with high quality images.

Citizens become the main source in self-production videos. Even journalists perform a fundamental role, not only as the guide of the information with the voice-over but also as a co-protagonist of the video appearing on the screen constantly. The use of self-production videos also contributes to the creation of corporative image, as they share certain stylistic features that standardize the video news published. The use of open and close credits and corporative infographics let to unify these pieces of news.

Despite the Scottish referendum is a hard news, the type of selfproduced videos is characterized by using a plain language and searching for irony in order to keep audience's attention.

For further researchers about this topic it would be necessary to analyse more self-produced videos of The Guardian in order to be able to determine the common characteristics they share. This preliminary analysis let to perform some hypothesis about the possible features. An in-depth analysis could determine if the strategy designed by cybermedia to create their self-produced videos resembles to the characteristics presented by TV infotainment programmes (OrtellsBadenes, 2011), as features such as, having a longer duration, using careful images despite prevailing the use of hand-held filming, citizens becoming the protagonist, journalist becoming coprotagonist of these video news and searching for an ironic tone, are characteristics easy to recognize elements of infotainment programmes. 


\section{References}

BOCK, A. (2012): "Newspaper journalism and video: Motion, sound, and new narratives". In New Media \& Society, 14(4), pp. 600-616.

BRADSHAW, PAUL y ROHUMAA, LLISA (2011): The online Journalism Handbook. Skills to survive and thrive in the digital age. Essex: Pearson.

CABRERA GONZÁLEZ, M. A. (2001): “Convivencia de la prensa escrita y la prensa online en su transición hacia el modelo de la comunicación multimedia". In Estudios sobre el mensaje periodístico, 7, pp. 71-78.

CANAVILHAS, J. (2007): Webnoticia. Propuesta de modelo periodístico para la www. Covilhà, Livros Labcom.

CEBRIÁN HERREROS, M. (2009): “Comunicación interactiva en los cibermedios". In Comunicar, 33 (17), pp. 15-24.

DÍAZ ARIAS, R. (2009): “El vídeo en el ciberespacio: usos y lenguajes”. In Comunicar, XVII (33), pp. 63-71.

DÍAZ-NOCI, J. y MESO-AYERDI, K. (1998): “Desarrollo del periodismo electrónico". In El profesional de la información, 7 (12), pp. 4-11.

DEUZE, M. (2003): "The web and its journalism: considering the consequences of different types of newsmedia online". In New Media \& Society, 5 (2), pp. 203-230.

GREER, J. y MENSING, D. (2006): “The evolution of online newspapers: a longitudinal content analysis, 1997-2003”. In Xigen Li (Ed.): Internet newspapers: the making of mainstream medium. New Jersey: Lawrence Erlbaum Associates.

GUALLAR, J. (2008): "Prensa digital en 2007”. In Anuario ThinkEPI, pp. 102-108.

GUALLAR, J. y ABADAL, E. (2010): “The digiatal press archives of the leading Spanish online newspapers". In Information Research, 
15 (1). Retrieved from: http://InformationR.net/ir/15$1 /$ paper424.html.

GUALLAR, J., ROVIRA, C. y RUIZ, S. (2010): "Multimedialidad en la prensa digital. Elementos multimedia y sistemas de recuperación en los principales diarios digitales españoles". In Elprofesional de la información, 19(6), pp. 620-628.

LARRONDO, A. (2009): Los géneros en la redacción ciberperiodística. Contexto, teoría y práctica actual. Bilbao: Servicio Editorial de la Universidad del País Vasco.

LÓPEZ, G. (2008): "La eclosión del vídeo como mecanismo de comunicación política en Internet". In Congreso fundacional de la Asociación Española de Investigadores de la Comunicación, Santiago de Compostela.

LUCKIE, M. S. (2010): The digital Journalist's Handbook. Estados Unidos: Mark S. Luckie.

MARRERO SANTANA, L. (2008): “El reportaje multimedia como género del periodismo digital actual. Acercamiento a sus rasgos formales y de contenido". In Revista Latina de Comunicación social, 63, pp. 348-367.

MAYORA, J. y EDO, C. (2014): “Evolución de la producción audiovisual en cinco cibermedios españoles". In Journal of Communication, 9, pp. 233-262.

MASIP, P. (2008): "El vídeo en los cibermedios: algunas certezas y muchas dudas". In Anuario Think EPI, 4, pp. 180-185.

MASIP, P., DÍAZ-NOCI, J., DOMINGO, D. y MICÓ-SANZ, J. LL. (2010): "Investigación internacional sobre ciberperiodismo: hipertexto, interactividad, multimedia y convergencia". In El profesional de la información, 19 (6), pp. 568-576.

MASIP, P. MICÓ-SANZ, J. LL Y MESO, K. (2012): “Periodismo multimedia en España. Análisis de los contenidos multimedia en la prensa digital". In III Congreso Internacional de la Asociación Española de Investigación de la Comunicación "Comunicación y riesgo", Tarragona. 
MICÓ-SANZ; J. LL. y MASIP, P. (2008): "Recursos multimedia en los cibermedios españoles. Análisis del uso del vídeo en ElPaís.com, El Mundo.es, La Vanguardia.es y Libertad Digital”. In Tripodos, 23, pp. 89-105.

MICÓ-SANZ, J. LL. (2011): "Periodistas audiovisuales inmóviles ante el periodismo multimedia móvil". In Casero-Ripollés, A. and Marzal, J. (eds.): Periodismo en televisión. Nuevos horizontes, nuevas tendencias. Zamora, Comunicación social.

ORTELLS-BADENES, S. (2011): El infoentretenimiento en el periodismo audiovisual. La transformación del género informativo en televisión. Doctoral Thesys directed by Andreu Casero-Ripollés.

RINTALA, N. y SUOLANEN, S. (2005): “The Implications of Digitalization for Job Descriptions, Competencies and the Quality of Working Life". In Nordicom Review, 26 (2), pp. 52-67.

SCOLARI, C. y otros (2008): "El periodista polivalente.

Transformaciones en el perfil del periodista a partir de la digitalización de los medios audiovisuales catalanes". In Zer, 13(25), pp. 37-60.

SALAVERRÍA, R. (2005): Redacción periodística en Internet. Pamplona: Eunsa.

VAN DER HAAK, B., PARK, M. y CASTELLS, M. (2012): “The Future of Journalism: Networked Journalism. In International Journal of Communication, 6, pp. 2923-2938. 



\title{
Video as added value at Mexican print media website
}

\author{
Claudia Alicia Lerma Noriega, Tecnológico de Monterrey, \\ Campus Monterrey, México. \\ Profile in (D) orcid.org/0000-0001-9480-9289 \\ and in $\mathrm{G}$ http://goo.gl/2cY9LE
}

\begin{abstract}
The traditional media can take advantage that gives the network when they decide to be in it, but not all use them or use them efficiently. One of these advantages is the inclusion of video generated by the same media or by their audience. In this paper we can see how the Mexican newspapers that have a presence on the Internet $(56 \%$ of all printed newspapers) do not use the video or leverage a social network that has more presence on the web: YouTube, as a service value added to their readers.
\end{abstract}

Keywords

Online Media; YouTube; Video; Digital News; News media Web.

\section{Added Values Web Sites}

7 HE new and traditional media have their place in the Web must

1 compete with different distractions and possibilities to continue receiving information to maintained in the spectrum of possibilities news media. 
Only a few institutions use video this has the consequence of wasting of testimonial that can give more information. In this era still images or moving around the interest of Internet users can be used as a window to understand the everyday reality and should not be long. The testimonial and power of the image in the construction of the link with objective reality, added value in journalism, are the keys to this new trend.

The media who want to grow (and stay) in the net provide different possibilities for users of traditional media; if well used, the public can become regular and can even increase the number of users if the advantage is perceived by most people who see an exploitation of the variety of resources.

By using the Internet as a medium for transmitting information can not only change the pattern and the amount of information transmitted but can also alter relationships between individuals.

Television, newspapers, radio and films can be disseminated through the network using all resources available including (multimedia); this new way of dissemination of traditional media through a technological innovation of transmission gives the user a value-added service (VAS) to both: the website and the environment in its traditional format.

The presence of audio and video (multimedia) with the immediacy and directness are some of the advantages of WWW; with this many mainstream media also seek a telematic presence and developed sites that complement the information presented in their native formats. This generates the user assume that when browsing the Web will present their preferred mass media (radio, television or newspapers), and in any place, any time can provide information that is useful.

However, according to Lopez Carreño (2004) for the combination of the elements involved in creating a website to achieve the following objectives: to inform, reach a large number of users, the information is found and understood, or that fidelity is achieved by users; needless to follow some basic settings on your special preparation for the digital environment which are known as Web Usability and develop a functional web architecture. 
The parameters set by the specialist in information dissemination are the basis for the development of this work in addition to display whether a use of video and value-added services on news websites the various Mexican print media present in the Internet and see if they are creating unique spaces of information in the social network that greater use worldwide is considered the main: YouTube.

The presence videographic analysis lies in the fact that the information on each of these sites is covered by the presence and positioning of the traditional medium.

The development of this project let's see how resources that provide both Internet and YouTube to disseminate information using various media resources for the benefit of users who are take advantage of.

According to Albornoz (2006) journalistic enterprises have a greater wealth of information materials and supports that can be promoted in the press, in the same way that websites can promote the print medium; complementarity between media occurs. This complementarity may be overlooked by some companies with a large position in the entertainment industry and the dissemination of information in general. And is that as Lopez Carreño (2004) notes

These news sites, news portals, dynamically combine three essential elements for consolidation: the content, products and services. These portals are established as new media, being autonomous and multimedia, thanks to universal vehicle that supports the Internet.

The emergence of these sites is due, among other things, the consolidation of the web portals as the main points of access to the website by users and the need for the media who wants to be on the Internet. At this point it is important to note that in this type of sites you can find information products (interviews, special supplements) and documentaries products that are not necessarily linked to a story (agenda, guides, notices). These products enhance the informative documentary site and can provide value-added services can make the user returns back to the site, on the other hand, the extra values can strengthen the personal, local or regional identity, and thus tend to segmenting the audience. 
Guillermina Franco (2005) notes that the web portals of the TV networks are in a certain way a form of a newspaper, only that the Internet offers services to conjoined with other media give an added value, but at the same time are elements that require further development and that both are attractive to cyber reader if done well and can be found for them. Among the services we can provide are newsletters, access to files and resources developed by the media itself as computer graphics, databases, guides and exclusive services for subscribers.

Lopez Carreño (2004) proposes a classification of VAS in this type of news sites and encompasses the following areas:

\begin{tabular}{|l|ll|}
\hline TABLE 1 & \multicolumn{2}{|l|}{} \\
\hline Value Added Services & Typology \\
& 1. & Help; \\
& 2. & Navigation bar / Home; \\
& 3. & Search news; \\
Access to Information & 5. & Web search; \\
& 6. & Tools; \\
& 7. & Directory; \\
& 8. & Vertical / Channels Portales; \\
& 9. & Latest news; \\
\hline \multirow{3}{*}{ Interactive } & 10. & Chat; \\
& 11. & Forums; \\
& 12. & Webmail; \\
\hline Participation & 13. & Letters to the Editor; \\
& 14. & Contests; \\
& 15. & Surveys; \\
& 16. & Submission of accounts; \\
& 17. & mailNew to a friend; \\
& 18. & Open Page; \\
& 19. & Postcards; \\
& 20. & Suggestions; \\
\hline & & \\
\hline
\end{tabular}




\begin{tabular}{|l|ll|}
\hline \multirow{4}{*}{ Multimedia } & 21. & Photographs; \\
& 22. & Interactive graphics; \\
& 23. & Digital Radio; \\
& 24. & Videos; \\
& 25. & Digital Television; \\
\hline \multirow{5}{*}{ Custom } & 26. & Alerts; \\
& 27. & MailNews; \\
& 28. & My daily; \\
& 29. & My home; \\
& 30. & Reminders (events); \\
& 31. & WAPnews; \\
& 32. & Virtual Pets; \\
\hline \multirow{5}{*}{ Entertainment } & 33. & Horoscopes; \\
& 34. & Games / Hobbies; \\
& 35. & Webcam; \\
\hline \multirow{5}{*}{ Comercials } & 36. & Shop/s; \\
& 37. & Travel online; \\
& 38. & Classifieds; \\
& 39. & Selling content (e-contents); \\
& 40. & Online Banking; \\
\hline & 41. & Dictionary; \\
& 42. & Links to other media; \\
& 43. & Mobilenews; \\
& 44. & Translation; \\
\hline & & \\
\hline
\end{tabular}

This VAS maybe is present in different ways inside the web portal or may be omitted.

A complement to the analysis regarding the presence of these VAS is to emphasize multimedia use in information portals, specifically video. An analysis of this type can then not only check for the VAS and multimedia presence in the generalist newspapers with the largest presence in Mexico but also allow verifying employment and versatility of resources that these media companies have to their audiences (print and online). 


\section{Definition of Objectives}

Today you can see what Albornoz (2006) calls a crossmedia synergy between this production of different lines of a particular media conglomerate, which leads to innovative formats and emphasizes the values added in all media with virtual profit for user-viewer. That is why what is sought in this work is displayed if there is a presence of added value services on the websites of Mexican print media especially the presence of video and a channel for disseminating information through YouTube.

These media as an object of study because of the problems continuously print media of various countries claim regarding the disappearance of traditional media and search using the Internet to try to survive the crisis are defined. Both video and other multimedia elements can serve as a factor to attract readers and many overlook.

From the findings of this analysis conclusions that will help determine what might be the advantages that the reader will find Internet-user from the average conventional communication emerge.

These analyzes also allow you to see areas of opportunity to improve the environment and enhance the benefits that they are having; all this in order not to waste resources that could be for the benefit of users and administrators of the communication media. It suggested the value of the analysis shows because they can make recommendations for professionals in the dissemination of information.

\section{Methodology}

As noted the media have a testimonial presence and if pursued in this work is displayed if there is a presence of video and a channel for disseminating information through YouTube proceeded to assess whether 2014 print media registered in the National Media Board (of Mexico) value-added service are inside of these.

The study determined by observing whether each medium enrolled in the Board (which has a presence on the Internet) has a space dedicated to video or have and promote your YouTube channel. 


\section{Analysis}

According to the observation made was seen that all registered print media in Mexico Board amounts to 1278, of which only 719 have a web portal.

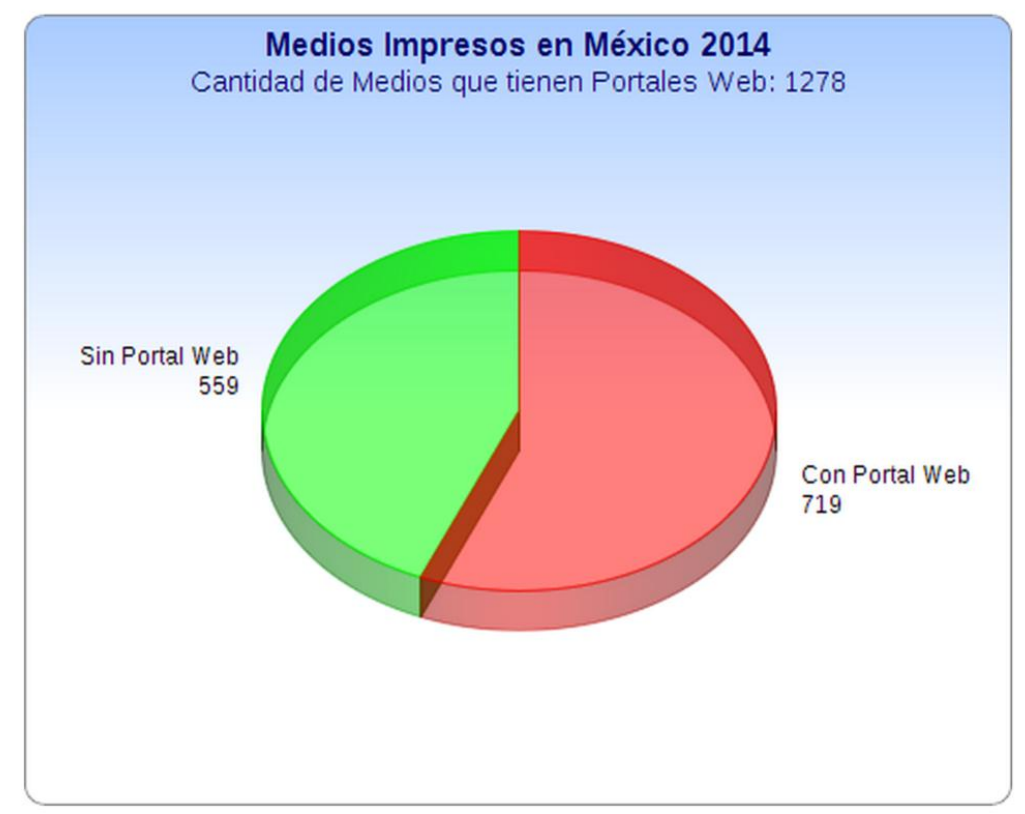

Source: Prepared by the author

Make it clear that there are some who share the same site regardless if they belong to cities or states (websites Organización Editorial Mexicana, Milenio, El Debate, El Diario de Sonora, AZ Diario, Contralínea y Síntesis, among many others), which lessens the amount of supply of online diaries.

As regards the use of the videos as value added services that should have these webstes you can see that is an item that overlook most sites because of the 719 gates only 117 have online videos different themes and developed either by the medium itself or sent by readers. This represents $16.27 \%$ of all print media Mexico.

On the other hand, of the 719 gates only 164 have an own YouTube channel for transmitting related material put in their news portals, this represents only $22.80 \%$ of only those who have a website, if we compare with all print media, this percentage would drop drastically. 


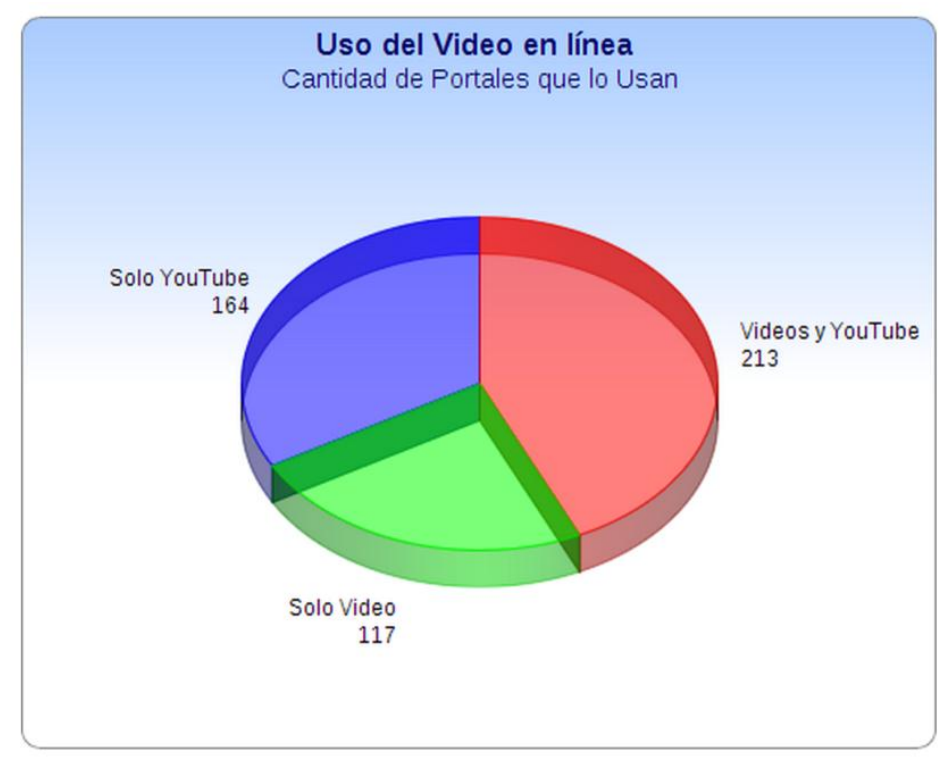

Source: Prepared by the author

\section{Conclusions}

One of the main problems faced by print media around the world is the struggle to stay in the public taste and declining readership. This struggle becomes more complicated if traditional media profiles do not match the new technologies and do not transmit information to all Internet elements offered.

Provide additional elements to the printed information such as video, interactive computer graphics, using social networking, audio is an attraction that can provide to gain more followers to informative sites, both online and traditional, so we must seize that exist for offer them before your competition and gain an advantage.

In the case of the Mexican press, you can see that only half advantage to have a web presence $(52 \%)$, and of these, very few are those who are watching and using the advantages that can be generated in a medium like the Internet.

It should be noted the traditional press, and emphasized, the notion that the user can find plenty of information and services because the analysis results show otherwise. 
The analysis developed in this 2014 suggests the possibility of making more evident the need to include in journalistic portals search items news and videos that complement what is presented in television news and the opportunity to open a channel in social network as YouTube, created by an extension of their brand and have a greater presence on the Internet.

This analysis type is particularly important to detect that it has increased the number of Internet users in Mexico (51.2 million users on 2014 according to the Mexican Internet Association) and the number of people who search information by web grows daily.

The Mexican press faces a major challenge not only for the crisis in the print media but by the ignorance that apparently have managers and administrators regarding the advantages of using and presence in the Web.

Services of interactivity for the user, entertainment, and various accessories like news options over other electronic devices or custom options; are areas of opportunity for the Mexican press and many other news sites and promote them among their community of readers.

For the user there is also a lack of knowledge of the possibilities a site related to a television network can be found.

According to studies by the Mexican Internet Association (2014) one can see that users are informed through this media more frequently at specific times of the day, which is an area of significant opportunity to develop offering news are backed by reliability recognized by the public in each region.

An electronic portal is an area of opportunity to break geographical, temporal and geographic barriers, which offers a wide and varied number of users, the social events; this fact not only goes beyond the some mentioned obstacles lines before, but also the elements of age, distribution and relation to other media, which are essential to present an attractive product for the user since the first time it faces a complement to traditional media and you see it as an informative proposal according to the technological advance of the century. 


\section{Bibliography}

ALBORNOZ, LUIS A. (2006). "Los principales diarios online en español. El empleo de recursos audiovisuales y multimedia, e hipervínculos", Telos. N. 66, Second period. Retrieved from: http://www.campusred.net/telos/perspectivaImprimible.asp?idarticu $\underline{\mathrm{l}}=2 \mathrm{krev}=66$. (Access 17.02.2006).

ASOCIACIÓN MEXICANA DE INTERNET (2014) "Estudio de hábitos del mercado en línea en México 2014". Asociación Mexicana de Internet. Retrieved from:

https://www.amipci.org.mx/estudios/habitos de internet/Est udio Habitos del Internauta Mexicano 2014 V MD.pdf. (Access 4.02.2015).

FERNÁNDEZ COCA, Antonio (1998). Producción y diseño gráfico para la World Wide Web. Barcelona: Paidós.

FLEMING, JENNIFER (2004). "Web Navigation”. Designing the User Experience. Net library. Retrieved from:http://biblioteca.itesm.mx/cgibin/nav/salta?cual=bases:30. (Access: 22.06.2004).

FRANCO ÁLVAREZ, GUILLERMINA (2005). "Los portales periodísticos españoles. El valor añadido de la información de proximidad" Telos. N 63, Segunda Época. Retrieved from: http://www.campusred.net/telos/perspectivaImprimible.asp?id articulo $=2 \& \mathrm{rev}=63$. (Access 20.02.2006).

LÓPEZ CARREÑO, ROSSANA (2004). "Análisis taxonómico de los portales periodísticos españoles”, Anales de documentación, $\mathrm{N}^{\mathrm{o}}$ 7, 2004, 123-140. Retrieved from: http://www.um.es/fccd/anales/ad07/ad0708.pdf. (Access: 1.03.2006). 


\title{
Multimedia, multiscreen, multitask, and emotions
}

\section{Video games as multimedia process \\ Enrique Morales Corral, Universidad Camilo José Cela - UTAD, Madrid, Spain \\ Profile in orcid.org/0000-0001-5886-2672 \\ and in $\mathrm{G}$ http://goo.gl/FD9eBq}

\begin{abstract}
This article tries to show how video games, in recent years, have been created a naturally multimedia environment process. How they have developed all their potential as new digital cultures, presenting special and unique features.

Four themes will be described. At first, the close relationship they have always kept the video game and the development of technology, especially ICT briefly discussed. The second section will show the
\end{abstract}


most visible relationship: the economic factor. In a third section briefly display the status of the creation of this cultural industry in Spain, and finally new uses that are giving the game will be shown.

\section{Keywords}

Video games; cultural industry; creative industry; multimedia; ICTs; communication.

\section{Introduction}

\section{$\mathrm{T}$ \\ HIS article try to provide a series of conclusions and data on why}

the current success of the video game industry as a form of natural leisure. For this purpose a (qualitative and quantitative) mixed research was done with four standardized interviews unscheduled, that made twenty six speech codes, with which were created the First Independent Games User Survey of Spain, with 455 complete answers in only 16 days active in 2013. It was performed an initial study of supply of the video game industry, and a study on the demand from users, allowing us to offer a valid radiograph of this cultural industry.

The original research's main objective is to mark the guidelines of the current demand of the game. Have focused profiles, especially the most common Spanish users, and have contrasted the different sections and analysis of descriptive research. It has articulated the main hypothesis, which attempts to answer why and how there was this massive phenomenon: the main reason that today's cultural industry is the most important game in Spain and the world, responds to a massive use of video games as a form of entertainment among a large proportion of the population, especially under 35 years old people, who have grown up playing, becoming active players standardization. These causes the developers must constantly innovate, because of the large number of players and profiles, which grows daily. The weariness of old narrative techniques will be another factor that will force feeding experiment entire system. 


\section{Video games begin their journey}

Games are a natural process, especially as a basic element for development, learning and discovery in the early years of life (Huizinga, 1987). They are more common in early life and childhood, but we are performing them throughout our lives, especially as a relational element. There are many examples that we can put in everyday adult life: sports, cards, domino... And in a few years we should incorporate video games in this category because it has similar characteristics (Estallo, 1995).

The road to get to the invention of video games themselves began with the creation of the first arcade machines to carnivals in the early nineteenth century. These machines are precursors were mechanical leisure and aimed to raise technological curiosity among the public in exchange for a coin. Some machines used a system, for example, to reveal a picture of a sexy girl, and challenged participants to try their hand with a small caliber gun. Its construction was very expensive, due to the mechanical difficulties of the time and there were not many units at first. It was a success that led inventors to attempt to create increasingly complex machines. A second step was the invention in the mid- nineteenth century of pinball machines with great success too, which began to be introduced in bars and arcades where you could find all kinds of models. The third step was, from advances in electronics and computers, creating electronic arcade, which is already electronic entertainment: the video game. Stay the way for the creation, in the late 60 s of 21 st century, the first home video game that saw the start of the game model that we understand today.

But what is a game? According to the RAE a video game is an electronic device that allows, through appropriate controls, simulate games on the screens of a television or a computer. From this starting point we can make as a number of important elements that we have highlighted in this research. It is important to separate the concepts of the video game industry (hardware software) and video game culture industry (software). The second is included in the first. Quite a few studies that do cause confusion in the reader. In this study we have taken special care to separate as models refer to economic, 
social, cultural and communication that need not be exactly the same, but vary according to their particular characteristics.

The main objective of this paper is to answer how was the process that led to the game for everyday use in our society. Why play today from three year olds children to grandparents of ninety. The answer is simple, not its explanation. There has been a video game naturalization use in our society (Morales, 2011a), its role has changed: from a marginal activity to a normal and regular activity. This process has been caused by several factors that can be summarized into four main groups: cultural, technological, economic and new uses. These four categories refer to the four cross-cutting themes that form the structure of the paper.

A first factor is cultural. The game itself was a subculture only a few years ago. It was something of geeks, of a minority who spent many hours in front of a computer or TV screen, with a bad reputation among the general population who did not understand its use (Levis, 1997). For a long time only children and young people played video games because products were created just for them, creating an initial base of players. The industry opted for creating more open markets generally simple and easy to use, looking for new users. Now almost everyone plays, has extended its use among the general population. In a way society has changed the way you look at this practice, accepting and naturalizing use.

An interesting debate is the consideration of the game as a cultural and artistic expression by society in general and in particular the users themselves. In the interviews we have seen expressions under both perspectives are refuted with survey data. Eight out of ten users recognize games as an artistic expression. In fact, an interesting debate to ask why. According to users there are basically three main reasons: it is a creative expression, conveys emotions and is a mixture of arts. These three reasons can be summed up in two, because the very definition of creative expression implies the capacity to transmit emotions. Make a mixture of arts is an important point to consider because it can present arguments for and against on stable social recognition. It may be to the contrary, it may imply that the medium itself is not adequate to essentially someday be recognized as art itself, 
and may be in favor, because it brings together recognized arts into one element, giving it essentially own. This is the key element on which turns on this discussion and should be done in-depth study.

Following this line of argument were asked users about the term most reflect the use of video games: Entertainment \& Leisure keywords were voted, with $51 \%$ and $20 \%$ respectively, reflecting the playful vision that has already associated the practice. It is interesting to see the graph 1, it reflects as the consideration of the keyword Arts decreases with age cohorts, showing the high naturalization of this concept among younger users have electronic entertainment.

\section{Graph 1: Evolution by age cohort of the three main keywords that summarize better for users to video games}

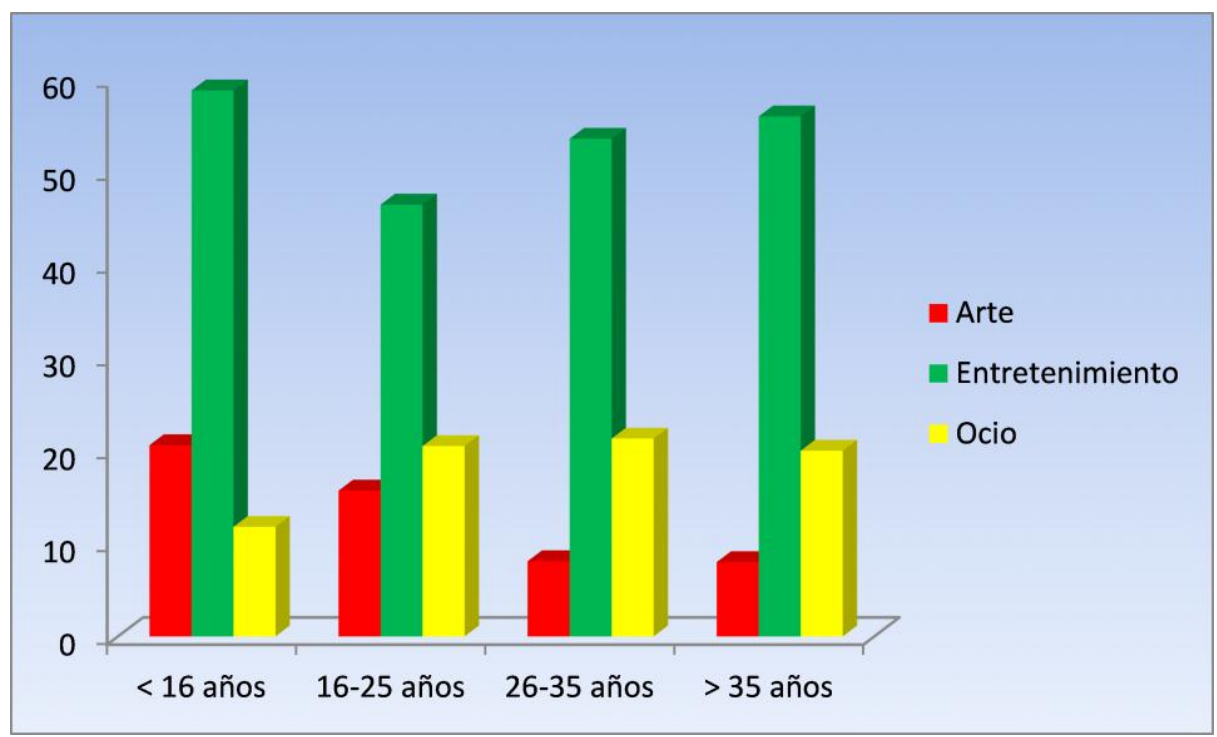

Own elaboration

PEGI code (http://www.pegi.info/es/) is the European system who is used to catalogued video games by their contents, is the principal mechanism available to educators and parents to avoid inappropriate content in video games to minors. As we can see in graph 2, the PEGI system is more useless as more age have their users, except in the $>35$ years old, who have balance recognition of this situation. Nine out of ten users say they know the PEGI age rating of content in Europe, but of these, only $57 \%$ consider it useful when making 
purchases for minors. That is, even with the campaigns that most years AEVI (Spanish Video games Association:

http://www.aevi.org.es/, old aDeSe) and others perform in order to inform users of this system, there is still a very high percentage of users not even knowing its use. Advertising should change this system, betting on new strategies, because they can be of great help in the purchase of products for certain ages. The assimilation of this regulatory tool by the majority of the population would favor changing view branded sectors still all violent video games, when in reality there are products suitable for all ages and tastes (Morales, 2011b).

\section{Graph 2: Usefulness of the PEGI system by age group of those who know the system}

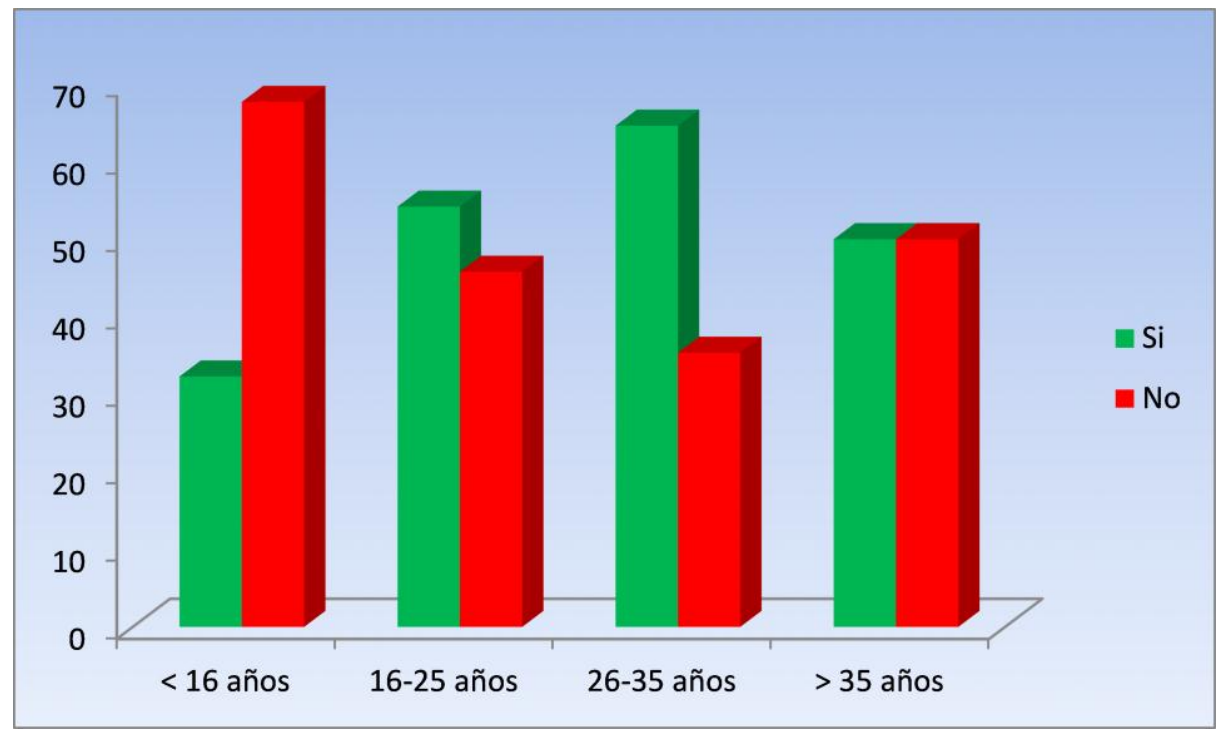

Own elaboration

An important and little noted by scientific studies on video games, is the relief they have taken the Western development studios when making games against the Japanese, who had maintained a creative hegemony in the last twenty years. This has meant that there are products more suited to Western customs and realities, and that many users feel more attracted to these products to feel more identified by the narratives, one of the reasons for the conquest of new users (Gee, 2004). 


\section{Video games and technology}

A second factor is how technological advances have meant in gaming devices for every tastes, prices and needs. They have also led to the creation of professionals who have developed new themes, interfaces, interactions with the screen... causing that population had never been interested in trying the game I did, and many would like it. Advances in technology made it possible for the product to get cheaper and can be allowed for the vast majority of the population of first worlds. It was a good gift for children and nephews who started playing at an early age getting an amazing player base in no time, that parents and grandparents were drawn in with social and group games.

At this point deserves special analysis company Nintendo, with his portable DS, 3DS, and especially with the Wii and its new controller that detects movement (Wiimote), revolutionized video game use among the general population because of their intuitive play and strong advertising campaigns it became fashionable. It created a new type of user: the casual, simple demanding games, social and intuitive. The creation of this new type of user base multiplied game sales, as in hardware as in software. We could speak of a golden generation, sales also drew from other devices and video games. After opening the new hobby many users became interested in video games more suited to their particular tastes (sports, shooting, history, strategy, driving...) paving the way for new experiences.

Special attention deserves the fact that consoles today are total domestic multimedia centers, each day increase their services, especially those related to visual possibilities. Internet has also revolutionized the game, facilitating their expansion and possibilities. It has created new forms of interaction between user and machine, new genres, themes, distribution and purchasing models... Nine out of ten respondents said they had played games online in one or more of the platforms possible. If we analyze according to age cohorts, we observe that this percentage rises to $97 \%$ for those under 16 years, which makes sense when talking about digital natives who were born in the Google generation, and that their world would crumble without the Internet almost. In the intermediate cohort represents a $94 \%$ for $16-25$ years, and $89 \%$ for $26-35$ years. The most interesting 
fact is that down to $76 \%$ in those over 35 years old, with less reliance and interest of online services and opportunities.

It is also important to know the main problems facing Spanish users to play online. For those who had responded that they had ever played online, the main drawback is the connection problems. For almost half of the users the problem is the connection, is that Spain is not known for its stability online. Currently is the main problem, because most have ADSL connections based on cable, much more stable. Recently Sony has announced that its streaming video game service Gaikai will be implemented from 2015 in Europe, mainly due to the large number of existing ADSL connections, which cannot guarantee service correctly.

The desktop consoles are still the mainstay for playing games in Spain, eight out of ten users play in them, followed by PC $(56 \%)$ and portable game consoles (44\%). The supposed smartphone and a gaming platform for the $24 \%$ of users, bringing the tablet to $9 \%$. These data clearly reflect the common use of multi-device game a reality in these times and will increasingly. Regarding the majority gaming platform: for half of the home game console users is their primary gaming platform, the PC is for the $27 \%$ handheld video representing an astonishing $15 \%$ and $6 \%$ for smartphones, leaving the percentage of tablets by $1 \%$. In the coming years we will see how these two latter percentages rise, to the detriment of the other options, due to changing gaming devices that is already happening, especially since portable consoles to smartphones. In the game show Tokyo Game Show 2013, the third largest in the world, two of every three new games presented were for smartphones and tablets, reflecting this trend.

The video game industry has always been heavily dependent on technological innovations. The renewal of the generations of consoles well attested. In the current scenario where smartphones and tablets are inroads into the market, further tilts the balance towards the search for a new gadget or revolutionary technology that supports and sell video games. In this light users were asked which technologies they thought that would be present in the video game market in an interval of ten years. The two majority responses, with 
response rates of two-thirds of users are likely to dominate the hyperrealistic graphics and there will be more online connectivity. Something quite plausible, since today and one could argue that these two factors are part of the structures present in the current generation, which debuted in late 2013. As a third option the most votes, with almost half the response rate, users said Video game streaming technology, which involves playing games hosted on servers from a screen, youtube to play, current examples are Onlive or Gaikai. This suggests an anxious wait for a large part of the users to this type of business model in the game, either by subscription or temporary catalog. Not to forget that the majority of user profiles that have answered the survey is for hardcore players who play more than five hours a week, and that this business model seems especially geared to their profile. The fourth option reflects an interest in a more realistic 3D due to the mixed results today, and has not been exploited to its full potential yet. Finally, with percentages above $30 \%$ found the raid Glasses 3D immersive virtual reality and the Matrix style as usual interface tool.

\section{The economic factor in video games}

The third factor is economics. Games initially inherited the business model of pinball arcades, evolving from there to its own models developed by taking advantage of other cultural industries. The retail distribution model, sales of a video game per box, comes with the start of the first home video game console created by Ralph H. Baer in 1968 and is still active today. Gradually the digital distribution model will be imposed against the retail, due to the great benefits it provides, both the user and the supplier or developer (convenience of home shopping, catalog, speed of access...) whenever the price drops. Already in the interviews, was argued that it would require a significant price drop for changing definitely this type of distribution, because of the economic loss would be the sale of second hand used its physical play.

We can see, at present, six sub-models within the digital distribution of video games: online download (distributes video games for digital 
download online), online casual (Internet browser used or the social networks in support of game), MMOs (games where a large number of users can simultaneously participate in an online virtual world), mobile games (specifically designed for smartphones and tablets), social games (designed specifically for social networks, this model is included in online casual, but for its particular characteristics creates a category of its own) and cloud gaming (video games to play through streaming technology). All this group of business models does nothing but expand the possibilities of an industry that does not seem to know the current crisis we are experiencing (Morales, 2012). Its great ability to assimilate business models is one of its great virtues but can also be a weakness, to complicate compensation mechanisms on the products offered. At the moment we are experiencing a transition obviously should be finished in the next few years, leaving only the retail model for nostalgic, packs and special editions.

The new mobile gaming platforms (smartphones and tablets) present in large distribution models portals (Google Play, Android Marquet, AppStore...), and new special video game genres such devices, using its touch options. Another aspect are the trends in new funding such as crowdfunding, which are already being used by small and medium studios to develop projects without the help of producers. By engaging directly, through small financial contributions, users get a true basis, involved in the development of production, with access to the entire process. It can be an important source of financing in the medium and long term projects rejected by the big producers or studios that want to be independent and rely only on the opinion of its users. Surely we will see in the coming months or years, a crowdfunding label as a product, as the essence of value added, offered outside of the big producers and distributors. An indie label that offers more risky games (themes, interfaces, gaming devices...), as already happens in the music or movie into fashion eventually forgetting their primal essence. Or even that big producers try this system of funding for riskier products, innovation with less risk seeking investment.

The U.S. is the largest market in the world, both in production and consumption. European production has risen sharply in recent years and the crisis has led to sharp declines in consumption. China is an 192 
emerging market where consoles have been banned (except for the DS) a long time; it corrupts the youth, although it seems to be open to other hardware soon. Its market exists mainly because online games for PC, highlighting models and free to play subscription. It is ironic that in the country where they make almost $100 \%$ of the gaming devices, they are prohibited. The Spanish market has an enviably healthy consumer impressive numbers. It is the fourth largest turnover in Europe and sixth in the world, but the creation is only 3\% of what is consumed. There is an imbalance between production and consumption which should try to be compensated in the coming years. The label Games from Spain, is a major institutional success in order to ensure the presence of Spanish development companies (especially small and medium), in major international fairs, that without this initiative, promoted by ICEX and the Academy of Interactive Arts and Sciences, would have been unable to market their products throughout the world.

\section{The video game creation sector in Spain}

The video game industry can become strategic in the coming years in Spain, where there are great professionals, specific grades and an abundance of trained unemployed. If the political will existed to support specific business plans, it could emerge as an important productive sector. Spanish professionals are highly regarded abroad, having to migrate mostly due to the lack of opportunities at home. Currently there are several initiatives proposed by the Ministry of Industry as part of the new plan to boost the digital economy and digital contents (Boix - Lazzeretti, 2012), in which the Spanish video game industry can participate. It is divided into three main areas: digital content adaptation scheme copyright and reuse program public sector information. It also aims to encourage the participation of private informal investors, the so-called business angels. The difference of this system compared to venture capital is not offered any specific tax treatment, the taxes being similar to any Investment. It is not only investors but also provides initial capital, business knowledge and contacts. 
The survey provided interesting data on the average consumption of video games in Spain, especially for regular players, the hardcore, representing nearly eight out of ten respondents. They are high consumption. The 30,99\% spent more than 100 euros in the first four months of the year, the $31,87 \%$ between 50 and 100 euros, and only $25,71 \%$ less than 50 euros (see graph 3).We are saying that almost one in every three spent more than 150 euros in the past year, and also one in three over 300 euros. The biggest spender average profile is that of a man between 26 and 35 years and is very common or hardcore player.

\section{Graph 3: Average recognized spending by the user between January to April}

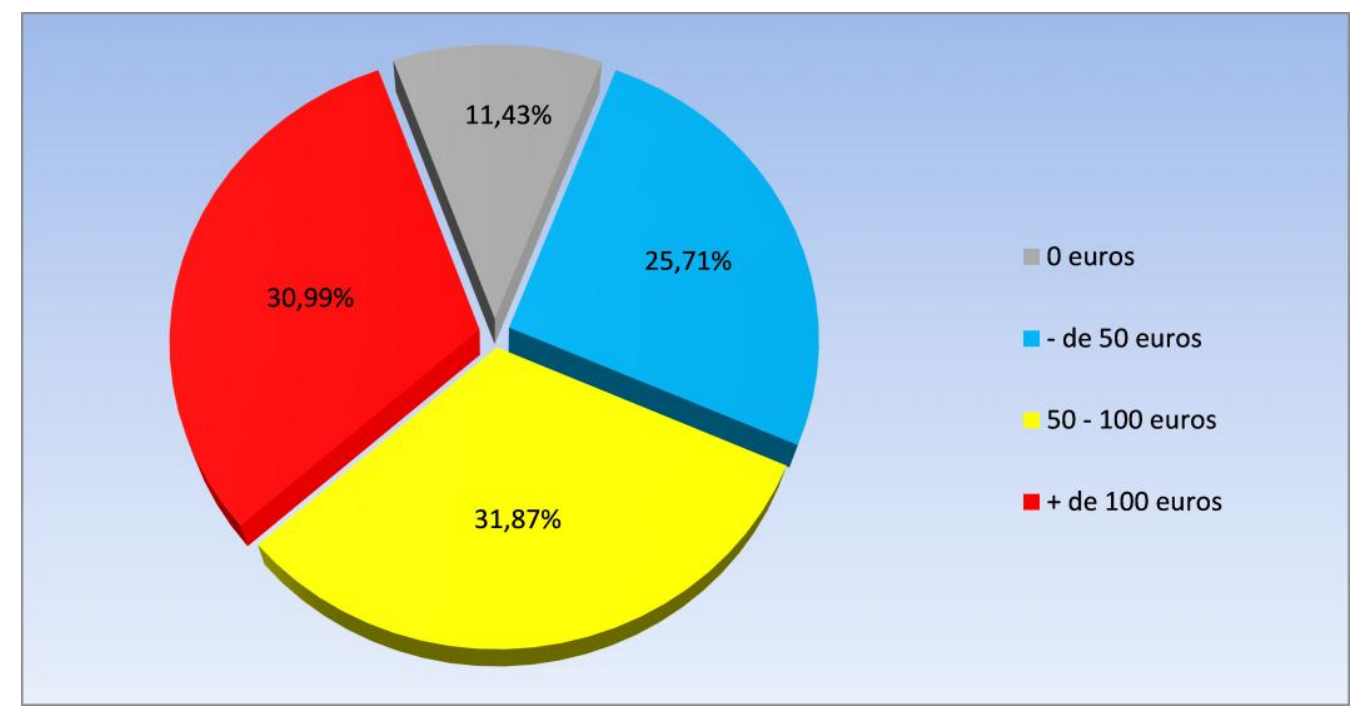

Own elaboration

Until recently times it was difficult to find secondary data that took into account online shopping for games. Nearly three out of four respondents said they purchased digital download video games online in one of their gaming devices. This percentage decreased significantly to almost $62 \%$ for the age group under 16 years. In this case we assume that the lack of access to their own money and the usual methods of payment at this system (credit - debit card, PayPal...), to buy online suppose the main reason for this significant decline over ten points from half of the respondents. If we analyze this data by type of players online shopping this percentage drops to 
almost $53 \%$ for casual players and increases to $78 \%$ for the hardcore, confirming that these players are more used to this type of transaction.

It is interesting to analyze what drives users to choose this system over traditional retail purchase, an issue rarely delved into the studies consulted. When digital purchases of game users especially are choosing the option of having the product they want is only in that format (43\% response rate). At this point it is important to note that all video games for smartphones and tablets have this distribution, there is no retail. We believe this is the main reason for the high response rate in this category, but there are also games for console and PC with this format, which highlights the digital sales platform Steam for PC, which soon achieved a catalog of more two thousand titles and more than forty million users worldwide. In the case of games with two types of distribution users still prefer the traditional boxed sales model (retail) because there is no significant price difference. Only one in four claimed the Specials category and one in five Best Price. It takes a significant decline in the prices of digital download games for users to opt for this format over the traditional retail model.

The growing video game industry spends more on advertising their products in the traditional media as part of traditional marketing campaigns. The business increases, the user base is larger advertising campaigns encouraging greater. More and more product announcements within the game, due to its high penetration among the population and greater recall rate, for the great care they should take the user to play. In the coming years we will see a lot more advertising in video games as part of the economic strategy of many companies. To produce games that offer cheap or free will their business model, and for the most expensive productions a way to recover investment quickly.

Another important area is the issue of piracy. It is a serious problem but it requires non-punitive measures for users, because they reinforce the very meaning of piracy. Today video games are pirated because it is usually cheaper, easier, more comfortable and faster to get the same content legally. Nearly nine out of ten Spanish users 
believe that if the price goes down, video games will be pirated less. If the balance was more cost - adjusted product, users would pirate less. There is also the belief that not enough money goes to developers: if they were more transparent compensation policies users would like their favorite creators. Users complain that they believe that there is not enough money from the sale of games to its creators, with distributors keeping much of the profit. This response shows a great ignorance of the business model from those surveyed. Distributors are a fundamental part in the whole process of the sector. Even if you do not talk about the retail model, and we focus on online, it requires a proper marketing campaign and SEO, work is usually conducted by publishers. What we can say is that the user often blames high prices of video games more on distributors than developers, nearly two out of three said they should avoid intermediaries (consumer to development study).

Digital distribution limits piracy easier failing physical disk by copying susceptible. The shift to digital distribution models began already in the mid of the last decade, but it was not until very recently that it is starting to work. The emergence of new desktop consoles later the 2013 accelerated this process even more, where philosophy that video games longer service products will become a revolution in the whole trading system. It is only a matter of time that all video games are associated with user accounts, as it has done the Steam platform for PC and video game portals for smartphones and tablets, adding value and social choices that pirated games can never offer. It is worth the legal purchase, not only for the product itself, but by the potential of selling platform. The gaming experience is becoming more feasible increase the belief of a fair balance between cost-effective. If we add to this simplicity, speed and security when buying, the formula works alone.

\section{New uses for video games}

The fourth factor is that games are also being naturalized because new uses being made. Video games are already being used as a teaching resource to support in schools (Bishop, 1998 and Cuenca - 
Martin, 1988), for their wide acceptance among children and youth in various educational programs (Gros, 2008), that facilitate the provision of content scheduled. We could get the kids learn without realizing it. Use in all types of simulations is now common for decades (Abt, 1970), because they are learning mechanisms cheaper and safer (airplanes, cars, boats, spaceships...). It also highlights their use in all types of military training, advertising (adgames), medical research (Foldit), physical and mental rehabilitation, to marketing... the list is growing daily.

Two important aspects discussed in this work, which appeared in two experimental codes tested in the interviews and transferred to the user survey were: the relationship between video games and the values of gender equality, and the relationship between video games and the general media. The first showed that users believe that video games do not reflect well the values of equality. It has traditionally been a product created by men for men. Today this is beginning to change, being the female audience one that has grown in the last decade. More and more specific products with specific characteristics. The generalization of users has brought about this change of trends that will continue in the coming years, and even increase, as they are incorporating video game creators a sector traditionally dominated by men. Diversification and specialization has just started. The conflict is obvious, and studies are needed on the relationship between the values of equality in video games because they are conspicuous by their absence.

Perhaps the PEGI system should establish a separate category for this problem, in order to prevent parents and educators of content unsuitable for children. They should show a value that today should be almost universal in an advanced society such as the Spanish: the social conception of gender equality. Video games aimed at children should take special care of this kind of behavior, because they are important leisure and nature. Only from prevention and visibility of a problem we tackle in the future appropriate behaviors. Within the system of pictograms and Sex Discrimination appears, but reading its definition, refers to other factors (sexual scenes or discrimination based on race), being useless for the work here described and claimed. 
From this study it is claimed that a separate category of visibility to the problem.

The second aspect is how the mainstream media have treated and how they treat news regarding video games. There is an overwhelming opinion that does not do well. The explanation is based on a traditional bad press and lack of interest among news directors who decide what is newsworthy and what is not. This also will change, as active users reach editors and cover positions this cultural representation with the importance it deserves. Another explanation is that the target audience of traditional media is not interested in these issues, a situation that will change over time.

\section{Conclusions}

After careful consideration of the offer of the video game industry and the original study on the demand from users, we must conclude the large capacity of this sector to adopt new business strategies and topics requested by users. It is very common to achieve change trade policies of big business. A recent example is the changes in strategy that has made Microsoft launched in late 2013 of its new video game console, Xbox One Microsoft intended to implement a series of measures to integrate the games to a user account, require permanent online connection... well, just a Steam console but that were not well received by the mass user. So they changed their policies towards a smoother transition than intended. Because we cannot be mistaken, that is the future of video games, like it or not. It will be a model that we will see in a few years and significantly reduce piracy. But to be accepted you have to give added value to convince users that the game will cease to be a product to become service. We will not only have the game, we will have a social network associated with the product, exclusive items, achievements, notoriety for use, access to exclusive offers, ease of payment options in the cloud, audiovisual quality, integration with smartphones and tablets... a host of new options this sector projected to create synergies with other, offering services, not products. 
Video games now account for the largest sector of global cultural entertainment. It is the largest cultural industry in terms of sales figures and users, growing every day. The main reason for this phenomenon is that there has been a naturalization of using video games in our society, there is already a culture of gaming as a normal leisure activity. People play because they like to and continue playing. The themes, interfaces, devices, distribution... will change over time, but what will never change is the desire to play a game and have fun with your favorite video game, whether simple or complex, long or short, on your TV or on your smartphone... people will continue playing.

\section{Bibliography}

ABT, C. (1970). Serious Games. Nueva York: Viking Press.

BISHOP, A. (1998). "El papel de los videojuegos en la educación matemática”. Revista de didáctica de las matemáticas, 18, pp. 9-19.

BOIX, R., LAZZERET'TI, L (2012). "Las industrias creativas en España: Una panorámica”. Investigaciones regionales, 22, pp. 181206. Retrieved from:

http://dialnet.unirioja.es/servlet/articulo? codigo $=3911846$ (Access 15.02.2015).

BUSTAMANTE, E., ZALLO, R. (Coord.) (1988). Las industrias culturales en España. Madrid: Akal Comunicación.

CUENCA LOPEZ, J. M., MARTIN CACERES, M. (2011).

"Historia y videojuegos: Una propuesta de trabajo para el aula de $1^{\circ}$ de ESO". IBER: Didáctica de las Ciencias Sociales, Geografía e Historia. ISSN 1133-9810, No 69, pp. 64-73.

ESTALLO, J. A. (1995). Los videojuegos: juegos y prejuicios. Barcelona: Planeta.

GAITAN MOYA, J. A., PIÑUEL RAIGADA, J.L. (1998). Técnicas de investigación en Comunicación Social. Madrid: Síntesis.

GEE, J. P. (2004). Lo que nos enseñan los videojuegos sobre el aprendizaje y el alfabetismo. Málaga: Aljibe.

GROS, B. (2008). "Videojuegos y aprendizaje". Barcelona: Graó. HUIZINGA, J. (1987). Homo ludens. Madrid: Alianza. 
LEVIS, D. (1997). "Los videojuegos, un fenómeno de masas". Barcelona: Paidós de Comunicación.

MORALES CORRAL, E. (2011a). "Los videojuegos: apostar por la cultura multimedia”. En BUSTAMANTE, E. (Coord.). Informe sobre la cultura española y su proyección global. Fundación Alternativas, Madrid: Marcial Pons Ediciones Jurídicas y Sociales, pp. 133152.

MORALES CORRAL, E. (2011b). "El videojuego y las nuevas tendencias que presentan al mercado de la comunicación". Revista Disertaciones, V. 4, No 2 july-december, pp. 36-54. Retrieved from:

http://erevistas.saber.ula.ve/index.php/Disertaciones/article/v iew/3464/3366 (Access 15.02.2015).

MORALES CORRAL, E. (2012). "El reconocimiento institucional español de los videojuegos como industria cultural: propuestas para crear industria". Derecom, No 11, september-november, pp. 17-33. Retrieved from: http://derecom.com/numeros/pdf/morales.pdf (Access 15.02.2015).

PIÑUEL, J. L., LOZANO, C. (2006). Ensayo general sobre la comunicación. Barcelona: Paidós. 


\title{
Multitask, multiscreen and social practice of the use of Media among young Spanish people between the ages of 16 to 29 years old
}

Gemma Teso Alonso, Universidad Complutense de Madrid, UCM, Madrid, España

Profile in 1 http://orcid.org/0000-0001-9852-0255 and in $G$

José Luis PiñuelRaigada, Universidad Complutense de Madrid, UCM, Madrid, España

Profile in (- http://orcid.org/0000-0003-1354-0770

and in $\mathrm{G}$ http://goo.gl/QKDfoQ

\begin{abstract}
Nowadays, the youth is part of the society who does not use convencional Social Media Comunication (SMC), and use more Information and Communication Technology (ICTs); however, it is the way that all the SMC have already been integrated in the Internet creating a new communicational ecosystem (Jenkins, 2009), as well as youth have access through the internet to certain messages linked by the media and media corporations (messages -opinion and information source, educational and/or publicity, and specially science fiction messages: video games, films, series, etc.) According to several surveys, there is an empirical evidence that the main source of scientific knowledge for youth comes not only from the educational source, but also from the messages supplied particularly by the SMC and by the multinational media, accesible in different supports or platforms (Lopera, 2013, Meira, 2013).
\end{abstract}


In this type of communication it is shown and discussed data about the social practice of media that youths use, which nowadays is carried out in the frame of virtual conversations among people through social network, using "multitask" and multiscreen (TV, mobile phones, tablets...).

The data, in this article, is taken from researches done on audiovisual consumption by youth and from a survey done in the doctoral thesis titled "Media Messages, representation of climate in youth and social change" by Gemma Teso Alonso and conducted by Jose L. Piñuel y Rogelio Fernandez.

\section{Keywords}

Multiscreen; media consumption; social network; youths.

\section{Introduction: some data about the consumption of multiscreen and users' socio-demographic characteristics.}

OME of the daily places that are normally frequented to connect
us to the world through an "audiovisual" screen, are changing. While the screen that occupied the central scenario at home becomes bigger and with a more panoramic and spectacular format (up to 82" inches nowadays), others change to a more portable and lighter format, as it is the case of the screens of a laptop, tablets and mobile telephone. If we compare the number of users that connect simultaneously to share the same message, we find that bigger devices are to gather groups of a bigger number of people, while those that are smaller adjust to the individual, in terms of their use, personal dedication time and availability of any place that makes possible a minimal isolation, giving place to what it is known as mobile devices.

However, these devices (that are shown in Figure 1, are been integrated in different proportions to the domestic devices) are not just available in a simultaneous, sequential and directly way in the TV listing schedule, but they are customized and they are also giving the user the possibility to enter their lives to interact and contact with other individuals or any other users interchanging opinions and audiovisual messages in a multidirectional conversation and in a 
network way (friend's network, follower's network, conversation network...). However, its availability requires a more complex industry to produce the services (connection, data transmition, etc.), in order to be this situations more simpler in terms of accessibility, effictiveness and familiarity.

The informatic industry, the internet network, mobile network, the access to spend on equipment and subscriptions, etc., all these are an essential infrastructure whose business success and market of opportunities increase exponentially with the consumption of audiovisual spectacle which give very close and personal situations...

\section{Figure 1.Home technological equipment in Spain.}

\section{Equipamiento tecnológico en el hogar}

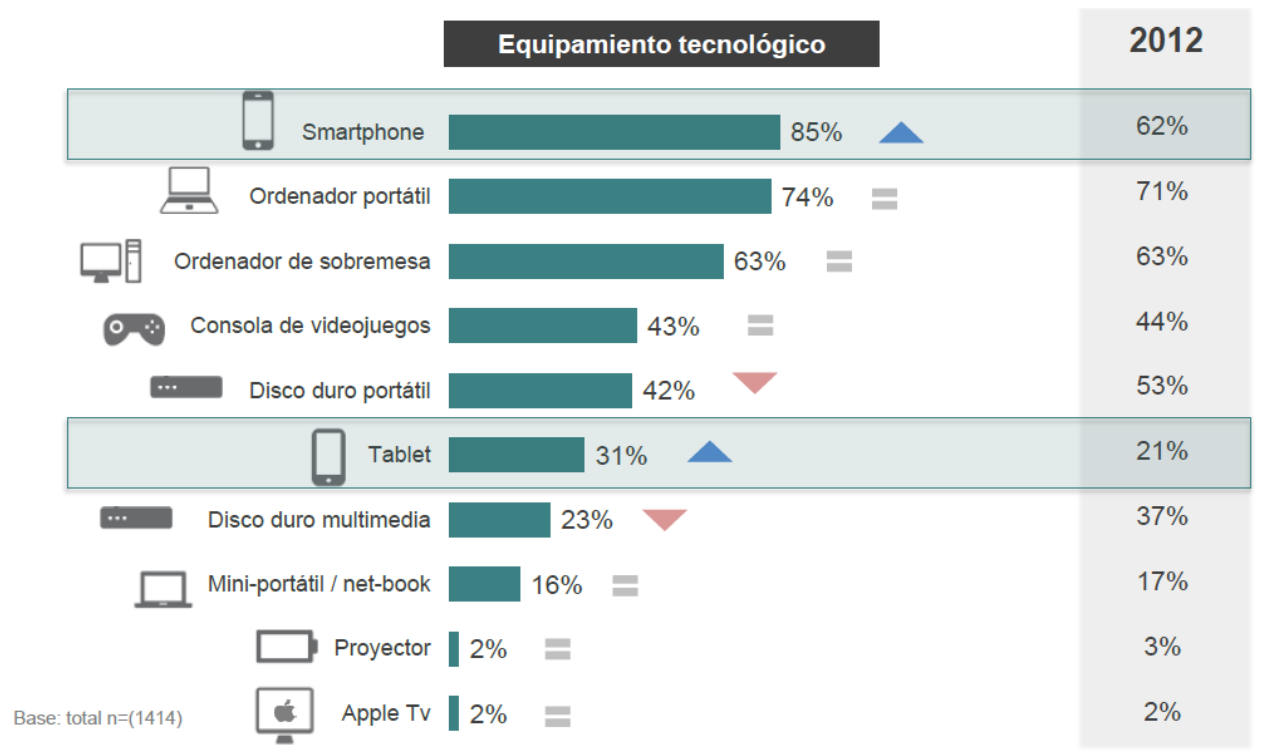

Los dispositivos en movilidad son los únicos que crecen en penetración

Mobile devices are the only ones that grow in terms of inclusion.

$$
\text { Source: Cocktail Analysis, } 2013^{43}
$$

And, how do we use such situations, such screens, such devices, and what do we use them for while we watch TV? Thanks to the convergence of the traditional communication media within the social

\footnotetext{
${ }^{43}$ COKTAIL ANALYSIS. Televidente 2.02013 (VII Oleada). This public report is available in: http://www.slideshare.net/TCAnalysis/informe-publicotelevidente-11102013 (02-11-2014)
} 
networks, we are witnesses of new ways of consumption of media contents, in other words, social consumption (Quintas-Froufe, N. \& González-Neira, A. 2014). Both consuming radio and television content through social networks, as well as the opportunity for the user to interact among them and with the transmitter interchanging written opinions and audiovisual messages in a large and polyphonic conversation of friends, followers, has left out-dated the traditional way. The quoted report of Cocktail Analysis in the graphic that is shown in figure 2 , shows ingeniously the types of mobile devices that are used while watching TV, allowing to access in the social networks and different kinds of interaction tasks causing a social parallel message, to the contents shown.

\section{Figure 2.The activity of each device while watching TV}

\section{Actividades de cada dispositivo mientras ve televisión}

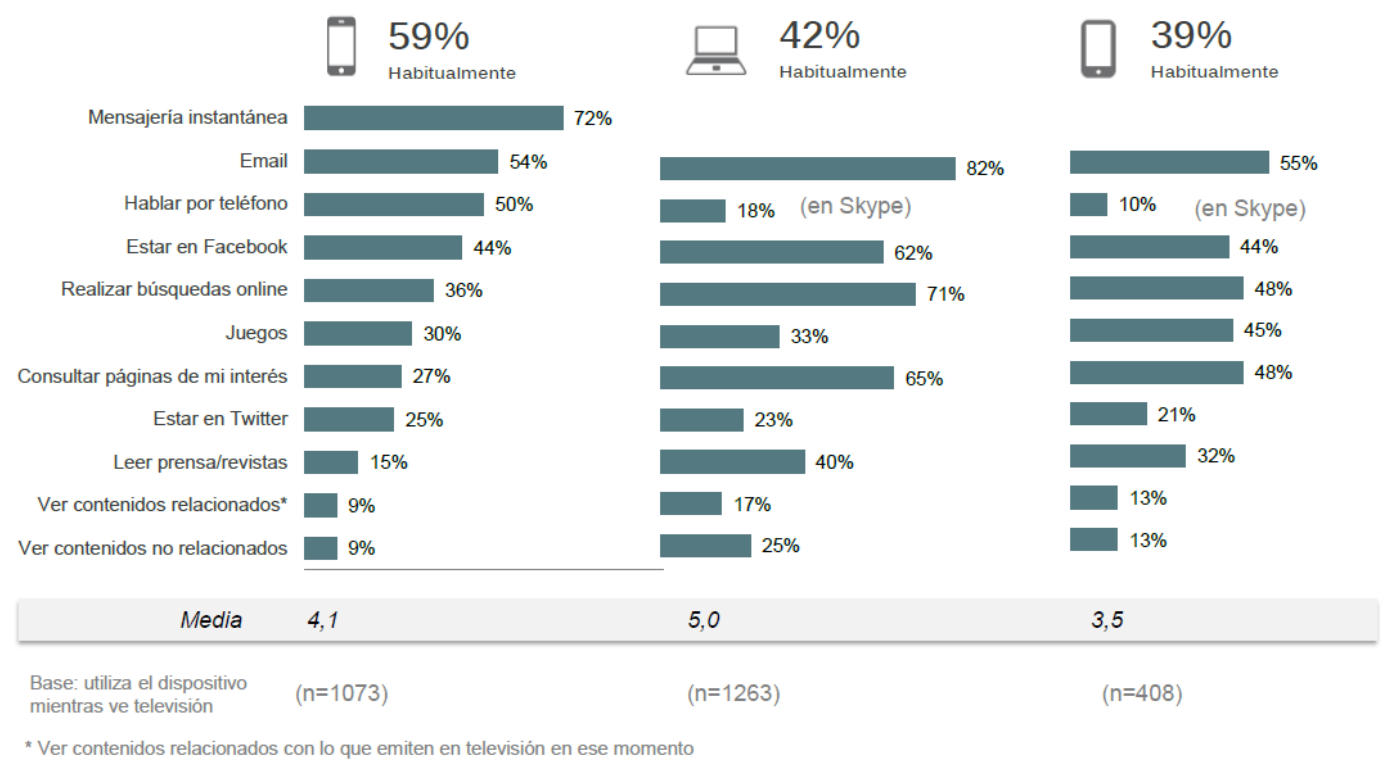

Diferentes dispositivos de interacción se traducen en diferentes usos concurrentes Siendo el ordenador el que ofrece mayor amplitud frente a Smartphone y Tablet.

Different interactive devices can be seen as devices that consume several types of media at the same time. The computer is the one that is wider than Smartphones and tablets.

Source: Cocktail Analysis, 2013

Finally, we have also taken data from the viewers report 2013 of Cocktail Analysis where we can notice that TV is seen á la carte, as it 
has been said at the beginning, Furthermore, it does not only occur among young people, but also adults adopt these habits through downloads or streaming, as shown in Figure 3.

\section{Figure 3. Downloads and streamingin Spain}

\section{Evolución de descargas y streaming}

El cambio en el uso del numero de usuarios de descargas y/o streaming ha sido muy intenso:

Si caía 8 puntos en el 2012 por el cierre de Megaupload, en el 2013 no solo se ha recuperado, sino que ha llegado a crecer 17 puntos.

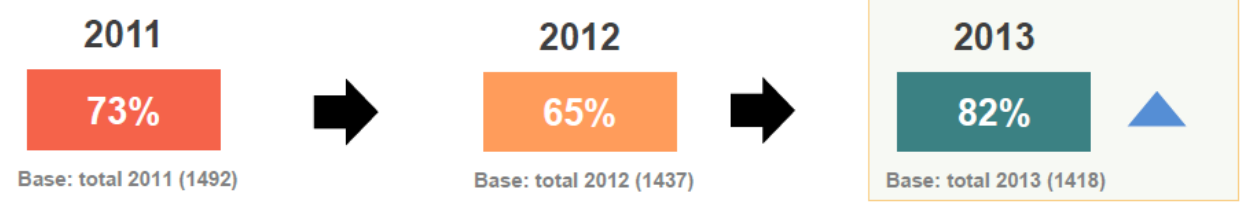

Este aumento se concentra en los perfiles de mayor edad:

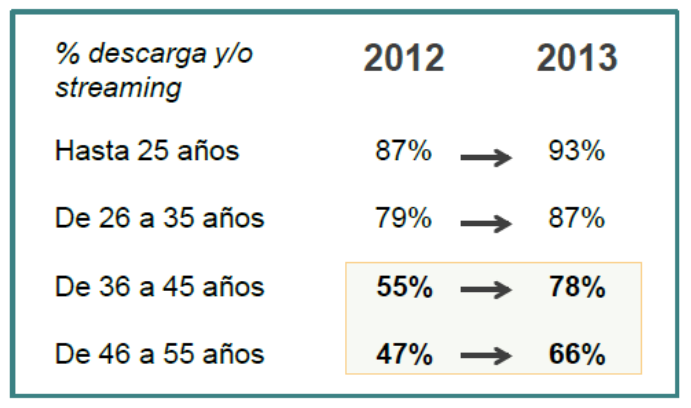

Los perfiles de menos de 35 años siguen estando a la cabeza en la búsqueda de contenidos de su interés vía internet.

Son los más adultos, que el año pasado habían abandonado estas prácticas como consecuencia de la mayor dificultad en el acceso, los que más se han incorporado en mayor medida a esta pauta de uso habitual en la búsqueda de contenidos de interés.

Source: Cocktail Analysis, 2013

\section{A question to be raised: Social Network as a "meeting point" among media and users}

It is advisable to consider the most relevant tendencies that in the last years have experienced what we could named as "the social meeting place". The characteristic of the new "social meeting place" is that it is virtually localized through the internet, where Media is situated with the purpose of getting close to the user in a more "personal" way, and where the users gather to "keep in touch". And this contact is not available bringing the users together at fixed hours that the TV listing schedule show, but providing them contents á la carte. 
Unlike the traditional "social meeting places" which can physically be found in a place, socially built before the "arrive and meet", or temporally situated to certain times in a day, the virtual meeting lacks of every physical closeness or even temporal, which was avoided by the media in order to get close to its users and the users to get close to the media. Today, the meeting between the media and the users works through virtual conversations thanks to the multitask given by the simultaneous use of different devices and screens. Moreover, thanks to social networks that nowadays are established in a virtual market, we can find symbolic value of their profile or identity always under construction.

The social practice of journalism gives individuals resources and social skills, and it also gives them the opportunity to notice the social reality where contact, friends networks and the acknowledge of oneself turns into security and permanence. We can mention previous data, related to social perception processes that are to happen and also its failures (news), studies done and focused on the uncertainty by Ulrich Beck, 1998 and 2002; Lozano Ascencio, 2002 and 2003; Gil Calvo, 2003, and several works done related to the social construction of reality, by Berger and Luckmann, 1976; Gergen and Warhus, 2003, etc. Regarding the context of a new social relationship by the use that both media and users give to social networks, we can quote Johnson, S. 2003, Castells, M. 2001, and Ontalba-Ruipérez, J. 2006. Manuel Castells confirmed, in the interview published the 4th of August, 2013 in the Blog of Sociology and actuality named Ssociologos, that the real sociability happens nowadays on the internet ${ }^{44}$.

Therefore, we have considered that Media and users use social network creating this way a new "social meeting place" characterized by its virtual location on the internet. Media approaches "personally" its users and the users get together "to keep in touch" or "to pay attention", and they have conversations because they are friends or followers. They all introduce themselves, they follow each other and interchange opinions, images, videos and work on their relationships without running the risk of close contact andprotecting their privacy.

\footnotetext{
${ }^{44}$ The interview is available in: http://ssociologos.com/2013/08/04/manuelcastells-la-sociabilidad-real-se-da-hoy-en-internet/(02-11-2014) 
We can even say that is it a little bit old (2011) that Media Communication is present in social networks (Facebook, Twiter, YouTube...) as you can see in the report published in 2011 by the Cabinet of Analysis of public opinion survey (GAD3) titled Media Communication of Social Networks.

\section{Figure 4}

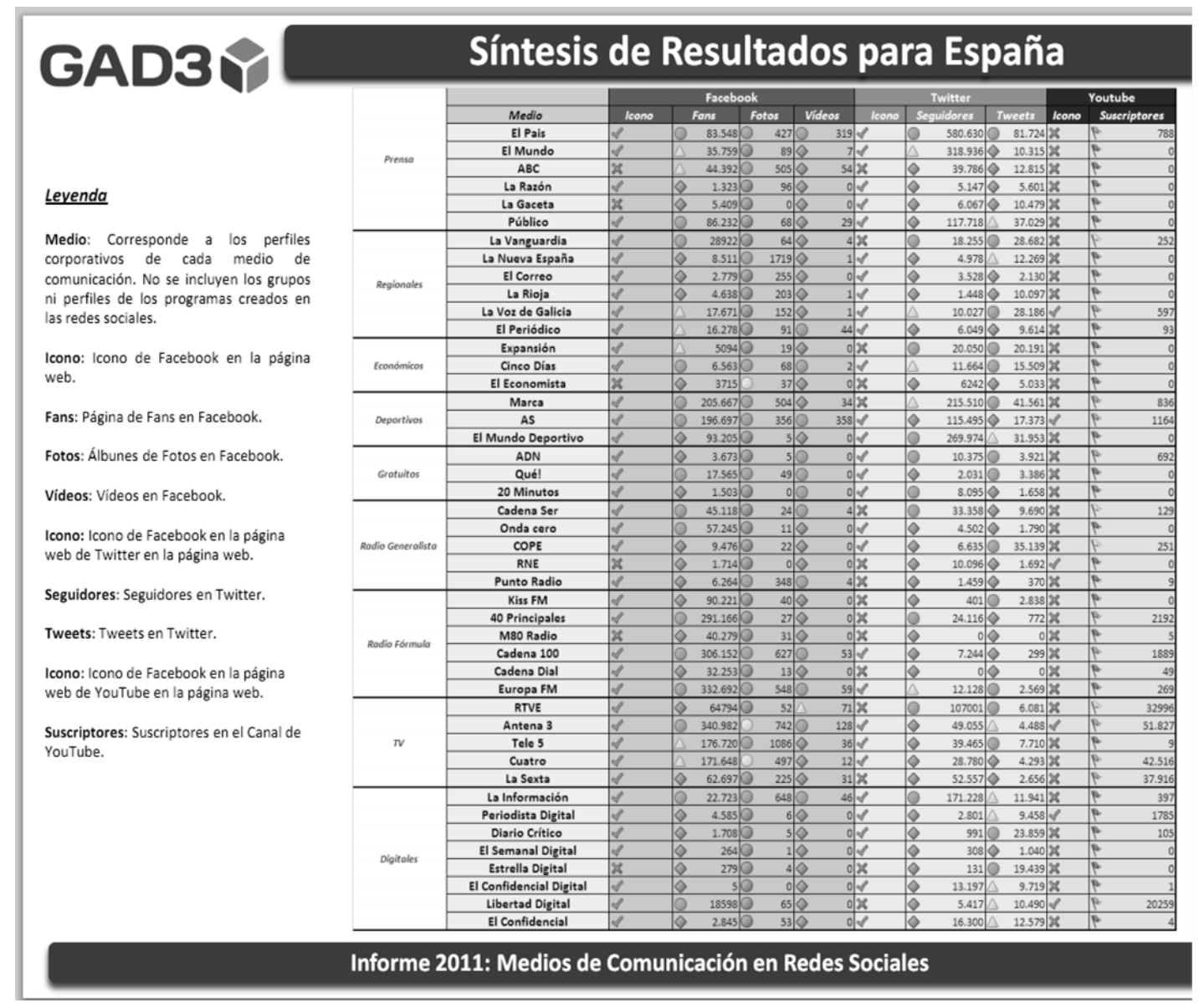

Source: Report 2011, Media Communication of Social Networks, by $G A D 3$ (Cabinet of Analysis of public opinion survey).

In this table we can see, for example, that El Pais was in the lead, in terms of social networks. Twitter was the one that had more followers, more than 580.000. El Mundo was second in rank with more than 350.000 followers, whereas Público was the leader, regarding the number of fans in Facebook, with more than 85.000, it even had more than El Pais and El Mundo in this type of social network. Among the local ones, La Vanguardia stood out in 
Facebook, followed by $\mathrm{La}$ Voz de Galicia. Among the economic papers, Expansión was the leader with 25.000 followers.

On the one hand, users use social networks as a virtual market where they meet with other individuals who have a similar profile to strengthen the relationship and on the other hand to share their knowledge and opinions.

The TV programmes that are been watched or that have been watched, are things that cause comments in virtual conversations as important as the rest of the contents shared by users regarding to the interchange of pictures and expressions or the interchange of information that is happening at the same time a user is connected. (See Figure 5).

\section{Figure 5: Types of content regarding the comments that different social platforms have in Spain}

\section{Tipos de contenidos sobre los que se realizan comentarios en plataformas sociales}

\section{Tipos de contenidos}

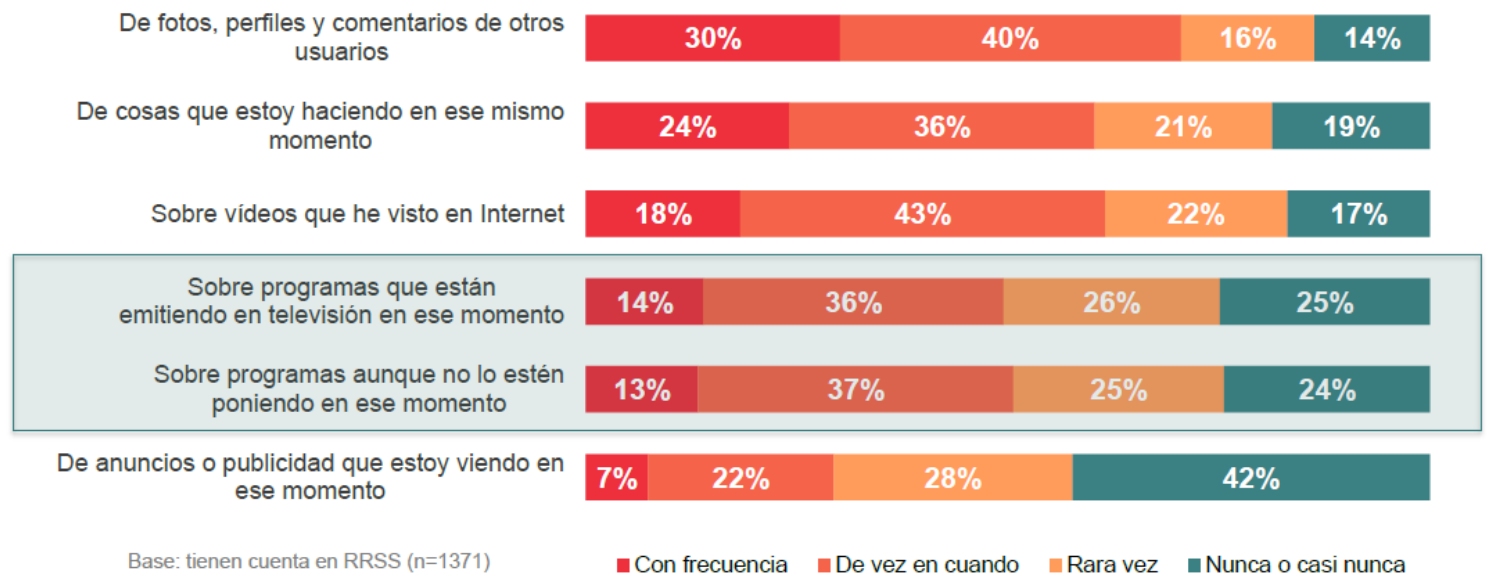

Source: Cocktail Analysis, 2013

A special platform among the youngsters is YouTube, which has become one of their favourite channels to watch audiovisual contents that have been produced apart from the conventional media. 
According to the last General Mass Media Survey, YouTube is the most visited website in Spain, 20.431 .000 visits a month, which can be considered the 4th most visited channel. In this channel, young youtubers are becoming the new creators of content. They manage, in many cases, to make money out of their works in quantities that can reach 3000 euros a month when they pass the number of 50.000 subscribers. Toni Garrido who works for Marker Studios in Spain and who is responsible for producing and distributing content in YouTube, explained to El Pais newspaper that youtubers with a great number of followers can make between 500.000€ and 5.000.000€ a year ${ }^{45}$.

Definitely, the "meeting place" where communication media meets, gets full of content that is linked to interpersonal relationships that users create in virtual conversation among users.

\section{A survey done to young people from18 to 29 years old. Tracking and monitoring in class about the use of media}

The context described consists in questions and answers of a survey about the use of media communication, applied to 756 students in their early years in university or vocational training, which is stated in a doctoral thesis titled Media messages, representation of climate change in youth and social change.

The survey used an on-line questionnaire. It was filled out in school hours in an educational stablishment with a teacher in charge and with a previous knowledge of the content and the possible incidents that could happen.

A priori a probabilistic sample was chosen and an area sampling or a mixture sampling (Gaitan, Juan A. and Piñuel, Jose L. 1998:153) ${ }^{46}$.

\footnotetext{
${ }^{45}$ The interview is taken from an article called "When I grow up I want to be a youtuber" published in the printed edition of the El País journal on the 15th November, 2014.

${ }^{46}$ Among a probabilistic sample, we calculated the size of the sample for an infinite universe and taking into account a margin error of $+-5 \%$. The size of the sampling was of 756 people.
} 
Taking into account that the age of the survey respondents were from 16 to 29 years old and their educational level already mentioned, the most efficient option was considered and that was to survey individuals from the same age, from the same educational level with the purpose of getting more accurate results.

The result of heterogeneity in this area is high, because the survey has been done to groups of young people from different autonomous communities in Spain paying attention to their different and particular identities, linguistic characteristics and the variety of cultures in the different autonomous communities, shown in the sample. This heterogeneity, which is characteristic of Spain, balanced the possible existence of homogeneity in the students groups. The autonomous communities that participated were: Madrid, Cataluña, Galicia, Andalucía, País Vasco, Valencia and Castilla y León.

Figure 6. "Point out and rate the media that you prefer to watch in your free time. From low (1) to high (5)".

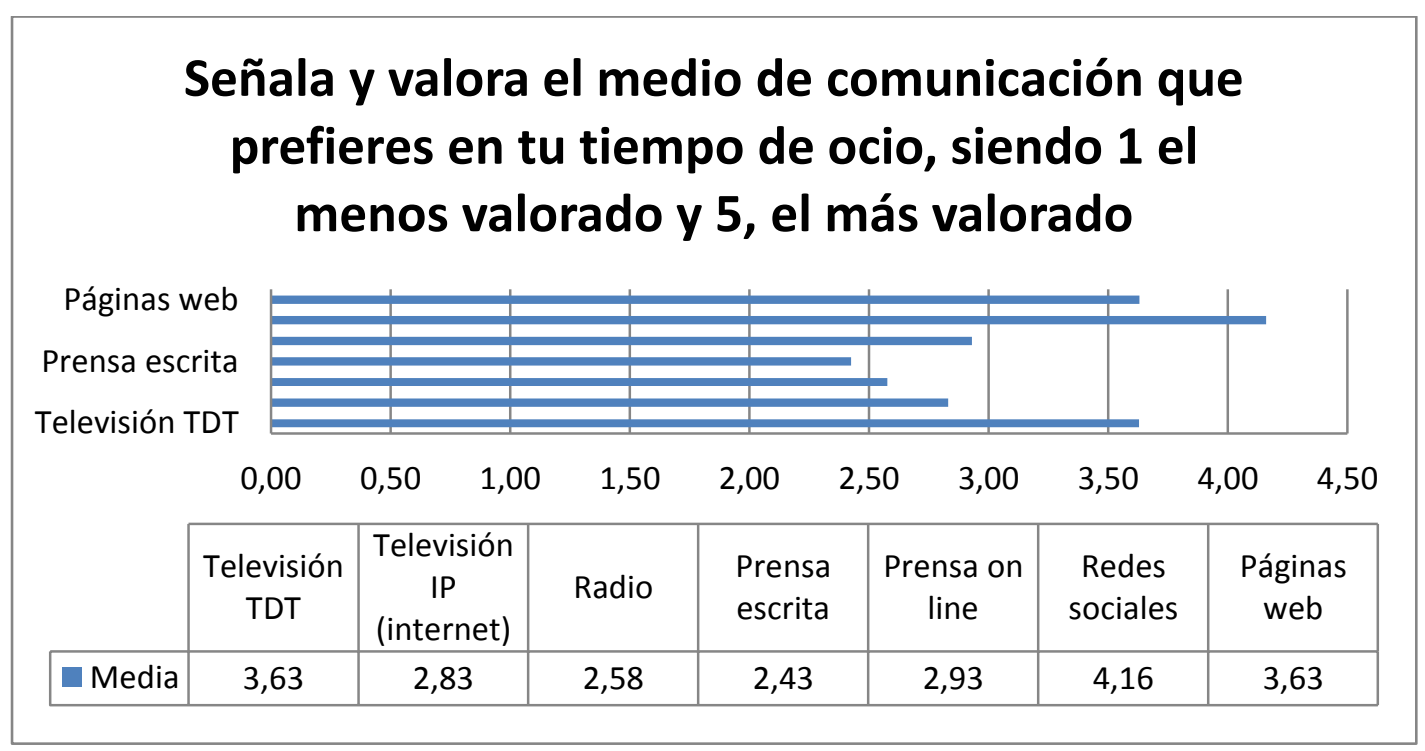

$\underline{\text { Source: Personal compilation }}$

The first relevant piece of information for our purpose was to confirm how youth rated, from 1 to 5, different media that they prefer to watch in their free time and as we can see in Figure 6, social networks are the ones that stand out, followed by the access to on- 
line TV and web pages. The fact that the EPG (Electronic programming guide) gets close to a 4 and TV on the internet is not even rated with a 3 , proves the use of multitask and multiscreen devices.

When we asked about the number of hours that were devoted to pay attention to the same media, it is important to highlight (see Figure 7) that they devote more than 3 hours to social networks, more than 2 hours to web pages and almost 2 hours to EPG Television, proving the previous data.

Figure 7. "Point out the number of hours that you dedicate to this Media"

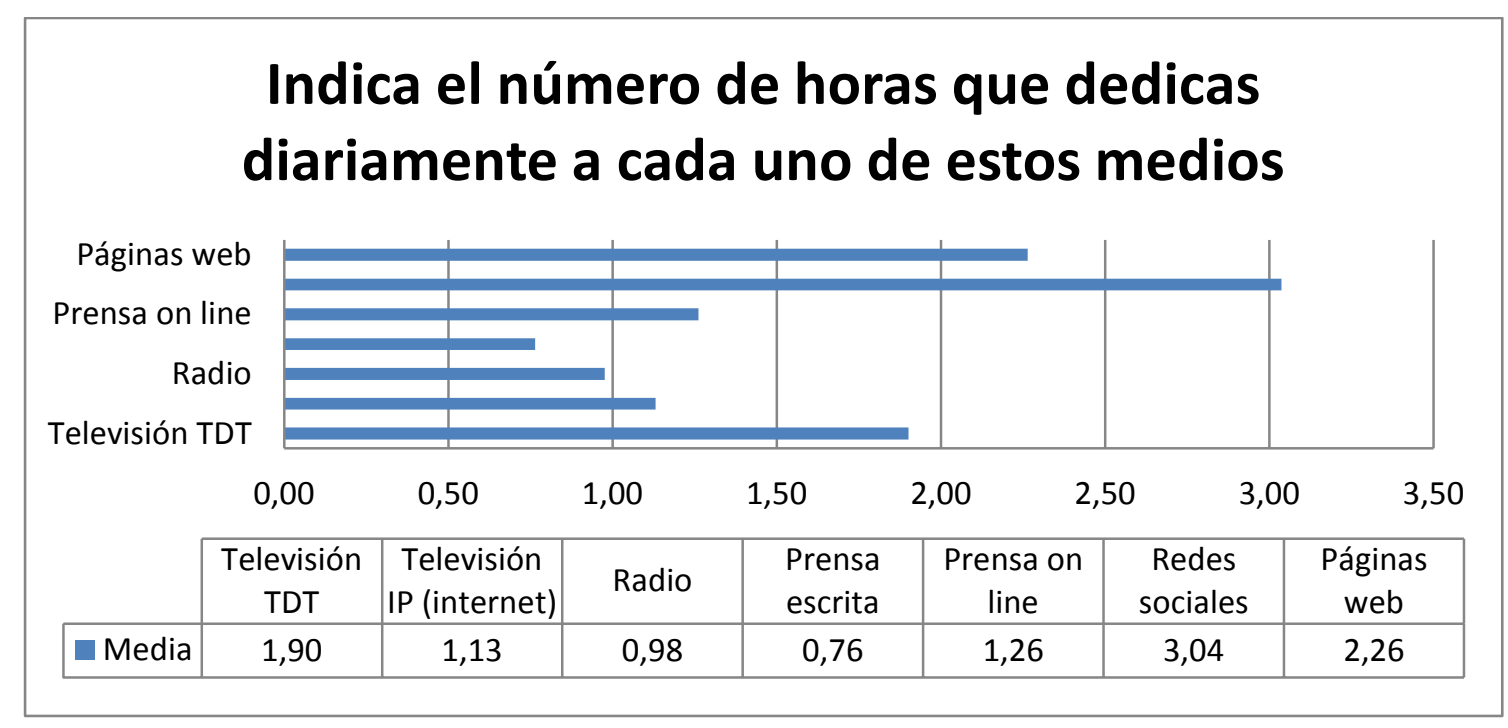

$\underline{\text { Source: Personal compilation }}$

As social networks were so relevant, the following questionwas asked:Which ones were the most popular? And the results can be seen in Figure 8. 
Figure 8. "What is the social network that you prefer?"

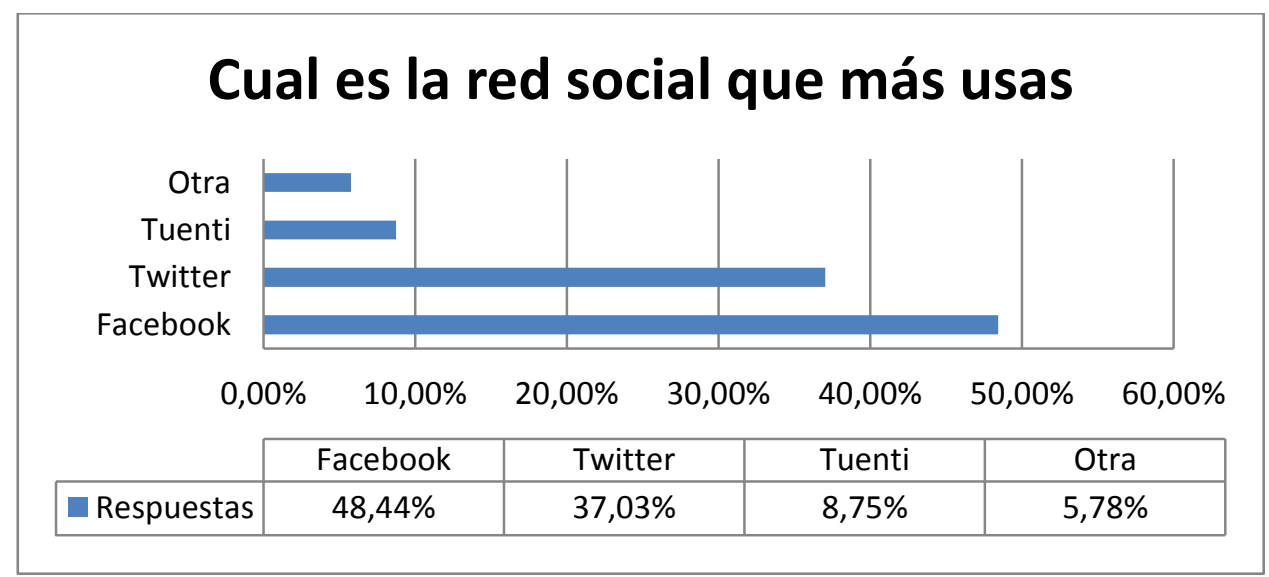

\section{Source: Personal compilation}

Figure 9. "Where have you obtained more information about climate change? Rate from 1(low) to 5 (high) the most frequent source of information".

$\underline{\text { Source: Personal compilation }}$

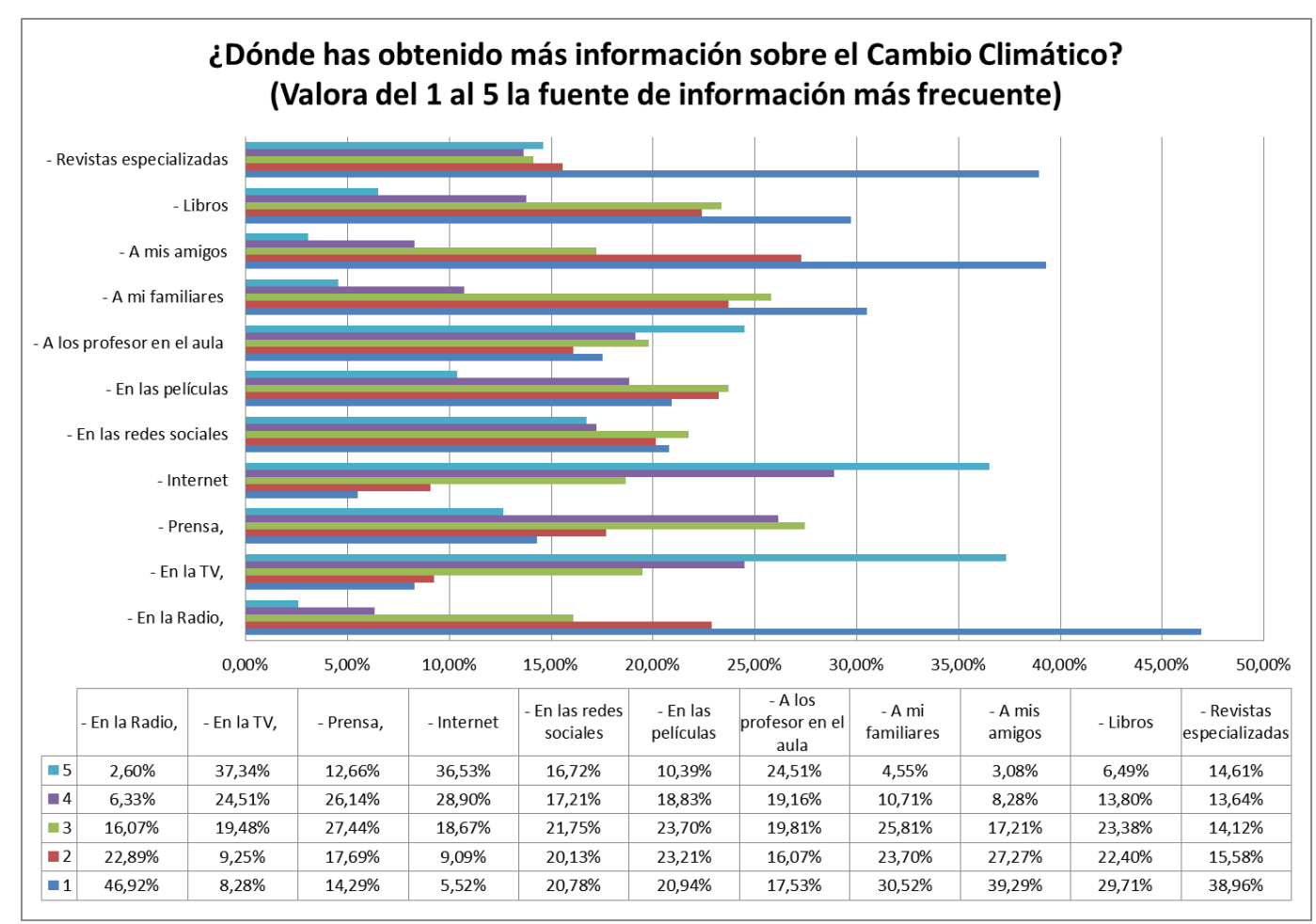

To conclude, as this survey was done during a research about the social representations of the climate change among young Spanish people, we thought it was relevant the profile of answers to the question about which source was richer and great infomation, in 
terms of scientific information. In this case, the topic was climate change, but these data can show, in general, the way youth appreciate their sources of scientific information. Results are shown in Figure 9. In it we can see that most of the information comes from the internet, but also from the TV and the social networks, they gavethis information as much importance as to teachers and specialized journal. On the other hand, newspaper, radio as well as friends and relatives are rated as the worse source of information.

\section{Conclusions}

Having shown the previous data, it can be proved that although they come from different sources or researches, they come to the same point which is to offer a profile of audiovisual consume, which primarily in youth, is used with several devices at the same time converging with the TV screen. Its consumption, preferably á la carte and without following a TV listing schedule, works by following the course of a virtual conversation whose sequential synergy is formed in the social networks. This can explain the interest of media in taking part in social networks to find media consumers, which develops in a competition among media to win their followers trust. In addition to this, their purpose is to stimulate the growth of connections, social networks and the contents which if they have a great spectacularly could feed conversations as more efficient devices can increase sociability.

\section{Bibliography}

BECK, U. (1998). La sociedad del riesgo. En camino hacia otra sociedad moderna. Barcelona: Paidós.

BERGER, P.L. y LUCKMANN T. (1976). La construcción social de la realidad. Buenos Aires: Amorrortu.

CASTELLS, M. (2001). La era de la información: economía, sociedady cultura. Madrid: Alianza Editorial.

THE COKTAIL ANALYSIS. "Televidente 2.02013 (VII Oleada). Informe Público". Retrieved from: http://tcanalysis.com/blog/posts/el-62-de-los- 
internautas-usa-otro-dispositivo-a-la-vez-que-la-televisionde-manera-habitual (Access: 14.03.2015).

CRESPO, K. (2006). "Comunidades virtuales y construcción de conocimientos". Retrieved from:

http://portal.educ.ar/debates/educacionytic/debate/comunid ades-virtuales-y-construccion-de-conocimientos-.php (Access 22.02.2008).

CROVI DRUETTA, D. (2006). Educar en la era de las redes: una mirada desde la comunicación (1 ed.). México: UNAM Facultad de Ciencias Políticas y Sociales; SITESA.

GAITAN, J. A. y PIÑUEL, J. L. (1998). Técnicas de Investigación Social en Comunicación. Elaboración y registro de datos. Madrid: Ed. Síntesis.

GERGEN, K. y WARHUS, L. (2003). "La terapia como una construcción social: dimensiones, deliberaciones y divergencias". Revista Venezolana de Psicología Clínica Comunitaria, 3, pp. 3-44.

QUINTAS-FROUFE, N. y GONZALEZ-NEIRA, A. (2014). "Audiencias activas: Participación de la audiencia social en la televisión”. Comunicar, no 43, pp. 83-90.

JOHNSON, S. (2003). Sistemas emergentes: o qué tienen en común hormigas, neuronas, ciudades y software ( $1^{\circ} \mathrm{ed}$.). Madrid: Turner

ONTALBA-RUIPÉREZ, J. (2006). Las comunidades virtuales como herramientas para la socialización del conocimiento tácito. Huelva: Book Chapter.

PIÑUEL, J.L. y LOZANO, C.H. (2006). Ensayo general sobre la Comunicación. Barcelona: Paidós.

PIÑUEL, J.L. y LOZANO, C.H. (2007). "Incertidumbre y comunicación. Dominios de supervivencia y estructuración del acontecer". Diálogos de la Comunicación, nº 75 FELAFACS. Lima, Perú.

TESO ALONSO, G. (2015). Discursos mediáticos, Representación del Cambio Climático en los jóvenes y Cambio Social. Tesis doctoral. Universidad Complutense de Madrid.

VARIOS (2013). "El 46\% de los españoles navega con sus tabletas mientras ve la televisión". Retrieved from:

http://www.puromarketing.com/12/18593/espanolesnavegan-tabletas-mientras.html (Access 2.11.2014). 


\title{
٪ 6 \\ Emotions - Importance and basics in the TV contents
}

Maria Jose Labrador, Universidad Mayor, Santiago, Chile

\begin{abstract}
In the analysis of the digital platforms, the future of television and proliferation of channels what does constitute as substantial for the functioning of television, and on which we should focus our attention, is normally forgotten: contents. This work presents as object of analysis, the emotional dimension in television in its different manifestations: through its contents, personalities, characteristics of the television storytelling and audiovisual language (images, codes of illumination, edition, and sound effects, among others), for which integrating to the discipline of Communication other areas of knowledge, such as Psychology and Philosophical Anthropology, which address said matter from its deepest root, has been considered fundamental.

The study presented here in a first step, through the reflexive method, addresses the basics of the emotional dimension and how it is being addressed, going further in the knowledge of the emotions, their influence in the human behavior, and planning of the TV contents in emotional key, among other perspectives. This investigation is currently at a second stage of analysis with a qualitative-quantitative methodology on emotions and children television's contents.
\end{abstract}


From the above, the use of certain skills and aspects which can be implemented in the creation of the TV contents and multiplatform is proposed. It is also sought to advance in the debate for defining possible guidelines that, on one side, guide the Communication industry to searching an approach towards the innovation in said subject, and on the other, to knowing and valuing the children's audiences as for its status of intelligent, selective, critic, interactive and globalized.

\section{Keywords}

TV; television; childhood; emotions; consumption; contents

\section{Theoretical Framework}

\section{Emotions - Importance and basics in childhood, and the audiovisual products aimed to them}

$\mathrm{HE}$ title faces us with a challenge involving several areas of the
knowledge, and to address it from the rationale of the emotional dimension in its deepest root with the purpose of being able to apply this knowledge regarding the education in the media -understood as dialogue-, which should have as consequence, in short and medium term, a double process, is therefore of fundamental importance. First, the formation of a critical and participative conscience of the young audiences in relation to the analysis of the contents, and specially to the knowledge of how are the emotions addressed in TV in its different manifestations: The characteristics of the television storytelling and audiovisual language (images, codes of illumination, edition, and sound effects, among others), and their influence in the cognitive, social, family and of course, emotional development. Second, the progressive acceptance by the media of a deep commitment with education and planning of the emotions in the contents, audiovisual products or multimedia, in an innovative and positive way.

Through a line of investigation about the subject, the emotional dimension has been addressed from three scopes of knowledge, then the work we have done together with other researchers will gather up 
(Labrador and Rebeil: 2013), trying to sum up as concrete as possible the aspects that bring us together in this section.

The integrality of human faculties makes clear the interdependence of faculties of the person in action. In this, the superior structure (intellect and will) interacts with the vital and endothymic background -with its pulsional and emotional experiences, and persistent moods-. Such verification endorses the study of Goleman (1997), which states that more than $90 \%$ of our conducts are emotional in its first instance; however, it is evident that a rational and free being as the human being, in its realization is called to guide them -not repress them- with knowledge and freewill (both updated), it is therefore typical to each one: having knowledge of the beings allowing to see the real good, which will always be beneficial for the individual development of the human person structure).

Below the scheme of the person's structure is presented:

\section{Scheme 1. Person's Structure}
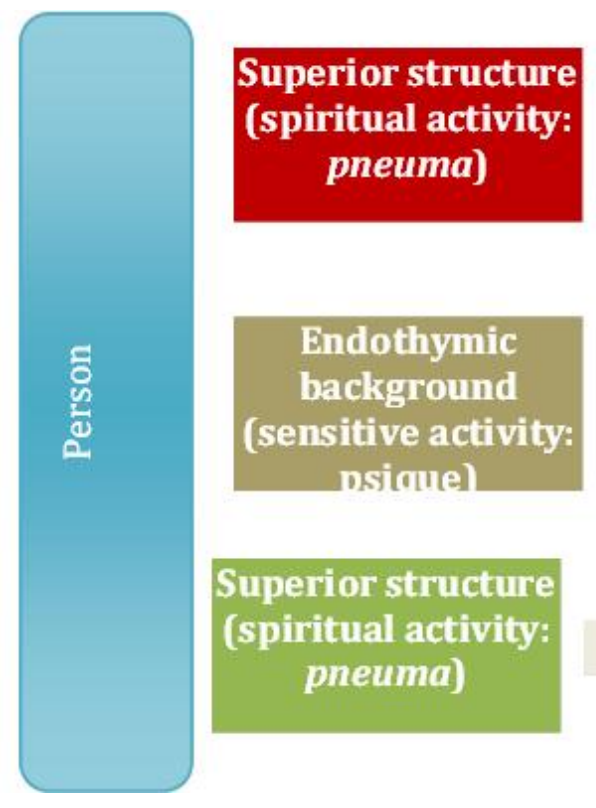

- Intellect

- Will

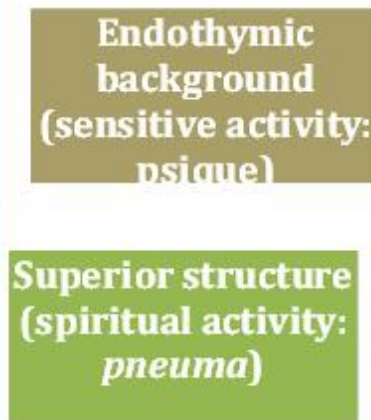

- Tendencies or drives

- Emotions

\section{Superior structure pneuma)}

- Physiological

Source: Lersch (1966: 77-484)

Emotions are one of the three natural components of the person's affective-sensitive background. These originate in the tendencies or 
natural sensitive forces of the human (instincts in the animal), and in turn, they influence the persistent moods. The emotional capacity in the person is, in human action, before the intervention of the intellect and will. The binding studies evidence that the development of emotions is realized in the meeting of the acting subject with the real, immediate surrounding world; they are therefore the root of the action of the human being under normal conditions and even more in the abnormal ones, wherein it is not possible to demand the intervention of reason (Vidal, 2013).

Scheme 1 shows the person -each one of us- in a triple structure containing all of itself, its personal self, its aseity, its self-centredness of creature. The three aspects -as experience shows- are intimately related in the person as co-principles (inseparable). It is inconceivable to suppress one of those and speak of human person.

The vital background contains the organic faculties, place of all corporal, somatic activity. It is the anatomical, histological, physiological, etc. constitution of the individual, a basal reality for the existence of the other two structures (which does not mean that the person does not exist if there are physical damages or deterioration in the corporeal nature).

The endothymic background is the place where the sensitive or emotional faculties of the person lie (psyche), from which the affective-sensitive activity originates, that is, where the tendencies or drives, the emotions or moods (the person's scope, which will be referred later in more detail for its relation with the emotions) originate.

The superior structure is the one containing the very spiritual strengthsintellect and will- which define the human being as it is and enable the exercise of freedom.

In this, the superior structure (intellect and will) interacts with the thriving vital and endothymic background -with its pulsional and emotional experiences, and persistent moods-. Goleman's study (1997) evidence what has been said: The author recognizes that more than $90 \%$ of our conducts are emotional in its first instance. However, it is evident that the human being, because of its rational and free condition, is called to guide - not repress- its emotions in the 
acting, auto guiding them to something superior to simple feeling. The condition to do it is the kind possession of the knowledge of him/herself and of the human reality, which will allow you to see and accept the real -not only emotional-good. This would be described as such, when observing the contribution to the undivided development of the human person, not to a partiality of that.

Lersch distinguishes three big groups of emotions (Lersch, 1966: 194256) - in the same way that three groups of tendencies or drives are distinguished-, with the purpose of evidencing the deep relations between the different aspects of the emotional dynamics. This does not mean that each emotion should be referred to as a group of emotional tendencies exclusively, but this is about emphasizing the fundamental tone or quality by which one emotion corresponds to a certain tendency. It is to be remembered that, at an emotional level, in the same way as in the emotional realities, the emotions manifest in a constant flow, and it is difficult to precisely determine their outlines. They are brief and vague, so they represent obstacles for its individualized description. According to Lersch, two sides which are connected and complemented would have to be distinguished: One refers to the current mood, that is, to the quality or endothymic color or tonality. The other one refers specifically to the emotion.

The depth of an emotion is captured by the major emotional field it comprises, and receives from said area its coloring and shade.

The experience will be superficial if, for example, when hearing music or a piece of news its content goes in one ear and out the other; however, these same audition can make us experience a transformation: Our thoughts take a new direction, and all our past and future life acquires a new light (emotional depth). The coloring (or quality) and the depth are two directions that vary the emotional experiences. Each emotion characterizes in that the degree in which the trendential or pulsional components are experienced (Lersch, 1966: 1942).

Emotions manifest through the following signs:

- Interruption of the regular psychosomatic rhythm. 
- Feeling of corporal disorder, specially the part regulated by the vegetative nervous system: fright, excitement, terror (common with the animals); horror, enthusiasm, outrage, anger (typical in humans).

The emotional reply in the human action is prior to the intervention of intellect and will. The binding studies evidence that the development of the emotions is realized in the meeting of the subject with the real and immediate surrounding world (Umwelt). Therefore, they are the root of the action of the human being under normal conditions (and even more in the abnormal ones) wherein -in many cases- it is not possible to demand the intervention of reason. Consequently, we recognize that the first step of all conduct is emotional (e-movere), due to an affective-sensitive movement of the subject, in reply to the perception that arises in its relation with another one and the world. Lersch distinguishes three big groups of emotions (Lersch, 1966: 194-256) -in the same way that three groups of tendencies or drives are distinguished-, with the purpose of evidencing the deep relations between the different aspects of the emotional dynamics. This does not mean that each emotion should be referred to as a group of emotional tendencies exclusively, but this is about emphasizing the fundamental tone or quality for which one emotion corresponds to a certain tendency. The basis of the distinction is the objective axiological qualities, the endothymic coloring and the emotional configuration.

Following the emotions comprised in each classification are outlined, which have been particularly studied and then the development of several skills in the different TV contents for the childhood has been proposed. $^{47}$

\footnotetext{
${ }^{47}$ It is suggested to read chapter 1, Anthropology of the emotions from Dr. Carmen Vidal, author of said text in Labrador, Rebeil 2013, The emotional dimension of the TV speech, México, Tirant Lo Blanch
} 
- $\quad$ Pain, pleasure, boredom.

- Satiety and revulsion.

- Physical and mental disgust.

- Fun and bore.

- Joy and affliction.

- Fascination and panic.

\section{Emotions of the individual self}

- Conservation of the individual:

- Fright, agitation, fear, trust, suspicion.

- Of egoism, desire of power, need of esteem:

- Happiness, unhappiness, envy, triumph and defeat, flattery, insult.

- Of the vindictive impulse:

- Payback, joy for other's pain, gratitude.

\section{Transitive emotions}

- Destiny emotions:

- Hope, fear of the future, resignation, concern, despair.

- Emotions directed to the neighbor:

- Coexistence; sympathy and antipathy; esteem and disgust of the neighbor; respect, joke.

- Of the shared feeling:

- Lover for your neighbor (friendship, family).

- Erotic, human.

- Cheer up with others.

- Compassion.

- Hate towards the fellow men.

- Emotions of the creator and cognitive tendencies:

- Joy of creating

- Noetic feelings

- Emotions of the loving and moral tendencies:

- Extra human love for things

- Normative feelings

- Emotions of the transcendental tendencies:

- Artistic feelings

- Metaphysical feelings

- Religious feelings

In the neuropsychological perspective and the health field, the emotional behavior has a prevailing place in our society. The study of 
the emotions in children, young people and adults is object of interest in the worldwide community. From different points of view, as the psychological, neurological, and other, we know what are the emotions, how do they affect the person in order to carry out his/her life project, and the importance of the development and emotional handling in all of our scopes of action for living with life quality. The investigations in the scope of intelligence and emotions have brought the researchers to make neurological studies for finding scientific answers to the questions proposed today.

From William James, Cannon-Bard (1927), Schachter-Singer, LeDoux (2000), Ekman (2003), to Damasio (1999), today, among other philosophers, psychologists, neurologists, and scholars of the subject, relate the emotional life with the feelings and emotions of different characteristics. These terms indicate a longer duration and less intensity in the case of the feelings; shorter durations and greater intensity in the emotions, with repercussions in our organism. The brain modularity (the relation between emotional brain and rational brain) is expressed through a complex game of interactions. The modules interact between them, for good or bad. Ekman writes in EmotionsRevealed (2003) that "the emotions determine the quality of our lives." He's been dedicated to the study of emotions recognizing them in the face, in different peoples and cultures, for fifty years. His master and first mentor, Tomkins (1962), wrote something related with the concept of quality: "the emotions motivate our life."

Rizzolatti and Craighero (2004) show the existence of neurons "mirror" (mirrorneurons), which allow the detection of the emotions and enable imitating the emotions from those who surround us, which turns into a fundamental point of study as for its application to the TV viewers regarding the TV contents. This way and because there is that neuronal web, it is observed the expression and detection of the emotions from very early in life.

Said studies facilitate the understanding of feelings and emotions favoring harmonic development of personality, or otherwise they can cause psychological disorders in the infancy, childhood, and adolescence, that negatively impact family, school, and social environments. Contributing ideas and procedures in order to improve 
and develop the emotional states and processes in the most optimal way through media support, such as television -currently immersed in a huge change-, can mean a big a help to enjoy a programmatic industry that encourages interesting and novel contents, a better quality of life, as well as an improvement in society, respectively. (Martin, in Labrador and Rebeil, 2013: 3-5)

\section{Audiences and the New Form of Consuming Television}

In Chile, the number of TV sets per home has increased an average of 2.7 sets per house, representing a sustained growth, although not explosive compared to the 2.4 on 2008. Many of those new TV sets are installed in the children's bedrooms, generating a double effect. On one hand, the quantity of minutes they are exposed increases, but also the possibility of them being exposed to contents not appropriate to their age if there is no appropriate control by the parents.

Broadcast TV continues to be the main news medium, and an important one of education, culture, entertainment, and company for the citizenry. The news, movies, articles, and cultural shows are the best evaluated contents. For their part, the most criticized shows for their contents were precisely infant and teen shows, where $70 \%$ believes that they show a shallow image of youth, and where their contents are largely eroticized.

Today, the group between 8 and 10 years old is hard to classify as many are active subjects who sometimes behave as adolescents and not as children, which seems to go hand in hand with early and frequent contact with the mass media. ${ }^{48}$

The last survey of the CNTV showed that children tend to see contents not directed to them. They admit having certain degree of freedom to see the shows they like despite their parents' warnings. ${ }^{49}$

\footnotetext{
${ }^{48}$ Report 8/13: los Tweens Chilenos (Chilean Tweens), Consejo Nacional de Televisión (National Television Council), 2003.

${ }^{49}$ Seventh National Television Survey, Consejo Nacional de Television (National Television Council), 2011.
} 
This position of independence arising in many a home contrasts with the surveyed parents stating that they control, restrict, and prevent their young children from being exposed to contents not appropriate to their age.

Parent dissatisfaction with the contents in broadcast TV dissents with the opinion they have in regards to paid television, where $85 \%$ is satisfied with the offer, being variety the main drive to their feeling. ${ }^{50}$ The little group that appears to be unsatisfied is so on account of they believing that in certain spaces content with too much violence is emitted.

It is also observed that the growing displacement of the children's audience from broadcast TV to the cable channels is increasingly clear. Ibope Media data for various countries in this region show that channels such as Cartoon Network, Nickelodeon, Discovery Kids, Jetix, Disney Channel are at the top places in the total tuning cable television; even there are certain hours some days of the week (Saturday and Sunday mornings), where the total tuning cable television surpasses the broadcast TV tuning by the leverage of the children's audience. ${ }^{51}$ Even some of them have started with a sub-segmentation directing their schedules towards more little niches: Dicovery Kids for six-yearolds and under, and others towards older kids, such as Nickelodeon, Jetix, and Disney.

The broadcast TV is not behind, and in different countries in Europe specific products may be found for children. In Germany, the public television created the Kinder Kanal, which broadcasts from 06:00 to 21:00; while RTL -paid channel- launched Super. The BBC in its digital offer, has segmented channels for children and France Telévisions has also followed this tendency. ${ }^{52}$ This way, the paid children's channels and of digital TV increase their screen fees, being those with payments the ones that concentrate a greater percentage of children achieving a greater rate of affinity with the public of

\footnotetext{
50 Ibid.

${ }^{51}$ Fuenzalida, V., Los niños y la televisión (Children and Television) in Revista

Chasqui, available on the Web: http: //www.chasqui.comunica.

org/content/view/455, dated07.20.12.

52 Ibid
} 
between 4 and 12 years old.

The technological transformations have also generated changes in the way in which the little children watch television. For many of them turning the TV on is a habit almost instinctive, more than a preference. They feel accompanied while doing other activities, being the main one, the computer. More hours are destined to the Internet and a lot of times from this platform, they access audiovisual contents (Disney, Nick, etc.). Today, 55\% of the total content consumed in the Web is video and the prognosis for the next years is that it will continue increasing. ${ }^{53}$

This habit shows that the younger generations have incorporated a convergent use of screen, wherein the consumption restrictive barriers start to disappear in form and substance. This way, many companies have been forced to modify their strategies. The current tendency shows a greater orientation to the creation of more global trademarks, which provide new opportunities. There is no longer thinking in one product only for television, but instead, products exportable to different supports should be conceived from the beginning.

But these actions also aim the effort of the big corporations for reinforcing the reputation through the relations they establish with their audiences in their different scopes. ${ }^{54}$ This new way of comercial exploitation (videogames, DVDs, music, etc.) constitutes as an additional way to make the contents profitable, besides being an additional support to the more traditional marketing tools. ${ }^{55}$

\section{Valuations Before the Changes in the Television Scenario}

In the last years particularly, television has experienced processes of fragmentation of audiences and diversification of the cultural

\footnotetext{
${ }^{53}$ Cisco Visual Networking Index: Forecast and Methodology, 2011-2016

${ }^{54}$ Cfr. Melgarejo I., Rodriguez M.M., La creación de imagen de marca en los canales infantiles politemáticos de televisión, En MHCJ No 3 -2012, art. 3-28, pp. 37-54.

${ }^{55}$ Dunlap, B., El poder de la mercancía, Revista TV Latina, WSC INC, enero 2006, retrieved from http://www.tvlatina.info/, access 03.11 .06
} 
consumption. In several investigations and studies, is observed that the television still is the dominant medium for young people, although the way of watching it changes.

The current generation of adolescents from Argentina, Brazil, Chile, Colombia, Mexico, Peru, and Venezuela can communicate, study and have fun through a screen, either the TV, computer, cellular phone, videogames, or the Internet. Their communication styles and their way of having fun have evolved; they are now capable of living within the virtuality. (Bringué and Sádaba, 2010).

It is interesting to point out how in some countries, the profile of creator of contents for children is remarkably high. In Chile, for example, $50.3 \%$ of the adolescents has their own blog, wherein they express their emotions, the information and contents that seem appropriate to put on the Internet (ibid).

On the other hand, it is also observed in some countries, like the USA, that the attention of the young people between 8 and 18 years old to the social communication media is still increasing from approximately six to seven hours a day (Kayser Foundation Family, 2010).

One concern that is gathered from the results of the first cited investigation, and that constitutes as a fundamental aspect in the analysis of the emotional answers of the audiences -towards the contents as in its family, educative and social environments-, lies in the consolidation of the room culture or the reality of some adolescents that live in their own habitat, isolated from the family life and in many occasions, equipped to open globally to an interactive universe; and the access alone to the screens as the most common way of use and learning.

The current opportunities are not only generated with the emergence of new devises of contents, and signs digitalization, but also with the creation of contents that do not lose from the sight the commitments and responsibilities for the new citizenship. The children's programming in the immediate future, with the emergence of new channels -public and private- should increase, which will generate a bigger competence as a result of a greater fragmentation, which in 
turn will translate into a bigger dispute for gaining viewers. This fight should translate into an improvement of the quality of what is broadcast and produced having as fundamental elements the knowledge of neuropsychological processes of the current audiences, the emotional dimension, and the contents proposed in emotional key.

The digital television, understood as audiovisual offer, is every day more thriving, regardless of the technological systems and signal broadcasting. Its challenge consists in truly becoming a platform that achieves a variety of contents systematically seeking quality, generating content of significant importance for the audiences. The opportunities that currently have the channels with the social networks constitute themselves as a very useful forum for listening and valuing the opinion of the new audiences through the nets, without doubt.

As a result of these changes in the consumption habits of the users, Twitter and Nielsen presented their tool for measuring social audiences together. "Nielsen Twitter TV Rating" will measure the total TV audience according to their participation in Twitter. In the measuring of these social activities, the tweets from people who comment on a determined TV program and those who are exposed to their comments will be included.

In this new scenario, the people responsible of the chains manifest extreme interest for the active audiences. The tendency of this phenomenon, known as Social TV, is increasing. It consists in watching TV while interacting in social networks. This way, the users not only can interact with other users and exchange points of view over the contents of a particular program, but also with the host, and in some cases, even with the characters of a show. According to the last study of Ericsson (2012), the growth of the Social TV has been constant: $68 \%$ of the users worldwide watches TV while surfing the Web and discussing their contents through social networks.

The Social TV could represent a conventional television strategy for the users to achieve a deeper degree of involvement or engagement with its programming. The idea of having close competitors, as strong as 
the television on demand, has forced the media to look for alternatives that prolong and broaden the experience of enjoying a show or a TV series.

\section{Final considerations}

We can state that it is important to culture in the children's audiences the habits of the mind, the development of neuropsychological skills and of the affectivity, which together with the referents of family, personal and educative values, will make possible the comprehensive and harmonic development of personality.

On this regard, in the media field, it should be pointed out that recent studies address several perspectives on the quality on TV contents for the childhood from said premise. These propose that the quality in the children's television as promoter of the development of the intelligence in the child necessarily implies admitting that the interaction between the child and the television in relation to the time of consumption, to the hierarchy of the TV set in the house and its impact in the cognitive and emotional processes, as well as the guidelines of communication, attitudes and values the child learns with the TV, cannot be limited to verbal aspects, certain learnings, successful production and then, valuation of influences and effects. But it is crucial to admit and point out a new type of relation that today is simultaneously to the process of socialization: The relation of the child with the television contents, multiplatform and their emotions. This relation has become more frequently and more intensively part of their lives, characterizing their development, so we think that it should become an effective way to promote the development of thinking skills.

It is possible to develop in the contents of several forms, skills that are proposed on the base of the emotional intelligence. Some of these skills are the skill for using the logical thinking, skill for the search of critical thinking, skill for resolving problems, skill for controlling impulses, motivation skill, skill for assertiveness, interpersonal and empathy skill, inspiration and imagination skill, musical skill. 
At the same time, the educational centers should become aware of promoting the emotional development of their students, because this benefits the learning, maturation and personal wellbeing, advancing this way towards the self-fulfillment and coexistence.

The emotional education presents as a recourse for strengthen the positive perception that the person should have of itself, of a capacity to act and trust in its own judgment, of being able to recognize its inclinations, both positive and negative, of being open to the other's needs. In one word: To achieve the necessary cognitive-affectivebehavioral equilibrium in order to face the needs of this globalized world, from the responsible exercise of their freedom.

From the comprehension of the emotions and the strength of the audiovisual experience, the emotional education can be encouraged. It is very interesting challenge, with a great personal, family and social scope.

\section{Bibliography}

BRINGUE, X., SÁDABA, CH. (2010). "La generación interactiva en Iberoamérica. Niños y adolescentes ante las pantallas". Foro generaciones interactivas. Fundación telefónica.

CANNON, W. B. (1927). "The James-Lange Theory of Emotions: A Critical Examination and an Alternative Theory". American Journal of Psychology (39).

DAMASIO, A.R. (1999). The Feeling of What Happens. New York: Harcourt.

EKMAN, P. (2003). Emotions Revealed. Nueva York: Times Books.

GOLEMAN, D. (1997). La inteligencia emocional. Buenos Aires: Javier Vergara.

KAISER FAMILY FOUDATION STUDY. (2010). "The lives of 8 to 18 year olds". January 2010

LABRADOR, M.J, REBEIL, M.A. (Coords) (2012). La dimensión emocional en el discurso televisivo, Valencia: Tirant lo Blanch. 
LEDOUX, J.E. (2000). "Emotion circuits in the Brain". Annual Review of Neuroscience (23).

LERSCH, PH. (1966). La estructura de la personalidad. Barcelona: Ciencia.

MARTÍN LOBO, P. (2013). "Bases neuropsicológicas de la emoción”. En Labrador, MJ y Rebeil, MA. La dimensión emocional en el discurso televisivo, Valencia: Tirant Lo Blanch

RIZZOLATTI, G., CRAIGHERO, L. (2004). "The Mirror-Neuron System”. Annual Review Neuroscience (27), pp. 169-92.

TV AND VIDEO (2012). And analysis of evolving consumer habits. Ericsson consumer insight summary report, August 2012.

TOMKINS, S. (1962). Affect. Imagery. Consciousness. (Vol. 1). New York: Springer Publishing Co.

VIDAL MONTECINOS, C. (2013). “Acercamiento antropológico filosófico a las emociones humanas". En Labrador, MJ y Rebeil, MA. La dimensión emocional en el discurso televisivo, México: Tirant lo Blanch. 